\title{
Des brèches dans la ville
}

Organisations urbaines, environnement et transformations des rapports de genre

\section{Textes réunis par Christine Verschuur et François Hainard}

Les colloques genre de l'IUED: Collection Yvonne Preiswerk
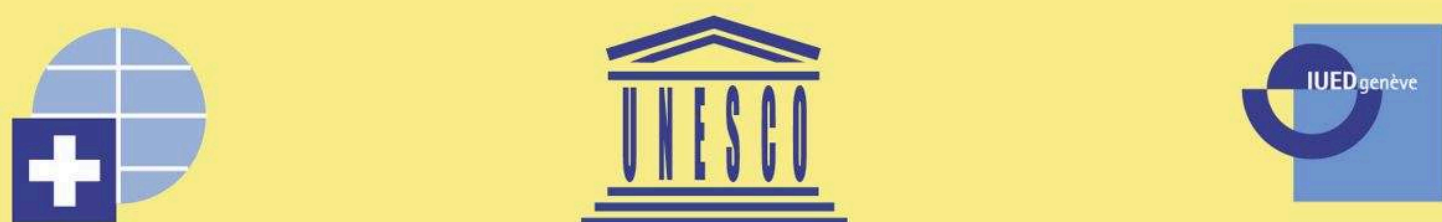

Commission uisse pour l'UNESCO, Berne

DDC, Direction du développement et de la coopération

Département fédéral des affaires étrangères, Berne

IUED, Institut universitaire d'études du développement, Genève

Berne, 2006

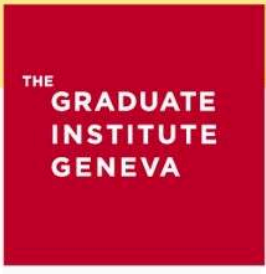

-

ÉTUDES INTERNATIONALES

ET DU DÉVELOPPEMENT

GRADUATE INSTITUTE

OF INTERNATIONAL AND

DEVELOPMENT STUDIES

NOUVELLE ÉDITION

\section{GENRE ET DÉVELOPPEMENT | RENCONTRES}




\section{Graduate Institute Publications}

GRADUATE

INSTITUTE

GENEVA

\section{Des brèches dans la ville}

Organisations urbaines, environnement et transformation des rapports de genre

\section{Christine Verschuur et François Hainard (dir.)}

DOI : 10.4000/books.iheid.6543

Éditeur : Graduate Institute Publications

Lieu d'édition : Genève

Année d'édition : 2006

Date de mise en ligne : 27 octobre 2016

Collection : Genre et développement. Rencontres

EAN électronique : 9782940503810

\section{(2) OpenEdition \\ Books}

https://books.openedition.org

\section{Édition imprimée}

EAN (Édition imprimée) : 9782882470638

Nombre de pages : 294

\section{Référence électronique}

VERSCHUUR, Christine (dir.) ; HAINARD, François (dir.). Des brèches dans la ville : Organisations urbaines, environnement et transformation des rapports de genre. Nouvelle édition [en ligne]. Genève Graduate Institute Publications, 2006 (généré le 28 janvier 2022). Disponible sur Internet : <http:// books.openedition.org/iheid/6543>. ISBN : 9782940503810. DOI : https://doi.org/10.4000/ books.iheid.6543.

Ce document a été généré automatiquement le 28 janvier 2022. II est issu d'une numérisation par reconnaissance optique de caractères.

(c) Graduate Institute Publications, 2006

Creative Commons - Attribution - Pas d'Utilisation Commerciale - Pas de Modification 3.0 non transposé - CC BY-NC-ND 3.0 


\section{EXTRAIT}

Cet ouvrage se propose de transmettre des connaissances élaborées par la recherche sur les inégalités de genre dans les quartiers de villes du Sud et de discuter de la manière de soutenir les nouveaux mouvements sociaux où les femmes jouent un rôle central et cependant non reconnu. Sont présentées ici les réponses données par les femmes et les hommes aux problèmes les touchant directement. Les recherches ont portées sur les réponses locales, collectives, de rejet de situations inacceptables et de lutte pour des conditions de vie plus dignes. L'approche des auteurs a été de soutenir les processus de prise de conscience, de compréhension des causes des situations inacceptables, la recherche de solutions à la base, sur proposition des femmes et des hommes des quartiers, dans le cadre d'espaces nouveaux d'organisations, et non la promotion de programmes venant d'en haut. Dans une approche « éducation populaire » ils ont, en tant que chercheurs acteurs, soutenu l'élaboration de nouveaux rapports de pouvoir dans les mouvements de quartiers.

\section{CHRISTINE VERSCHUUR (DIR.)}

Anthropologue, titulaire d'un doctorat de l'université de La Sorbonne, chargée de cours en genre et développement à l'Institut universitaire d'études du développement, Christine Verschuur travaille depuis de nombreuses années dans le domaine du genre et développement, dans des projets de recherche et d'enseignement. Elle est coordinatrice du projet Suisse «Villes, environnement et rapports sociaux entre hommes et femmes » du programme MOST de l'UNESCO depuis 1996 avec François Hainard.

\section{FRANÇOIS HAINARD (DIR.)}

Professeur et directeur de l'Institut de sociologie de l'Université de Neuchâtel, Suisse. Ses travaux de recherche portent sur l'économie, l'environnement et les problèmes sociaux. Depuis 1997, il est l'un des deux coordinateurs du projet MOST-UNESCO «Genre, ville et environnement ». 


\section{Emprise du genre dans le développement et recherche}

Dix ans de colloques internationaux genre et développement à l'IUED. Justice sociale et justesse des analyses : la puissance du genre

Christine Verschuur

Emprise du genre et développement

Sept ans de recherche sur sept terrains à la fois !

François Hainard

Une recherche particulière à différents points de vue

Questions de méthode et originalité de la démarche

Les limites à la comparaison?

Des questions et des doutes légitimes

Une problématique utopique?

Quels enseignements et quelles conclusions tirer?

La perspectiva de género en investigaciones sociales

Norberto Inda

Introducción

Perspectiva de género

¿Género o mujeres?

El género varón

Complejización de la perspectiva de género

\section{Mouvements de quartier, recherche-action et rapports de genre}

Déploiement des mouvements de quartier à forte participation féminine : la réinvention culturelle du politique

Christine Verschuur

La educación popular y las relaciones de género en las organizaciones de base en República Dominicana y Cuba

Isabel Rauber

1. Los «terrenos» y los actores

El problema de investigación

Primeros pasos de la investigación: Imaginarios y roles

Una riqueza metodológica: la educación popular

Conclusiones a modo de reflexión general

Las mujeres en los espacios comunitarios. «La matriz comunitaria de sociabilización», un espacio político en gestación? Las manzaneras de San Cayetano, Campana, Argentina Álvaro San Sebastián

Introducción

Los nuevos escenarios políticos, económicos, sociales y culturales

Programa VIDA: las características de un programa focalizado

El fenómeno de la participación de las mujeres en la comunidad

El triple rol: un concepto que deberíamos problematizar

La matriz comunitaria de sociabilización 
Droit au logement: le mouvement des femmes au Brésil et l'expérience dans la favela Gamboa de Santo André, São Paolo, Brésil

Sonia Alves Calió et Iranilde José Messias Mendes

Introduction

La crise du logement urbain : une question de politique publique de genre ou comment les femmes peuvent accéder au logement et au titre de propriété

Quelques considérations finales

\section{Citoyenneté, environnement et politiques publiques dans une favela au Brésil}

Marta Cassaro-Silva

Introduction

Le terrain

L'écosystème urbain dans la Gamboa

La participation citoyenne

L'« alphabétisation » à l'environnement

L'essor du mouvement urbain à Sofia, Bulgarie

Iskra Dandolova

Introduction

Le point de départ : la dégradation de l'espace urbain et des espaces verts à Sofia

La société civile : combattre la peur pour s'opposer aux autorités et défendre les espaces verts - une nouvelle réalité pour les Bulgares

La lutte pour sauver les espaces verts : les femmes, suivies par les hommes

La lutte pour l'environnement durable : ensemble contre l'adversaire commun

Les premiers résultats positifs suite à l'essor du mouvement urbain

Conclusions : reconnaître les habitants comme acteurs dans la gouvernance urbaine

Bénéficiaires actives ou citoyennes critiques? La participation des femmes pauvres dans la gouvernance locale, Kerala, Inde

Sandra Walter

Introduction

Les réformes et le développement des quartiers défavorisés

Kudumbashree : la lutte contre la pauvreté devient une affaire de femmes

La participation des femmes pauvres au processus de planification

Conclusion

Groupements d'Intérêts Economiques Féminins, privatisation des services publics et accès équitable au politique : enseignements tirés à Ouagadougou, Burkina Faso

Kadidia Tall

Avant-propos

Introduction

Nos vécus sur le terrain et avec l'équipe

Ma conviction sur les résultats obtenus

La capitalisation des acquis

Organisations associatives, espace public, accès au débat public et à la prise de décision par les femmes à Santhiaba, ville de Pikine, Sénégal

Mohamadou Abdoul

Introduction

Les sites de la recherche-action

Vers un espace public local plus ouvert aux femmes?

Hommes et femmes dans l'environnement urbain

Conclusion 
Instrumentalisation des femmes ou nouvelles perspectives ? Recherche et politiques publiques

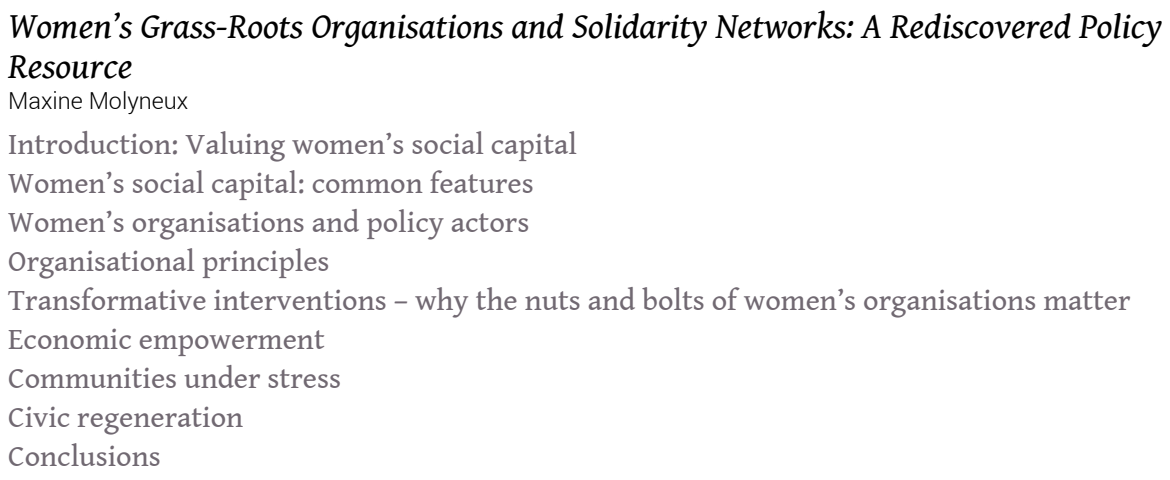

Les défis actuels qui se posent à la recherche et aux décideurs en matière de politique de développement dans un monde globalisé

Serge Chappatte

Introduction

Les frontières traditionnelles s'estompent, les lignes de démarcation et de clivage se modifient Les défis actuels constatés sur le marché international de la recherche

Etablir et renforcer des ponts entre la recherche et la politique

Que fait la DDC dans ce domaine?

Gestion des transformations sociales

Christina Von Fürstenberg

Développer la recherche en sciences sociales

Impératifs sociaux et intervention politique

Un outil pour la diffusion des résultats des recherches en sciences sociales Vincent Maugis

Enjeux de l'action publique dans la ville face aux mouvements sociaux Isabelle Milbert

La vulnérabilité des villes du Sud et des quartiers pauvres

La construction de normes au niveau supranational

La construction de quatre types d'outils communs aux objectifs d'inclusion sociale et d'équité de genre

Conclusion

\section{Postface}

L'introduction progressive de la perspective de genre à l'IUED

Christine Verschuur

\section{Annexes}

Présentation des intervenant-e-s

Presentation of the speakers 
Emprise du genre dans le développement et recherche 


\title{
Dix ans de colloques internationaux genre et développement à l'IUED. Justice sociale et justesse des analyses : la puissance du genre
}

\author{
Christine Verschuur
}

1 L'influence des colloques genre a été décisive dans la dynamique d'institutionnalisation du genre à l'IUED'. Depuis dix ans, l'IUED organise des colloques sur des thématiques qui lient études du développement et rapports de genre. Le premier colloque international s'est tenu en 1995, en même temps que la IV ${ }^{e}$ Conférence mondiale sur les femmes organisée par les Nations unies à Beijing. Chacun de ces colloques a donné lieu à une publication, largement diffusée, depuis quelques années maintenant également accessible par Internet.

2 Les colloques genre ont porté sur des thèmes aussi variés que les villes et l'environnement, la créativité, la santé, la masculinité, l'économie, les conflits, le pouvoir, les migrations...

3 Les colloques sont l'occasion de présenter des recherches, des réflexions, des activités militantes ou des programmes novateurs, d'avoir des débats contradictoires, de tisser des liens, de rencontrer des personnes travaillant dans des contextes différents (géographiques, disciplinaires ou institutionnels) et avec des cadres conceptuels non nécessairement semblables.

4 Le premier colloque s'intitulait «Femmes, villes et environnement». Une recherche internationale a émergé à la suite de ce premier colloque, conduite avec un réseau d'équipes de chercheurs, durant sept années dans sept pays différents: Argentine, Brésil, Cuba, Burkina Faso, Sénégal, Bulgarie, Roumanie. Dix ans après, c'était l'occasion de faire le bilan de cette recherche.

5 Le thème du dixième colloque reprend donc celui du premier, en tentant d'y apporter des perspectives et regards nouveaux, des questionnements différents, de contribuer 
avec des apports conceptuels, de présenter les résultats de la recherche menée durant toutes ces années.

6 En 1995, la recherche s'intéressait aux réponses apportées par des organisations des quartiers à l'accroissement des inégalités engendrées par ce processus d'urbanisation dans les pays du Sud, avec une perspective de genre. Cela passait par la reconnaissance de la forte présence - pourtant généralement non reconnue - des femmes dans ces organisations. Cela signifiait analyser le fonctionnement de ces organisations, structurées selon les asymétries féminin-masculin, et les changements des rapports de genre que la participation à ces organisations pouvait ou non encourager.

7 La forte urbanisation entraîne de rapides transformations des conditions de vie et des rapports sociaux, notamment ceux entre hommes et femmes. Les inégalités sociales s'approfondissent, la mondialisation néolibérale a des incidences considérables sur les transformations du travail (notamment celui des femmes), sur l'accès aux services de base et sur l'environnement.

8 Particulièrement affectées par la dégradation de l'environnement, dans l'urgence, et devant le manque de services publics, les femmes interviennent activement dans les mouvements de base, dans les quartiers, ou à d'autres niveaux pour s'organiser, résister, proposer. Dans cette entreprise, elles sont soumises à des pressions (menaces, déconsidération) ; mais elles revendiquent aussi et obtiennent l'ouverture de nouveaux espaces de négociation, d'action et d'intervention, de remise en question des rapports de pouvoir au niveau domestique ou dans les organisations et la vie politique.

9 La perspective de genre donne des clés de lecture pour comprendre la représentation et l'utilisation différentielle de l'environnement et de l'espace urbain. Elle demande de se pencher sur les représentations féminines ou masculines, sur le fonctionnement des institutions et des organisations, sur le pouvoir entendu comme constellation dispersée de rapports inégaux et, à l'intérieur de ces processus et structures, sur les capacités d'action de la personne comme sujet.

10 Pourtant, il ne suffit pas d'interroger l'asymétrie des rapports de genre et son implication sur l'environnement et le développement, il faut encore se demander de quelle manière il peut y avoir conscientisation de l'inégalité de ces rapports sociaux entre les hommes et les femmes et quelles seraient les possibilités de les changer afin de permettre à tous, sans exclure les femmes, une véritable participation aux choix et aux processus de prise de décision.

11 L'objectif du colloque en 2005 était de rendre compte comment l'introduction d'une perspective de genre ouvre de nouveaux horizons, de nouvelles pistes de compréhension et de réflexion, pour comprendre, mais aussi pour appuyer les mouvements de base, et fournir ainsi des éléments de compréhension aux diverses instances qui interviennent dans le domaine de l'environnement urbain, et plus largement dans les villes et le développement.

\section{Emprise du genre et développement}

12 Comment les différences entre hommes et femmes se traduisent-elles en inégalités? Comment expliquer la persistance des inégalités structurelles entre hommes et femmes? Quels sont les mécanismes qui reproduisent cette asymétrie ? La construction de la masculinité et de la féminité présente certes des différences selon les contextes 
dans lesquels elles se construisent et se reproduisent, historiques, culturels, géographiques, ethniques, religieux, selon l'âge et les différentes classes sociales. Mais ce façonnement asymétrique se traduit toujours en inégalités entre hommes et femmes.

Y a-t-il maintenant réellement une prise de conscience que ces inégalités-là ne peuvent être passées sous silence sous peine de déformer la réalité ? Pourquoi relever et dénoncer ce type d'inégalités là est-il souvent plus difficile que dénoncer les inégalités de classe, raciales, de caste, et autres? S'intéresse-t-on aux rapports inégaux entre hommes et femmes dans le développement parce qu'on vise la défense des droits - plus bafoués chez les femmes - et la justice sociale, ou parce que l'on vise des objectifs d'efficacité en incluant les femmes? Ne parvient-on à dénoncer ces inégalités que par l'artifice qui dit qu'elles sont contre-productives? Inclure les femmes n'est pas toujours, loin de là, et parfois même au contraire, synonyme de réduction des inégalités, si cela ne touche pas aux mécanismes de reproduction des inégalités.

Le genre est un outil pour analyser et comprendre la reproduction des inégalités entre hommes et femmes, pour éclairer le pouvoir insoupçonné et considérable qu'a cette asymétrie entre féminité et masculinité pour façonner les rapports sociaux. Cette dimension, peu incorporée dans d'autres cadres d'analyses (c'est un euphémisme), donne une profondeur nouvelle à la compréhension des faits sociaux.

15 L'analyse de genre passe par la compréhension de la manière dont les valeurs symboliques s'inscrivent dans les institutions, dans les processus sociaux, dans la perception et l'organisation sociale concrète. Les discours de légitimation se servent de la façon dont chaque société se représente le genre pour justifier, naturaliser, les inégalités. Ainsi peut-on observer de quelle façon le genre possède ce pouvoir de production et reproduction des inégalités entre hommes et femmes.

analyses des mouvements sociaux, la présence majoritaire des femmes et la division inégale des tâches en leur sein est rarement prise en compte. Lorsque les femmes se chargent de préparer les repas de milliers de piqueteros ${ }^{2}$, assurant au mouvement piquetero la possibilité de réaliser une action d'éclat, cette tâche est considérée comme allant de soi pour des femmes, comme une extension naturelle de la division des tâches domestiques; elle n'est ni reconnue ni valorisée et les femmes n'accèdent pas aux postes de responsabilité dans le mouvement. Sans leur présence massive, sans leurs encouragements, sans leur aide concrète, pourtant, ces mouvements auraient fait long feu.

17 Inclure une perspective de genre signifie se poser des questions comme celles-ci: comment expliquer la division inégale des tâches dans la sphère domestique, que celleci se perpétue, se reproduise et se traduise dans des inégalités dans la sphère productive, et dans la division internationale du travail ? Quels mécanismes permettent de maintenir les liens organiques entre sphère productive et reproductive, et donc la prospérité du secteur capitaliste?

18 En préservant l'économie domestique, qui permet de produire et reproduire la force de travail à moindre coût pour l'économie capitaliste, on assure la prospérité de cette dernière. Comme l'indiquait déjà Meillassoux en $1975^{3}$, l'économie domestique appartient à la sphère de circulation du capitalisme, qu'elle approvisionne en force de travail et en denrées, mais reste en dehors de la sphère de production capitaliste. C'est en maintenant ces liens organiques entre économie capitaliste et domestique que la première assure sa croissance et sa prospérité. Les enjeux actuels sont de maintenir 
cette articulation, en préservant l'une pour continuer à lui soustraire sa substance, sans la détruire, pour alimenter l'autre. Cela implique de conserver la sphère domestique en dehors de la sphère de production capitaliste, tout en maintenant les liens organiques entre elles.

Chacun sait que la majeure partie du «travail » au sein de l'économie domestique est réalisée par les femmes. Ce sont elles les principales responsables de la production/ reproduction de la force de travail, au sein de la famille, dans le cadre de rapports de production de type domestique.

Une partie de la force de travail produite - en grande partie - par les femmes du Sud, est exportée vers les pays du Nord ou vers les zones de production industrielle. Le nombre de migrants se monte actuellement entre 185 à 192 millions de personnes ${ }^{4}$ (OIM, 2005). Par ailleurs, on assiste à une internationalisation du marché du travail domestique: la moitié des migrants sont des femmes. Elles assurent des tâches reproductives dans des familles plus privilégiées (dans les pays tiers ou dans des pays du Nord), pour remplacer les femmes qui s'intègrent au marché du travail salarié. Le recours au marché mondial de la domesticité, chez des particuliers ou dans des institutions de soins est un phénomène croissant. L'articulation entre économie domestique et productive prend d'autres formes, mais repose toujours sur le travail non rémunéré à toute sa valeur - des femmes, dont celui des migrantes. Des études montrent que l'argent envoyé dans leurs familles d'origine par ces travailleuses migrantes représente des sommes considérables ${ }^{5}$, qui serviraient surtout à assurer la reproduction sociale dans les pays d'origine. Ceci tendrait encore à montrer que ce secteur appartient toujours à la sphère de circulation du capitalisme, consommant des biens, produits au Nord (gadgets notamment) ou dans les pays d'origine (frais d'alimentation, de logement, de santé et d'éducation), mais non à la sphère de production.

21 Souvent, les femmes ont été considérées comme une catégorie homogène, sans que soient prises en compte les différenciations de classe, ethniques, ou autres, entre elles. Longtemps aussi, les femmes sont restées invisibles en tant que travailleuses. Ces représentations erronées des femmes ont maintenant évolué, mais la reconnaissance $\mathrm{du}$ «travail» de reproduction sociale, sans laquelle pourtant l'économie ne pourrait tourner, n'est toujours pas un fait.

Une question centrale pour comprendre la persistance des inégalités sociales est celle de l'articulation entre ces deux « modes » de production. Les rapports de genre inégaux permettent de maintenir ce lien organique inégal, à travers les mécanismes qui reproduisent ces inégalités entre hommes et femmes.

Lors du colloque de 1995, je posais cette question : «Repenser, reconstruire le rapport entre ces deux sphères et entre les genres permettrait-il de bousculer la triste absence actuelle de perspectives de développement ? [...] Les organisations de base ont un rôle fondamental à jouer en tant qu'espace de transformations et de luttes pour favoriser les changements de pouvoir entre hommes et femmes et rendre ses droits au genre exproprié $»^{6}$. Dans le projet de recherche qui est né à la suite de ce premier colloque genre, nous avons justement accompagné, durant plus de sept ans, diverses organisations de base. Les résultats de ces travaux ont été discutés lors du dixième colloque genre de l'IUED, présentés dans ces actes ainsi que dans un livre sorti à l'occasion de ce colloque ${ }^{7}$. Ils ont notamment montré l'importance de l'effort à fournir sur les identités féminines et masculines. 

travail de production et va au-delà de la prise en charge de travaux utilitaires. Ce «travail», «naturellement» réservé aux femmes, à travers les mécanismes de reproduction des inégalités de genre, peut être à la fois source d'exploitation et de gratification. Dans la recherche mentionnée, qui s'est penchée sur les rapports entre hommes et femmes dans les mouvements de quartiers, ce constat apparaît également : les femmes s'investissent beaucoup dans ces organisations de base, mais leur engagement va bien au-delà des intérêts utilitaires, fussent-ils collectifs et en défense du bien-être social. Paradoxalement, cette surcharge de travail est aussi source de satisfaction, du fait de se retrouver entre elles, de sortir de leur confinement, de s'amuser, de partager des joies et des peines, de prendre conscience de situations oppressives similaires mais souvent tues. Cet élargissement de l'espace privé, fermé, vers un espace de quartier, plus public, avec une identité territoriale forte, occupé par un ensemble de personnes, et particulièrement investi par des femmes, est un passage qui ouvre la voie à des possibilités de changements des identités, de transformations sociales.

L'engagement particulièrement important des femmes dans les organisations des quartiers étudiés correspond à un mouvement culturel, à un effort de compréhension de ce que signifie être homme et être femme, de renégociation des rapports de pouvoir. Tout en reproduisant à l'échelle du quartier les asymétries entre hommes et femmes, il ouvre un espace de liberté, même si cela est exigeant en termes d'investissement en énergie et temps - parfois lourds. Il s'articule autour de la notion de prise de conscience de droits. Il esquisse des perspectives pour changer le monde au niveau d'un quartier, donc pour tracer une autre manière de faire de la politique, selon d'autres valeurs. Il force aussi le questionnement sur le fonctionnement des organisations de quartier, sur les rapports ambigus entre "société civile » et Etat. Ce processus paradoxal révèle les brèches dans lesquelles il est possible de s'engouffrer, grâce à l'espace de manœuvre ouvert par les différents types d'organisations de quartiers pour entamer les mécanismes de reproduction des inégalités.

N'est-il pas illusoire de penser pouvoir changer les rapports de genre? Einstein, on le sait, avait dit qu'« il est plus difficile de désagréger un préjugé qu'un atome »... Les rapports de genre seraient-ils aussi résistants au changement qu'un atome? Ils sont construits à partir de ce que représente, symboliquement, être femme et être homme dans chaque société, dans un groupe social, à un moment donné. Préjugés féminins et masculins traversent les institutions sociales. Celles-ci sont ainsi résistantes aux changements.

Si les préjugés sont résistants, il n'empêche que chaque femme et chaque homme, dans un effort de compréhension de la manière dont le genre structure l'organisation concrète et symbolique de toute la vie sociale, peut agir sur cette réalité. En prenant conscience des causes des inégalités, en prenant conscience du droit à avoir des droits, en développant la volonté de changement pour réclamer leurs droits, et en construisant leurs capacités pour obtenir leurs droits, les individu-e-s deviennent sujets-femmes et sujets-hommes de leur propre histoire ${ }^{8}$.

Le genre est, non seulement un outil d'analyse, mais un outil pour l'action. Il s'inscrit dans une démarche de transformation proche de celle de la recherche-action et des principes de l'éducation populaire. Loin d'être un concept normatif, il fournit des 
instruments d'analyse critique des fondements des inégalités, permettant à chacune et à chacun de repenser le développement.

\section{NOTES}

1. Voir l'article de l'auteur «L'introduction progressive de la perspective de genre à l'IUED » dans ce même volume.

2. Mouvements de chômeurs en Argentine, qui organisent des barrages de route pour réclamer le droit au travail.

3. Meillassoux, 1975, Femmes, greniers et capitaux, Maspéro, Paris, pp. 145-149.

4. OIM, 2005, Etat de la migration dans le monde en 2005, Genève.

5. Selon la Banque mondiale, l'argent envoyé sous forme de mandats par les travailleurs immigrés, qui sont pour moitié d'entre eux des femmes, représentait un montant de 167 milliards de dollars en 2005 , le double d'il y a cinq ans. Les fonds transmis par des voies informelles pourraient accroître l'estimation officielle d'au moins $50 \%$. Cela représente environ le double de l'aide publique au développement, et une source majeure du financement extérieur. World Bank, 2006, Implications économiques des envois de fonds et de la migration, Washington, dossier de presse sur Internet : <http://web.worldbank.org/WEBSITE/EXTERNAL/ACCUEILEXTN/NEWSFRENCH/ 0,contentMDK:20726363 pagePK:64257043 piP:437376 theSitePK:1074931,00.html>.

6. Verschuur, Christine, 1995, «Du bon genre... ou des relations de genre appropriées », Femmes, villes et environnement, Actes du colloque Genre, Commission nationale suisse pour l'UNESCO, DDC, IUED, Genève, 229 p. p. 77-78.

7. Hainard, F. et Verschuur, Ch., 2005, « Mouvements de quartiers et environnements urbains, la prise de pouvoir des femmes dans les pays du Sud et de l'Est », éd. Karthala, Paris, 370 p.

8. Voir : Rauber, Isabel, 2003, Movimientos sociales y representación política, Ed. Ciencias Sociales, La Habana, $117 \mathrm{p}$.

\section{RÉSUMÉS}

Les colloques internationaux "genre et développement» de l'IUED ont lieu depuis dix ans. Le premier colloque s'intitulait «Villes, environnement et genre». Une recherche internationale a émergé à la suite de ce premier colloque, conduite avec un réseau d'équipes de chercheurs, durant sept années dans sept pays différents: Argentine, Brésil, Cuba, Burkina Faso, Sénégal, Bulgarie, Roumanie. Dix ans après, c'était l'occasion de faire le bilan de cette recherche.

La recherche s'intéressait aux réponses apportées par des organisations des quartiers à l'accroissement des inégalités engendrées par ce processus d'urbanisation dans les pays du Sud, avec une perspective de genre.

La construction de la masculinité et de la féminité présente certes des différences selon les contextes dans lesquels elles se construisent et se reproduisent, historiques, culturels, 
géographiques, ethniques, religieux, selon l'âge et les différentes classes sociales. Mais ce façonnement asymétrique se traduit toujours en inégalités entre hommes et femmes.

L'analyse de genre passe par la compréhension de la manière comment les valeurs symboliques s'inscrivent dans les institutions, dans les processus sociaux, dans la perception et l'organisation sociale concrète. Les discours de légitimation se servent de la façon dont chaque société se représente le genre pour justifier, naturaliser, les inégalités. Ainsi, peuton observer de quelle façon le genre possède ce pouvoir de production et reproduction des inégalités entre hommes et femmes.

Dans les analyses des mouvements de quartiers, la présence majoritaire des femmes et la division inégale des tâches en leur sein est rarement prise en compte.

Cet article montre qu'il est essentiel d'analyser le fonctionnement de ces organisations, structurées selon les asymétries féminin-masculin, et les changements des rapports de genre que la participation à ces organisations peut ou non encourager, dans un souci de plus grande justice sociale.

The gender and development colloquia have existed for ten year at IUED. The first colloquium was entitled: «Cities, environment and gender». It brought about an international research conducted by a network of researchers teams for seven years in seven different countries: Argentina, Brazil, Cuba, Burkina Faso, Senegal, Bulgaria, Rumania. This project's tenth anniversary gave us the opportunity to share our assessment of this research.

The research addressed the responses of neighbourhood associations to growing inequalities resulting from the urbanisation process in the countries of the South with a gender perspective.

The construction of masculinity and femininity vary according to the historical, cultural, geographical, ethnic, religious, age and social class contexts in which they are built and reproduced. But it is an asymmetrical pattern that is always reflected by inequalities between men and women.

A gender analysis entails understanding how symbolic values are engraved in the institutions, in the social processes, in the perceptions and in the concrete social organisation. Legitimising discourses use each society's way of representing gender to justify, naturalise, inequalities. Therefore we can see how gender has the power to produce and reproduce the inequalities between men and women.

In neighbourhood movements analysis, the fact that women are the majority and the unequal division of tasks within the movement are rarely considered.

This article shows how important it is to analyse the functioning of these organisations, structured as they are by female-male asymmetries, as well as the changes in the gender relationships that can or cannot be encouraged by participation in these organisations, in order to bring about more social justice.

Los coloquios internacionales "género y desarrollo» del IUED tienen lugar desde hace diez años. El primer coloquio trataba del tema «Ciudades, medio ambiente y género». Una investigación internacional surgió de este primer coloquio, conducida con una red de equipos de investigadores, durante siete años en siete países diferentes: Argentina, Brasil, Cuba, Burkina Faso, Senegal, Bulgaria, Rumania. Diez años después se hizo el balance de esta investigación.

La investigación se interesó por las respuestas dadas por organizaciones barriales al crecimiento de las desigualdades generadas por el proceso de urbanización en los países del Sur, con una perspectiva de género. La construcción de la masculinidad y la feminidad presenta ciertamente diferencias según los contextos en los cuales se construyen y se reproducen, históricos, culturales, geográficos, étnicos, religiosos, según la edad y las clases sociales. Pero esta construcción asimétrica se traduce siempre en desigualdades entre hombres y mujeres. El análisis de género pasa por la comprensión de la manera cómo los valores simbólicos se inscriben en las instituciones, en los procesos sociales, en la percepción y la organización social concreta. 
Los discursos de legitimación se sirven de la forma en que cada sociedad se representa la género para justificar, naturalizar, las desigualdades. Así se puede observar de qué manera el género posee este poder de producción y reproducción de desigualdades entre hombres y mujeres.

En los análisis de los movimientos barriales, la presencia mayoritaria de las mujeres y la división desigual de las tareas en su seno raramente se tiene en cuenta.

Este artículo defiende que es esencial analizar el funcionamiento de estas organizaciones, estructuradas según las asimetrías femeninomasculino, y las transformaciones en las relaciones de género que la participación en estas organizaciones puede o no fomentar, en vista a mas justicia social.

\section{AUTEUR \\ CHRISTINE VERSCHUUR}

Anthropologue, titulaire d'un doctorat de l'université de La Sorbonne, chargée de cours en genre et développement à l'Institut universitaire d'études du développement, Christine Verschuur travaille depuis de nombreuses années dans le domaine du genre et développement, dans des projets de recherche et d'enseignement. Elle est coordinatrice du projet Suisse « Villes, environnement et rapports sociaux entre hommes et femmes » du programme MOST de l'UNESCO depuis 1996 avec François Hainard. Directrice de la publication Les Cahiers genre et développement, qui paraissent annuellement depuis 2000 chez L'Harmattan, elle est coresponsable du pôle genre et développement de l'IUED et des colloques genre. 


\title{
Sept ans de recherche sur sept terrains à la fois !
}

\author{
François Hainard
}

1 Est-ce nécessaire de dire qu'il est très difficile de présenter rapidement l'essentiel d'une recherche qui aura duré au moins sept ans dans sept pays différents sur trois continents? Une des particularités de cette recherche est certainement d'avoir osé combiner à la fois une approche méthodologique comparative articulée sur une démarche de recherche-action, dans une perspective de genre, le tout dans une dimension internationale! La manière choisie ici pour rapporter succinctement quelques-uns des résultats se fera à travers deux axes principaux. Le premier reprendra quelques interrogations portant sur les aspects méthodologiques et épistémologiques qui ont nourri cette recherche. Puis, en second lieu, nous procéderons à une présentation factuelle et analytique des enseignements issus spécifiquement des terrains, de sorte à pouvoir saisir les enjeux propres à la gestion d'environnements locaux très problématiques et connaître les réponses que les populations concernées, en particulier les femmes, leur ont données.

\section{Une recherche particulière à différents points de vue}

2 Les questionnements relatifs à la méthodologie valent en effet la peine d'être abordés puisqu'une telle entreprise de recherche (de longue durée et internationale) soulève de nombreux problèmes du fait de la diversité des champs d'investigation et du nombre élevé d'équipes à faire travailler en réseau sur une même thématique, mais dans des contextes très différents. Dès lors, l'exercice d'un bilan offre une excellente occasion pour revenir sur le contenu et la pertinence d'une problématique définie au début du travail et qui aura orienté la recherche durant toutes ces années. En quoi celle-ci s'estelle révélée appropriée aux objectifs initiaux? Quels enseignements peut-on tirer d'un travail de recherche organisé en réseau? Quels sont les apports et les difficultés inhérents à la technique de la recherche-action participative? Comment a joué la mise en comparaison internationale des résultats et selon quelle pertinence? Quelle est la force de l'analyse de genre? Quels rôles joue-t-elle dans les processus de 
conscientisation des populations compte tenu des problèmes qu'elles rencontrent et comment gère-t-on la difficulté de l'appliquer à des contextes culturels très différents ? Telles seront quelques-unes des questions abordées spécifiquement ou transversalement tout au long de la première partie de notre propos.

3 La seconde partie tentera de reprendre certains des acquis émanant des terrains proprement dits, en nous interrogeant sur ce que nous avons appris «à chaud»en termes d'expériences concrètes et d'analyses utiles pour mieux comprendre, voire gérer les transformations sociales. En effet, durant la seconde phase de notre recherche (2001-2004) nous avons mis sur pied, en concertation avec les populations concernées et en fonction de leurs souhaits, toute une série d'actions dans les différents terrains.

4 Pour toutes ces raisons, nous avons recouru à l'analyse transversale de la construction sociale des rapports sociaux entre hommes et femmes. D'abord en décrivant, puis en accompagnant les populations locales dans leurs actions régies par la nécessité de gérer ces environnements urbains problématiques, c'est-à-dire d'être dans l'urgence de trouver tant que possible les solutions qui permettent de résister dans des contextes difficiles en terme de conditions de vie... ou de survie! Notre travail a voulu intégrer les rapports de genre qui passent par plusieurs perspectives incontournables étroitement liées les unes aux autres. Nous synthétisons ici leurs contenus en les articulant selon deux perspectives principales. Tout d'abord, vouloir considérer les rôles sociaux liés aux sexes suppose une analyse des images et des symboles véhiculés par les hommes et les femmes dans leurs représentations respectives du féminin et du masculin, de fait, à l'origine d'interprétations métaphoriques et hiérarchisées à valeur normative et ce jusque dans les identités "genrées ", c'est-à-dire socialement et culturellement construites. Ensuite, une démarche recourant au genre réfère intrinsèquement à la notion de pouvoir, à savoir non seulement celui qui est politique et s'exerce publiquement et institutionnellement, mais aussi celui qui plus sournoisement se lit dans des rapports de force qui affectent les relations sociales, y compris domestiques, sous le couvert de stratégies de domination, conscientes ou non.

5 Ces deux perspectives telles que nous les résumons peut-être un peu trop schématiquement ici renvoient donc essentiellement aux dimensions sociale et culturelle d'une part, et politique d'autre part ${ }^{1}$. Elles supposent dès lors une démarche constructiviste qui fait constamment appel à ce qui permet d'expliquer et surtout de légitimer des différences entre les sexes tout en les considérant respectivement dans leurs référents spatiaux, temporels et institutionnels. A cette nécessité de construire, ou plutôt de transiter par une déconstruction des catégories populaires ou scientifiques nécessaires aux justifications des inégalités, s'ajoute encore l'exigence (certes évidente pour des sciences sociales) d'une contextualisation pour permettre la saisie véritable des mécanismes propres aux rapports sociaux de sexe. En ce sens, la perspective genre peut donner lieu à des études spécifiques sur la structure des relations sociales entre hommes et femmes, mais peut aussi être utilisée, ainsi que nous l'avons fait avec l'environnement urbain, comme démarche pour une lecture de ces relations dans une problématique plus circonscrite.

6 C'est bien cette seconde manière de faire qui nous a intéressés ici, puisque c'est la dimension transversale de l'analyse de genre qui est reprise pour mieux saisir les stratégies mises en place par des hommes et des femmes soucieux de remédier à des réalités environnementales très difficiles vécues au quotidien. "Environnement » au sens large puisque s'il s'agit en effet pour la plupart du temps des aspects naturels ou 
écologiques en milieu urbain, ils sont abordés sous l'angle de l'habitat et de sa réhabilitation, des infrastructures en général (eau, transport, énergie...), de la santé, de l'alimentation, de la sécurité, des déchets, mais aussi de la solidarité et des manières de faire propres aux hommes et aux femmes qui tentent de résoudre tout ou partie des problèmes qui se posent à eux souvent en urgence.

\section{Questions de méthode et originalité de la démarche}

7 Cette recherche présente un triple intérêt. En premier lieu, les différents terrains révèlent la manière dont les problèmes environnementaux (tels que nous les définissons ci-avant) sont perçus, interprétés et évalués selon le sexe. C'est ici qu'intervient en force la notion de risque dont on peut mesurer les particularités attachées aux représentations et aux perceptions propres aux femmes et aux hommes. En effet, la nature, l'environnement, le risque sont des objets qui se construisent en rapport avec l'univers symbolique des acteurs, leurs émotions et leurs valeurs, l'héritage culturel collectif et l'habitus de chacun. Les rapports aux risques et à la connaissance des risques étant culturellement déterminés (Douglas et Wildavsky, 1984), les comportements déployés sont donc fortement contrastés selon les systèmes de valeurs privilégiés et l'environnement social et naturel auquel chaque acteur se réfère. Il s'agit notamment des connaissances dont les personnes disposent ou ne disposent pas, et qui jouent dans la compréhension des problèmes environnementaux, des valeurs auxquelles elles adhèrent et qui interviennent dans leur vision de la société et leur projet individuel, de l'image qu'elles se font des rapports qu'elles entretiennent avec l'environnement et des responsabilités individuelles et collectives qui en découlent. Nous ne vivons plus dans des sociétés où seule la répartition des richesses est source d'inégalités mais où celle des risques pèse toujours davantage (Beck, 1992) et en l'occurrence s'articule « étrangement » avec le genre.

Le deuxième intérêt de notre travail réside dans l'examen des politiques publiques (ou dans le constat de leur absence) directement concernées par les problèmes vécus par les populations des quartiers étudiés. Quels sont les dispositions et dispositifs envisagés par les autorités locales? Comment sont-ils décidés et concrétisés, que ce soit en termes de définition des urgences, du choix et de l'importance des moyens, que de la mise en place des procédures? Dans quelle mesure la population y est-elle associée, et en particulier de quelle manière les doléances et requêtes des femmes sont-elles considérées?

9 Enfin, le troisième grand intérêt de cette recherche concerne les stratégies retenues par les populations concernées pour tenter de remédier aux difficultés rencontrées au quotidien. C'est sur quoi nous avons le plus travaillé dans la première phase de ce vaste projet (1997-2001).

De nombreux éléments communs apparaissent dans les différents terrains investigués : persistance de décalages, voire de contradictions entre l'imaginaire et la réalité des rapports entre hommes et femmes; participation croissante des femmes à la prise en charge économique de la famille; reconnaissance sociale accrue des femmes du fait de la participation aux luttes, aux activités d'intérêt communautaire ou du soutien économique; accroissement de l'estime de soi et ouverture à l'extérieur; manque de participation visible aux instances de pouvoir. 
11 Dans le repérage et la compréhension de ces mécanismes, la prise en compte du droit joue comme un analyseur incontournable. On sait que le droit est l'expression des rapports de force, mais qu'il peut aussi fonctionner comme élément de transformation de ces rapports. Nous le considérons vraiment comme un élément clé à prendre en compte, soit parce qu'il convient de l'adapter aux transformations que connaissent les sociétés, soit pour s'y référer dans les actions qui vont dans le sens de plus de justice sociale et d'autres formes de développement économique.

Si le premier objectif est bien évidemment de saisir les manières dont règles et normes s'élaborent et s'appliquent à travers le prisme des représentations des rapports entre les sexes de ceux qui les édictent, c'est surtout dans la dimension des politiques publiques que les aspects juridiques émergent de manière la plus évidente. Il y a dans la définition de la règle à la fois une des clés de la construction des inégalités selon le genre, mais aussi une des manières de les limiter, voire de les éradiquer puisque c'est dans leur véritable application que les solutions existent. Nous savons que le droit, en général, quel que soit son champ d'application, est souvent beaucoup plus progressiste pour ce qui est de l'égalité entre les sexes dans son énonciation que dans son application. Certes, il existe des législations conservatrices ou rétrogrades, et de fait très défavorables aux femmes parce qu'élaborées sur des références religieuses ou traditionnelles qui peinent à s'adapter aux changements (nous pensons à nos terrains africains). Mais il existe aussi un droit tout à fait égalitaire et progressiste qui dans son énonciation ne lèse en rien les femmes, mais pourtant les désavantage scandaleusement dans leurs vies privées et publiques parce que les règles ne sont pas respectées dans leur application. Cela est presque universel et n'épargne pas les pays du Nord, bien que le principe de l'égalité entre les sexes figure en bonne place jusque dans leurs constitutions, mais où son application, par exemple dans le monde du travail en terme de salaire ou de promotion peine, à se concrétiser. La situation est certes encore plus manifeste dans les pays d'Amérique latine ou d'Afrique, où cela se vérifie dans de multiples domaines et jusque dans l'égalité d'un accès à la propriété immobilière ou foncière qui reste beaucoup plus difficile, comme cela a été particulièrement étudié avec les exemples du Brésil et du Sénégal.

\section{Les limites à la comparaison?}

13 Cette vaste recherche a offert la possibilité de s'interroger sur la pertinence d'une démarche comparative pour des situations étudiées qui, pour le moins que l'on puisse dire, se caractérisent tout de même par des spécificités très marquées. Mais rappelonsnous que sans comparaison, aucune différenciation, opposition, distinction ou au contraire similarité ou convergence ne peut être faite entre réalités géographiques, historiques ou sociales. Il s'agit là d'une question primordiale, voire intrinsèque aux sciences humaines et sociales. Comparer c'est provoquer le doute sur ce que l'on voit, exigence incontournable des sciences sociales, mais aussi de fait sur ce que l'on est, ce qui suppose un travail de soi sur soi. (Lenclud, 1995)

14 Cette recherche, faut-il le dire, tant cela peut paraître évident, s'est caractérisée par une folle diversité des terrains, mais aussi une incroyable diversité des équipes de par le panachage des formations scientifiques, richesses incontestables, mais aussi on peut s'en douter, des freins considérables de par certaines dissonances en termes d'approche ou d'analyse. A cela s'ajoutent les spécificités culturelles inhérentes à l'inscription 
contextuelle de chaque équipe, quelle que soit la formation du responsable. Un sociologue sénégalais n'a pas les mêmes sensibilités et préoccupations qu'un sociologue roumain ou suisse, même si les références théoriques de base sont certainement les mêmes. Car, par-delà les trajectoires personnelles, qui comptent considérablement dans les manières dont nous appréhendons la réalité, les situations politiques, économiques, culturelles et sociales sont-elles aussi multiples et modèlent à leur tour les représentations sociales des problématiques et les processus de construction des réalités étudiées.

Pour que les bases d'une approche comparative puissent au moins être réunies, il aura donc fallu revenir régulièrement et collectivement à la problématique, aux concepts et aux théories, à la méthodologie tant pendant les collectes de données, que lors de l'accompagnement des projets avec les populations concernées et le travail d'analyse. Il s'agit là à coup sûr d'une condition élémentaire, mais indubitablement incontournable à remplir si l'exercice de la comparaison veut être mis en place dans de bonnes conditions opératoires.

Pour certains, la comparaison serait donc habitée par une tendance technocratique qui, par souci d'efficacité, inviterait à gommer leurs spécificités culturelles. La comparabilité ne peut être alors «obtenue qu'au prix d'une mutilation des réalités comparées ». Cette pensée délaisserait l'analyse des valeurs ou de l'observation des pratiques réelles, au profit, par facilité, du recueil de l'information et des exigences bureaucratiques, d'organigrammes, de dispositions juridiques, de recensements d'effectifs ou d'indicateurs chiffrés, aspects plus que partiels d'une réalité multiple. (Bourdieu, Passeron, 1967, p. 22)

17 Mais il n'y a pas que la comparabilité des objets de recherche qui fasse problème, il y a aussi la cohérence des critères de comparaison, donc du choix et de la définition des catégories d'analyse et des indicateurs considérés. Nous n'échappons pas au fait que le réel n'est pas donné mais n'est que le produit d'une exploration qui passe par la médiation de constructions intellectuelles, se rappelant que "la réalité n'est qu'un idéal que le savoir rationnel se propose d'atteindre ». (Baechler 1986, p 32) Il faut donc, pour avancer dans la réflexion, passer à la fois de la juxtaposition d'effets nationaux à la construction des cohérences sociétales (Maurice, 1989), et mettre en place un inventaire critique des pratiques comparatives. Cela permet de constituer un corpus des pratiques sociales de recherche qui expliquent les logiques à l'œuvre dans les comparaisons, et en même temps cela aide à saisir les logiques des réalités étudiées et des nôtres. En d'autres termes, cela signifie s'arrêter à une démarche comparative fondée itérativement «davantage sur les contrastes et les différences que sur les similitudes, les analogies et l'identité ». (Busino, 1986, p. 216)

18 Contextualiser le fait social pour l'analyser c'est mieux échapper au risque de tomber dans la comparaison d'éléments particuliers, et c'est se donner la chance de le comprendre dans ses structures. Rendre la comparabilité possible suppose donc une activité réflexive sur le mode de penser notre rapport aux autres, puisqu'il s'agit de traduire des réalités différentes, par le détour de la compréhension de l'autre, facilitant ainsi un regard différent sur nous-mêmes. (Berthoud, 1986, p. 12) Encore faut-il être conscient de la langue-étalon de la comparaison, de son rattachement à un courant théorique et à un contexte socio-économique particulier. 


\section{Des questions et des doutes légitimes} de la contextualité des situations de terrains. Il est indispensable de se placer dans des perspectives historiques, politiques et sociales pour saisir les phénomènes étudiés. S'arrêter au rôle des femmes dans des environnements urbains précaires exige que l'on tienne aussi compte des réalités économiques et politiques. Ce ne sont pas seulement des données factuelles qui sont rapportées des différents terrains d'investigation, mais ce sont aussi des processus qui sont décrits, des systèmes de pensée et des manières de faire. Cela rend sans doute l'exercice de la comparaison encore plus délicat et difficile. En aucune façon nous ne sommes partis du principe d'une mise en évidence opératoire et exclusive des similarités, car il s'agissait aussi pour nous, le cas échéant, de souligner les différences. Ce qui fait certainement l'intérêt d'une telle démarche est donc à la fois la présentation contrastée des réalités de terrain, les spécificités des stratégies choisies par les femmes pour tenter de résoudre des difficultés selon les contextes et une similarité des rapports sociaux entre hommes et femmes, expression universalisée de la domination masculine.

La comparaison conduit à une hybridation des analyses ! Le produit de cet " exercice » est donc le fruit à la fois d'une «traduction» comparative pluriculturelle et pluridisciplinaire ne négligeant ni n'oubliant pour autant les particularismes locaux. Cette pluralité de lectures à différents niveaux a non seulement enrichi l'analyse propre à chaque terrain et celle comparative de l'ensemble, mais elle a aussi en quelque sorte neutralisé les dérives idéologiques conduisant à des interprétations inappropriées, même si les contaminations théoriques et conceptuelles ne sont pas à occulter, les rapports de domination existant aussi, on le sait bien, dans les champs scientifiques, et jusque dans chaque recherche empirique conduite collectivement.

\section{Une problématique utopique?}

22 Il est bien évidemment utile aux personnes préoccupées de transformations sociales découlant de paradigmes de développement différents de ceux qui dominent actuellement, de pouvoir analyser, comprendre et soutenir les actions sur le terrain avec les mouvements de base qui les animent. Pour cela, il convient de travailler à la diffusion d'expériences qui signalent la montée d'une confiance chez les femmes liée à un réajustement légitime de leur pouvoir. Il faut que ces actions, souvent novatrices et courageuses, soient connues des décideurs politiques, des responsables locaux et bien 
sûr dans les quartiers où les hommes et les femmes trop souvent ignorent tout bonnement ce qui se passe à côté d'eux.

Ce travail d'information fait à ce titre pleinement partie des dispositifs pour le changement. Mais si cela est une condition nécessaire, elle n'est malheureusement pas suffisante. Il faut encore qu'à la connaissance de ces actions, à cette confiance qui se construit, s'ajoute encore la garantie d'une application de tous les droits, qu'ils soient civils, économiques, sociaux, culturels, politiques. Nous sommes certains qu'il s'agit là d'une des lignes conductrices à privilégier si l'on souhaite influer sur les déséquilibres dans les rapports de genre et penser de nouvelles stratégies pour d'autres formes de développement. Notre problématique ne fut donc pas si utopique que cela et, par sa forte prise en compte du local, elle a conduit à des projets et des actions très concrètes.

Arrivés en fin de recherche, une des grandes interrogations est de savoir dans quelle mesure notre travail a véritablement renforcé les capacités d'action des femmes et favorisé des rapports plus équitables avec les hommes? En premier lieu, on a assisté à une conscientisation croissante de la réalité objective de leurs conditions de vie et, de fait, à un éveil quant aux situations de domination qu'elles subissent dans les relations de genre, tant au niveau des réalités domestiques et éducationnelles que politiques ou économiques. Cette prise de conscience a souvent passé par la mise en évidence des fragilités et des frustrations des femmes et des hommes, mais elle a aussi permis d'en repérer les forces à la fois manifestes et latentes. Elle transite presque toujours par un même processus, celui de la confiance en soi à travers le lent et inédit apprentissage de savoir s'estimer soi-même. Cette valorisation de la personne conduit à une réorganisation de ses sentiments identitaires, palier incontournable pour la construction d'une confiance nécessaire à l'entreprise de toute action individuelle ou collective. Ce processus de déconstruction/reconstruction de l'identité, certes se déroulant selon des modalités et des intensités très diverses, est visible sur presque chacun des terrains. Il se concrétise dans des initiatives multiples et d'envergures différentes: au niveau domestique ou du couple d'abord, par la revendication de nouveaux droits et l'acquisition de nouveaux rôles et statuts.

Mais un véritable empowerment s'exprime aussi par une capacité d'analyser sérieusement les situations dans lesquelles les personnes baignent au quotidien. Cette lecture lucide de la réalité conduit à ce que les femmes se rendent compte des interactions entre l'économique, le politique et le culturel, et à ce qu'elles apprennent à interférer avec les pouvoirs institutionnels. Elles réalisent alors que si ce pouvoir est incontournable, il est aussi joignable et interpellable selon des modalités fort diverses qui vont de la démonstration de rue, au soutien politique ou non lors d'élections, en passant dès lors par une aptitude (acquise souvent en formation) au dialogue et à la négociation. Cette nouvelle lecture des rapports de force leur fait comprendre le rôle et le poids des politiques publiques et la nécessité d'influer sur leurs contenus. Elles vont le faire à l'aide de compétences apprises qui, combinées à cette nouvelle confiance en elles, les rendent courageuses, novatrices et combatives. Le changement vient par elles, d'en bas; il se construit avec beaucoup de luttes et d'abnégation, mais aussi parfois avec de solides appuis et de fructueux partenariats.

26 La situation des femmes ne se transforme pas toujours, ni dans les communautés, ni dans tous les ménages; les actions entreprises pour l'application des lois et l'accès aux droits ne suppriment pas si rapidement l'aliénation culturelle d'une intériorisation séculaire des rapports de domination. Pourtant, toutes le disent: en sept années 
d'accompagnement avec les chercheurs locaux, leur vision du monde s'est transformée, leur personnalité aussi. Elles n'acceptent plus d'être déconsidérées, tues, ignorées, voire même battues comme avant. Elles reprennent possession d'une liberté de penser et de faire qui va jusque dans une réappropriation de leur corps (par exemple en transformant leur apparence ou plus fort encore en décidant de gérer leur fertilité par une ligature des trompes après de nombreuses grossesses successives, ce que selon leurs dires elles n'auraient jamais envisagé auparavant). Si toutes les aliénations et les difficultés sont loin d'avoir disparu pour autant, elles se sentent mieux dans leur peau et plus fortes pour résister ou agir parce qu'elles se connaissent mieux et comprennent mieux ce qui se passe autour d'elles et avec elles. Mais il faut noter qu'un gros travail de formation (enseignements divers: alphabétisation, initiation à l'informatique, apprentissage de la coiffure, éducation à l'environnement, cours d'auto-estime, de comptabilité, analyse de la situation économique et politique, etc.) et de réflexion collective (ateliers, forums, exposés) a été mis sur pied, parfois animé par les équipes de chercheurs, en accord ou à la demande des populations concernées

Dans cette nouvelle donne de rôles, certains hommes ont aussi trouvé du réconfort parce que, il faut le dire, il n'est pas facile d'être homme dans une culture machiste ou dans un contexte religieux qui vous attribue tous les pouvoirs et donc toutes les responsabilités, alors que justement il n'est plus possible de les assumer. Un rééquilibrage des relations de genre est alors ressenti comme un soulagement surtout s'il est amené délicatement, dans des conditions intelligentes qui ne font pas perdre la face à l'intérieur du groupe familial ou dans la communauté restreinte. Cette transformation des rôles sociaux entre hommes et femmes se fait d'autant plus facilement et en douceur que l'on voit des personnes relais se mettre à l'encourager : autorités politiques, enseignants, notables locaux, syndicalistes, assistants sociaux, médecins, chefs religieux.

\section{Quels enseignements et quelles conclusions tirer?}

Parmi les multiples enseignements à relever, nous mentionnerons d'abord le nécessaire renforcement des collaborations avec les autorités politiques de différents niveaux, du local jusqu'à celui de l'Etat, voire au-delà.

Puis la dimension très fortement initiatrice des identités individuelles et collectives (y compris masculines), par la confiance en soi ou les sentiments d'appartenance, dans l'élaboration de projets; le rôle aussi récurrent qu'incontournable de l'éducation populaire sur des thématiques très diverses allant de la compréhension des mécanismes sociaux, des inégalités de genre, à la construction d'un savoir local environnemental ; l'urgence d'une véritable mise en application des règles d'un droit trop souvent bafoué, tout particulièrement pour les femmes qui cumulent les injustices et les désavantages; ou encore la nécessité pour elles de collaborer avec les hommes (les mâles!) pour réussir dans leurs entreprises, en particulier celles liées au renforcement de leurs capacités et à la valorisation de leurs rôles et statuts, processus complexe conceptualisé dans cette recherche par le terme d'empowerment difficilement traduisible par un seul mot en français.

Enfin, la gestion des transformations sociales de la ville et la mise en forme d'un développement local où les femmes ont leur juste place ne se feront pas sans la dénonciation de ce processus particulier qu'est la privatisation d'un Etat qui délègue 
toujours davantage ses responsabilités et en l'occurrence ses fonctions régulatrices à des groupes situés en dehors de la sphère publique. Il est vrai que partout nous avons rencontré la situation récurrente « de quasi-impossibilités » à mettre en œuvre dans les niveaux politiques et organisationnels les plus bas, là où naissent les processus décisionnels ascendants facilités par la proximité et l'interconnaissance, et là où il y a aussi une vraie perception des problèmes vécus dans les quartiers. Ces carences sont démobilisatrices tant pour les populations que pour les élus locaux, car il faut pouvoir disposer d'un minimum de moyens pour répondre aux nombreuses attentes et entretenir de la sorte un précieux capital social, sans parler d'une bonne qualité de vie.

31 Un travail de décentralisation du pouvoir politique et des ressources fiscales semble toujours plus nécessaire si l'on veut tendre vers un véritable fonctionnement démocratique dans les structures organisationnelles de base et aller dans le sens de cette fameuse «bonne gouvernance»! Nous sommes convaincus en effet qu'un vrai renforcement de l'Etat ne transite que par une sérieuse décentralisation des pouvoirs et d'efficaces mécanismes de redistribution des richesses.

Sans aucun doute cette recherche fut un peu mégalo, peut-être présomptueuse, mais elle fut à coup sûr passionnante et attachante de par les multiples rencontres et amitiés construites durant ces années, même si elle fut difficile à mener. Faut-il rappeler que l'empowerment des femmes n'est pas simple à soutenir, que le travail d'encouragement est complexe à mettre en œuvre tant les blocages et les résistances sont aussi divers que solides?

Outre ce constat irréfutable, nous pouvons nous interroger si nous avons vraiment produit des connaissances susceptibles de mieux expliquer les transformations sociales que connaissent les villes et que vivent les populations marginalisées. Sommes-nous à même de prétendre avoir contribué par cette recherche à la mise en place de politiques susceptibles d'améliorer la qualité de vie des populations avec lesquelles nous avons travaillé ? Nos résultats sont-ils véritablement utilisables pour l'action collective et la prise de décision? Et nourrissent-ils avantageusement l'interface entre une recherche en sciences sociales et l'élaboration de politiques publiques urbaines? Il serait prétentieux de répondre haut et fort par l'affirmative à ces questions qui correspondent à quelques-uns des objectifs initiaux du programme MOST, tant les réalités sont complexes, les avancées fragiles et les certitudes discutables. Mais il serait tout aussi malhonnête et injuste de répondre par la négative eu égard aux résultats obtenus et à tous les efforts fournis par les populations qui se sont investies dans des initiatives originales et des revendications parfois douloureuses, sans oublier le travail des chercheurs qui les ont accompagnées dans leurs démarches.

La question des retombées scientifiques est plus compliquée qu'elle en a l'air. Ce dont nous sommes certains est que cette recherche fait partie d'un long processus collectif de compréhension des mécanismes sociétaux et plus particulièrement de celle des dégradations économiques et sociales qui caractérisent notre époque. Nous savons aussi que nous rendons compte de pratiques novatrices initiées dans des contextes sociaux et environnementaux difficiles, menées au quotidien et qui ont parfois à faire avec la survie. Nous en avons signalé les enjeux importants ainsi que la place et le rôle d'acteurs incontournables. Nous rendons compte de leur abnégation, leur imagination, leur force investies dans les batailles conduites, mais nous disons aussi leurs fatigues et leurs désespoirs face aux inerties, aux mystifications ou tout simplement aux forfaitures auxquelles ils sont confrontés. Face à la complexité de la réalité et à 
l'urgence qui la caractérise, cette recherche et le dernier livre collectif qui la résume (Hainard, Verschuur, éd., 2005) ne sont sans doute qu'une modeste étape dans une longue démarche soucieuse d'expliquer les problèmes de ce monde et de les dénoncer.

\section{BIBLIOGRAPHIE}

BAECHLER, J. 1986. « Les présupposés de la comparaison ». Revue européenne des sciences sociales $\mathrm{n}^{\circ}$ 72. La comparaison en sciences humaines et sociales, pp. 17-32.

BECK, U. 2001. La société du risque. Sur la voie d'une autre modernité. Paris : Aubier.

Berthoud, G. 1986. « La comparaison : une idée ambiguë ». Revue européenne des sciences sociales no 72. La comparaison en sciences humaines et sociales, pp. 5-16.

BOURDIEU, P., et PASSERON, J.-C. 1967. « La comparabilité des systèmes d'enseignement ». In R. Castel et J-C. Passeron, éd., Education, développement et démocratie. Paris : Mouton et Ecole pratique des hautes études, pp. 21-58.

BUSINO, G. 1986. « Pour une théorie de la comparaison ». Revue européenne des sciences sociales $\mathrm{n}^{\circ}$ 72. La comparaison en sciences humaines et sociales, pp. 209-216.

DOUGLAS, M., et WILDAVSKY A. 1984. Risk and Culture An Essay on the Selection of Technological and Environmental Dangers. Berkeley : University of California Press.

HAINARD, F. et VERSCHUUR, C. 2001. « Filling the Urban policy Breach : Women's Empowerment, Grass-roots Organizations and Urban Governance ». International Political Science Review, vol. $22, \mathrm{n}^{\circ} 1, \mathrm{pp} .33-54$.

HAINARD, F. et VERSCHUUR, C. 2003. « Gender Relations and Grass-roots Urban Movements ». International Social Science Journal, $\mathrm{n}^{\circ}$ 177, pp. 473-488.

HAINARD, F. et VERSCHUUR, C. (éd.). 2005. Mouvements de quartier et environnements urbains. La prise de pouvoir des femmes dans des pays du Sud et de l'Est. Dakar : ENDA et Paris : Karthala.

LENCLUD, G. 1995. « Quand voir, c'est reconnaître. Les récits de voyage et le regard

anthropologique ». Enquête, $n^{\circ} 1$, pp. 113-129.

\section{NOTES}

1. Contraint d'être bref, nous renvoyons à quelques-unes de nos publications plus conséquentes, notamment Hainard et Verschuur 2001, 2003 et 2005. 


\section{RÉSUMÉS}

Cet article explore les interrogations méthodologiques et épistémologiques qui ont nourri le projet de recherche-action MOST-UNESCO mené sur sept terrains différents. Il présente ensuite les enseignements issus de cette recherche de façon à saisir les enjeux propres à chaque terrain de la gestion d'environnements locaux très problématiques et pour connaître les réponses que les populations concernées, en particulier les femmes, leur ont données.

This article explores the methodological and epistemological questioning that nourished the research-action MOST-UNESCO project developed in seven different sites. Then it presents the results that came out of this research so as to understand each site's own challenges related to the management of very problematic local environments and in order to find out the responses of the concerned people, especially women.

Este artículo explora las interrogaciones metodológicas y epistemológicas que alimentaron el proyecto de investigación-acción MOST-UNESCO llevado a cabo en siete terrenos diferentes. Luego se presentan las lecciones aprendidas como resultado de esta investigación, de tal modo que se pueda entender los intereses puestos en juego, propios de cada terreno, y de la gestión de entornos locales problemáticos. Se destacan las respuestas que dieron las poblaciones respectivas, en particular, las de las mujeres.

\section{AUTEUR}

\section{FRANÇOIS HAINARD}

Professeur et directeur de l'Institut de sociologie de l'Université de Neuchâtel, Suisse. Ses travaux de recherche portent sur l'économie, l'environnement et les problèmes sociaux. Depuis 1997, il est l'un des deux coordinateurs du projet MOST-UNESCO « Genre, ville et environnement ». 


\title{
La perspectiva de género en investigaciones sociales
}

\author{
Norberto Inda
}

\section{Introducción}

1 Estas reflexiones parten de nuestra participación en el capítulo argentino de la investigación-acción «Ciudad, medio ambiente y relaciones entre varones y mujeres», que comenzara en 1997 y se extendiera hasta el 2004. La misma que tuvo lugar en el barrio de San Cayetano, ciudad de Campana, Provincia de Buenos Aires, el territorio más vasto y poblado de la República Argentina, donde además se dirimen y definen los lineamientos políticos del resto del país. Justamente en esta Provincia se implementa desde el año 1995 el Plan Vida, un programa de carácter asistencial impulsado con el esfuerzo del estado, las organizaciones intermedias y una red solidaria de mujeres. Fue puesto en marcha por Hilda G. de Duhalde, esposa del gobernador de la Provincia en aquel momento, el dirigente peronista Eduardo Duhalde.

2 La particularidad de este programa de política pública, - el Plan Vida - es que estuvo y está implementado por mujeres, las propias beneficiarias, llamadas «manzaneras». Sus objetivos prioritarios son la lucha contra la pobreza, brindando apoyo nutricional particularmente a mujeres embarazadas y niños, como también tender a la disminución de las enfermedades. También son mujeres las protagonistas del «Programa Comadres» cuyo objetivo específico es contribuir a disminuir los riesgos de morbimortalidad materno-infantil en las mujeres embarazadas, beneficiarias del Plan Vida.

Las manzaneras como sujetos de asistencia social forman parte de una red de 40.000 mujeres en los distintos distritos de la Provincia de Buenos Aires. Ellas fueron protagonistas de nuestra investigación, en la cual destacamos sus relaciones con los varones y el resto de los actores sociales de su comunidad. La misma propulsora del Plan Vida, explica hasta que punto, los rasgos conocidos y atribuidos «naturalmente» a las mujeres guiaron la elección de las mismas, como actrices principales: «la propuesta de la participación de la mujer en las redes barriales solidarias cumple un doble objetivo: tomar para la formación de la red al actor social más capacitado para el desempeño de la función y 
motivarla con tareas y capacitación para proyectarse en una realidad más abarcadora que las cuatro paredes de su casa» ${ }^{1}$. Ya analizamos en dos trabajos anteriores ${ }^{2}$ en qué medida esta delegación de funciones, que amplifica hacia la comunidad algunas de las características de género, es un pasaporte al empoderamiento o una ampliación del rol conocido de las mujeres, ahora dirigido a los vecinos y a la comunidad.

Intentaremos abordar qué entendemos por "perspectiva de género» a partir de la experiencia que durante casi ocho años sostuvimos en Argentina. También nos han enriquecido las visitas a algunos de los diferentes terrenos en que se desarrolló esta Investigación-acción, como la lectura de los informes de nuestros colegas en otros países. Los seminarios anuales y también los regionales se constituyeron en una ocasión privilegiada para el intercambio de ideas, la discusión de disensos, y hecho de abrirse a diferentes perspectivas. Varias de las ideas que a continuación desarrollamos nacieron en esos encuentros.

Observamos que, en estos contextos, - como parece esta ocurriendo planetariamente un hecho decisivo es la creciente participación comunitaria de las mujeres en la promoción de mejoras sociales y ambientales. Y un marcado retraimiento de los varones, reticentes a estas nuevas modalidades de intercambio. Trataremos de problematizar porqué se habla de «Perspectiva de Género», término relacional por excelencia, cuando luego, los pasos y trabajos imprescindibles para la promoción de la mujer se desarrollan excluyentemente. Esto va en paralelo al vacío que observamos con relación al conocimiento de las condiciones de vida de los varones (que también son seres de género) y la dinámica de las relaciones entre ambos, además de sus relaciones con el medio. El propósito es particularizar estos fenómenos en los actuales contextos de cambio en Latinoamérica, relacionándolos con los devastadores efectos de la globalización de las políticas neoliberales, el debilitamiento de los estados, la privatización de los servicios y la pobreza creciente, entre otros aspectos.

\section{Perspectiva de género}

6 La denominada perspectiva de género se ha tornado un instrumento indispensable en las investigaciones sociales al dar a luces sobre las diferentes formas de construcción de identitaria de mujeres y varones, sus maneras particulares de actuar, percibir, entender, sentir, hablar e interactuar, además de los diferentes vínculos que se establecen entre ellos. Desde el comienzo de nuestra tarea en el barrio se perfilaron con claridad las diferentes maneras de percepción del espacio, del entorno, de las casas, de las diferentes prioridades, etc., por parte de las vecinas y los vecinos del barrio. La perspectiva de las relaciones de género (que son relaciones de poder también) ha devenido en una herramienta política clave en las prácticas emancipatorias, toda vez que las diferencias de género derivan en desigualdades.

7 Por el contrario las estadísticas, informes e investigaciones que no diferencian el mundo de lo masculino y lo femenino recaen en la abstracción de hablar del hombre o de los seres humanos como si se tratara de un continuo homogéneo. Por ejemplo, cuando en nuestro país se describe el número de accidentes de tránsito y las consecuencias que esto provoca, además de quedar delatada una de las primeras causas de mortandad, queda invisibilizado el hecho de que los muertos por accidentes de todo tipo son porcentualmente, en su mayoría varones. Y cómo, por otro lado, todo este problema delata una manera de «hacerse varones». O que, para citar otro ejemplo, en 
muchas regiones de África, los guarismos de producción agrícola sin perspectiva de género dejarían de destacar que los trabajos en ese sector lo realizan básicamente las mujeres.

8 Como la lengua que nos precede desde la gestación, ingresamos en una bi-partición planetaria que divide a los seres humanos en mujeres y varones, una determinación tan universal como el tabú del incesto, como una precondición de la cultura. T. de Barbieri, 1992: 114, define al género como «el conjunto de prácticas, símbolos, representaciones, normas y valores que las sociedades elaboran a partir de las diferencias anatómicas, que dan sentido a las relaciones entre las personas». La noción de género nos habilita para poder comprender la dimensión simbólica de la femineidad/masculinidad fuera de todo resabio naturalista. Diferenciamos entonces el sexo biológico, es decir la anatomía que portamos al nacer, del género, que es mas bien una construcción cultural.

El proceso de hacer de las personas seres de género comienza con el nacimiento, con las particularidades culturales de las diferentes geografías. En nuestro país, a la niña la vestirán preponderantemente de rosa y al niño de celeste, así, desde ese momento se pone en funcionamiento una tarea sistemática (en la escuela) y asistemática (en la vida cotidiana) de hacer de la niña una mujer y del niño, un hombre (o un varón como lo mencionaremos en adelante para evitar las generalizaciones androcéntricas que hacen de la palabra hombre un sinónimo del ser humano como conjunto).

Mas allá de las diferencias contextuales de los distintos terrenos de la red que nos ocupa, de sus formas organizativas, de variables sociales, religiosas, étnicas, de clase, etc., notamos que se repite la percepción de una mayor facilidad de las mujeres para ingresar a contextos cambiantes, suerte de plasticidad que les permite ejercer diferentes roles en relación a las urgencias del momento, además de una mayor capacidad para participar en los movimientos y en las luchas por mejoras que beneficiarán a su comunidad y a su medio ambiente. Estos fenómenos también estarían en la base de lo que se ha dado en llamar «el ajuste invisible» de las mujeres ${ }^{3}$, una disponibilidad permanente de las mismas para intentar revertir o al menos paliar las situaciones de riesgo que plantea el entorno, con acciones que implican un esfuerzo adicional a sus tareas habituales. Sin embargo, no hay que desestimar tal riesgo, ni tampoco subestimar el potencial de abordaje de situaciones nuevas que practican y reinventan muchas mujeres sin quedar amarradas a las viejas prácticas.

11 Los varones en cambio, desde Senegal hasta la Provincia de Buenos Aires, son visualizados, al menos por las mujeres, como renuentes a los cambios. En efecto, tienen bastante dificultad para el ejercicio de tareas nuevas, particularmente aquellas que suponen, son propias de mujeres.

12 Como si sostener los emblemas de la masculinidad representara una carga pesada que resta eficacia en la solución de las problemáticas urbanas, y un menor interés aún, en las problemáticas ambientales. Recordamos el caso de un vecino de San Cayetano que abandona las tareas de limpieza de una calle porque otros varones lo abuchean gritándole que lo que hace son cosas de mujeres. $O$ el ejemplo que describe el informe de Senegal: un varón polígamo que a pesar de no poder mantener a sus diferentes familias prohíbe a sus esposas que realicen tareas generadoras de ingresos. La practicidad de estas mismas esposas es que se las ingenian e inventan estrategias para seguir alimentando a sus hijos. La «dominación masculina» aquí ¿no será una ficción que hay que sostener aunque nadie se la crea del todo?. 
dicotómicas a costa, frecuentemente, de una cierta amputación de habilidades que potencialmente podrían desarrollar tanto mujeres como varones. Las mujeres van conquistando espacios y tareas propias del mundo externo tradicionalmente ejercidas por varones. Lo opuesto no se verifica en el caso de los varones. Las cualidades atribuidas a las mujeres deben ser constantemente vigiladas y erradicadas de la definición de sí para controlar las fantasías temidas de volverse femenino. Por ello, se vuelve tan difícil su ingreso a las tareas propias de lo doméstico, de la crianza de los hijos, e incluso de las tareas de mejoramiento de los vínculos humanos y los vínculos con el medio ambiente, que pondrían en tela de juicio la tradicional definición de «lo masculino». Ahora bien, Hemos observado repetidamente este tipo de fenómenos durante nuestra tarea en el barrio de San Cayetano. Evidentemente para las mujeres, acceder a los espacios tradicionalmente ocupados por los que dominan - los hombres es algo que, en la mayoría de los casos, fortalece su autoestima. No olvidemos que los varones ocuparon históricamente el lugar de privilegio. Por otro lado, no ocurre lo mismo con los varones que investigamos: ingresar a los espacios femeninos, debilita su autoestima. formando parte de representaciones sociales más complejas con las que se realimentan tales expectativas. Foucault, M. (1978) plantea a la subjetividad como «el modo en que el sujeto hace la experiencia de si mismo», y además, en la línea de adquisición de progresiva autonomía agrega que, «mostrar las determinaciones históricas de lo que somos, es mostrar lo que hay que hacer». La subjetivación en tanto ampliación del conocimiento acerca de lo que nos determina es un capítulo en todo proceso de empoderamiento.

\section{¿Género o mujeres?}

El movimiento feminista, en su crítica al modelo patriarcal de dominación masculina, ha resaltado la distribución desigual e injusta de las expectativas y roles de género asignados que delínean las vidas de las personas. Desde hace varias décadas las prácticas teóricas y políticas del movimiento feminista están dando a luz las maneras 
en que la naturalización de las diferencias propició la opresión de la mujer en relación al hombre. Y cómo los sistemas de poder trocaron esas diferencias en desigualdades, desde el uso de «el hombre» para referirse al ser humano en general hasta las prácticas discriminatorias, sociales, científicas, jurídicas, económicas, que transforman al 52\% de la humanidad en «el segundo sexo» (De Beauvoir, S., 1977).

Esta situación histórica de inequidad ha propiciado un enorme trabajo orientado a reparar esa injusticia padecida a lo largo de los años y a analizar las diversas formas en que la subordinación de género aún persiste. Reuniones, convenciones, congresos, publicaciones, organizaciones de mujeres, movimientos e investigaciones dan cuenta cotidianamente de los esfuerzos para conocer desde ellas mismas, - y no desde el discurso androcéntrico - sus voces, sus experiencias, sus luchas, y las vías posibles de superación. También este fue el espíritu que organizó el trabajo de los distintos equipos en esta red de investigación.

Desde hace años, la búsqueda de legitimidad académica llevó a los estudiosos/as del tema a ir sustituyendo «mujeres» por "género». Al parecer «género» suena mas neutral y objetivo que «mujeres», término cargado de la estridente política del feminismo. Pero este movimiento de ingreso a la Academia y el reconocimiento universitario desalojaría, según algunos, el peso reivindicativo y pasional a la lucha de las mujeres y le quitaría el peso político del feminismo, en la denuncia de la histórica dominación masculina.

20 Nos preguntamos si lo desalojado por una puerta no reingresa por la ventana, en tanto el cambio de nomenclatura no destierre el protagonismo de las mujeres, en tanto género como una palabra a ser revisada, comprendida y promovida. ¿Género es sinónimo de mujeres? Lo cierto es que en muchas de las publicaciones de organismos internacionales, si bien al nivel de los títulos se plantea la necesidad de la incorporación del tema de género al inventario de proyectos y a sus políticas, luego aparecen preponderantemente iniciativas que apuntan al «bienestar de la mujer», la capacitación creciente de las mujeres en el acceso a la economía, los desarrollos sociales, la agencia personal, etc. Los desafíos de la integración se focalizan en consejos y asesoramiento sobre «la mujer en el desarrollo». Un buen ejemplo de ello son las recomendaciones finales del Informe de Senegal sobre la primera parte de esta misma Investigación, de la cual formamos parte ${ }^{4}$. La unidimensionalidad de estas recomendaciones contrasta con la riqueza y complejidad del resto del informe.

21 No es necesario aclarar la pertinencia de estos objetivos. Más allá de la mira puesta en el afianzamiento de los derechos humanos, como bien desarrolla Abdoul, M, 2001, 145. en el artículo recién citado, también resalta una cuestión creciente: los beneficios económicos y sociales de la inversión en la mujer. El tema no es restar atención a las problemáticas específicas de las mujeres, sino más bien, no perder de vista que los varones también son seres de género, y no siempre, al menos no exclusivamente, victimarios de las mujeres. Como dice Scott, J. «la información sobre las mujeres es necesariamente información sobre los hombres» y agrega: «el estudio de las mujeres por separado perpetua la ficción de que una esfera, la experiencia de un sexo, tiene poco o nada que ver con la otra». Sólo agregaríamos que la no mención de los varones de esos contextos puede dejar entre líneas la sensación de que esos varones son, o victimarios de las mujeres, o que ya han alcanzado un grado de empoderamiento que no amerita ningún esfuerzo más. Por cierto, nada más lejano de esta conjetura que la experiencia habida en San Cayetano y en otras Investigaciones de las que estamos formando parte. La 
categoría «hombres» es omniabarcadora en tanto situación de privilegio, pero también existen hombres sin trabajo, sin palabras, sin recursos, subordinados a múltiples determinaciones para quienes la «dominación masculina» es una ficción instituida que habría que sostener aunque en forma de impostura.

Para mencionar un ejemplo repetido, cuando incluimos la idea de feminización de la pobreza, producto entre otras razones, de la mundialización de la hegemonía liberal, nos referimos a la manera particular en que las mujeres padecen esas transformaciones. Bien, pero cómo podemos dejar de considerar los efectos de la pobreza y el desempleo para los varones, teniendo que, por ejemplo, el trabajo es uno de los pilares constitutivos en la consolidación de la masculinidad (al menos en Latinoamérica y hasta ahora). ¿Feminización de la pobreza implica que los varones ya se han empobrecido previamente? ¿O significa que aún no? ¿Qué sabemos sobre las formas propias de masculinización de la pobreza? Además, como el género es un concepto relacional por excelencia es indudable que la posición de los varones se vuelve tambaleante en función del cambio de posición social, laboral y política que van logrando crecientemente las mujeres. Es útil recordar que en Latinoamérica el «machismo» se conformó por medio de la proyección masiva sobre las mujeres, de las fragilidades e inconsistencias que ellas padecían, producto a su vez, de las relaciones con los varones. Detalle que obligaría a un constante control de esas mujeres.

En una encuesta que hicimos entre las manzaneras y comadres de San Cayetano, a la pregunta ¿Qué piensa de los hombres del barrio con relación a su compromiso en las tareas comunitarias?, la mayoría de las respuestas es negativa: abundan apelativos como «flojos», «poco comprometidos», «sin trabajo comunitario», los visualizan como evasivos, como personas que no aparecen. Una de las encuestadas dice: «muchos hombres se sienten discriminados al ver tantas mujeres trabajando en la caridad». Estas respuestas básicamente denostosas nos invitan a escuchar las voces de los mismos hombres para eventualmente poder trabajar con ellos en la deconstrucción de sus propias determinaciones de género que hasta el momento son tan poco propicias para la creación de salidas que sean más convenientes que la evasión.

El Informe «Relaciones de género en la Argentina», realizado con el aporte del Banco Mundial, en su introducción, y luego de definir al género como «las diferentes experiencias, preferencias, necesidades, oportunidades y limitaciones a las que se enfrentan hombres y mujeres debido a sus roles socialmente asignados", a partir de la premisa de que tanto hombres como mujeres son "prisioneros de sus roles de género», aclara, con infrecuente honestidad que por diversos motivos «la información sobre los problemas de los varones es limitada» (Correia, M., 1999, 5). Esto no es lo que ocurre con numerosas publicaciones y estudios que pasan del enunciado de la perspectiva de género a ocuparse unidimensionalmente de la problemática femenina.

Si tanto hombres como mujeres son «prisioneros de sus géneros», ¿por qué sólo intentar liberar a las mujeres? Por otra parte, nunca dejaremos de destacar que en el sistema mujer-varón es imposible que la modificación de uno de sus aspectos no conmocione al sistema sexo-género en su totalidad. En identidades de género planteadas y construidas dicotomicamente, cualquier variación afecta al conjunto, en particular cuando, como en el sistema de los géneros, sus atributos y expectativas están construidos en forma complementaria. Muchas de las conductas violentas por parte de los varones, pueden explicarse en parte, como reacción a lo que perciben como arrebato de algunos de sus 
atributos (poder-razón-destreza, sexualidad, etc.), ya que ahora, y cada vez más, tal característica es también patrimonio de las mujeres.

\section{El género varón} enguaje es masculino y la ciencia androcéntrica - como pasa con las ciudades masculinas - ¿Cómo poner en crisis el eje a partir del cual el resto es significado? Alguna de estas afirmaciones y de estas preguntas seguramente explican en parte el porqué, como decía el Informe del Bco. Mundial, se piense que «la información sobre los varones es limitada», que va en paralelo con el hecho de que también los mismos varones saben poco sobre sí mismos. En los talleres de San Cayetano en los que también participaban varones, comprobamos repetidamente la pobreza de sus argumentos y opiniones, la tendencia a buscar algún rostro de mujer que le diera significación plena a aquello que intentaban expresar. Y los pocos que participaban lo hacían desde un rol social $u$ ocupacional (Soy director de...) jerarquizado, y asegurador de sí mismo, pero casi nunca desde su ser varón. Otro ejemplo lo constituyen las resistencias de los varones a participar en tareas comunitarias y lo difícil que es abrir y sostener un grupo de discusión entre varones, como ocurrió en nuestra experiencia y también en la del equipo del Brasil. La tarea de desnaturalizar las conductas y neutralizar los núcleos de género es todo un desafío para varones e investigadores, como alguna vez lo fue para el feminismo.

M. Kauffman, 1989. trabaja las contradictorias experiencias con relación al poder: en un mundo dominado por los hombres se supone que los hombres detentan el poder. Sin embargo las experiencias singulares - y privadas - de muchos hombres desmienten esa afirmación. La asociación entre masculinidad y potencia dista mucho de ser verdadera. Como en los ejemplos recientes, las experiencias subjetivas de poder nos delatan otra realidad: el que cree dominar lo público tiene poco dominio sobre sí. Por otra parte, masculinidad y violencia se alimentan mutuamente. El autor mencionado describe su triple versión acerca del tema en cuestión: «violencia contra las mujeres», «violencia contra los otros hombres» y «violencia contra sí mismo». Las primeras versiones tienen más visibilidad y forman parte de síntomas sociales preocupantes y actualmente vigentes. La tercera en cambio, amasada con ideales y nombrada como logro viril por su cotidianeidad, tiende a quedar naturalizada por los varones mismos y por la mirada social. Nos preguntamos por ejemplo ¿Porqué en las guerras los varones son mayoritariamente el sexo descartable? Pero, por cierto, violencia no es sinónimo de poder sino todo lo contrario, es más bien expresión de impotencia, tendencia a la acción impulsiva y falta de argumentaciones por otros medios. las diferentes geografías que conforman la red, delata que, paradójicamente, sin la 
inclusión fuerte del estudio y la deconstrucción de las emblemáticas que pueblan los sujetos varones, el desarrollo mismo de la mujer se ve obstaculizado y demorado. Va quedando claro entonces que el avance de las mujeres es percibido por no pocos varones como un peligro para su propia posición de dominio, en ocasiones más imaginado que real. El sistema de los géneros planteado con atribuciones oposicionales favorece la mutua proyección de habilidades y rasgos de unos en otras y viceversa. Si el poder real o deseado de los varones se asienta en la colocación de atributos devaluados para sí mismos sobre las mujeres, el reingreso de los mismos en la definición de aspectos de la masculinidad (del mismo modo que en la femineidad) será resistido fuertemente, y las conquistas de las mujeres miradas con temor y/o sospecha de su propia definición.

El sabotaje de esos avances casi aparece como una reacción «natural» y defensiva cuando los varones los perciben unilateralmente como una pérdida de sus anteriores privilegios, y no como una ocasión para coparticipar con las mujeres en todas las tareas que las nuevas realidades les demanden. Una tarea pendiente para muchos varones, además de la deconstrucción de sus poderes imaginarios que generen ideales inalcanzables de sí mismos, es ir dándose cuenta de todo lo que tienen por ganar al estar cerca de una mujer (como par político), y no como un personaje devaluado. Por supuesto, esto irá a la par de la revisión del estereotipo de varón que también muchas mujeres suponen y esperan, además de las formas políticas de enfrentar a sistemas sociales injustos que - como muchos hombres - hacen de la competencia despiadada, una virtud socialmente reconocida.

31 Las mujeres están accediendo al mundo de lo público, de la cultura, - los currículos de las universidades argentinas reconocen en algo más del 53\% la presencia femenina que también se va visualizando en todos los enclaves tradicionalmente masculinos. No ha ocurrido en cambio lo mismo con los varones, es decir, no han accedido al mundo de lo doméstico, de los vínculos, de los afectos que siguen pareciendo inherentes a lo femenino, y que, es correcto admitirlo, muchas mujeres no se resignan a compartir, al sentir que el ingreso de los varones las privaría de su auténtico dominio. Allí donde fueron, son ahora, efectiva e ilusoriamente "amas de casa». Comentarios de este tipo fueron muy frecuentes en nuestros encuentros con las mujeres manzaneras. En una reunión, una de ellas exclamó convencida: - No, el reparto lo hacemos nosotras, los hombres son más un estorbo, que una ayuda!-

Si en muchos tramos de nuestra investigación nos encontramos con mujeres que comienzan a ocupar cargos de decisión y con importante capacidad de adaptación a nuevas funciones, también se da la paradoja de no mediar una fuerte deconstrucción de los ideales viriles, que aquellas mujeres, al mismo tiempo que se empoderan y amplían su campo vital, se ven nuevamente agobiadas por la doble tarea de ocuparse de sus casas y de sus barrios. Una «doble maternidad» no remunerada, salvo en la ratificación personal de una posición sacrificada o heroica, de un conjunto de valores tradicionales y apreciados por imaginarios educativos y también por la religión católica, absolutamente mayoritaria en Latinoamérica. La promoción de valores solidarios (¿femeninos?) en los varones no sólo apunta al empoderamiento propio, sino, como va quedando claro, a la equiparación con las mujeres en todas las esferas del vivir.

Algunas de las ideologías que arquitecturan las masculinidades de los varones observados, implicarían que:

- Emocionarse es poco masculino. 
- La violencia es la forma de superar los conflictos.

- Para considerarse bien hombre hay que decir que sí a cualquier propuesta de sexo.

- En el juego es más importante ganar que disfrutar.

- No solo ser hombre, sino estar demostrándolo todo el tiempo.

- Que los trabajos y los deportes de riesgo nos virilizan, etc.

Que a su tiempo dan por resultado:

- Perderse la crianza de los hijos.

- Adiccionarse a drogas, vino, o cualquier tipo de vicio.

- Participar poco en acciones comunitarias.

- Aparecer mucho protagonizando accidentes, homicidios, suicidios.

- Abandonar familias, hijos, morir 7 u 8 años antes que las mujeres, etc.

Una agenda imprescindible para poner a trabajar las realidades, expectativas, búsquedas, y fundamentalmente las interrogantes con relación al género de los varones, además de recuperar las «especificidades» masculinas, también supondrá otros desafíos como:

- Sensibilizarse al enorme peso que el sexismo tiene en las trayectorias de los hombres.

- Advertir el peso que la homofobia y la heterosexualidad como norma tienen en el carácter opresivo del género.

- No dar por sentado nada, no naturalizar las concepciones instituidas.

- Deslindar deseos de ideales y mandatos, de las capacidades posibles.

- Saber que se puede ser varón de muchas maneras.

- Recordar siempre que varones y mujeres son producciones sociohistóricas y no esencias prediscursivas.

- Tener en cuenta que los varones están aún más sujetados a los ideales de género que muchas mujeres. De ahí lo imprescindible de su abordaje.

- Deber estar atento, en el abordaje a los varones, a temas como: situación laboral, situación conyugal y/o matrimonial, vínculos con las mujeres, vínculos con otros varones, la paternidad, su vida sexual, sus objetivos y deseos como padre, hijo, hermano, amigo, trabajo, profesión, placer, etc.

También sería oportuno pensar cuáles son los dispositivos más aptos para el trabajo con hombres, cuáles son las formas de motivar su participación. Hemos comentado con las mujeres de San Cayetano y también con funcionarios municipales, cómo algunas convocatorias al trabajo comunitario que en apariencia estaban dirigidas a todos, contenían un discurso más ligado a valores femeninos.

El tránsito del hombre como sinónimo de persona, al estudio de los varones como género, en sus singularidades y diferencias es también el tránsito de la categoría a priori (ya dada) a la noción de una construcción social de la masculinidad. Por lo que venimos argumentando, esta concepción no es sólo un postulado teórico, es también un desafío ético. Tampoco se nace varón, se adviene a serlo.

\section{Complejización de la perspectiva de género}

Sostenemos que no se avanzará solo estudiando a las mujeres, el objeto es más amplio. Se requiere analizar todos los niveles, ámbitos y tiempos las relaciones mujer-varón; mujer-mujer y varón-varón, y sus múltiples formas, que van desde la dominación hasta la 
subordinación de un género al otro (y dentro del mismo género), apuntando siempre en los trabajos de investigación-acción a las relaciones igualitarias.

Cualquier complejización de la perspectiva de género va a implicar revisar los paradigmas con los que abordamos los campos estudiados. En las ciencias humanas, un paradigma (Bonder, G. 1980) es «el conjunto de concepciones generales acerca del ser humano $y$ de la realidad social, de los métodos y las maneras consideradas legítimas para plantear las cuestiones». Estos discursos brindan modelos, creencias y valores a una comunidad en un tiempo dado. En cada uno de nosotros, lo sepamos o no, un paradigma como visión del mundo opera como un selector perceptual que organiza relatos sobre el mundo y nos compele a que lo observado entre en los límites preestablecidos.

Por lo desarrollado hasta este punto es válido destacar dos observaciones: una tendencia en los estudios de campo a la no inclusión de los varones como seres de género y al relevamiento excluyente de la situación de las mujeres junto a las recomendaciones para revertir o mejorar esas condiciones. Tampoco se percibe una propuesta de trabajo ni una confección de dispositivos para trabajar específicamente con los varones. La otra observación es la referida a la resistencia de los varones en el sentido de repensar sus propias determinaciones de género, una de las cuales es su no inclusión en propuestas de cambio y de trabajo social en la comunidad, temas que suponen pertenecen a la agenda de las mujeres.

41 Estas observaciones nos hacen pensar en un curioso paralelismo entre la suposición de los varones de que su lugar como género, es decir, como varones, no debería ser analizado y el silencio reiterado de los estudios e investigaciones sociales de los varones como género no hace más que confirmarlo. Efectivamente, los hombres suelen definirse, en primer lugar, más como obreros, ingenieros, directivos, albañiles, esposos, jefes, que como varones. En talleres amplios que realizamos en San Cayetano, cuando participaban algunos varones lo hacían más desde el rol social que desde su ser genérico. Así lo hacían el Presidente del club o el entrenador del equipo de fútbol por ejemplo. Evidentemente, es tarea de los investigadores cuestionar estos supuestos naturalizados que aliarse inconcientemente con el sentido común, que por lo general, ratifica las líneas más conservadoras, en lo personal y en lo social.

Es necesario, en la perspectiva de un pensamiento complejo, tener en cuenta dos riesgos:

- No permanecer atento ni sensible a los índices y determinaciones de género. Hablamos del principio sobre las tendencias a la generalización y homogeneización.

- Suponer que la única variable a tener en cuenta, es el género.

La perspectiva de género es una herramienta válida cuando podemos entenderla como una, y no como la única de las determinaciones que producen las acciones entre hombres y mujeres. Además de estar alertas cuando esa variable ocupa todo el campo de la causalidad. Es decir, cuando la categoría de género se usa de manera general, descontextualizada y sin correlacionarla con las determinaciones de clase, de religión, de etnia, de pertenencias políticas, de edad, por lo menos. ¿Cómo comprender y evaluar cierta actitud caritativa o sacrificada de algunas manzaneras sin urdirla con valores preconizados también por la religión católica y los del partido peronista, además de las determinaciones de género? encuesta. A la pregunta ¿Crees que es justo que tus actividades en el Plan Vida sean 
remuneradas? Un $75 \%$ de estas mujeres opinan que son contrarias a la remuneración, argumentan que las tareas para la comunidad y las de ayuda a los demás, no deben cobrarse, «son cosas que se hacen de corazón». El 25\% restante justificaría el ser remuneradas en función del tiempo que demanda esta tarea y por necesidades económicas. Decía Castoriadis, C. (1993) que «las significaciones imaginarias instituidas tienen más perdurabilidad que las transformaciones que se operan en el período histórico que legitiman». En momentos en que distintos foros

Estos paradigmas que operan a nivel individual y social en forma automática, facilitan en la promoción de las condiciones de vida de las mujeres una tendencia a la victimización de las mismas. Esto no implica, por supuesto, desconocer las situaciones de injusticia, sino una alerta a las causalidades únicas y lineales. En nuestras realidades, en las que aún algunos varones ejercen violencia sobre las mujeres puede simplificarse un estado vincular atribuyéndole a todos los hombres un carácter de victimarios de las mujeres. Y desprenderse de aquello de «ahí está el enemigo». Una mirada más amplia nos permite ver que, además hay gobiernos que no cumplen, servicios que no se prestan, obscenas diferencias de posibilidades, políticos corruptos. La demonización de los varones puede hacer perder de vista que son otras las fuerzas que es necesario enfrentar, y otras las estrategias a seguir. Una de las cuales, suspendida la guerra de los sexos y reubicando al enemigo puede unir a mujeres y varones cooperando, no litigando.

Hacer trabajar la perspectiva de género en una investigación-acción va a suponer:

- Que los sujetos a ser abordados, investigados, deberán ser identificados por el género que cada cual porta (y soporta). Ir desterrando, por engañoso y tendencioso, el uso de términos generales del tipo «ser humano», «hombre», etc.

- Que las interacciones entre varones y mujeres van a ser el objetivo privilegiado, toda vez que esos vínculos sociales estén constantemente sesgados por determinaciones genéricas que también son siempre relaciones de poder.

- Que la variable género - según la índole del trabajo - será correlacionada con otras variables, por ejemplo, edad, etnia, religión, orientación sexual, clase social, posición política, etc.

- Que la formulación de las preguntas, cuestionarios, modos de la coordinación, diseño de la investigación, etc. deberán priorizar la variable género.

- Que la condición genérica de los investigadores también deberá tenerse presente para elucidar su propia implicación en el abordaje y análisis de los resultados, esto incluye las formas del preguntar, los formatos de los dispositivos empleados y la manera de convocar a las distintas tareas para la comunidad. Sensibilizarse a las condiciones de género requiere de los investigadores, - además del estudio - revisar su propia condición de género que va a operar como lente frente a las realidades de sus terrenos.

- Que en algunos tramos de la investigación puede ser importante cotejar respuestas, expectativas, búsquedas, soluciones posibles con respecto a problemáticas comunes, comparando los enunciados diferentes entre los actores (mujeres-varones).

- Un alerta especial a la tendencia aquella en que los imaginarios instituidos con respecto a ideas generalizadas sobre los hombres ó sobre las mujeres, deban ser analizados en distintos tramos de la investigación-acción. Con los conjuntos a trabajar y con los miembros del equipo investigador.

- Que aunque la investigación tuviera como objeto principal y único, por ejemplo, los grados de desarrollo y acción de un grupo de mujeres en la promoción de una tarea cualquiera, 
nunca debiera omitirse que ese grupo está en constante interacción no sólo con los varones de esa misma comunidad, sino sobre las ideas que se tienen sobre esos varones, sobre sí mismas y también sobre las representaciones sociales vigentes sobre el par mujer-varón.

Varias de las ideas esbozadas guardan relación con el espíritu y la metodología de la investigación-acción, en el sentido de que no se trata sólo de conocer la realidad, sino de transformarla, (Marx dixit). Es el carácter deconstruido de los devenires de los sujetos y sus vínculos, lo que posibilita la tarea teórica y política de su transformación.

\section{BIBLIOGRAFÍA}

Boron, A., «Pensamiento único y resignación política: los límites de una falsa coartada», Unidad 1, Seminario PRIGEPP-FLACSO, Bs. As. 2004.

Bourdieu, P., «La domination masculine», Editions du Seuil, Paris, 1998.

Castoriadis, C., «La institución imaginaria de la sociedad», Tusquets Edit Bs. Aires, 1993.

Connell, R. W., «Gender and power», Stanford University Press, 1987.

Correia, M., «Relaciones de género en la Argentina: un panorama sectorial», Banco Mundial, Region de America Latina y el Caribe, 1999.

$\mathrm{DDC}$, «Au fait qu'est-ce l'empowerment», Un seul monde, $\mathrm{n}^{\circ} 2,1998$.

De Barbieri, T., «Sobre la categoría género. Una introducción teórica-metodológica», Edic. de las mujeres n 17, Isis Internac., México, 1992.

De Beauvoir, S., «El segundo sexo». Edit. siglo XX, Buenos Aires, 1977.

Duhalde, H. G. de, «El Plan Vida», Temas Grupo Edit., Bs. As. 2002.

Hainard, F., Verschuur, C., «Empoderamiento de las mujeres en lascrisis urbanas». Edit. IEPALA, MOST-UNESCO, Madrid, 2001.

Hainard, F., Verschuur, C., «Femmes et politiques urbaines. Ruses, luttes et strategies», Edit. UNESCO, KARTHALA, Paris, 2004.

Inda, N., «L'homme: le sexe surévalué» en Bisillat, J., Verschuur, C., Le Genre: un outil nécessaire, Cahiers genre et développement nº 1, L'Harmattan, Paris, 2000.

Kauffman, M., «Hombres, placer, poder y cambio», Edit. CIPAF, Santo Domingo, 1989.

Lamas, M., «La construcción cultural de la diferencia sexual», PUEG, México, 1996.

Scott, J., «Genre, une catégorie utile d'analyse historique» en Bisillat, J., Verschuur, C., Le Genre: un outil nécessaire, Cahiers genre et développement n 1, L'Harmattan, Paris, 2000.

\section{NOTAS}

1. G. de Duhalde, 2002, pag. 96. 
2. Informe publicado para uso en Argentina: «Ciudad, Medio Ambiente y Relaciones de Género» (Primera etapa de la investigación) y también el Informe «Manzaneras ¿Empowerment o asistencialismo?».

3. Ver Hainard, F. y Verschuur, C., 2001, pag. 30.

4. Abdoul, M. «Senegal. Relaciones sociales entre hombres y mujeres a través de las actividades económicas femeninas». En Hainard, F. y Verschuur, Ch. 2001, pag. 145.

\section{RESÚMENES}

Se intenta definir y desarrollar una «Perspectiva de Género» en las investigaciones sociales que no quede reducida a la promoción de la mujer. Dado que el sistema de los géneros siempre es relacional, cualquier modificación en las mujeres, supondrá modificaciones en los varones, también seres de género. Esta perspectiva se propone conocer las diferencias, para que no se tornen desigualdades, en las tareas del desarrollo social y el empowerment personal. Se toma como objeto de estudio el «Plan Vida», un programa asistencial que articula a 40,000 mujeres argentinas (manzaneras) con el objetivo de lograr una mejora en sus recursos y capacidades para la gestión social.

Notre étude essaie de définir et de développer une "perspective genre » dans les recherches en sciences sociales. Cette étude ne se limite pas à la promotion de la femme du fait d'être femme, cela en prenant comme exemple le "plan vie», un programme d'aide qui concerne 40.000 femmes argentines (manzaneras) qui cherchent à obtenir de meilleures ressources et de meilleures capacités de gestion sociale. De même, et étant donné que le système des genres est toujours relationnel, toute modification chez les femmes provoquera des modifications chez les hommes. Les tâches de développement et d'empowerment personnel requièrent également une perspective de genre dans laquelle les différences doivent être connues pour qu'elles ne dérivent pas vers des problèmes d'exclusion et d'inégalité.

Our study aims at defining and developing a "gender perspective" in social sciences research. It is not limited to the promotion of women per se and is based on Plan Vida, a support programme that concerns 40,000 Argentinian women (manzaneras) who seek to get more resources and improve their social management abilities. At the same time, as the gender system is always a relational system, any change among women will stir up change among men. Personal development and empowerment call for a gender perspective enabling to identify the differences so as not to lead to problems of exclusion and inequalities.

\section{AUTOR}

\section{NORBERTO INDA}

Psychologue à l'Université de Buenos Aires et professeur sur les questions de dynamique de groupe et de liens sociaux à l'Université de Quilmes et à l'Université de Mar del Plata, Argentine. Membre de l'International Association Studies on Masculinities (IASOM), il est chercheur dans le domaine du genre et plus spécifiquement de la condition masculine. Il est membre de la partie argentine du projet MOST-UNESCO « Genre, ville et environnement ». 
Mouvements de quartier, rechercheaction et rapports de genre 


\title{
Déploiement des mouvements de quartier à forte participation féminine : la réinvention culturelle du politique
}

\author{
Christine Verschuur
}

\author{
«When Queen Victoria wrote to Sir Theodore \\ Martin complaining about "this mad, wicked folly \\ of 'Woman's Rights"' she may have \\ underestimated the power of the "wicked folly". \\ The role and extensive reach of woman's agency \\ have been having a profound impact on the \\ world, affecting the lives of all: women, men and \\ children.» \\ Amartya SEN, $2005^{1}$
}

1 Dix ans après notre premier colloque international genre à l'IUED sur « Femmes, villes et environnement ", dix après la Conférence internationale des femmes de Beijing, quel bilan peut-on faire sur la prise en compte des inégalités de genre dans le développement?

2 L'UNRISD affirme que les politiques néolibérales constituent le principal obstacle à la réalisation des objectifs de justice sociale réaffirmés lors des multiples conférences internationales, y compris les objectifs d'égalité de genre affirmés à Beijing. Les gains politiques des femmes sont compromis par les échecs des politiques sociales et économiques ${ }^{2}$.

3 Reconnaitre et soutenir la force créatrice des mouvements de femmes et de quartiers, où s'instaurent de fugaces nouveaux rapports sociaux, pourrait-il contribuer à faire plier les désastreuses politiques néolibérales actuelles et progresser vers plus de justice sociale? 
Le colloque se proposait deux objectifs :

- transmettre des connaissances élaborées par la recherche sur les inégalités de genre dans les quartiers étudiés,

- discuter de la manière de soutenir les nouveaux mouvements sociaux où les femmes jouent un rôle central et cependant non reconnu.

5 Notre colloque genre d'il y a dix ans a donné naissance à une longue collaboration de recherche avec un réseau d'équipes de chercheurs de pays du Sud et de l'Est sur l'environnement dans les villes et les inégalités de genre. Les résultats ont été présentés et ont donné lieu à une réflexion sur les liens entre la recherche et la définition de politiques publiques qui puissent répondre aux objectifs de justice sociale. L'urbanisation mondiale croissante nous avait incités à étudier les changements des rapports entre hommes et femmes dans les villes. En effet, si en 1950, seuls $30 \%$ de la population mondiale était urbaine, en 2030 on devrait compter $60 \%$ de citadins. La population urbaine des pays moins développés devrait passer de 1,9 milliard en 2000 à 3,9 milliards en 2030 .

6 Nous nous sommes intéressés dans la recherche aux réponses données par les femmes et les hommes aux problèmes les touchant directement. La recherche a porté sur les réponses locales, collectives, de rejet de situations inacceptables et de lutte pour des conditions de vie plus dignes : organiser ou réclamer un système d'assainissement ou de collecte des déchets inexistant, réclamer l'accès à l'eau ou à l'électricité à des tarifs abordables; revendiquer un environnement immédiat non nuisible et des espaces verts ; obtenir un droit de propriété de son logement ; requérir le droit à des revenus propres; exiger de ne pas être soumis à des violences domestiques; prendre le droit à la parole et participer aux choix environnementaux et urbains.

7 Nous avons accompagné et soutenu les lents cheminements dans les prises de conscience - ou non - de droits et dans la mise en œuvre des actions pour améliorer, sans plus attendre, la vie quotidienne.

8 Nous avons constaté que l'engagement des femmes - et d'hommes - dans ces mouvements de base va plus loin que la prise en charge de travaux utilitaires, fussentils d'intérêt collectif.

Les mouvements de base auxquels nous nous sommes intéressés dans les villes ne sont pas construits autour de revendications liées au travail. Les actrices et acteurs sociaux de ces mouvements se réunissent autour d'autres intérêts qui les rassemblent. Il y a derrière cela une certaine idée de l'intérêt collectif. Ces mouvements qui n'affirment pas une identité particulière, liée au travail salarié par exemple, mais qui tournent autour d'autres valeurs constituent ainsi des mouvements culturels importants.

Les femmes sont généralement les principales actrices de ces mouvements de base. Elles s'investissent au-delà du foyer, comme par extension "naturelle » de ce qui est souvent par elles-mêmes - considéré être de leur responsabilité - les soins et l'entretien de la famille, (tâches reproductives). Elles s'engagent à l'extérieur de la sphère domestique, en découvrant un espace libérateur, mais parfois en contradiction avec les stéréotypes, avec ce qui est considéré être leur place (rester à la maison) ou ce dont elles rêvent parfois que devrait être leur place (être prises en charge par leurs époux). Elles affrontent parfois des combats très concrets, contre les autorités locales qui ne les soutiennent pas dans leurs initiatives, contre les difficultés administratives, matérielles, quotidiennes pour aller au bout de leurs projets. 
11 La sensibilité envers l'environnement représente souvent un élément central, mobilisateur, dans ces luttes pour une vie plus digne.

Ces «combats» sont souvent menés par des femmes qui ne se réclament pas du féminisme et ne cherchent pas à renverser les rapports de pouvoir entre hommes et femmes. Elles ne cherchent pas non plus forcément à renverser le système économique néolibéral dominant, sous la direction d'un parti politique ou d'un guide idéologique.

Le féminisme - et les autres mouvements sociaux - ont eu tendance à instaurer une temporalité politique du présent. [...]

Une temporalité politique du présent, c'est d'abord et avant tout la recherche d'alternative ici et maintenant plutôt que d'attendre les lendemains qui (dé)chantent d'après le grand soir révolutionnaire. [...] Cette temporalité du présent et la mise en place d'alternatives, qui ne constituent pas en soi des ruptures fondamentales mais qui ne les empêchent pas non plus, peut assez bien être reliée à une conception du pouvoir qui n'a pas tant à être pris qu'à être répandu. ${ }^{3}$

Comment expliquer la division inégale des tâches dans la sphère domestique, comment expliquer que celle-ci se reproduise dans les mouvements de quartiers? Dans quelle mesure les rapports de genre inégaux contribuent-ils à maintenir les liens organiques entre sphère productive et reproductive? Pouvons-nous observer malgré tout des changements dans les rapports entre sphère productive et reproductive dans les quartiers étudiés, qui ouvriraient des espaces de changements des rapports de genre? Le travail sur les identités de genre - masculine et féminine - peut-il contribuer, à la base, à modifier ces rapports de pouvoir inégalitaires?

14 Nous n'avons pas l'illusion de penser que des mouvements de quartiers, par eux seuls, sans transformations du système économique, des rapports Nord-Sud, des rapports entre l'Etat et la société, pourraient renverser le système de reproduction des inégalités. Néanmoins, l'instauration fugace de nouveaux rapports sociaux, la mise en lumière d'interstices dans lesquels peuvent s'introduire des femmes - et des hommes pour modifier le système, nous semblent des pistes encourageantes dans la voie des transformations contre les inégalités sociales et de genre. Sans illusion, donc, nous observons tout de même des perspectives de changement, des ouvertures.

Développer un soutien aux nouveaux mouvements sociaux en prenant en compte la forte présence des femmes en leur sein et les inégalités de genre serait urgent, novateur et radicalement nouveau.

Notre approche a été de soutenir les processus de prise de conscience, de compréhension des causes des situations inacceptables, la recherche de solutions à la base, sur proposition des femmes et des hommes des quartiers, dans le cadre d'espaces nouveaux d'organisations, et non la promotion de programmes venant d'en haut. Dans une approche "éducation populaire" nous avons, en tant que chercheurs acteurs, soutenu l'élaboration de nouveaux rapports de pouvoir dans les mouvements de quartiers.

Dix ans après notre premier colloque genre à l'IUED sur ce même thème, nous voulons aujourd'hui montrer le lent chemin parcouru par les femmes et les hommes, avec les chercheurs et chercheuses, et celui encore à parcourir, sans illusions, mais habité-e-s par un sentiment d'urgence et par une forte dose d'utopie. 


\section{NOTES}

1. "Foreword", in Devaki Jain, Women, Development and the UN, A Sixty-Year Quest for Equality and Justice, United Nations Intellectual History Project Series, Indiana University Press, Bloomington and Indianapolis, p. xix.

2. UNRISD, 2005, Gender Equity, Striving for Justice in an Unequal World, Geneva.

3. Lamoureux, Diane, 2004, « Le féminisme et l'altermondialisation », Recherches féministes vol. 17

(2), Université de Laval, Québec, Canada, pp. 171-194.

\section{AUTEUR}

\section{CHRISTINE VERSCHUUR}

Anthropologue, titulaire d'un doctorat de l'université de La Sorbonne, chargée de cours en genre et développement à l'Institut universitaire d'études du développement, Christine Verschuur travaille depuis de nombreuses années dans le domaine du genre et développement, dans des projets de recherche et d'enseignement. Elle est coordinatrice du projet Suisse «Villes, environnement et rapports sociaux entre hommes et femmes » du programme MOST de l'UNESCO depuis 1996 avec François Hainard. Directrice de la publication Les Cahiers genre et développement, qui paraissent annuellement depuis 2000 chez L'Harmattan, elle est coresponsable du pôle genre et développement de l'IUED et des colloques genre. 


\title{
La educación popular y las
} relaciones de género en las organizaciones de base en República Dominicana y Cuba

\author{
Isabel Rauber
}

\section{Los «terrenos» y los actores}

1 Santo Domingo es una ciudad de aproximadamente dos millones y medio de habitantes, de los cuales, cerca de un millón vive en condiciones de pobreza, y de ellos, cerca de la mitad hacinados en casas precarias enclavadas en terrenos generalmente considerados inhabitables, que fueron ocupados silenciosa y gradualmente por la población. Emigrados desde otras zonas de la ciudad donde fueron desplazados, desde el interior del país en busca de una vida mejor o tras un pasaporte para ir a EEUU, la realidad es que, salvo casos aislados, los pobladores no han podido abandonar el lugar que un día los acogió, supuestamente, de modo provisorio. Así, zonas semidesérticas o pantanosas, además de las orillas de algunos ríos, fueron transformadas en el curso de los últimos 40 años, en lugares de residencia por los propios moradores, al margen de cualquier planteamiento urbanístico.

2 En general, en estas áreas, la infraestructura para la habitabilidad agua potable, desagües para las aguas albañales, calles, servicios de saneamiento ambiental, escuelas, centros de salud, transporte público y vías de acceso al centro de la ciudad, resulta escasa y precaria, convirtiéndose por ello, su mejoramiento o dotación, en el centro de las reivindicaciones y luchas de los movimientos barriales periféricos.

3 Nuestro estudio se centró en los barrios La Ciénaga y Los Guandules, ubicados en la zona central de la ciudad, aunque con las características de los barrios periféricos y marginales. Terrenos cenagosos y parte de barrancos que entrecortaban el panorama, aislando la ciudad del río, constituían el paisaje original de los primeros asentamientos humanos, extremamente precarios en todos los sentidos. Divididos casi 
imperceptiblemente por un canal de aguas negras, Los Guandules y La Ciénaga de Guachupita conforman un aglomerado urbanísticamente caótico y extremadamente deficiente en cuanto a servicios y áreas verdes, caracterizando de un modo específico a la realidad humano urbano ambiental del lugar.

4 Los barrios inician su andadura en los años sesenta, con la muerte de Trujillo y se estabilizan como asentamientos también a lo largo de esa década. A finales de los años sesenta se realizan los primeros desalojos en Los Guandules, hasta que es construida una línea de apartamentos de dos y tres plantas en lo alto de los barrios, ocultándolos así a la visibilidad directa del resto de la población de la ciudad. En los años setenta sigue llegando población del campo y también de otras áreas marginadas de la ciudad, pero en menor medida. En 1981, estos barrios cuentan con una población aproximada de 14.000 habitantes en Los Guandules y 9.000 en La Ciénaga. En 1991 la población de Los Guandules alcanza las 22.000 personas y en La Ciénaga aproximadamente 14.000. En 1997 es de 26.000 y 18.000 respectivamente. En total, en 1997 la población de ambos barrios es de 44.584 habitantes, un $51.63 \%$ son varones y un $48.37 \%$ mujeres, según los datos del muestreo elaborado por Ciudad Alternativa.

El área abarcada por los barrios es de 102,49 ha (45,15 ha de la Ciénaga y 57,34 de los Guandules), lo que da una densidad de población de 501,66 habitantes por hectárea (398,67 en la Ciénaga, y 463,62 en los Guandules). La media de edad de la población de ambos barrios alcanza los 22 años, lo que sí nos habla, por un lado, del perfil juvenil de la población y, por otro, de la importancia relativa (peso específico) que los grupos de edad más jóvenes tienen en todos los procesos. Entre los principales focos de conflicto ambiental se encuentran los vertederos, las cañadas, las áreas verdes (ausencia o contaminación), el inadecuado abastecimiento de agua y la presencia de una planta de tratamiento para aguas servidas.

6 En Cuba, centramos el estudio en Cayo Hueso, un barrio capitalino del Municipio Centro Habana. Inscrito oficialmente en 1912, debe su nombre a que en sus terrenos se asentaron a principios del siglo pasado, emigrantes cubanos que en significativo número procedían de Tampa y Key West ${ }^{1}$, Estados Unidos.

7 Con una extensión de $0,8 \mathrm{~km}^{2}$, Cayo Hueso cuenta con algo más de 35.800 habitantes. De ellos, 15.294 son mujeres (45,8\%), 16.368 son hombres (54,2\%), 741, menores. Su lado norte llega hasta el mar, abarcando una parte del malecón habanero (costanera), lugar muy transitado y concurrido tanto por visitantes nacionales como extranjeros. Su ubicación en la zona central de Ciudad de La Habana, junto con sus valores históricos y culturales, hacen de Cayo Hueso un barrio con espíritu cosmopolita.

8 Lugar de residencias estudiantiles, y centros de formación de líderes sociales, tiene en su seno a la antigua Sociedad de Torcedores, lugar donde radicó la Universidad de los trabajadores en épocas de José Martí. Centro cultural donde nacieron la rumba de cajón, el guaguancó y el filing, Cayo Hueso se levanta hoy como un fuerte patrimonio de la cultura habanera y cubana.

9 El parque Trillo, el cementerio de Espada, la Zanja Real, la Iglesia del Carmen, junto a solares (ciudadelas) tradicionales del barrio, y al pintoresco y afrocubano Callejón de Hammel, contornean un ambiente urbano sazonado muy especialmente por los orgullosos hombre y mujeres que habitan el barrio.

10 La Calle Espada, céntrica y tradicional del barrio por constituirse en unas de sus transversales neurálgicas, constituye para nosotros un motivo especial de estudio, 
particularmente en la manzana entre San Miguel y San Rafael. La cuadra, tranquila y silenciosa, nos deja pasear la mirada sobre las viejas y sólidas edificaciones que se levantan a ambos lados de la calle. Las fachadas están alineadas directamente sobre las aceras carentes de portales, lo que arquitectónicamente se atenúa con altos puntales que llegan a los 5 metros y en dos viviendas, con patinejos (cajas de aire) que forman corrientes de aire que ventilan las estancias interiores.

11 Los balcones permiten a los moradores asomarse a la calle desde el interior de la vivienda. En la concepción constructiva prevalecieron las líneas verticales, apreciable en las puertas y ventanas de altos vanos. Las ventanas que se abren sobre las aceras tienen rejas de hierro sólidas y forjadas en líneas sencillas.

El Consejo Popular, estructura básica de la organización gubernamental y lugar de concurrencia para el tratamiento de múltiples asuntos relacionados con la comunidad, tiene sus oficinas a cuatrocientos metros de la cuadra, sobre la calle San Lázaro.

13 A setecientos metros, en dirección al mar, está el hospital Hermanos «Ameijeiras», un centro hospitalario de primer nivel. Bajando cinco cuadras hacia el sur, en el borde mismo con la avenida Salvador Allende, el hospital «Freire de Andrade» (Emergencia) constituye, junto al anterior, testimonio de una segura, humana y gratuita atención médica.

14 En los últimos dos años, se completó la recuperación de todas las escuelas primarias y secundarias del barrio, objetivo prioritario de la sociedad que ha contado con el apoyo material del Estado y la participación de todas las organizaciones y la población. Los 9000 niños de la localidad de Cayo Hueso asistieron a este curso escolar en instalaciones de muy buena condicione constructiva, dotadas con televisores y equipos de computación, con capacidad para un máximo de 20 alumnos por aula.

\section{El problema de investigación}

15 La interrogante clave fue: ¿Cómo se construye la identidad de género a través de la disímil utilización del espacio urbano por los hombres y por las mujeres?

Sobre la base de las distintas respuestas obtenidas, los objetivos fueron: analizar cómo esto se traduce en la transformación de su entorno, particularmente, en la formulación de políticas públicas para impulsar o realizar las transformaciones propuestas, y cómo incide en la aplicación de las mismas.

En ambos casos el tema central fue el planeamiento comunitario participativo.

- En R. Dominicana: para buscar alternativas al hacinamiento y la carencia de infraestructura urbana.

- En Cuba: para el mejoramiento urbano ambiental del barrio.

\section{Primeros pasos de la investigación: Imaginarios y roles}

Fue fundamental en nuestro trabajo centrar la primera parte en la identificación de los imaginarios de predominantes en los hombres y las mujeres para trabajar la temática a partir de allí. 

ellas apenas de una o dos habitaciones, viven de cuatro a seis personas. Muchas están en malas condiciones de construcción; un porcentaje relevante no tiene baño interior, sino una letrina construida en un patio común que frecuentemente es compartida entre varios vecinos. Las edificaciones tienen generalmente una sola planta y la puerta de entrada suele estar junto a la calle - asfaltada o no -, la cual a menudo permanece abierta, manteniendo en contacto el espacio de afuera y de adentro. Están literalmente pegadas unas a otras mediante una red de pequeños callejones que resultan ser, a la vez, el patio de una casa y el frente de otra. En ellos, las mujeres, sobre todo, se sientan a dialogar acerca de su vida personal, de las cosas que suceden en su entorno y en el barrio. Los muros de la casa - de madera o cemento - generalmente sirven de pared a dos viviendas, factores todos ellos que empujan a los inquilinos, mayormente mujeres y niños, a permanecer mucho tiempo fuera de la vivienda, en el entorno. Así resulta una apropiación diferente del espacio por parte de hombres y mujeres (con sus hijos): en la vivienda y su entorno se mueven permanentemente las mujeres con sus hijos e hijas, mientras que los hombres utilizan la casa más como dormitorio.

21 En principio, el entorno circundante se erige como una extensión de la vivienda, aunque está más allá de la frontera que separa la casa de la calle. Podemos considerarlo como un entorno circundante (espacio físico) unido a la vivienda (construcción física), ya que uno y otra entran dentro del espectro espacial físico de la familia. Las condiciones de ambos espacios redundarán significativamente no solo en las condiciones de vida de cada quien, sino también en su percepción de las mismas. Si el patio de la vivienda (entorno) y ésta misma, muestran un aspecto saludable con unos servicios mínimos, la percepción proyectada hacia fuera será más positiva que si ese espacio físico inmediato (el entorno y la vivienda) presenta un aspecto menos lustroso (calles sin asfaltar, vertedero, aguas negras, etc.), y peores servicios.

22 La casa y la calle, articuladas permanentemente a través de la puerta, diferencian no obstante, dos esferas extremas que, aunque convivan en una turbia cohabitación, muestran de forma palpable en el imaginario de las mujeres la distancia entre lo otro (la calle) y lo propio (la casa), el mundo ajeno y la familia.

23 Establecer la articulación que surge entre dichas categorías: vivienda patio entorno y casa calle, facilita en gran medida comprender la inserción de la mujer en el barrio, su modo de relacionamiento con un espacio que es una fuente de conflictos permanente en su vida cotidiana. A raíz de esa configuración la mujer trata de generar explicaciones que le permitan entender (o explicarse) el lugar en el que vive, sin desligar el ambiente de sus condicionantes sociales.

Los imaginarios que ubican a la mujer en la casa y al hombre en la calle, vuelven a asomarse aquí poniendo en jaque la participación de las mujeres más allá de la frontera «permitida», en primer lugar, por ellas mismas, y también por los hombres y por la comunidad que como todo social observa, participa y valora. 

afirmar que no, ciertamente hay discriminación respecto de las mujeres, pero también hay autoexclusión, ya que las mujeres no pocas veces entienden que ellas no pueden participar en ámbitos de representación porque ello requiere tiempo extra, salir de la casa más tiempo, desatender a los hijos... otras alegan problemas de capacidad, por no saber supuestamente qué decir, y qué decidir... facultades que culturalmente ellas descargan naturalmente en los hombres. Pero esto no es evidente.

31 A primera vista la situación de presenta es simple y maniquea: hombres versus mujeres, mujeres versus hombres, sin llegar a descubrir los nexos diversos entre una y otra 
situación, por ejemplo: «las mujeres no participan más en cargos de dirección de las organizaciones porque los hombres no las dejan». El concepto género se traduce como problema de las mujeres y pierde así gran parte de su carga cuestionadora acerca de las bases sociales de poder de la interrelación hombremujer. Profundizar en ello una vez más, a partir de las reflexiones concretas que emergieron de esta realidad, fue parte de nuestro quehacer y se cuenta entre los logros de nuestro estudio.

Por otro lado, en el caso de los roles hombre-mujer (los imaginarios acerca de ellos, y las identidades construidas a su alrededor) los estudios han encontrado la presencia tradicional, cultural y nostálgica de los roles tradicionales: «Necesito un hombre que se haga cargo de mi familia», reclama una mujer, mientras otra sentencia con igual fuerza: «Los hombres son malos pues abandonan a la familia y a la mujer...»

La figura del varón es parte del universo que ellas forman y es una pieza clave para entender todo el proceso de la mujer en su enfrentamiento cotidiano con el barrio y la pobreza. Ésta, inmisericorde, se vuelve contra ella misma, a través de patrones culturales ajenos a su realidad, pero condicionantes de su conciencia, para lograr la magia del fetichismo de la realidad, acentuando las contradicciones entre pobres, levantando una cortina de humo entre pobreza y sociedad, y descargando todo el peso de la miseria, de la exclusión y impotencia, en un culpable: el hombre. Este, a su vez, tampoco tiene muchos elementos para explicarse toda la situación y tiende también a descargar su frustración hacia el interior de la familia o contra ella, ya sea mediante el empleo de la violencia o el abandono del hogar, con la consiguiente carga para su propia conciencia como ser humano hombre padre que es.

34 En el caso de Cuba, encontramos una participación más horizontal, en pie de equidad entre mujeres y hombres en lo referido a la formación profesional, cultural, educativa, laboral y salarial, etcétera.

Aparentemente no habría aquí nada nuevo que investigar en lo referente a relaciones de género. Sin embargo, apelando a la duda cartesiana y la hermenéutica de la sospecha, tan cara a las teología feminista de liberación, ha sido posible arriesgar una pregunta: ¿Puede considerarse entonces que existe igualdad total en la toma de decisiones y en las distintas miradas a los problemas?, ¿cómo interactúan entre sí unos y otras?

Los estudios y los intercambios realizados con las organizaciones y con la población del barrio, permiten cuestionar esta afirmación y abrir el espacio a la complejidad de las relaciones hombre-mujer en condiciones de igualdad jurídica, económica y social.

La situación del hábitat resulta incomparablemente positiva respecto de otras realidades latinoamericanas. Si se realizara este cotejo, los pobladores del barrio saldrían ubicados con amplias ventajas en todos los órdenes. La infraestructura social creada por la revolución da una amplia cobertura a la seguridad de mujeres, hombres, niños y ancianos. En esta realidad destaca sin dudas aquello que posibilita una mayor y segura inserción de la mujer a la vida social sin restricciones ni discriminación de ningún tipo. Sin embargo, pese a los innumerables progresos de las mujeres en materia de derechos, a su desempeño real en los diversos ámbitos de la vida social, en los imaginarios de la mujer encontramos presentes todavía ciertos patrones de viejos supuestos acerca del deber ser de la mujer y su correspondiente deber ser del hombre.

Ocurre que las mujeres estudian, trabajan, participan, se organizan y protagonizan su historia, pero todavía - mayoritariamente - ven a la vida familiar y los roles allí 
adjudicados a hombres y mujeres como algo divorciado de lo social; no han logrado penetrar con fuerza crítica el ámbito de su vida privada y modificar de raíz los viejos paradigmas de la relación hombre mujer. Esto ocurre no solo en lo que hace a la relación de ellas con sus maridos, sino en primer lugar, respecto a ellas mismas.

El resultado es una sobrecarga de tareas y responsabilidades en lo público y privado que resulta muy difícil de llevar delante de modo individual. Es por ello que la familia naturalmente alcanza al menos dos generaciones, siendo «natural» por ejemplo, que las abuelas se hagan cargo de los nietos para que las madres puedan cumplir con sus actuales obligaciones; ${ }^{2}$ los hombres se incorporan en cierta medida, pero muy rezagados en proporción a la velocidad de los cambios que en esta relación produce la plena inserción de la mujer en la vida social. Así lo ilustra por, ejemplo, el siguiente testimonio: «La mujer cubana en un amplio porcentaje, continúa siendo el centro del trabajo doméstico, sin abandonar su función productiva y reproductiva, lo que trae consigo desigualdad familiar en la distribución de recursos como el descanso, el trabajo, la organización del hogar y el cuidado de los hijos (testimonio experta).» (César, 2005, p. 100-101)

El enfoque de género se consideraba realizado por las organizaciones sociales del lugar al contemplar las dos miradas: de un lado las mujeres y sus planteamientos, y del otro los hombres y sus planteamientos, para considerar luego a ambos. ¿La ausencia?: Las interrelaciones, los cruces y los nexos interdependientes de unos y otras. Se puso de manifiesto que predominaba una visión binaria de la relación entre hombres y mujeres.

41 Así lo reconoció María del Carmen, trabajadora social del Taller de Transformación Integral del barrio, responsable del área de la mujer: «Para mi fue toda una revelación comprender esta significación crítica del concepto género. Nosotros lo empleábamos pero sobre todo como una guía para ver lo que decían los hombres y lo que decían las mujeres, sin articular los nexos entre una y otra posición. No íbamos más allá; no nos adentrábamos en la crítica a las desigualdades entre ellos ni en cómo superarlas en la conformación de las soluciones colectivas. Por eso ha sido muy importante este investigación: darnos cuenta de ello.»

El problema, para nosotros, ha sido cómo hacer que esta realidad sea aprehendida por los actores comunitarios y por los hombres y mujeres que habitan en sus barrios. En tal sentido, nuestro objetivo se centró en analizar la construcción del planeamiento comunitario, la participación que en él tuvieron hombres y mujeres y los puntos de vista de unos y otras. En este caso, el planeamiento comunitario resulta un instrumento concreto empleado por la población para intervenir en la formulación de las políticas públicas que hacen a la vida del barrio, a su mejoramiento urbano ambiental, es decir, a sus condiciones integrales de vida, que con el tiempo hacen a la vida familiar, una vida cotidiana. Profundizar crítica y colectivamente en el desarrollo de dicho planeamiento, ha contribuido también al fortalecer el proceso de empoderamiento efectivo que venía ocurriendo en la vida de la población del lugar respecto a sus hogares, calles, parques, barrios y ciudades.

Este empoderamiento que es capacidad de poder hacer, supone poder conocer, poder proponer, decidir y actuar, y tiene como punto de partida la participación de los habitantes del barrio, y particularmente, la participación de las mujeres, también aquí, omnipresentes en el ámbito doméstico y comunitario, con capacidad de intervención y acción. 

familia fue impulsada hacia nidos insospechados, la obligatoriedad de compartir tareas y responsabilidades para garantizar la sobrevivencia diaria derribó prejuicios y barreras que los avances jurídicos habían podido derrumbar: hombres con jabas (bolsas) en la mano haciendo mandados (compras de pan, de verduras, etc), padres cuidando a niños en los hospitales para que la esposa cumpliera con sus tareas laborales 
si ello era necesario, mujeres aceptando que los hombres se hagan cargo de la cocina y de las compras, o del planchado y lavado de la ropa.

«En el período especial (...) ha crecido mucho la participación del hombre. Porque en las naciones subdesarrolladas no es fácil tener un microwave, equipos modernos para facilitar la tarea doméstica (la computadora para la planificación). Las mujeres cubanas son las heroínas del Período Especial. Pero los hombres hacen la reparación doméstica, (...) los mandados, van a los mercados campesinos, a recoger los niños, etc. Se ha puesto al descubierto el valor económico del trabajo doméstico y el valor social ideológico del trabajo educativo de las mujeres (testimonio-experta).» (César, 2004, p. 1003-104) Los códigos de convivencia familiar cambiaron para enriquecer las interrelaciones y provocaron fuertes movimientos en los cimientos de las identidades de hombres y mujeres impulsándolas con fuerza hacia nuevos horizontes. Es por ello que, en este plano del análisis, puede decirse que esta etapa ha tenido consecuencias positivas para la organización de la familia, de la comunidad y de la vida de la sociedad, sin embargo, no dejó en todos los hogares un saldo positivo para las mujeres. «En la primera etapa del período especial, (...) La mujer, por problemas domésticos, tuvo que renunciar a algo, y se vio afectada su participación más plena en la vida pública (testimonioexperta).» (César, 2005, p. 103)

Todo ello nos permite decir que no podría afirmarse que el machismo ha desaparecido en Cuba, puesto que no es un «aditamento» cultural del que uno/a pueda «desprenderse» rápidamente. Sí consideramos que a partir de los grandes avances obtenidos por la mujer cubana, se ha abierto un proceso hacia una mayor interiorización de la necesidad de superar los lastres culturales que la imposición de paradigmas patriarcales en relación a la conformación de las identidades y roles de género ha legado como herencia a esta sociedad y que sobrevive agazapada en la formación de las identidades de hombres y mujeres.

\section{Una riqueza metodológica: la educación popular}

Articuladamente con las metodologías propias de la investigaciónacción participativa, fue fundamental enriquecer nuestra labor con la educación popular.

Lo que en Latinoamérica denominamos educación popular data de la década del 50, de las experiencias educadoras impulsadas y teorizadas por el gran pedagogo brasileño Paulo Freire. Su propuesta resultó (y aún resulta) profundamente revolucionadora del andamiaje educativo, elitista y anquilosado establecido desde el poder $\mathrm{y}$, a la vez, con ello, cuestionadora del contenido y la labor docente e intelectual.

Sobre la base de la aceptación del postulado: «El pueblo tiene un saber, que hay que hacer emerger y tornar conciente», se despliegan diversas concepciones, metodologías y métodos, y a partir de ellos diversas líneas de intervención práctica de la educación popular. En casi todas sus variantes, estas aparecen siempre vinculadas a procesos de transformación social. Las interpretaciones son múltiples y no pocas veces resultan contrapuestas entre sí. Algunos ponen el énfasis en lo popular, otros en lo educacional, y en virtud de ello enfatizan alternativamente en los protagonistas del proceso educativo o en las características de su desarrollo.

Esto ha abierto, a su vez, una enorme gama de vertientes y corrientes de la educación popular en Latinoamérica y en otros países del Tercer Mundo donde ella se lleva a cabo. 
Todas ellas - quizá en honor a su creador Paulo Freire - se refieren al mundo de los oprimidos. Mencionaré ahora tres de estas corrientes: Las que concentran su mirada y acción en la alfabetización, las que la identifican con métodos y técnicas participativas de reuniones, conferencias, debates, etc., y las que la entienden como una concepción - y posición - respecto del saber poder hacer. En tal caso, concepción y metodología son el sustrato de una sola práctica.

Nuestra labor comparte las miradas con la última corriente mencionada y, en base a ella, a sus concepciones y presupuestos metodológicos, trabajamos enriqueciendo la de por sí rica mirada de la investigación-acción participativa (IAP).

Ambas concepciones - nacidas y acunadas en los brazos de la imaginación indo-afrolatinoamericana -, presuponen el reconocimiento del «otro» como ser humano pleno, capaz de conocer su realidad, de pensar con cabeza propia y actuar basándose en objetivos previamente definidos.

\section{Investigar, aprender, enseñar, transformar}

61 El «otro» adquiere en esta dimensión un valor sustantivo sin el cual es impensable acción ninguna, ni del conocimiento ni del saber de la acción. Se trata de una relación de interdefinición entre los investigadores y los investigados al punto tal que las fronteras de uno y otro se diluyen o se borran y, más de una vez, durante el proceso investigativo los roles de unos y otros se intercambian, contribuyendo a alcanzar - de conjunto - un crecimiento común de los participantes del proceso de conocimiento, ya sea en términos individuales o colectivos.

62 La investigación acción participativa que desarrollamos se entrelaza con la educación popular y se nutre vivamente de ella, concretamente, asumiendo como principio propio que la relación saber poder y poder-saber es igualmente válida con la que existe entre conocerpoder y poder conocer. $\mathrm{Y}$ así como la educación popular reclama transformar radicalmente el papel y el sentido educativo y social del educador, la IAP reclama la modificación radical de los roles entre investigadores e «investigados», del sentido y el papel social de las investigaciones, pues las involucra directamente con los procesos sociotransformadores en los que toma parte $\mathrm{y}$, más concretamente, con los actores protagonistas de dicho proceso. Es por ello que, en sentido estricto, no existen sujetos ni objetos de la investigación; se trata de un diálogo complejo en constante desarrollo que da cabida al proceso de investigación.

63 Precisamente, a partir de posibilitar este diálogo y desarrollarlo, la educación popular abrió senderos para profundizar colectivamente en las identidades de género y en sus interrelaciones asimétricas. Con ella fue posible articular:

- La deconstrucción de las miradas y los imaginarios presentes en hombres y mujeres, que caracterizó principalmente la primera a etapa de nuestra investigación.

- La identificación de los nudos problemáticos a trabajar.

- La reconstrucción crítica de sus imaginarios y de sus modos de plantearse la intervención y la participación de cada uno, en los ámbitos social, comunitario y familiar.

Una interrogante ha sido central:

¿Qué nos aporta a nosotros como investigadores, a las organizaciones sociales del lugar, y a los hombres y las mujeres que viven en los barrios?, ¿cuál es la ventaja de su 
empleo? Es decir: Por qué y para qué la educación popular, el sentido de su incorporación al centro de la concepción metodológica de la investigación-acción participativa.

En este sentido cabe subrayar que la educación popular refuerza la concepción de la IAP, facilitando el diálogo con la realidad, con los actores y las actoras sociales, sugiere, convoca y organiza el diálogo entre ellos y entre nosotros, abre los horizontes hacia la complejidad de la problemática de género y posibilita - en nuestro caso - encontrar pistas concretas a partir de la propia realidad para modificar esas relaciones junto con la modificación del medio ambiente urbano-ambiental, es fundamental para construir propuestas que contemplen integralmente el componente cultural del poder de dominación y discriminación hombre-mujer en lo comunitario y en lo familiar.

Todo ello a partir de promover y organizar la participación plena de los actores y las actoras del lugar en el proceso de investigación. Un papel importante en esta labor lo desempeñaron las organizaciones de la comunidad en cada lugar: El Comité para la Defensa de los Derechos Barriales (Copadeba), la Coordinadora de Organizaciones de La Ciénaga y Los Guandules (Codecigua), y Ciudad Alternativa, en República Dominicana. Y, en Cuba, el Taller de Transformación del barrio de Cayo Hueso, junto a la Federación de Mujeres Cubanas y el Consejo Popular del barrio.

Las conclusiones de la investigación resumen - en la medida que un proceso de este tipo lo permite - la mirada crítica sobre las prácticas de los actores, como si se tratase solo de un ejercicio teórico. Es por ello que los resultados de la investigación contribuyen a definir qué hacer para modificar las relaciones sociales de poder entre hombres y mujeres a partir de las transformaciones urbano-ambientales del lugar, y sobre esa base -, contribuyen a construir una agenda de tareas a realizar desde las organizaciones con la población. Todo ello abre caminos para proponer políticas públicas (elaboradas desde un nivel micro) convergentes con tales objetivos.

Otra cara de la moneda es si los sectores gubernamentales están interesados en escuchar esta voz e incorporarla a la formulación de sus políticas. La experiencia indica que esto es realmente un capítulo pendiente, puesto que en gran medida las propuestas no pasan de archivos y gavetas abultadas y, rara vez, las investigaciones concitan la atención de los políticos y gobernantes. Lograr esto es parte de los desafíos para la construcción de un nuevo tipo de interacción entre ciencias sociales y política de gobierno.

\section{Conclusiones a modo de reflexión general}

70 En las investigaciones mencionadas que hemos llevado a cabo activamente, articulada con la investigación participativa, la educación popular ha contribuido eficazmente a:

- Fortalecer procesos democrático participativos al interior de las organizaciones sociales.

- Profundizar la toma de conciencia para la transformación de la sociedad.

- Reconocer (auto-reconocimiento) a las mujeres como actoras sociales.

- Toma de conciencia de la dimensión política de la desigualdad y discriminación en las relaciones sociales (y familiares) entre hombres y mujeres.

- La formación política de la militancia de base.

- Promover procesos tendientes a la constitución del sujeto social y político popular de la transformación. 
71 Su metodología adquiere una especificidad propia, pues existe enlazada con su intencionalidad (objetivos), su vocación práctica de transformación social, y su apuesta ética (coherencia hacer-decir-vivir y medio-fin-proceso). Resulta por tanto, inmersa en la construcción de sentidos colectivos de la acción social de los actores y las actoras sociales. $^{4}$

72 Por ello adquiere una relevancia peculiar en la construcción desde abajo de procesos cognitivos de movimientos sociales y organizaciones populares, en la definición de sus objetivos y los medios para alcanzarlos, en la auto-constitución de actores sujetos y de su capacidad de empoderamiento de los procesos socio transformadores donde toman parte activa, particularmente - en nuestro caso - en lo que respecta al empoderamiento de las mujeres de base, a su participación no discriminada en las organizaciones sociales, y a los modos en los que esta ocurre y se desarrolla. ${ }^{5}$

73 En nuestra experiencia, los nexos que construimos entre la educación popular y la investigación acción participativa, influyen directamente en la conformación de dos aspectos de los procesos de conocimiento-transformación autotransformación en los que hemos participado:

1. La construcción colectiva de conocimiento y saber responde a un para qué también colectivo, es decir, tiene un sentido convergente con el desarrollo de los procesos sociotransformadores en los que participan todos los actores involucrados (investigadores e investigados).

2. El resultado de las investigaciones alcanza un interés doble para unos y otros: no solo como conocimiento nuevo, sino también como herramienta capaz de fortalecer (críticamente) los procesos en curso: las identidades colectivas en formación, la organización sectorial o intersectorial, las capacidades individuales, grupales y colectivas para la acción, la autoconciencia del conjunto de sí y para sí, es decir, el empoderamiento de actores y actoras del proceso investigativo destrabando fuentes de asimetrías y discriminación entre hombres y mujeres.

74 En esta perspectiva la acción (transformadora-empoderadora) es parte del proceso mismo de investigación que se potencia con los resultados concretos que se van alcanzando y, a su vez, plantea nuevos y crecientes retos y demandas a la misma.

La devolución de lo investigado al conjunto de actores participantes del proceso, resulta para todos, parte de la reapropiación crítica (autoconciencia) de su experiencia, de su historia y por tanto, un fortalecimiento (empoderamiento) de sus capacidades de intervención y transformación social.

76 Esto pone de relieve el componente ético de investigadores/as, actores/as, y del desarrollo del proceso investigativo como tal. Combate las posibles tendencias a instrumentalizar la educación popular o el proceso de IAP, que se desencadena, en lo fundamental, por comprimir la educación popular en razones metodológicas y en el empleo de un conjunto de métodos, técnicas y pasos a seguir para alcanzar los objetivos propuestos, con lo cual, supuestamente, el proceso del conocimiento estaría "concluido».

77 Esto nos recuerda una y otra vez que se puede hacer como que se hace IAP y educación popular $\mathrm{y}$, sin embargo, alimentar prácticas elitistas del saber-conocer-actuar. El prolongado y fastidioso desencuentro entre el saber académico - pretendidamente el único «científico» y válido -, y el saber popular es una muestra de ello; no es casual que 
- a pesar de las décadas de experiencia y saberes acumulados -, se haya avanzado muy poco en la construcción de un necesario y fecundo diálogo de saberes.

Las transformaciones materiales, objetivas, visibles y tangibles son escasas y no durables si no van acompañadas de transformaciones culturales de los imaginarios y de la interiorización en la subjetividad del porqué y el para qué de tales cambios.

Es parte de nuestros logros el hecho de que (considerando que para nuestro equipo siempre fue una hipótesis de partida) al final del proceso, se haya conseguido un resultado colectivo, el cual emergió de nuestra labor de investigación acción realizada conjuntamente con las organizaciones comunitarias y los hombres y las mujeres del lugar, en los barrios de República Dominicana y Cuba.

\section{BIBLIOGRAFÍA}

Bisilliat, Jeanne et Verschuur, Christine, Le Genre: un outil nécessaire, Cahiers genre et développement $n^{\circ} 1,2000$, L'Harmattan, Paris, 2000.

César, María Auxiliadora, Mujer y política social en Cuba, Mercié Ediciones, La Habana, 2005.

Hainard, Francois et Verschuur, Christine, Femmes dans les crises urbaines, Karthala-MOST, Paris, 2001.

Rauber, Isabel. «Movimientos sociales, género y alternativas populares en Latinoamérica y El Caribe», itinéraries, No. 77, IUED, Ginebra, 2005.

- Argentina: «Mujeres piqueteras». En: Genre, mondialisation et pauvreté, Cahiers genre et développement No. 3, 2003, L'Harmattan, Paris, 2002.

- Género y pobreza, UNESCO, Santo Domingo, 2000.

- Género y poder, UMA, Buenos Aires, 1998.

- «Ciencias Sociales y educación popular: ideas para un diálogo de saberes». En: Harnecker, Marta y Rauber Isabel, Memoria oral y educación popular, reflexiones metodológicas, CENDAL, Bogotá, 1996.

Reysoo, Fenneke et Verschuur, Christine, Mondialisation, pouvoirs et rapports de genre. IUED, UNESCO, DDC, Genève, 2003.

Vasallo Baurreta, Norma, «Ecos del pasado, voces del presente», en Femeninas, María Luisa (Comp), Perfiles del feminismo iberoamericano, Catálogos, Buenos Aires, 2002.

\section{NOTAS}

1. Cayo Hueso se deriva de la «traducción» cubanizada de Key West, Cayo Oeste.

2. Así lo refiere, por ejemplo, Norma Vasallo, cuando señala: «la mujer cubana sufre la sobrecarga doméstica, multiplicada por las condiciones en las que debe desarrollar esas tareas actualmente, se siente parte del ámbito público y no quieren renunciar a él.» (Vasallo, 2002, p. 24) 
3. El impacto que ello tuvo sobre hombres y mujeres de los barrios durante el proceso de devolución fue notable, puesto que si bien el término «ayuda» es de uso corriente entre ellos, la racionalización y reapropiación crítica de la significación social y cultural del mismo, les ha permitido un autoreconocimiento y autoconciencia acerca de los avances y obstáculos de sus empeños sociotransformadores $\mathrm{y}$, en general, recogimos un crecimiento de la autoestima colectiva al comprobar ala vez, que estas reflexiones eran un producto de la labor colectiva que habíamos llevado a cabo investigadores e ¿investigados?

4. Para ello se apoya también en la deconstrucción de procesos concretos, de experiencias de lucha y construcción de organizaciones, de colectivos sociales, para sobre esa base extraer todo el conocimiento, el saber, el pensamiento contenido en la práctica desarrollada por esos actores.

5. En la actual situación de crisis civilizatoria global marcada por la voracidad destructiva del capital y la consiguiente concentración de poderes supranacionales mundiales, pudiera parecer a algunos que apelar a procesos constitutivos de conciencia, poder (empoderamiento), organización, propuestas y actores sociales desde abajo es una postura contra-razón, sin embargo, solo seres humanos autoconcientes serán capaces de enfrentarlo y de construir una alternativa de vida social con equidad, justicia, dignidad humana y cuidado humanonatural.

\section{RESÚMENES}

El artículo se centra en destacar los aspectos teórico-metodológicos más relevantes de nuestras investigaciones en los procesos de cambio y desarrollo urbano ambiental con perspectiva de género, realizadas durante siete años en las ciudades de La Habana y Santo Domingo, con la investigación acción participativa y la educación popular. La articulación de estos elementos conforma y estructura el cuerpo del trabajo. Al abordar las políticas que para ello se despliegan en y desde el territorio con participación de la comunidad, focalizamos en el seguimiento y estudio de aquellas dirigidas a elevar y cualificar la participación de la comunidad en el diseño de su vida en el territorio comunitario a partir de criterios equitativos de «inclusión urbana». Ello contribuyó a animar y profundizar el debate acerca de las asimetrías, particularmente, las de género. Teniendo en cuenta que la investigación aborda integralmente las transformaciones urbano-socio-ambientales y de género en la peculiar realidad del proceso revolucionario en Cuba, sus reflexiones resultan de alto interés.

Cet article vise à souligner les aspects théoriques et méthodologiques les plus significatifs de nos recherches sur les processus de changement et de développement de l'environnement urbain avec une perspective de genre. Ces recherches ont eu lieu pendant sept années dans les villes de La Havane et Saint-Domingue et ont utilisé l'approche de la recherche-action participative et de l'éducation populaire. L'articulation de ces éléments a donné sa structure à notre travail. Parmi les politiques qui se sont mises en place sur les sites de recherche avec la participation de la communauté, nous avons plus particulièrement suivi et étudié celles qui promeuvent la participation de la communauté à la définition de leur projet de vie sur le territoire qu'elles occupent, en respectant les principes d'équité et d'" inclusion urbaine ". Ces études ont permis d'animer et d'approfondir le débat sur les asymétries, particulièrement celles de genre. Cette recherche, qui aborde notamment les transformations sociales, de l'urbain, de l'environnement et du genre dans la réalité particulière du processus révolutionnaire à Cuba, fait naitre des réflexions très intéressantes. 
This article aims at highlighting the main theoretical and methodological aspects of our researches on the processes of change and development of the urban environment with a gender perspective. For seven years these researches were conducted in the cities of Havana and Santo Domingo with the participative research-action and popular education approach. Our work was structured by these elements. Among the policies that were established on our research sites with the participation of the communities, we followed and studied more specifically those policies that promote community participation in the definition of their projects for life on the territories where they live, following the equity and "urban inclusion" principles. Our studies helped stir and deepen the debate on asymmetries, especially on gender asymmetries. Our research, addressing social, urban, environmental and gender transformations in the specific context of the Cuban revolutionary process, generates very interesting reflections.

\section{AUTOR}

\section{ISABEL RAUBER}

Docteure en philosophie, professeure de la faculté de philosophie de l'Université de La Havane, directrice de « Pasado y Presente XXI ", chercheuse du Centre d'études de l'Amérique basé à La Havane, responsable du projet MOST-UNESCO « Environnement, villes et rapports sociaux entre hommes et femmes » en République dominicaine et à Cuba. Elle étudie les mouvements sociaux latino-américains, elle est spécialiste du genre et des processus de participation citoyenne. Depuis 1997, elle est responsable du projet MOST-UNESCO «Genre, ville et environnement » à Cuba. 


\title{
Las mujeres en los espacios
} comunitarios. «La matriz comunitaria de sociabilización», un espacio político en gestación? Las manzaneras de San Cayetano, Campana, Argentina

\author{
Álvaro San Sebastián
}

\section{Introducción}

1 Sin duda el trabajo de investigación-acción desarrollado a lo largo de estos años, por el conjunto de equipos (la red) de diversos países y continentes, nos ha permitido compartir procesos y situaciones analizables en el marco del cruce de las variables iniciales: ciudad, medio ambiente y relaciones entre varones y mujeres.

2 Si bien una de las consecuencias de esta diversidad ha sido la cuestión de la comparatividad (desde lo metodológico y lo conceptual) ${ }^{1}$, es cierto que desde el inicio existieron variables o hipótesis que nos brindaron un común denominador a la hora de elegir y seleccionar el terreno de investigación y sus condicionantes.

3 Estas consideraciones han surgido fundamentalmente de nuestra experiencia de trabajo en Argentina, y desde allí estamos planteando algunas de estas ideas. Sin embargo, percibimos por el conocimiento ya adquirido (motivado por visitas a otros terrenos y en los intercambios producidos en los seminarios de la red) que algunas de estas hipótesis pueden ser válidas como eje de comparaciones y elaboraciones conceptuales posteriores en el caso de la temática que nos ocupa.

4 En nuestro caso el desarrollo de la investigación-acción se centró en el análisis de la concepción e implementación del Programa Vida², diseñado y puesto en marcha por la 
Sra. Hilda González de Duhalde ${ }^{3}$ (la «Chiche» en la jerga de la política y del público en general), en ese momento esposa del gobernador de la provincia de Buenos Aires. Este programa, de carácter asistencial, se desarrolla a lo largo de la Provincia desde el año 1995 (aún continúa, ahora bajo el nombre de «Programa Más Vida») y nos permitió analizar la implicación de las mujeres y los varones en un territorio particular, el barrio de San Cayetano en la ciudad de Campana ${ }^{4}$, ciudad límite del área metropolitana ${ }^{5}$.

Este programa, centrado en la aplicación de políticas públicas de asistencia social, constituye un paradigma en el sentido de la aplicación de un modelo de gestión de lo social centrado en la mujer como sujeto de asistencia (con la concepción que ésta representa desde su lugar en la familia, un eje comunitario), con la particularidad de que creó una red de 40.000 mujeres, llamadas manzaneras, actoras sociales encargadas de la implementación y consecución de sus objetivos en cada localidad y barrio de la provincia de Buenos Aires.

6 En este artículo planteo ideas que surgieron a partir de nuestro caso de análisis, en Argentina, y que considero pueden ser útiles, en tanto aplicación o contrastación de las hipótesis iniciales, tanto en nuestro terreno como en los otros terrenos de investigación de la red.

\section{Los nuevos escenarios políticos, económicos, sociales y culturales}

7 Argentina representa un claro ejemplo para analizar el impacto de las políticas neoliberales impuestas en los países (con diferencias regionales o continentales) por los organismos internacionales, y gestionados, en el caso de Argentina, por una sucesión de gobiernos dictatoriales y democráticos que adhirieron e implementaron con matices, estas directrices para lograr el «desarrollo de la región y de la nación». De la mano de un discurso sobre el proceso de globalización, el estado se transformó radicalmente, y como bien lo expresa A. Borón (2004: 8), «su carácter ficcional desempeñó funciones políticoideológicas sumamente importantes a la hora de legitimar esas políticas neoliberales».

Los efectos de la globalización no son simétricos para todos los implicados, no han tendido a homogeneizar. Muchas de las actuales narrativas, que lo definen como un proceso irreversible que afecta de la misma manera y en idéntica medida a la totalidad de las personas, no se cumplen. Se han ampliado las brechas entre ricos y pobres, se han generado más desigualdades étnicas, de género, de religión.

Sin duda, entre las diferentes causas de su implantación como modelo casi universal, son muchos los factores que confluyen y que han sido sostén y anclaje de su consolidación en el imaginario social y político. Pero quizás exista una constante en cada una de estas causas, o un sistema de interdependencias que, en todo caso, van produciendo un permanente fenómeno de ocultamiento y deslumbramiento conjunto. El fenómeno de la globalización me remite constantemente a la imagen del caballo de Troya.

10 Evidentemente, la globalización en tanto construcción históricocultural está atravesada por una gran variedad de posiciones relativas en cuanto a su interpretación, a sus consecuencias, a las acciones estructurales, y básicamente a la posición relativa que cada estadonación ha adoptado frente a este fenómeno neoliberal que se presenta con la apariencia de inevitabilidad (Bourdieu, 1998: 44) y donde pareciera que frente a este 
discurso homogéneo las alternativas se limitan a construir procesos de adaptación y gestión que permitan alivianar las consecuencias negativas en el universo cultural, social y económico.

11 Las políticas que se implementaron en Argentina significaron profundas transformaciones económicas, sociales y culturales; todas ellas aplicadas con escasa o nula transparencia, sin evaluación de las dimensiones de los deterioros que iban produciendo y con una anónima complicidad social, que como consecuencia del imaginario de esta globalización omnipresente e irremediable, acompañó - sobretodo inicialmente - el proceso de profundos cambios implementados. Cuando hablamos de las nuevas condiciones generadas por la exclusión y la pobreza, nos referimos a un cuadro particular e inédito en la historia del país (50\% de la población por debajo de la línea de pobreza) y constituye una experiencia inédita de exclusión no sólo del campo de la inserción laboral (economía) sino que se constituye en una exclusión estructural en campos como la salud, la educación y, por supuesto, la cultura.

En ese marco existió un cambio sustantivo del rol del estado, dejando de lado aquel rol de estado benefactor, promotor del desarrollo, convirtiéndose en un gestor de las políticas del neoliberalismo. El estado dejó de ser el garante para el logro de la condición universal en el acceso a los derechos de la salud y la educación, dejó de tener políticas de gestión y suministro de servicios básicos para la población (agua, electricidad, transportes, comunicaciones, etc.), ya que fueron entregados a manos privadas.

13 Además, en muchos casos estos servicios han sido privatizados a niveles nacionales o provinciales, lo que inhabilita a las autoridades locales (municipios) a tener alguna incidencia en los modos y tarifas como estos servicios se brindan, sin embargo, los habitantes siguen solicitando o reclamando al municipio por los problemas relacionados con ellos. A las ya precarias condiciones medio-ambientales se agrega un nuevo factor, la imposibilidad de lograr una gestión de lo urbano que contemple las situaciones de marginalidad y exclusión social en aumento.

En muchos casos, estas comunidades o barrios ni siquiera acceden a la prestación del servicio ya que las empresas no realizan las inversiones necesarias de infraestructura debido a que estos sectores no se presentan como un mercado rentable. Lógica de mercado que funciona como ordenadora de la inversión y que hace desaparecer el derecho de cada ciudadano.

15 Grandes franjas de la sociedad, principalmente las de menores recursos, vieron profundizada la crisis de su integración social y los derechos de ciudadanía frente a dos órdenes de factores: a) en relación al trabajo y b) en relación a la inserción relacional, una concepción material y otra simbólica. Aunque es bueno remarcar que la primera, la exclusión al trabajo, conlleva también a una situación de economías precarias, al quedar las personas fuera de los sistemas de derechos sociales que se ligan a una inserción laboral formal, y debido también a la salida (exclusión) del sistema educativo o de los sistemas de salud. "Se puede observar hoy una interrupción en el proceso de construcción histórica de la ciudadanía social, que se inicia con la crisis del Estado intervencionista y se profundiza en la actualidad. (Levin, 1998: 287)»

Frente a estas críticas e inéditas situaciones sociales, el Estado ausente o desplazado en muchos de los aspectos que producen y condicionan el medio ambiente (en lo físico), se presenta a través de planes sociales de asistencia, tratando de atender algunos aspectos de la crisis. Estas nuevas políticas ya no llegan en un sentido universal de integración y 
protección de sectores marginados, sino que empiezan a conformarse con una mirada focalizada que interviene definiendo grupos de alta vulnerabilidad (por ejemplo, las mujeres), con la consecuencia, en muchos casos, de que esta perspectiva aumenta la marginalidad y las diferencias.

En ese sentido comenzamos a transitar sobre "una nueva matriz de desigualdades: la desigualdad ante la precariedad, las desigualdades no son homogéneas, no afectan de la misma manera a toda la población, ni a todas las categorías sociales, e incluso en una misma categoría social la vulnerabilidad es desigualmente repartida». (Levin, 1998: 288). En este sentido, la dimensión del impacto de las políticas neoliberales y el nuevo rol del estado han afectado de diversa manera a varones y mujeres, y dentro de estas variables de género, también afectó a unos y otros, según sus condiciones sociales, económicas y culturales.

Por lo tanto, nos encontramos frente a un escenario en donde el territorio está signado por estas variables, y en donde se despliegan procesos sociales que tienen una doble característica. Una, la determinada por el accionar del Estado, produciendo políticas públicas que alcanzan a los ciudadanos, y la otra, surgida desde los propios habitantes que de diferentes maneras intentan adaptarse, luchar y crear formas de subsistencia que les permitan mantenerse dentro del tejido social.

En este sentido, me interesa detenerme en este análisis, también uno de los ejes de nuestro trabajo, tanto en nuestro caso como en el la investigación en general, y es el referido al análisis de la cuestión de género y de ciertas prácticas que se despliegan como consecuencia de procesos de autogestión de sus habitantes o producto de políticas sociales que se implementan en los terrenos.

\section{Programa VIDA: las características de un programa focalizado}

Nuestro trabajo centrado en el Programa Vida nos condujo a compartir múltiples experiencias con los actores de un terreno particular, un conjunto de mujeres, las manzaneras, que a partir de la convocatoria del programa desarrollaban prácticas específicas, diseñadas y definidas por el propio plan para disminuir algunos de los efectos de la crisis social y económica.

Este programa bautizó con el nombre de manzaneras al «conjunto de mujeres voluntarias (manzaneras y comadres) amas de casa pobres que asumieron las tareas básicas del Plan Vida, sin recompensas materiales, movilizadas por el deseo de servir. Consiguiendo, este programa, de modo intuitivo lo que hoy se proponen los principales organismos internacionales y algunos de los países más avanzados del planeta: movilizar el capital social latente en una comunidad» (G. de Duhalde, Kliksberg, 2002: 15)

Sólo algunos datos que considero relevantes para considerar la validez del ejemplo: el número de mujeres que trabajan actualmente en este plan de la provincia de Buenos Aires asciende a 40.000 y este número es constante desde el año 1999, siendo también, en años anteriores, de magnitudes significativas (97/98: 26.000, 96: 15.000 y 95: 5.000). Este programa ha atendido en su máxima expansión a más de 1 millón de beneficiarios directos, aplicándose en la totalidad del área metropolitana y en cada ciudad de la provincia con más de 20 mil habitantes.

Es muy importante señalar que pese a que Chiche dirigió en forma personal este programa hasta el año 1999, posteriormente con los cambios en la gobernación de la 
provincia, ella dejó esta tarea. Sin embargo, el Programa Vida, siguió con altibajos producidos por los cambios políticos, esta trama territorial de mujeres manzaneras, mantuvo su presencia fundacional y funcional en el terreno de la provincia, hasta el punto que hoy en día siguen siendo conocidas como las manzaneras de la «Chiche».

En síntesis: la magnitud, continuidad y presencia territorial de este programa, su construcción y desarrollo en el marco del proceso de globalización de Argentina, sus efectos en el plano concreto de la resolución del problema para el cual fue creado, la constatación de la importancia territorial de esta red, la construcción de la red de las mujeres manzaneras y su relación con la gestión estatal, la exclusión instituyente de los varones como gestores en los problemas de la comunidad y referentes de una política social implementada desde el estado, las bifurcaciones hacia tareas políticas de las manzaneras, su aparición en el espacio público/político del barrio, el impacto en sus propias subjetividades e identidades en tanto manzaneras, los niveles de empowerment alcanzados o imaginados, los imaginarios de género implícitos y explícitos, hacen de este programa (y de las prácticas de las mujeres que lo llevan adelante) un interesante ejemplo del trabajo comunitario y de las variables que nos propusimos conceptualizar en esta investigación-acción.

Las concepciones que se plantean en la creación de estas políticas sociales representan lo que Bourdieu (1998: 10) llama «la mano izquierda del estado, conjunto de agentes de los ministerios llamados gastadores, que son el vestigio, en el seno del estado, de las luchas sociales del pasado». En nuestro caso, además, la podríamos denominar la mano «femenina del estado», encarnada en ese momento, en la mujer del Gobernador de la Provincia, posición que no es menor en el sentido que propone un instituyente muy importante para este lugar de la mujer como la que viene a reparar y crea una línea de acción estatal que construye un modelo donde los varones gobiernan y deciden, y las mujeres que los acompañan, resuelven los problemas sociales producidos a causa de las decisiones y resoluciones de los varones. Este modelo, sin duda, tiene fuertes antecedentes en nuestro país y sobretodo en el peronismo en función de la figura de Eva Perón, matriz fundacional de un modelo de acción política de la mujer peronista.

Hay una fórmula que se instituye, que se inicia y se constituye verticalmente, que es la de una mujer (en reiteradas oportunidades «la esposa de...») a la que se otorga la potestad para «ocuparse» de los grupos más vulnerables en los que siempre se encuentran las mujeres, y en donde inclusive, toda la estructura que se institucionaliza está compuesta por mujeres. Las encontramos a distintos niveles de gobernaciones, municipios, secretarías, ministerios, direcciones a cargo de la acción o desarrollo social, ligadas a su vez a las estructuras partidarias en los terrenos donde actúan.

Este modo de actuar implica asimismo una cierta trampa en el sentido que se realiza desde un extremo voluntarismo de modificar las condiciones de vida de ciertos grupos vulnerables (en este caso en particular las mujeres y los niños), pero al no plantear la posibilidad de que esa situación pueda ser modificada en su estructura, se fundan acciones adaptativas, que inclusive pueden ser eficaces para enfrentar una realidad determinada, pero que no contienen en su formulación estrategias e ideas que vayan construyendo alternativas de anticipación a las desigualdades sociales producidas. Es decir, que ese capital social que movilizan, y de hecho lo hacen, precisa ser analizado en función de los imaginarios que naturaliza y consolida. 
Mucho se ha hablado, y con razón, de la feminización de la pobreza, pero también deberíamos hablar de la feminización de la gestión política de la pobreza, sabiendo que en esta definición de la pobreza uno de los sujetos incluidos es la mujer.

En las estructuras burocráticas o del poder la gestión está dividida, existen áreas netamente masculinas que se relacionan de un modo muy diferente con la comunidad, establecen distinto tipo de relación con la gente, y en muchos casos restringen información a sus pares funcionarias mujeres a las que identifican con las demandas de la población. El vínculo que establece cada área es diferente, en palabras de una ex funcionaria del área social trasladada al área de planificación urbana expresaba: «... aquí estoy alejada de los problemas afectivos de la gente, esto es una cosa muy distinta...», como si el lugar y la pertenencia modificaran parte de su sensibilidad social o le impusiera otra manera de vincularse, o dicho de otro modo, como si ese área no tuviera en su estructura la posibilidad de procesar las emociones de los ciudadanos. Obviamente, también en ese nuevo lugar la mayoría de sus compañeros son varones.

Estas mujeres, que se relacionan entre sí y disputan, a veces, espacios políticos, presupuestos y la administración de conflictos producidos por decisiones de los varones, trabajan en las bases con grupos de mujeres e implementan políticas donde la perspectiva de género no tiene correspondencia con sus acciones (que se corresponde en general con políticas hacia la mujer) y, entre otras cosas, no cuestionan la exclusión de los varones, naturalizando que ellos no participen.

Si bien por una parte existen ciertas configuraciones identitarias y subjetivas o imaginarios comunes que otorgan sentido a estas institucionalidades encadenadas de mujeres, detectamos entre ellas distintos niveles de agenciamiento, distintas prácticas, distintas ideologías, distintas pertenencias comunitarias/políticas, y por supuesto, diferentes niveles sociales.

Como señalamos anteriormente, el objetivo explícito e inicial del Programa Vida se centró en revertir los índices de morbimortalidad materno-infantil. Y para ello se definieron una serie de pautas metodológicas que caracterizaban el programa. A su vez, estas pautas implicaban definiciones sobre los ejes de la política social, el modelo de gestión, y uno más, que en nuestro caso nos interesa focalizar, referido al papel de la mujer, ya que lo encontramos presente en la definición de todo el proceso de gestación de las políticas sociales implementadas.

33 Una de las definiciones expresa que se realiza un proceso «de acción social unificado, interinstitucional y basado en la familia, acción solidaria organizada en redes, de las instituciones hacia el grupo primario y estos grupos sostenidos por otros en redes ínter vinculadas en lo horizontal por las mujeres participantes $y$ en lo vertical por las estructuras intervinientes.» (G. de Duhalde, 2002: 82)

4 Este cruce horizontal (individual/comunitario) con lo vertical (institucional/político) pretendía movilizar el capital social de la comunidad de la mano de las mujeres. Y en esta convocatoria a la movilización del capital social aparece una primera característica analizable desde una perspectiva de género, el agente o actor social privilegiado es la mujer porque se considera que es la más capacitada para el desempeño de esa función comunitaria, entonces la primera pregunta a formularse es: ¿Desde qué configuración de identidad de género se la convoca? y también ¿Por qué no preguntarse desde dónde y quiénes la convocan? 
Rescato aquí algunas de las configuraciones que se proponían desde el plan: (Kliksberg, G. de Duhalde, 2002: 13, 14, 44, 96)

«Los programas, en lugar de construir una extensa estructura burocrática (...) apelaron al capital social de los pobres de la provincia, convocando acertadamente a una de sus expresiones mayores, las madres, la respuesta fue masiva y de una calidad singular»

«Los resultados que superaron todas las expectativas, se basaron en el trabajo continuo de 35.000 voluntarias: amas de casa pobres que asumieron la tarea básica de ambos planes, sin recompensas materiales, movilizadas por su deseo de servir.» «La mujer es mucho más que el género en su participación social, porque en nuestra cultura sudamericana se transforma en la articuladora de la comunidad. Es a su alrededor que se construye la familia, que se establecen las redes solidarias naturales e incluso, en los últimos tiempos, son ellas quienes llevan adelante tareas de protesta o reivindicación que sobrepasan con mucho su rol de género.»

«Tomar para la formación de la red el actor social más capacitado para el desempeño de la función y motivarla a través de las tareas de organización y capacitación para proyectarse en una realidad más abarcadora que las cuatro paredes de su casa»

En estas breves definiciones queda claro que existen muchas predeterminaciones naturalizadas sobre el rol de la mujer y que la concepción de género pareciera referirse a una identidad social pre-establecida a la cual no se le cuestiona su particular condición, aunque se describen algunas características de su subordinación.

Nos encontramos con una valorización de la mujer (madre/ama de casa) que deviene del rol de la mujer en el espacio doméstico. Estaríamos frente a una concepción que se apropia de bienes que las mujeres producen en la comunidad o en el espacio doméstico (bienes simbólicos, económicos, productivos), pero también, en el mismo proceso, se produce una apropiación de sus potencias como ciudadanas para producir tales bienes. Se logra de esta manera una producción de consenso que sostiene determinados universos de significaciones imaginarias y construyen el sentido social estableciendo relaciones de género en el sentido hegemónico en lo cultural y simbólico.

¿Proceso de discriminación relacionado con esa cadena vertical que también se apropia de la potencia del movimiento de avance de las mujeres pero esta vez entre las propias mujeres?

Las mujeres manzaneras en algunos casos han ampliado sus prácticas, su presencia en el territorio las ha colocado como referente, son puntos de contacto con el poder, con un poder que aún se presenta como benefactor y protector en esos ámbitos marginalizados donde ellas actúan, por otro lado, su aprendizaje social las capacitó para enfrentar situaciones problemáticas en el seno de sus comunidades (violencia doméstica, gestión del entorno, participación en ciertas organizaciones de la comunidad).

Estas mujeres, sin duda, han comprometido su cuerpo junto a sus emociones. El lugar que han adquirido en cuanto a su propia experiencia subjetiva no es menor, han modificado su rol pero no el imaginario que portan, han adquirido mayor autonomía en lo personal, se sienten respaldadas (inclusive al interior del espacio doméstico) para defender algunos de sus derechos (no en igual medida los de sus vecinos).

41 Pero, ¿Qué pasó en el espacio público-social? Han accedido al espacio público no sólo de su propio territorio sino que además se han constituido, en tanto manzaneras, en un sujeto público, nominadas en los medios, homenajeadas, cuestionadas o defenestradas por ser consideradas «punteras encubiertas» de una red de clientelismo político; de 
cualquier manera, eso les otorgó visibilidad en lo grupal, reforzando lo personal. Sin embargo, esta posición no les ha proporcionado una reflexión sobre sus roles de género, ya que han sido colocadas en ese lugar de madres sociales desde una gestión que no propone rupturas a ese rol tradicional en sus espacios domésticos, sino que, por el contrario, desde ese lugar se las convoca para la tarea social.

«Algunas trabajamos en la unidad básica, sólo algunas de la unidad son manzaneras, pero nadie nos obliga, no nos obligan a hacer política, yo voy porque me encanta, es lindo, a mí me gusta trabajar por la gente. Yo a mi marido no le dejo que diga nada, no hacemos nada malo, estamos entre mujeres, yo no dejo que le haga falta nada, no puede decir nada,¿por qué va a decir? Limpio mi casa, cuido mis hijos, dejo el orden, tengo la comida, el mate listo, el baño listo y después salgo. Mi marido no va a la unidad, ni a ningún lado. Otra cosa es si viene tu marido y tenés la casa patas para arriba, un despelote, los chicos en la calle... igual yo tengo tiempo para todo»

(del testimonio de una manzanera).

La auto-exclusión de los varones, vecinos, maridos, compañeros, hijos, en estas actividades impide también que la gestión comunitaria incluya una visión abarcadora de los problemas de su entorno (varones a los que ellas consideran débiles y poco aptos para esta gestión, que es una opinión coincidente con el concepto del programa). La perspectiva de género entendida como «componente mujer» que aumenta la diferencia entre las personas, no colabora en construir al interior de las relaciones sociales un proceso de negociación y consenso donde varones y mujeres acuerden en un proceso tendiente al equilibrio y la equidad.

No estoy formulando que la exclusión de los varones constituye el problema, ya que ese tema es más complejo para analizar, pero sin duda esta nueva división del trabajo (en lo social y político-comunitario) reafirma roles tradicionales de nuestra cultura e impide la generación de procesos que otorguen a las mujeres el acceso a un poder y toma de decisiones, a la vez que tampoco genera en el conjunto de la comunidad un agenciamiento que aumente el poder local.

El capital social que han producido es incierto en términos de permanencia autónoma, está afianzado en esa cadena de sentidos instituida desde el estado, ha reforzado lo individual de cada mujer y su autoestima, pero la pertenencia a esa permanencia autónoma también las debilita.

Si bien podemos comprobar que estas mujeres han vivido un proceso donde su autoestima ha crecido, donde las tareas llevadas adelante, las prácticas y aprendizajes realizados, el nivel de socialización en relación a sus pares, ha producido modificaciones en su identidad como mujeres, no es menos cierto que este agenciamiento se ha construido en el marco de una dependencia, de una pertenencia a esa cadena vertical de gestión, y esta dependencia simbólica las ha colocado también en una dependencia, en la capacidad para generar acciones por fuera de la línea de representaciones de una política oficialista de asistencia marcada por los imaginarios presentes en este modelo de mujer voluntaria dedicada a los problemas de la comunidad donde, sin embargo, su tarea no puede ser remunerada.

Todo este proceso ha sido gestado con una fuerte impronta a partir de la concepción e implementación del Programa Vida. Sin embargo, existen líneas de acción, procesos subjetivos que han saltado por encima de los imaginarios establecidos como arquetípicos en su condición de mujeres, y sobre estas experiencias es que es importante describir algunas de las prácticas que les dan origen y sentido. 


\section{El fenómeno de la participación de las mujeres en la comunidad}

Una de las variables iniciales en la formulación de esta investigaciónacción se refería a la participación protagónica de las mujeres en las comunidades y el estudio de cómo esta participación y acción podía constituirse en un proceso de empowerment en la medida que las estructuras de participación autogestiva fueran consideradas e incluidas en las decisiones y en las políticas públicasm además de estar consideradas dentro una perspectiva de género a la hora de planificar políticas medio-ambientales relacionadas con la situación de los ciudadanos en esos terrenos.

4 Hoy, después de compartir en la red este rico proceso de trabajo conjunto y de conocer las diversas realidades de los terrenos analizados, podemos inferir algunas conclusiones o consideraciones, que si bien no podemos considerarlas de un modo general, podemos intentar realizar algunas comparaciones, encontrando similitudes en causas y consecuencias, teniendo siempre en cuenta la diversidad de escenarios culturales, políticos y sociales.

La experiencia que adquirimos nos condujo también a ampliar desde este mismo programa MOST y a compartir el análisis de otras experiencias de campo atravesadas por la misma situación. ${ }^{6}$

Frente a las críticas situaciones sociales (la pobreza, la exclusión, la marginalidad, el desempleo, etc.) en las mujeres aparece un motor que las lleva a salir de su espacio familiar (espacio doméstico, privado) que lo denominaremos la conciencia de necesidad. Se enfrentan a una situación donde sus hijos u otros niños no tienen alimentos, sufren problemas de salud producto de las malas atenciones o deficiencias en el servicio de salud estatal, viven en situaciones medio-ambientales de alta precariedad. Las mujeres se encuentran en un contexto donde los varones (generalmente sus compañeros) han perdido el trabajo, o peor, no han accedido nunca a un trabajo formal, ruptura del paradigma masculino del proveedor que no encuentra alternativas a una inserción laboral formal o informal y que, en general, no encuentra formas alternativas de subsistencia. En ese contexto, la mujer, llevada por esta conciencia de necesidad, comienza a desarrollar nuevas prácticas intentando abordar nuevos caminos para la construcción de alternativas de subsistencia, inicialmente, para su propia familia.

1 Inclusive, algunas de estas mujeres ya habían transitado experiencias de inserción laboral (doble rol) para aportar una ayuda (Rauber, 1998: 6) en lo económico, desde la construcción tradicional donde era el varón el que aportaba a la economía de la producción en el espacio familiar. Muchas otras se constituyen como jefas de familia y tienen en forma completa la responsabilidad de la manutención económica de sus hijos o del grupo que tienen a cargo. Muchas otras, sin embargo, cuentan inicialmente con la única experiencia de ser amas de casa, responsables de la reproducción en el seno del espacio doméstico.

52 La crisis, el desempleo de los varones, la marginación, la exclusión como ciudadanos de derecho, el hambre, los problemas medioambientales que afectan directamente a los sujetos del entorno más próximo, entre otros factores hacen que las mujeres motivadas en esta conciencia de necesidad y apoyadas en sus prácticas de reproducción irrumpan en el espacio comunitario. Si bien este no es un proceso que se inicia en la crisis que 
estamos describiendo, adquiere en este momento una magnitud diferente y significativa.

53 Es aquí donde es muy importante marcar una diferencia en cuanto al protagonismo de las mujeres en el espacio comunitario (espacio de sus prácticas y acciones). Existen casos como el que analizamos centralmente en nuestro trabajo (las manzaneras) donde estas mujeres son convocadas por el poder estatal y político para llevar adelante una función en el marco de un plan de carácter asistencialista, basado en la representación de que las mujeres, a causa de una determinación de género y experiencias de acciones anteriores a nivel comunitario, pueden desarrollar eficazmente este rol social.

Es diferente la situación, por ejemplo en el caso de las mujeres que participan en los movimientos de desocupados, o en varios de los terrenos de investigación de la red, donde estas mujeres actúan desde grupos de base mas bien auto-convocados y autogestivos, (tales son los casos de Santo Domingo, Bulgaria, Senegal o Burkina Faso) ${ }^{8}$. Esta mención nos permite plantear ciertos niveles de comparación para pensar el fenómeno de la presencia protagónica de las mujeres en el espacio comunitario y en las ausencias (en este tipo de actividades) de los varones.

Otro elemento a destacar en este accionar de las mujeres es que este compromiso o práctica social (militancia en lo social, por denominarlo de otro modo), no implica una postura de reivindicaciones de género, no se postula inicialmente como una militancia destinada a suprimir o a combatir diferencias y desigualdades de género. La conciencia de necesidad, motor de esta participación, está ligada a obtener soluciones sobre los problemas básicos (salud, alimentación, medioambiente) y en un principio pareciera que el hecho de que sean las mujeres las que salen a enfrentar la situación, es una de las tantas naturalizaciones incorporadas en el imaginario social. Es decir, pareciera que existe en las mujeres en tanto representaciones sobre el rol femenino, una capacidad de producir bienes desde determinados universos de significaciones imaginarias que se asientan en lo social.

56 Y cuando se diferenciaba esta presencia en el espacio comunitario producida desde el propio poder político o desde las propias bases comunitarias, en realidad se plantea la apropiación de una potencia como grupo o como individuos, desde una determinación de género que implica, por otra parte, y en los casos que se produce la doble apropiación (la de bienes y la de potencias), un proceso de discriminación que oculta las desigualdades de género.

Porque cuando las mujeres son convocadas para actuar como útiles agentes del estado en temas de asistencia social (tal cual el caso de las manzaneras) «el saber trasmitido está destinado a reforzar un saber intuitivo y emocional que les es atribuido naturalmente a las mujeres: la preparación de alimentos, la crianza de los niños y la educación» (Masson, 2004: 110) tratando de poner en práctica una maternidad social partiendo de una visión fragmentada de lo que es ser mujer.

\section{El triple rol: un concepto que deberíamos problematizar}

58 Tradicionalmente, en muchas de las concepciones del feminismo, sobre todo las que vienen del norte, se habla del triple rol de la mujer. Las definiciones o aproximaciones a lo que significa en la condición femenina el triple rol que encarnan las mujeres, están 
referidas a una sumatoria de prácticas. La reproducción considerada como un rol primario naturalizado. El doble rol ligado a la salida al espacio de producción, inclusión formal o informal (casi siempre) en el mercado de trabajo para complementar el sustento económico del grupo familiar. El tercer rol se define a partir de las actividades que las mujeres despliegan en el espacio comunitario, y en que, en nuestro trabajo; las podríamos ejemplificar a partir de por ejemplo: las motivaciones generadas por situaciones como la precariedad del hábitat (caso del terreno brasileño o búlgaro), gestión de temas urbanos como consecuencia de un estado ausente (caso del terreno burkinense), nuevas condiciones en el acceso a servicios primarios de infraestructura (caso rumano), o problemas ligados al desempleo, la salud o la educación (caso de los movimientos de desocupados argentinos).

Este tercer rol, el de gestoras del entorno, está reforzado desde la determinación de género, desde la figura de esposa/madre, posición subordinada que se construye sobre una división sexual del trabajo. Esta concepción tradicional define, además, al espacio comunitario como una ampliación naturalizada del espacio doméstico. (Kabeer, 1992: 3-22; Moser, 1989: 1801)

Desde esta perspectiva, este triple rol se basa en una naturalización de la capacidad de las mujeres para gestionar problemas referidos a lo reproductivo. También es, efectivamente, una sobrecarga de responsabilidades y actividades en relación a los varones de su misma comunidad, ellas se comprometen con su medio-ambiente (en un sentido amplio desde lo ligado a recursos físicos, como en la problemática social), y en esas actividades son nuevamente invisibilizadas y subordinadas a un poder patriarcal. Se trata de un rol de reproducción, producción y trabajos comunitarios.

61 Concatenada con esta perspectiva también se incorpora una noción espacial entre el mundo público de los varones y el mundo privado de las mujeres, donde el barrio o el territorio de pertenencia es considerado como una extensión de la esfera doméstica.

Esta perspectiva tradicional coincide cuando la situación en los terrenos se verifica como un proceso progresivo de división de tareas determinadas desde el género, que hacen que las mujeres vayan incorporando, de un modo naturalizado, las responsabilidades por el medioambiente, considerando en los imaginarios sociales a este espacio comunitario como una prolongación del espacio doméstico. Se trata de una división de tareas basadas en un varón que se hace cargo de las responsabilidades de producción que sostiene al grupo familiar desde el punto de vista económico, en donde la mujer se ocupa de las tareas de reproducción en el espacio doméstico y en donde este espacio se amplía a lo comunitario. Así, este espacio comunitario va siendo considerado como esfera de lo privado (salvo que en él desarrollen actividades ligadas a la política, en cuyo caso son los varones que adquieren protagonismo y por lo tanto hablaríamos de un espacio público), descripción hecha desde una perspectiva del modelo tradicional, que por efectos de suma de actividades las va determinando desde una división sexual de trabajo y de las representaciones de género que otorgan sentido a la organización familiar y comunitaria.

$63 \mathrm{Y}$ es en este punto que considero importante plantear algunas diferencias que a partir de nuestras experiencias problematizan este concepto, sobretodo en lo que se refiere a la concepción de que este triple rol (las tareas comunitarias) se constituye como una clara y definida ampliación del espacio doméstico, y que su práctica no cuestiona algunos órdenes de género. 
Por eso, me parece que la categoría de triple rol debería ser reconstruida en cada una de sus instancias y que no puede ser analizada como un conjunto homogéneo que actúa por pura asimilación de funciones iguales, o que surge de una base de prácticas femeninas que se van ampliando y donde en cada instancia se repite la práctica anterior.

Cuando hablamos de la conciencia de necesidad frente a la ruptura del modelo tradicional donde los varones dejan de poder cumplir con su rol de proveedores se produce, como lo mencionamos anteriormente, una salida de la mujer que incorpora la imperiosa necesidad y la voluntad de encontrar una solución productiva para garantizar la reproducción aunque no esté directamente asociada a lo laboral, pero si asociada a encontrar un sustento o un cambio en su situación medio ambiental, vía lo laboral, la ayuda social o un reclamo al estado. Salida que se produce de algún modo no sólo desde una conciencia individual sino con un sentido colectivo, no es ella en particular la que sufre los avatares de esta situación aunque a veces así lo pueda sentir inicialmente.

6 En esta caracterización de solución productiva estoy considerando el acercamiento a los planes sociales (que otorgan por ejemplo en Argentina un subsidio a través del plan de jefes y jefas de hogar, que fue otorgado a cerca de 2 millones de beneficiarios, siendo el $70 \%$ mujeres), o en otros casos, la participación en actividades comunitarias que organizan las mujeres en sus barrios (comedores, guarderías, roperos populares), $u$ otras organizaciones económicas que de un modo directo o indirecto intentan buscar la producción de bienes (el alimento, por ejemplo) que pueden colaborar con la situación en su conjunto.

En algunos casos también se acercan a planes que dan subsidios para el funcionamiento de estas actividades (sobre todo para los comedores), o como en el caso de las manzaneras que realizan un trabajo voluntario en el barrio, para garantizar la entrega de alimentos a todos los beneficiarios. En este caso además hay una adquisición simbólica otorgada desde el poder que las coloca como referentes del territorio a nivel municipal y político.

68 En la mayoría de las actividades que mencionamos - actividades identificadas, inicialmente, con esta prolongación del rol maternal del cuidado, la alimentación o la salud - los varones no participan. La conciencia de necesidad lleva a las mujeres a irrumpir en el espacio comunitario, en él despliegan una gran diversidad de tareas sin un objetivo político, es la propia práctica que empieza a determinar su protagonismo y su participación y que se convierten en una referencia de la política social difícil de soslayar por los varones o los poderes públicos.

Entonces podemos plantearnos como hipótesis que la mujer actúa sobre una ausencia, un vacío en la complementariedad naturalizada del género, es decir, la identidad relacionada con la responsabilidad de la reproducción se amplía, se modifica. La mujer sabe, en algún lugar de su subjetividad, que esta salida al espacio comunitario le debe brindar una respuesta en lo productivo (en el sentido que lo señaláramos). Aparece una resignificación de estas actividades domésticas, presentándoseles como trabajo de las mujeres en la comunidad. Y necesariamente este cambio produce de modo directo o indirecto una modificación en las relaciones de género (independientemente de que esto signifique una modificación en las representaciones de lo femenino, en tanto subordinación o desigualdad) le otorga un contacto con la capacidad de producir bienes y la potencia de sí misma (autoestima y autonomía). 
70 Esta doble constatación la vemos en las mujeres senegalesas, que en función de la participación en las cooperativas (donde han desarrollado una propuesta centrada en una rentabilidad económica), expresan que ellas tratan de, para evitar la humillación natural que sienten sus maridos, dejar que sean ellos (con el dinero que ellas obtienen) los que hagan, por ejemplo, las compras de alimentos para la familia. Interesante postura que evidentemente se tensiona entre la adquisición de un nuevo lugar en el espacio doméstico y su relación con el varón, intentándose siempre dentro del mismo discurso, que la ruptura no afecte los roles tradicionales de género según una representación imaginaria.

71 Como bien lo plantea Ramos Ávila (2003: 25), la colectivización de actividades domésticas ha producido algunos desplazamientos de sentido como por ejemplo:

a. Ha posibilitado que dichas tareas sean visualizadas como un trabajo, es decir como productoras de valor,

b. ha hecho posible que las mujeres sientan que sus actividades tienen influencia más allá de sus propios hogares y finalmente,

c. ha contribuido a generar lazos comunitarios y a destacar la importancia de los procesos de organización colectiva.

Por otra parte, pareciera que las categorías de espacio público y espacio privado (quizás hegemónicas de la modernidad, efectivamente discutidas por ejemplo por N. Fraser sobre la concepción de Habermas) $^{9}$, donde se intenta ubicar unívocamente las actividades desplegadas por varones y mujeres en los nuevos escenarios sociales, no nos permiten definir los límites entre espacios superpuestos, espacios en proceso de transformación, espacios conflictivos, espacios subversivos, espacios transgresores, intersticios de nuevas producciones, o espacios donde se realizan prácticas instituyentes que aún nos cuesta saber si tendrán un efecto sobre lo doméstico/ público/político o quedarán como parte de un mundo privado/personal/no-politizado, tanto en términos sociales como en las cuestiones de género.

De otro lado, principalmente porque en estas prácticas las mujeres no se plantean una lucha de género, ellas proponen la necesidad de desarrollar en esos espacios tareas que puedan devolver la dignidad a sus familias o vecinos, creen que los varones no están en condiciones de enfrentar esta situación de urgencia primaria y ni siquiera les reclaman su presencia, dicen «ellos se deprimen, se angustian, si no tienen trabajo, no saben que hacer, se emborrachan». Es importante de remarcar este punto, ya que uno de los elementos que surgen a causa de la metodología de la investigación-acción es que las mujeres tienen (sobre todo inicialmente) una naturalización de las desigualdades de género. $Y$ es en ese camino que empiezan a transitar, donde se van poniendo de manifiesto problemáticas en los vínculos con los varones (violencia, derechos sexuales, aborto, propiedad de la tierra, etc.).

74 Porque esa categorización taxativa, espacio privado/espacio público, nos hablaría entonces de un espacio comunitario domesticado regido exclusivamente por las jerarquías de subordinación de género de lo doméstico, y sobre todo, por la condición de espacio privado que se le otorga a lo doméstico, que produce que ciertas problemáticas no se transformen en temas de la política y de las agendas públicas (tal el caso de la violencia familiar o sexual al interior de los hogares).

75 Aquí, sin embargo, hemos observado la importancia de lo que significa esta salida al espacio comunitario, desde los roles domésticos, desde esta conciencia de necesidad. Y 
en función de nuestra experiencia en la investigación-acción, estas categorías aparecen interpeladas por las prácticas concretas que se desarrollan en el escenario de estos espacios comunitarios de encuentro y socialización.

Y esta problematización del espacio comunitario, es decir, su análisis connotándolo como ampliación del espacio doméstico por estar ligado a las actividades que en él realizan las mujeres, es interpelada por la magnitud y potencia que adquieren las prácticas femeninas que irrumpen en ese espacio, por las tensiones que se generan, o porque se politizan (directa o indirectamente), dándole nuevos sentidos sociales y políticos, y dicho sea de paso, es paradójico que en este espacio y en esas actividades los varones no estén presentes, siendo ellos los que, desde una perspectiva de género, le otorgaban al espacio el carácter de lo público. Creo que es apresurado otorgar a este espacio un carácter doméstico tan sólo por el hecho de que sean las mujeres las que lo habitan y lo producen, ya que otorgándole, eliminaríamos la posibilidad de considerarlo como una práctica instituyente, potente e impredecible en cuanto a sus consecuencias en las relaciones sociales de género.

La participación de las mujeres en estos espacios comunitarios provoca renovadas formas de participación colectiva, nuevas formas de representación y nuevos espacios de discusión y construcción social y, por momentos, de construcción política.

Es por esto que la consideración del triple rol desde esa perspectiva tradicional no da cuenta de la complejidad que adquiere la condición protagónica al espacio comunitario, por lo que considero que es necesario diferenciar a partir de las prácticas que encontramos en las comunidades y en los movimientos sociales (de los países del sur), su caracterización.

\section{La matriz comunitaria de sociabilización}

79 En función de estas diferencias de conceptos que nos parecen, pueden cerrar un campo incipiente de análisis y donde las prácticas y sus consecuencias se van modificando en un devenir socio-histórico, prefiero denominar a este espacio como matriz comunitaria de sociabilización. Porque acordamos con Di Marco (1998: 207) que la ciudadanía está ligada a los espacios de socialización donde se forman las identidades de sujetos corporizados y que estos espacios van marcando un tipo de ser varón y de ser mujer.

La defino como matriz porque en ese espacio se van construyendo prácticas, que si bien están enmarcadas, en un principio, en un orden de género tradicional, se van resignificando, van cuestionando ciertos principios del orden naturalizado y van produciendo también lo que Butler denomina una performance, ya que el género no es uno sólo sino lo que uno va encarnando en determinadas circunstancias y en función de ir construyendo una identidad engenerada socio-culturalmente.

81 Y se define como comunitaria, porque se despliega dentro de la comunidad y atendiendo problemas comunes, conformando una identidad grupal y social diferenciada de aquellas en las que participan.

Matriz comunitaria de sociabilización, lugar donde podemos preguntarnos, ¿Cuáles son los niveles de empoderamiento que obtienen las mujeres (dada las prácticas que desarrollan)? ¿Cuáles los varones? ¿y ambos en conjunto? ¿cuánta autonomía adquieren? ¿Qué espacios en la vinculación entre varones y mujeres modifica? ¿Y cómo? 
83 El concepto de empoderamiento ha sido definido en la red como un «proceso de desarrollo de las capacidades de negociación, a nivel doméstico y colectivo, para llegar a configurar un modo más igualitario y un ejercicio diferente del poder entre varones $y$ mujeres» (Verschuur, 2003: 236). Es decir, estamos frente a una conceptualización que nos presenta la idea de proceso, donde las desigualdades se deben ir reconstruyendo en función de una práctica concreta. Sin duda las experiencias por las que atraviesan las mujeres en esta matriz comunitaria de sociabilización producen efectos importantes en la construcción de sus subjetividades y nuevas construcciones identitarias, en la autonomía que despliegan (tamizada según los orígenes del movimiento o programa de política pública del que participan), en el desarrollo de su autoestima, y hasta en algunos casos donde podemos observar que esa inicial conciencia de necesidad se comienza a transformar en conciencia de derechos.

¿Qué quiero expresar con este tránsito de la conciencia de necesidad a la conciencia de derechos?

Las características iniciales en la motivación de las mujeres para irrumpir en el espacio comunitario están determinadas por las necesidades concretas que las aquejan, sus hijos, su familia, su compañero, su comunidad, ellas mismas se encuentran en riesgo debido a condiciones que no pueden garantizarle una vida digna y sustentable. Desde sus prácticas tradicionales salen más allá de sus hogares en búsqueda de soluciones. No cuestionan los valores de género o de ciudadanía que están presentes en sus realidades. Una de las consecuencias de esa salida es el encuentro con las otras mujeres, se organizan, se comprometen, socializan sus dificultades.

Esta sociabilización, también les permite ampliar sus horizontes de referencia, comienzan a cuestionarse ciertas realidades cotidianas que parecían ser naturales, se identifican con el conjunto de mujeres y van construyendo una identidad grupal de género. En algunos casos son apoyadas por organizaciones políticas, grupos feministas, por ONG's, reciben cursos, realizan talleres, se relacionan, se vinculan, se forman, aprenden, discuten, comparten, y ganan en autonomía, crece su autoestima, resignifican sus prácticas comunitarias y valorizan sus capacidades de gestión.

En estas nuevas prácticas comienzan a sentir que los problemas que padecen obedecen también a cierto orden al que se encuentran subordinadas, su propio hogar o su propia pareja. Comienzan a sentir que lo obtenido a partir de la participación en esta matriz comunitaria de sociabilización no es negociable, que la autonomía y la autoestima las fortalece en lo individual y en lo colectivo y que tienen el derecho de no someterse naturalmente a ciertas situaciones que padecen. La necesidad (producida por un sufrimiento) comienza a transformarse en la vivencia del derecho a no padecerlo.

Este pasaje es evidente en una de las temáticas más serias y reiteradas que surgen en los terrenos de investigación, el de la violencia doméstica, situación que se ha agravado considerablemente producto de esta aceleración en la figura del varón que pierde su trabajo y ve peligrar su identidad masculina al no encontrar otros referentes identitarios que le permitan generar una alternativa de sustento racional y emocional, en su propia condición de varón.

La presencia de las mujeres en la matriz comunitaria de socialización hace que esta problemática comience a emerger inmediatamente (producto de la comunicación que se genera en las prácticas compartidas), y se constituye, junto a los temas de derechos sexuales (maternidad, aborto, enfermedades sexuales, anticoncepción) en los 
principales temas de la agenda de las mujeres. Es decir, son temas que son considerados por ellas mismas, temas de la mujer. Esto se refuerza también desde las políticas públicas (consideradas como políticas de género) que trabajan exclusivamente con las mujeres sobre estos temas, planteando - con buen criterio - que en el caso de la mujer hay una primera urgencia que atender referida a la integridad física, psíquica y moral que está en juego producto de la violencia a la que se encuentran sometidas en el espacio doméstico.

Esta agenda que se empieza a construir entre las mujeres provoca la necesidad de atender esta problemática, generándose un circuito de atención al tema. Cursos o talleres que llegan desde los planes sociales, desde grupos de ONG's, o desde militantes feministas que se acercan a las mujeres, producen diversas vías de comunicación comienzan funcionar activamente.

Si bien esta es una problemática social complejísima (y complejas también las formas de su resolución), su emergencia en los espacios de comunicación y encuentro de las mujeres comienza a provocar un aprendizaje y una conciencia en el sentido de que este sometimiento en sus relaciones con los varones, físico o simbólico en términos de violencia, no es una situación natural y que tienen el derecho de ser defendidas y protegidas principalmente por el estado, pero que también el resto de las mujeres pueden convertirse en una red de ayuda y protección.

Los varones, por otra parte, comienzan a tomar conciencia - inclusive aquellos que son golpeadores - de que esta situación dejó de estar encerrada en el mundo privado/ doméstico y está expuesta ante la comunidad. No se trata ya de un problema privado, pasa a ser un problema público y por ende político. Si bien esta secuencia no es tan simple y lineal (tiene muchos matices antes de llegar a alguna solución definitiva), produce un cambio importante en la identidad de estas mujeres, que recorren este camino desde la conciencia de necesidad a la conciencia de derecho.

93 También es interesante ver cómo con la aparición de los planes de asistencia - basados en general en la idea de que la mujer necesita de la protección estatal no como sujeto de derechos sino como sujeto vulnerable digno de asistencia - esta mirada de tránsito entre la conciencia de necesidad y la conciencia de derecho comienza en algunos casos a ser cuestionada, empezándose a reclamar dicha asistencia como un derecho adquirido sin dotarla del concepto de tránsito antes mencionado.

La (im)potencia que se genera en esta matriz comunitaria de sociabilización está relacionada también, con la constitución de ese espacio y sus relaciones con el poder. Es notorio escuchar los diferentes discursos entre manzaneras y piqueteras, que si bien ocupan el mismo lugar en el tejido social, se relacionan de un modo diferente con el poder. Mientras que las piqueteras en sus prácticas lo cuestionan, se oponen, o demandan al estado, las manzaneras se sienten representantes de ese poder, el cual les da un reconocimiento simbólico a prácticas, y a su vez, les restringe un pensamiento crítico de su rol socio-político. Todo esto debido a que el capital simbólico que adquieren las manzaneras está constituido en gran parte e inicialmente por su identificación al poder, al círculo de la gestión política municipal, o a la responsable inicial del programa (Chiche Duhalde). Esta pertenencia las inhibe en muchas de las situaciones que analizamos en hacer este pasaje de la conciencia de necesidad a la conciencia de derecho, es decir, romper con la idea del «asistencialismo», o de este concepto de estado patriarcal benévolo que les otorga soluciones (por supuesto que parciales) a sus problemas o a los de sus vecinos. Esta situación está bien definida por 
Masson (2004: 115) cuando dice «Las manzaneras tienen acceso a un espacio público que se agota en "lo social", con dificultades para acceder al público que incluye "lo político"».

Son pocas las prácticas instituyentes en el espacio público que estas mujeres han generado por fuera de lo instituido por la cadena de sentido de su actividad como manzaneras, y la actividad las coloca en un lugar donde la representación de un tipo de política las inhibe a sentirse enfrentadas a ese poder establecido (constituido por una cadena de significaciones imaginarias), que así como les otorga una identidad, las limita para generar en ellas una conciencia de los derechos por fuera de los supuestamente otorgados. Cualquier acto que las diferencie se instituye como un peligro al sistema de interpretaciones instituido y es vivido por ellas como amenazante, pudiéndoles costar ser desplazadas de esta pertenencia adquirida.

Sin embargo, como contrapartida, nos podemos preguntar, en función de los grandes cambios y luchas que se han producido en la política argentina en los últimos años y los varios intentos de desarmar este programa, cómo estas 40.000 mujeres manzaneras han logrado constituirse en un colectivo dotado de una fuerte identidad social, con una entidad práctica y simbólica difícil de dejar sin efecto en función de las luchas políticas internas entre dirigentes.

De cualquier modo consideramos valioso el caso de estas mujeres manzaneras que en esta experiencia de trabajo comunitario han recorrido y construido prácticas, en muchos casos más allá de los objetivos específicos para los que las convocaron, y han generado una identidad grupal más allá de los condicionantes institucionales, políticos o simbólicos que intentan manejarlas. A nuestro entender esto se produjo en esa experiencia de la matriz comunitaria de sociabilización, porque esas prácticas también han dado lugar a la emergencia y construcción de la agenda de temas que les preocupan, temas que en general están atravesados por un orden de género.

¿Y los varones? En muchos casos los varones invisibilizan o secundarizan estos temas planteados por las mujeres, parece que fueran temas que no les conciernen, o que, cuando participan en ellos, terminan por considerar que hay temas más urgentes y prioritarios como el hambre, la política y la desocupación. Esta postura invisibiliza su propia pasividad para enfrentar los nuevos escenarios, sus propias dificultades para reconstruir una identidad hegemónica sobre la masculinidad que los limita y les genera sufrimiento, que les impide tomar conciencia de sus propias necesidades como sujetos engendrados y socialmente marginados. No logran acceder con naturalidad a esta matriz comunitaria de sociabilización porque la identifican, desde sus representaciones, como un espacio femenino donde a su vez están siendo interpelados, por ejemplo, por la temática de la violencia. ¿Espacio femenino y persecutorio?

Inclusive las propias mujeres sienten que esta ausencia les permite construir con mayor libertad un espacio propio, exclusivo, donde pueden encontrar altos niveles de comunicación y donde la presencia de los varones les impediría acercarse unas a otras del mismo modo. También plantean que los varones no están en condiciones de enfrentar estas nuevas situaciones, que perdida la identidad otorgada por el trabajo, quedan huérfanos de acción y desde allí muchas veces justifican sus depresiones o su pasividad, y es desde allí también que aumenta la percepción de que de ellas depende el cambio y que ellas son capaces de lograrlo. Ellas son el cambio.

Desde la matriz comunitaria de sociabilización también se producen prácticas ligadas al medio-ambiente físico o se empieza a luchar por derechos relacionados con los servicios públicos. Se adquiere una potencia en el reclamo, que en algunos casos, ha 
funcionado para mejorar las condiciones medio-ambientales del barrio. También a partir de esta participación encontramos mujeres que comienzan a participar en cooperativas, en programas de micro-emprendimientos, realizando muchas veces tareas tradicionalmente masculinas.

Lo que surge a partir del encuentro de las mujeres en la matriz comunitaria de sociabilización también modifica las agendas, y en este sentido es interesante retomar el tema planteado cuando hablábamos de feminización de la gestión.

Esta participación de las mujeres hace que surjan muchos de los temas ya mencionados y producidos al interior del vínculo con los varones (violencia doméstica o sexual, derechos reproductivos, aborto, etc.), temas relacionados con la agenda de las luchas políticas feministas (aunque no estén identificados de ese modo por las mujeres, que inclusive expresan ciertos reparos a que se las identifique con esos movimientos).

Esta aparición en los espacios de poder político produce un fenómeno interesante: los varones, desde sus lugares dirigenciales, parecen tomar conciencia de que estas temáticas deben ser abordadas de algún modo o por lo menos contenidas para que no se conviertan en espacios de riesgo que puedan desestabilizar un orden de género establecido. En general esto lo podemos ver no sólo en la política oficial o partidaria, sino también en grupos de base, donde se crean áreas destinadas «a la mujer o áreas de género» donde se involucran los temas que mencionamos, quizás negando desde el inicio la posibilidad de concebirlos como vinculares.

104 Estas áreas son conducidas por mujeres, y en reiterados casos, se repite el esquema que vimos en las políticas públicas: las responsables son las compañeras o esposas de los dirigentes. ¿Poder femenino de decisión o de influencia? ¿Dispositivo para controlar o atenuar una lucha política potencial que irrumpe a causa de las prácticas de las mujeres? Una vez más, el espacio de lo femenino se convierte para los varones en un espacio persecutorio o potencialmente desestabilizador de las relaciones de género tradicionales. Potencia de la participación de las mujeres.

Harcourt y Escobar plantean en un artículo (2002: 3) «que las mujeres están participando en una forma nueva y radical de hacer política que tiene como eje sus cuerpos, sus hogares, su medio ambiente y el espacio público y social».

Esta «secuencia de lugares» nos muestra que las prácticas desplegadas en el espacio comunitario generan consecuencias directas e indirectas en cada uno de estos lugares donde se plantea una acción totalmente ligada a lo político.

Cuando planteamos que las mujeres empiezan a recorrer el camino entre la conciencia de necesidad a la conciencia de derecho, por ejemplo, con relación a la violencia doméstica como producto de los aprendizajes que realizan en conjunto con otras mujeres, vemos también cómo esto tiene un efecto en sus espacios domésticos, además de poder saber en dónde se modifica la relación con el varón (en principio pasan a reconocer que no merecen ese trato, en algunos casos logran cambiar la situación o dejar la relación de sometimiento) que está produciendo un circuito donde ese espacio comunitario adquiere un valor político (un valor de derechos de ciudadanía), afecta sus cuerpos y sus hogares, esta presente en lo ambiental y afecta sus relaciones de poder.

Paradójicamente la ausencia de los varones y su salida de este espacio comunitario por considerarlo parte de una práctica femenina, instala una preeminencia en las referencias de la política. Es difícil encontrar un territorio donde no sea necesario, a la 
hora de trabajar políticamente, relacionarse con estas mujeres que actúan y realizan prácticas comunitarias como las que hemos descrito.

En general las mujeres reconocen la importancia que ha tenido en sus vidas esta experiencia dentro de la matriz comunitaria de sociabilización. Muchas mujeres expresan (más allá del origen de estas prácticas comunitarias) que no se imaginan volviendo a sus casas a realizar solamente las tareas domésticas, inclusive una de ellas expresaba con una fuerte ironía «nunca más volveré a la prisión domiciliaria porque, por otra parte, las necesidades de nuestras compañeras seguirán existiendo y yo puedo seguir trabajando por estos derechos», deduciéndose por un lado la toma de conciencia de una situación anterior e histórica, y por otro, la esperanza de poder seguir desplegando esas prácticas en un espacio que no es vivido como el espacio doméstico.

110 Si bien no quiero plantear que esto que presentamos modifica estructuralmente la relación desigual de género que viven las mujeres en cada uno de los terrenos, me parece que nuestra postura debería estar más cerca de poder detectar los incipientes devenires (que son potencialmente prácticos) que pueden ayudar a lograr un empoderamiento que equilibre las relaciones entre varones y mujeres, que pueda interpelar a los gobiernos e influenciar en las políticas públicas para que valoren y construyan propuestas en función de estas nuevas realidades, sin dejar de poner de manifiesto las resistencias que se generan en los actores que participan, y en las relaciones de poder que tratan de condicionar la situación social para adaptarse a un discurso hegemónico donde las cuestiones de género están soslayadas.

111 Se trata de huellas corporales y emocionales, prácticas sociales innovadoras difíciles de definir a partir de concepciones clásicas, en fin, procesos que cuestionan una realidad que está en permanente movimiento y no debe suponerse como inmodificable.

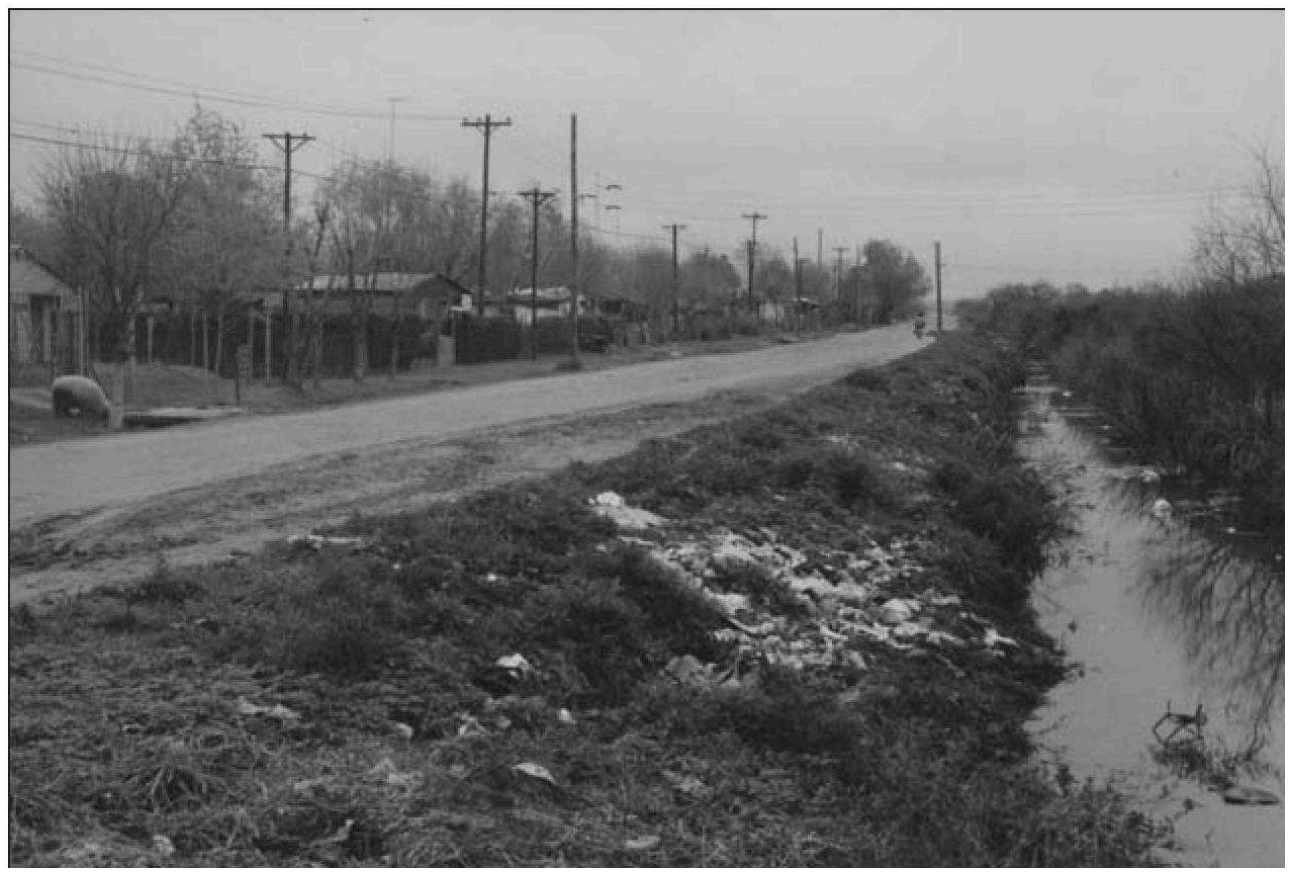

San Cayetano, Argentina. 


\section{BIBLIOGRAFÍA}

ADEUM, 1996, varios autores «Relaciones de género y exclusión en la argentina de los 90», Buenos Aires, Ed. Espacio.

Auyero, Javier, 1997, «¿Favores por votos?», Buenos Aires, ED. Losada.

Borón, Atilio, 2004, «Pensamiento único y resignación política,: los límites de una falsa coartada», Buenos Aires, PRIGEPP-FLACSO.

Bourdieu, Pierre, 1998, Contrafogos, Rio de Janeiro, Ed Jorge Zahar.

Bourdieu, Pierre, 2003, «La dominación masculina», Buenos Aires, Ed. Anagrama.

De Barbieri, Teresita, 2002, «Sobre la categoría género. Una introducción teóricometodológica». Buenos Aires, PRIGEPP-FLACSO.

Di Marco, Graciela, 1998, Ciudadanía femenina en «Relaciones de género y exclusión en Argentina de los 90» Buenos Aires, Ed. Espacio.

Fraser, Nancy, 1992, «Repensando la esfera pública: una contribución a la crítica de la democracia actualmente existente», England, Habermas and the public sphere. The MIT Press, Cambridge, Massachussets and London.

Fraser, Nancy, 2004, «Política feminista en la era del reconocimiento, una aproximación bidimensional a la justicia de género», Buenos Aires, PRIGEPP-FLACSO.

Friedman, Susan, 2002, «Globalización y teoría social feminista: identidad en movimiento». Buenos Aires, PRIGEPP-FLACSO.

Gónzalez de Duhalde, 2002, «El Plan Vida, una experiencia donde la solidaridad es el eje de la política social», Buenos Aires, Ed. Temas Hainard François, Verschuur Christine y otros, 2001, «Empoderamiento de las mujeres en las crisis urbanas», Ed. IEPALA, MOST-UNESCO.

Hainard François, Verschuur Christine, 2004, «Femmes et politiques urbaines, Ruses, luttes et stratégies» Ed. UNESCO-Karthala.

Harcourt y Escobar, 2004, «Mujeres y política del lugar» Buenos Aires, PRIGEPP-FLACSO.

Hériter, Francoise, 2002, «Masculino y femenino», Buenos Aires, Ed Ariel Antropología.

Levin, Silvia, 1998, «Ciudadanía y política social: continuidades y discontinuidades de una trayectoria» en «Relaciones de género y exclusión en Argentina de los 90» Buenos Aires, Ed. Espacio.

Masson Laura, 2004, «La política en femenino» Ed. Antropofagia.

Moser, Carolina, 2000, «Planification selon le Genre dans le tires monde: comment satisfaire les besoins pratiques et stratégiques selon le genre», en «Le genre un outil necesaire», $\mathrm{N}^{\mathrm{a}} 1$, Cahiers genre et d'veloppement, Ed. L'Harmattan.

Ramos Avila, 2003, Isabel «Mujeres y política, construcciones identitarias y políticas de representación en las prácticas de organización de las piqueteras argentinas», inédito, Tesis doctoral en la Universidad Andina Simón Bolívar, Ecuador.

Rauber, Isabel, 1998, Informe de contenido del equipo de trabajo MOST-UNESCO de Santo Domingo. 
Rivera, Marcia, 2000, «La participación: motor del desarrollo humano sostenible. (Cap. 5) Tejiendo los caminos posibles del desarrollo social», Buenos Aires, PRIGEPP-FLACSO.

San Sebastián, Álvaro, 2001, «Argentina. Mujeres manzaneras ¿empoderamiento o asistencialismo?» en «Empoderamiento de las mujeres en las crisis urbanas», Hainard F., Verschuur C. y otros, Ed. IEPALA, MOST-UNESCO.

Verschuur, Christine, 2003, «L'empowerment des approches contrastés, etudes des cas en Amérique Latine», en «Genre, pouvoir et justice sociale», $N$ a 4 , Cahiers genre et developpement, Ed. L'Harmattan.

\section{NOTAS}

1. Ver F. Hainard «Apports et limites de la comparaison», 2004.

2. El Programa Vida tenía como objetivo explícito: «revertir los índices de morbimortalidad maternoinfantil a través del esfuerzo compartido entre el estado provincial, los estados municipales, las instituciones intermedias de la comunidad y una red de mujeres y vecinos» (G. de Duhalde, 2002, 91)

3. En su condición de Presidenta del Consejo Provincial de la Mujer y luego Presidenta Honoraria del Consejo Provincial de la Familia y Desarrollo Humano de la provincia de Buenos Aires y esposa del Vicepresidente de la Nación $\mathrm{D}^{\mathrm{r}}$ Duhalde (que acompañó al Presidente Menem) y luego fue (1995) gobernador de la provincia (mismo período menemista) y posteriormente Presidente (2002-2003), en ese último período ella se hizo cargo, también de modo honorario, del Consejo de Coordinación de Políticas Sociales, por delegación de la presidencia.

4. Campana ciudad de 70.000 habitantes situada a $70 \mathrm{~km}$ de la capital federal.

5. Se denomina área metropolitana a la capital federal y al conjunto de 140 partidos y municipios que la rodean, sitio donde habitan 14.000 .000 de habitantes y se concentran los más grandes signos de pobreza y desocupación.

6. Iniciamos, junto a otro grupo del CEIL PIETTE, Conicet, un trabajo conjunto para analizar las relaciones de género en el seno de algunas organizaciones de desocupados (piqueteros).

7. «Las mujeres (y en otros casos los varones) califican su aporte como ayuda al esfuerzo de quien consideran es el protagonista real del rol y dueño de la responsabilidad. La ayuda se torna así en concepto-conflicto en cuyo nudo se cruzan todas las contradicciones de una época que no puede amoldarse a los roles que la crearon y que tampoco puede mantenerse sin ellos, por lo cual, tratando de ocultar la profundidad de los cambios que se van dando a pesar de unas y otras, de poderes, voluntades y caprichos, la transformación que viene caminando comienza a insinuarse disfrazada a través de las ayudas, facilitando el acercamiento y fusión de roles y responsabilidades sin herir frontalmente dignidades y modos histórico-culturales de ser varón o mujer» Este concepto surgió del trabajo del equipo de Santo Domingo, cuya responsables es Isabel Rauber.

8. En Santo Domingo las mujeres participan activamente en organizaciones barriales en los terrenos analizados. En Bulgaria fundaron, junto a los varones una ONG para proteger su entorno construido en función de nuevas leyes de restitución de terrenos posterior a la caída del muro. En Senegal organizan una cooperativa de carácter productivo, ligada a la explotación de la pesca y en Burkina Faso constituyen una cooperativa encargada de la remoción de los desechos domiciliarios a nivel de su propio barrio. En los dos casos africanos existe un fuerte componente económico en el desarrollo de la autonomía de las mujeres.

9. «Repensando la esfera pública: una contribución a la critica de la democracia actualmente existente», Nancy Fraser. 


\section{RESÚMENES}

La investigación-acción fue desarrollada a lo largo de 7 años en el barrio argentino de San Cayetano y se basó fundamentalmente en el seguimiento de un grupo de mujeres beneficiadas por el "Plan vida", un programa de carácter asistencial implantado desde 1995. Dicho programa hace intervenir de diversas formas la variable de género al momento de insertarla dentro de la gestión social, creando nuevos roles y espacios de participación femeninos en directa relación con su medio ambiente y con sus pares masculinos.

La recherche-action a été développée pendant 7 ans dans le quartier argentin de San Cayetano et a été fondamentalement basée sur le suivi d'un groupe de femmes bénéficiaires du "Plan vie » (Plan Vida), un programme à caractère social, implanté depuis 1995. Ce programme fait intervenir de diverses manières les femmes dans la gestion sociale, en créant de nouveaux rôles et espaces de participation féminins, cela en relation directe avec l'environnement des femmes et avec leurs pairs masculins.

The research-action was developed for 7 years in the San Cayetano neighbourhood in Argentina and was basically about monitoring a group of women who benefited from the Plan Vida programme, a social programme that was launched in 1995. This programme includes the gender variable in different ways in social management by creating new roles and spaces for women's participation, in direct connection with women's environment and with their male peers.

\section{AUTOR}

\section{ÁLVARO SAN SEBASTIÁN}

Architecte (UBA) et psychologue social. Il est chercheur à la faculté d'architecture, de design et d'urbanisme (FADU) à l'Université de Buenos Aires. Il a participé à divers projets de recherche nationaux et internationaux et est responsable de la formation du centre POIESIS. Il a coordonné pendant 4 ans le programme RED, un programme de coordination et de développement entre l'université et l'entreprise. Il a été Secrétaire des Relations Institutionnelles de la FADU. Il a participé à la gestion et l'organisation de projets de recherche et de gestion. Depuis 1997, il est responsable du projet MOST-UNESCO « Genre, ville et environnement » en Argentine. 


\title{
Droit au logement: le mouvement des femmes au Brésil et l'expérience dans la favela Gamboa de Santo André, São Paolo, Brésil
}

\author{
Sonia Alves Calió et Iranilde José Messias Mendes
}

\section{Introduction}

1 La crise économique et l'endettement accentuent davantage la situation de misère urbaine et d'exclusion sociale des pays pauvres. Le chômage, la chute du pouvoir d'achat et la pénurie des services publics provoquent une détérioration progressive de la qualité de vie. En plus, les problèmes d'environnement deviennent extrêmement préoccupants : de la dégradation des espaces verts des niveaux de pollution de l'air insupportables, en passant par la contamination des sources d'eau, toute une série de méfaits écologiques compromettent la qualité des ressources naturelles utilisées dans la production et la consommation des villes.

2 L'accélération du processus d'urbanisation de ces pays a fait de son manque de services et d'équipements sociaux un problème chronique, rendant plus difficiles l'accueil et l'établissement permanent des populations pauvres qui y vivent ou qui y arrivent. Une bonne partie de ce processus se déroule par l'occupation des zones démunies de toute infrastructure et de soutien social. La plupart du temps, c'est grâce aux femmes que ces zones sont rendues habitables. Directement concernées au quotidien par la survie de leur famille, les femmes deviennent de véritables gestionnaires de la configuration urbaine : en mobilisant les gens et en établissant des relations de solidarité mutuelle, elles transforment le quartier en un espace élargi où les carences et les nécessités deviennent des enjeux collectifs.

De cette façon, les femmes, particulièrement les plus pauvres, sont présentes dans les moments clefs des processus dits de consolidation urbaine: lors des luttes pour des logements, pour des services essentiels de base ou pour la conservation de 
l'environnement. Pour compenser le manque chronique d'infrastructures et de services sociaux, elles sont obligées de produire un volume considérable de travail quotidien, phénomène essentiel et susceptible d'éviter l'explosion sociale. En agissant de cette façon, les femmes démocratisent non seulement leur propre vie, mais également la vie urbaine. (Cali, 1992)

De par leur rôle fondamental dans le cycle de reproduction humaine, leurs responsabilités au sein de la sphère domestique et leur contribution au processus de production, elles se voient directement touchées par la crise sociale et économique. En conséquence, l'impact de la dégradation de l'environnement urbain sur leur vie est considérable. Par exemple, lorsque la température baisse brusquement, les enfants mal logés ont rapidement des problèmes respiratoires, et l'on observe de nombreuses femmes faire la queue au service des urgences. Ce sont pour elles des journées où tout va de travers, où l'agenda quotidien est perturbé, ce qui renforce encore leur stress : elles manquent leur travail, elles perdent des heures faire la queue en vue d'une consultation, il y a des dépenses inattendues pour l'achat des médicaments, etc.

5 Au Brésil, le modèle néolibéral imposé par les forces du marché et la globalisation crée une situation de crise économique et sociale qui accentue la dégradation des conditions de vie, de l'environnement et des relations sociales. Cette crise touche tout particulièrement la population la plus démunie. Alors, ses effets se manifestent par l'augmentation des invasions de terrains, par le gonflement des favelas déjà consolidées ou par l'apparition de nouvelles favelas, par la multiplication des lotissements illégaux ou irréguliers, et par l'augmentation du nombre des habitants de rue". Ce qui veut dire environnement insalubre, manque d'infrastructure et services essentiels, chômage, violence, etc. (FNRU, 2003)

6 Face aux ajustements économiques que traverse le Brésil, comment les familles pauvres parviennent-elles à survivre?

7 Pour répondre cette question, il est fondamental de penser la place des femmes dans la gestion de la vie familiale car ce sont elles qui supportent le plus directement les conséquences de ces ajustements. Devant cette crise vécue par l'Etat, les femmes se voient obligées d'assumer une partie des tâches quotidiennes qui devraient incomber l'ensemble de la société; elles cherchent des formes moins chères de gestion du quotidien et elles voient leur fardeau se multiplier par trois. A la maison ou au-dehors, leur travail augmente, leur quotidien devient plus lourd et elles sont, souvent, victimes du stress pour avoir dépassé leurs propres limites. A côté de ces responsabilités des femmes, nous observons dans notre milieu urbain une forte croissance du nombre de femmes chefs de famille de 30 a $40 \%$. (SPM, 2004)

Un des thèmes de la recherche MOST - l'exclusion sociale urbaine et ses effets dans les rapports sociaux de genre et l'environnement - met en lumière que cette exclusion a un rapport direct avec la pauvreté et la condition vécue par les habitants d'une favela : leur origine, en majorité du centre-nord du pays, et leur faible niveau de scolarité, contribuent, sans doute, leur discrimination et leur exclusion. 


\section{La crise du logement urbain : une question de politique publique de genre ou comment les femmes peuvent accéder au logement et au titre de propriété}

9 Pour les femmes, l'accès au logement revêt une importance particulière: contrairement aux hommes, elles perçoivent l'habitation comme un abri et un refuge sûr pour la famille et un élément de stabilité face aux incertitudes économiques, un endroit pour soi et pour ses enfants. Il faut que cela permette aux femmes de pouvoir disposer d'un titre de propriété soit du terrain pour construire le logement, soit du logement proprement dit.

10 Les stratégies de vie des hommes et des femmes sont totalement opposées car les femmes ont une stratégie d'enracinement et les hommes une stratégie de mobilité. En d'autres termes, quand les hommes, plus inconstants, changent de quartier, de ville, de travail ou bien souvent abandonnent leur famille, la première chose laquelle ils pensent est de vendre leur logement, car pour eux il représente, en règle générale, un investissement. Les femmes, au contraire, s'attachent leur lieu d'habitation comme un élément qui leur permet de structurer leur vie.

11 Il convient de rappeler que les difficultés d'accès un logement sont plus importantes pour les femmes qui sont dans les couches les plus pauvres de la population, car elles sont obligées d'accomplir des travaux de basse qualification professionnelle et peu payés, ou d'affronter les incertitudes du marché du travail. En outre, elles disposent de moins de ressources et d'opportunités.

\section{a) La question de la citoyenneté féminine}

Réfléchir au concept de citoyenneté féminine signifie, avant tout, poser la question de la justice sociale et des inégalités qui font partie de l'histoire de la femme. Il est impossible de passer sous silence que la question actuelle des relations sociales entre les sexes requiert une autre définition de la citoyenneté qui intègre la dimension sociale des femmes. (Marques-Pereira, 2003)

13 Tout en assurant une autre croissance, les nouvelles générations de politiques publiques doivent garantir, en même temps, l'équité sociale et le renforcement de la démocratie. Cela présuppose la présence d'un Etat promoteur de politiques et des actions avec contrôle social et d'une éducation basée sur des nouvelles stratégies qui réduisent le fossé existant entre riches et pauvres. (Guzm n, 2000) Dans ce contexte, il est important de relever que l'introduction de la perspective de genre doit conduire revoir le rôle de la production, de la reproduction et de la transformation des rapports sociaux et environnementaux car ce n'est que de cette manière que les politiques publiques feront face aux inégalités de genre, de race et d'ethnie.

\section{b) Le rôle du nouveau féminisme depuis les années 1970}

14 Le nouveau féminisme, apparu dans les années 1970, a remis en question les relations de pouvoir, l'organisation sociale et la vie quotidienne, en tendant la notion de politique. En passant l'égalité juridique des premiers mouvements électoraux, il a élaboré un nouveau concept d'égalité centré sur l'abolition des privilèges de sexe. Il a 
remis en question l'andro-centrisme social qui considérait l'homme comme le prototype de l'être humain universel. En modifiant les conceptions et les consciences, il a contribué à générer une nouvelle notion d'identité sociale, en cherchant l'individualité des femmes en tant qu'actrices sociales. En politisant le monde privé, il a tendu la notion de sujet: il n'existe plus seulement un sujet transformateur des relations sociales entre le capital et le travail, mais des sujets multiples qui vivent une relation de subordination partir de leur oppression spécifique, et sont ainsi appelés à participer à ce mouvement de transformation par leur diversité et leurs singularités, en produisant de nouvelles alternatives sociales. Autrement dit, le nouveau féminisme a invité la société à apprendre à se conjuguer également au féminin. (Cali, 1991)

\section{c) Le mouvement des femmes et les luttes pour le logement}

15 La précarité des conditions d'habitation touche principalement les femmes qui, en général, sont les responsables de l'administration de la maison. Etre mal logé signifie vivre confiné dans des espaces minuscules, mal aérés, humides, sans aucune intimité, exposés à des animaux venimeux, des rongeurs, des insectes et autres fléaux. Cela signifie un logement privé d'un assainissement de base, avec des gouts à ciel ouvert, exposée à la saleté et aux maladies. Cela signifie parcourir de longues distances à la recherche de l'eau, très loin de toute assistance médicale et des écoles pour les enfants, des centres commerciaux. La discussion menée par le mouvement des femmes et par des mouvements de logement sur la nécessité d'établir des politiques publiques favorables aux femmes, en leur assurant le droit d'être titulaires d'un logement, se base sur le fait que la femme, en tant que principale responsable de la cellule familiale, est la personne la plus intéressée par cette mesure.

Cependant, facteurs de haut risque pour les banques privées et pour les investisseurs de logements populaires, les familles très pauvres ne sont pas fiables car elles ont beaucoup de difficultés à prouver leurs revenus. Donc elles n'ont pas accès aux crédits ! Il ne leur reste qu'espérer des politiques publiques qui puissent mettre en place des programmes de logement d'intérêt social.

\section{d) Les politiques de logement appelées d'intérêt social}

17 La société civile brésilienne a réalisé un long parcours dans le domaine des luttes pour le logement, à partir des mouvements populaires pour le logement, des mouvements des sans-terre, du mouvement des sans-toit, en passant par les centres universitaires de recherche urbaine jusqu'aux organisations non gouvernementales, aux entités syndicales et professionnelles.

Depuis 1970, cet ensemble de mouvements est parvenu, à travers ses luttes, à améliorer la compréhension des questions urbaines. Articulant les droits civils et politiques avec les droits urbains (habitation, assainissement, santé, éducation, culture), il avance dans le sens d'un nouveau projet de civilisation qui repense la ville démocratique, sur des bases plus environnementales et plus équitables. Il engendre surtout des débats comme la cohésion sociale, la démocratie directe ou représentative, la participation et le contrôle social, l'éducation à la citoyenneté, la culture comme élément de résistance, la déconstruction du modèle de contrôle hégémonique de la violence urbaine, l'insertion des groupes sociaux vulnérables, l'articulation entre le local et le global. 
19 A partir de 1995, année de la Conférence de l'ONU sur la Femme et le Développement, à Nairobi, qui a abordé la question de la priorité des femmes sur le contrôle du logement, cette notion a été reprise au Brésil. Elle a surtout été évoquée par le mouvement des femmes, qui mettait en évidence que le logement a, pour la femme, une valeur d'utilité et représente la sécurité pour sa famille et ses enfants, alors que le logement a, pour l'homme, une valeur d'échange pouvant faire l'objet de commerce à tout moment et selon son envie. D'ailleurs, les témoignages des femmes "expulsées" de leur maison par leur mari ou leur conjoint étaient (et sont encore) révélateurs de cette problématique, comme le confirme le témoignage suivant:

Nous avons eu cet appartement grâce à un programme social du gouvernement... Comme je n'ai pas de revenu, le logement est au nom de mon compagnon. Maintenant, il pense vendre l'appartement pour faire des affaires. Je lui ai dit qu'on devait penser au futur de notre fils... et que si c'était nécessaire j'allais travailler et l'aider à payer les charges. Il n'a pas voulu discuter... en criant qu'il ferait ce qu'il voulait car tout était à son nom... il a fini par me battre en m'expulsant de la maison. Maintenant, je suis avec mon fils chez ma mère, je suis très déçue et $j$ 'ai peur... il est capable de tout! On m'a dit qu'il avait trouvé une autre femme et qu'il a fait tout cela pour me remplacer. Je ne sais pas quoi faire, je ne connais rien, je n'ai jamais travaillé car il m'en a toujours empêchée.

(ex-habitante de la favela)

20 C'est à cause de situations comme celle-ci que le mouvement des femmes - dans le cadre de plates-formes d'action définies lors de réunions et de conférences nationales et internationales - a propos de donner à la femme la priorité lors de l'attribution du titre de propriété dans les programmes de logement d'intérêt social et a fait de cette proposition son fer de lance. A partir de là, des propositions de politiques publiques incluant cette revendication sont apparues, mettant en évidence la question du titre de propriété dans les programmes sociaux.

21 Le gouvernement de l'Etat de São Paulo a été le premier à approuver cette proposition. Et, jusqu'aujourd'hui, il maintient cette décision dans ses politiques, comme dans le cas de l'entreprise publique Compagnie de développement d'habitation de logement urbain (CDHU). Malheureusement, nous n'avons pas trouvé de documents officiels sur ce sujet. Quelques rares références cette politique de la CDHU ont pu être trouvées dans le Bulletin de l'Institut Teot nio Vilela ${ }^{1}$ :

Lors de la signature du contrat, il existe une autre nouveauté: le nom de la femme apparaît en première place. En cas de mort du mari, la maison est déjà au nom de la femme, évitant ainsi les habituels problèmes administratifs. C'est également le cas lors d'une éventuelle séparation où, dans la grande majorité des cas, c'est la femme qui reste à la maison et qui garde les enfants.

(Boletim Inst. T. Vilela, 2003: 3)

La femme apparait comme titulaire du logement autant que son mari ou son concubin, dans le sens où le contrat contient la signature des deux. Bien que, dans le nouveau Code civil Brésilien approuvé en 2002, la notion le chef de famille disparaisse au profit de l'isonomie conjugale, ce simple acte de signer conjointement le contrat de logement donne un pouvoir symbolique aux femmes, même s'il n'a pas de valeur juridique.

Une autre loi - proposée en février 2004 par l'ex-maire de la ville de São Paulo, $M^{\text {me }}$ Marta Suplicy - demande également aux programmes de logement de la municipalité de donner la priorité aux femmes. Cette loi spécifie l'adoption des mesures qui favorisent l'insertion des femmes dans le processus de financement et de production des logements, indépendamment de leur participation au revenu familial et de l'état 
civil. Ses paragraphes établissent non seulement les modalités de ces contrats (financement mutuel, cession de possession, engagement d'achat et de vente, location sociale, bail résidentiel, carte de crédit ou conditions d'utilisation) mais également que, en cas de transfert de propriété, celui-ci soit effectué au nom de la femme. De plus, il signale que soit prévu un service préférentiel pour les femmes victimes de violence, pour les femmes âgées ou handicapées. Cette mesure constituera une défense des femmes battues qui seront ainsi moins vulnérables. (PMSP, 2004)

Il est certain que de nombreuses municipalités au Brésil adoptent ce type de mesures comme forme de prévention et de soutien aux femmes.

\section{e) L'accès des femmes au logement dans notre terrain de recherche} mesures sont en phase d'application avec un relatif succès depuis la fin des années 1990. Et elles ont été bien débattues lors d'un séminaire organisé en janvier 2005 par l'équipe MOST Brésil et l'AMVG - Association des habitants de la favela Gambo.

présence de représentants de la municipalité et de divers mouvements de logement, dont le Mouvement en défense des droits des favelados, ce séminaire a aussi discuté l'application des politiques de logement pour les femmes. Interrogé à ce propos, le secrétaire-adjoint au logement, a déclaré :

Il est essentiel de donner la priorité aux femmes dans les politiques de logement d'intérêt social. En général, les femmes ne pensent pas à vendre l'immeuble. Bien au contraire, elles le conservent avec beaucoup de soin. Il est clair qu'il existe des femmes qui n'entrent pas dans cette catégorie, mais il s'agit d'une minorité face à la quantité d'hommes qui insistent pour vendre le logement à n'importe quel prix ou qui veulent expulser leur compagne pour en mettre une autre à leur place. Il arrive même qu'ils deviennent physiquement violents !

\section{Quelques considérations finales}

La question abordée ici n'est pas simple. En réalité, depuis l'approbation du nouveau Code civil, les résolutions donnant la priorité aux femmes n'ont pas de véritable valeur juridique : l'union conjugale a été définie par l'exercice commun des droits et des devoirs. Il a fait disparaître la notion de chef de famille, instaurant effectivement l'isonomie conjugale dans les droits et dans leur exercice. Ce qui signifie que cette isonomie rend inconstitutionnelles toutes les mesures relatives la propriété au nom des femmes, ainsi que nous venons de le voir ci-dessus!

Comment expliquer l'adoption de ces mesures, alors qu'elles sont inconstitutionnelles? Nous pouvons l'expliquer surtout par sa valeur symbolique car elle cherche à rompre avec la logique de soumission dans laquelle vivent historiquement les femmes. Dans l'exemple d'une famille dont l'homme veut vendre le logement et retourner à la favela et sa femme refuse parce qu'elle sait qu'elle est également titulaire de l'immeuble, nous pouvons l'interpréter de deux manières :

- d'une part, sans informations suffisantes, les femmes croient que le simple fait de voir écrit leur nom comme première titulaire de l'immeuble leur donne la garantie de propriété. Ignorent-elles ou n'accordent-elles aucune importance au Code civil ? Non. Nous dirons plutôt qu'elles ignorent leurs droits en tant que citoyennes et que cette incompréhension des questions juridiques peut facilement être surmontée par un 
travail d'éducation sur la citoyenneté et un travail de conscientisation sur les droits économiques, sociaux et politiques.

- d'autre part, il est important d'observer que les mesures prises en faveur des femmes - qu'elles soient concrètes ou symboliques - leur donnent un appui qui leur garantit l'autonomie et renforcent leur estime de soi. Ce sentiment d'autonomie, de ne pas dépendre de l'autre, de comprendre que la vie peut est possible sans l'autre, n'a pas de prix ! L'estime de soi recouvrée est essentielle pour atteindre des niveaux avancés de conscientisation en tant que femme et citoyenne. Tel est le chemin conduisant à une prise de pouvoir qui passe par le recouvrement de son identité via le renforcement de l'estime de soi. Tout mouvement en direction du renforcement de l'estime de soi des femmes est aussi un pas important vers une conscience de genre. (Cali \& Silva, 2002)

Dans ce sens, établir un gouvernement bas dans sur le triple concept "participation de la société civile - inclusion sociale - démocratie" nécessite la construction d'un modèle institutionnel de processus démocratique qui va bien au-delà de la volonté politique et qui passe nécessairement par l'amélioration des conditions de vie de la population pauvre, et tout particulièrement des femmes pauvres.

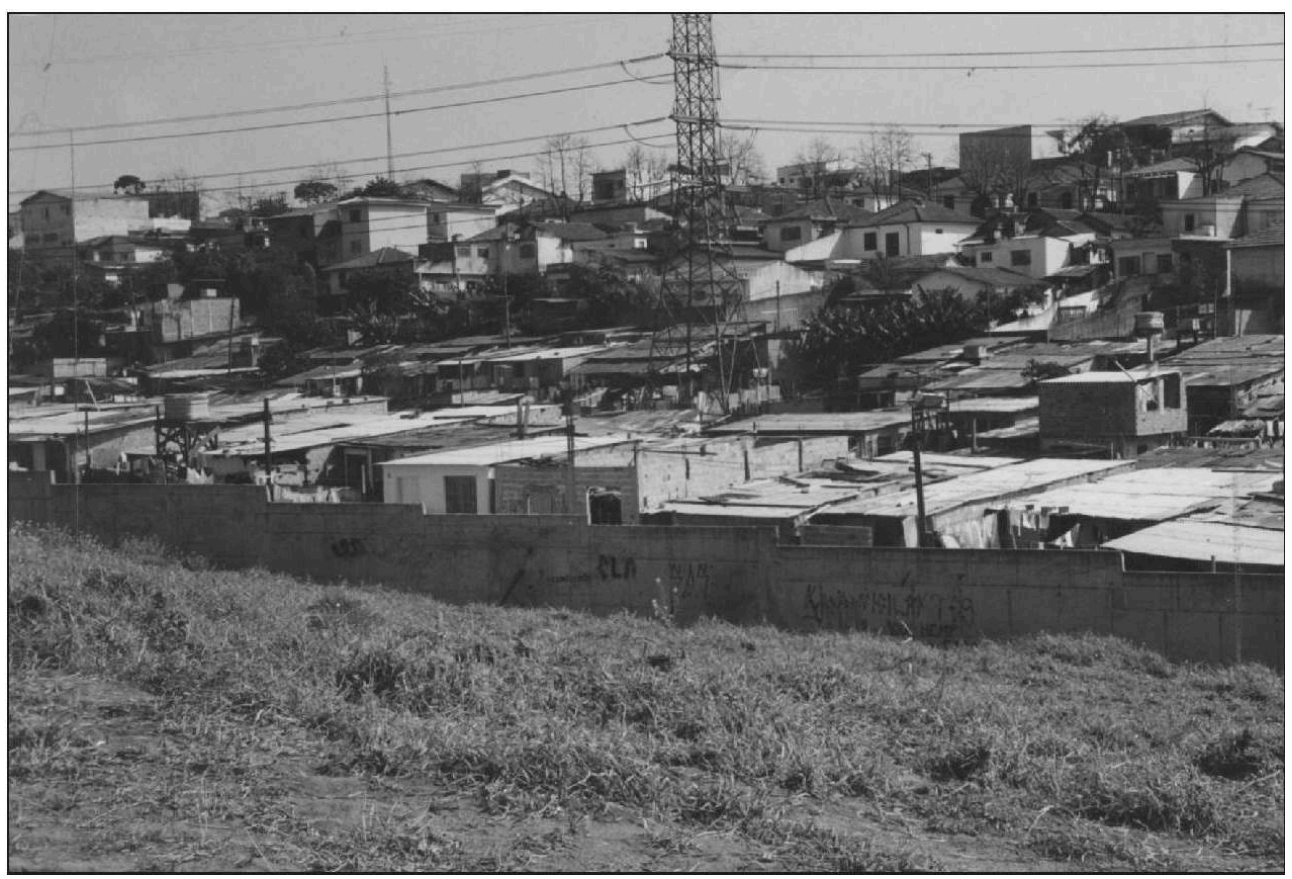

Favela Gamboa de Santo André, São Paolo, Brésil. 


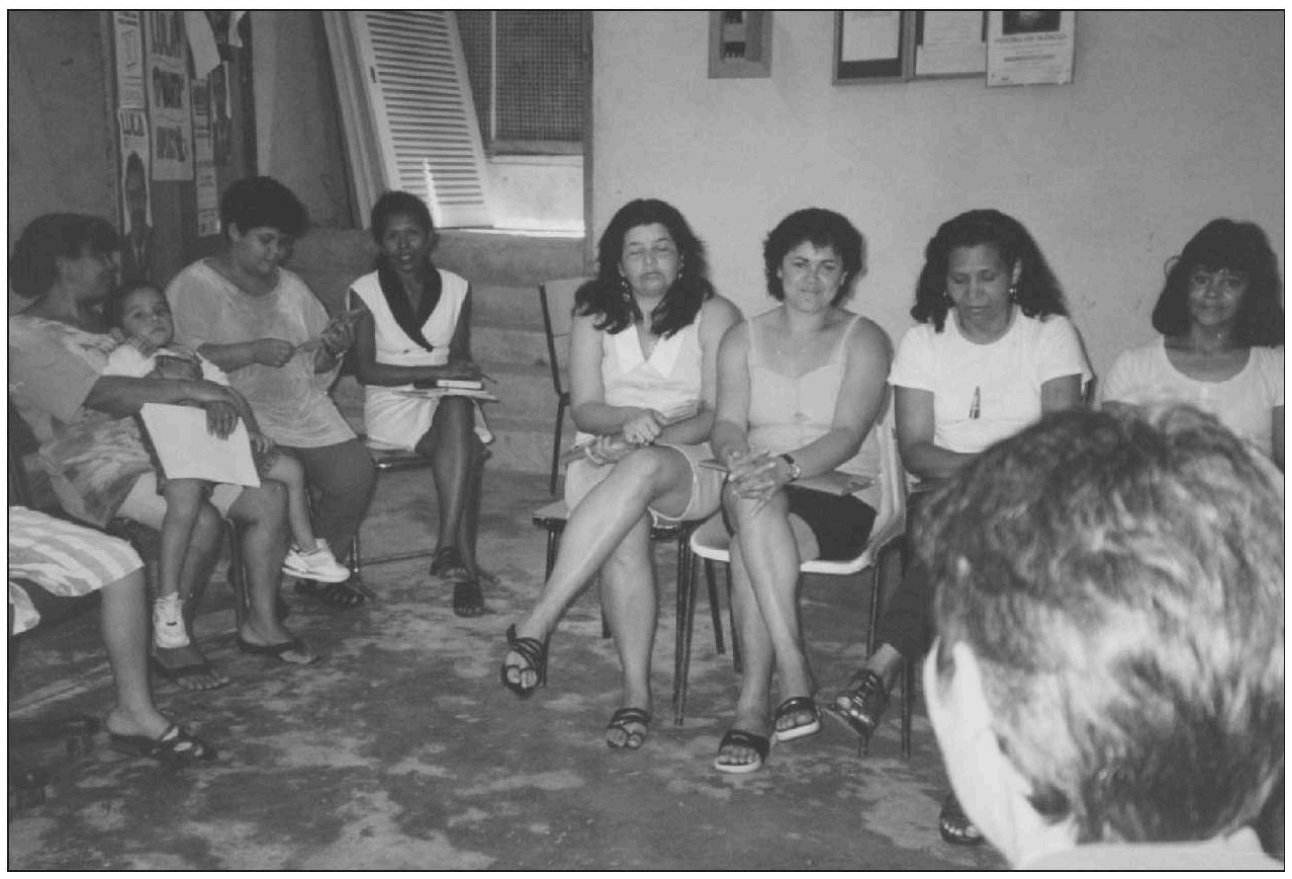

Association des femmes de la Gamboa.

\section{BIBLIOGRAPHIE}

Bonduki, N., 2003, Projeto de Lei 890/03, C mara Municipal São Paulo, SP.

Cali, S. A., 1991, Rela es de Género na Cidade : uma contribui o do pensamento feminista Geografia Urbana, Thèse de Doctorat, Depto. Geografia, Universidade de São Paulo, SP.

1992, Repensando a Cidade ao Feminino, Prefeitura Municipal de Santo André, SP.

Cali, S. A. \& Silva, M. C. V, 2002, Las mujeres de la Gamboa II. Toma de conciencia y límites“. In: Hainard, F. \& Verschuur, C. Empoderamiento de las Mujeres en las Crisis Urbanas : género, medio ambiente y barrios marginado, MOST-UNESCO, Iepala, Madrid.

F rum Nacional Reforma Urbana, 2003, Resolu es do Encontro Nacional FNRU.

Guzm n, V., 2000, A equidade de género como tema de debate e de políticas pùblicas“. In: Faria, N. \& al., Género nas Políticas Publicas, Cadernos Sempreviva, SOF, SP.

Instituto Teot nio Vilela, 2004, Programa Habiteto. In : Boletim - Realiza es, S. Paulo, 14 de abril.

Marques-Pereira, B., 2003, Citoyennet. In : Verschuur, C. \& Reysoo, F., Genre, Pouvoirs et Justice Sociale, IUED-EFI, l«Harmattan, Genebra.

PMSP - Prefeitura Municipal de São Paulo, 2004, Boletim Internet.

SPM - Secretaria Especial de Políticas para as Mulheres, 2004, Contribui o da SPM para as Conferéncias Estaduais, Documento base, Brasília, DF. 


\section{NOTES}

1. Publication du Parti de la Démocratie sociale brésilienne (PSDB), actuel gestionnaire de l'administration du gouvernement de l'Etat de São Paulo.

\section{RÉSUMÉS}

La présence des Brésiliennes pauvres dans les luttes urbaines pour les logements est une réalité qui a forcé, à partir des années 1990, l'apparition des politiques publiques mettant en évidence la priorité de ces femmes au titre de propriété.

Considering the participation of poor Brazilian women in the urban struggle for lodging, from the 1990s public policies have prioritised women's access to property.

La presencia de las mujeres brasileñas pobres en las luchas urbanas por viviendas es una realidad que forzó, a partir de los años 90, la aparición de políticas públicas, tendientes a legitimar la prioridad de estas mujeres en la tenencia de los títulos de propiedad.

\section{AUTEURS}

\section{SONIA ALVES CALIÓ}

Géographe de formation, elle a un post-doctorat en géographie urbaine à l'Université de São Paulo. Chercheuse en urbanisme, elle travaille actuellement sur les questions de l'habitat à la Companhia de Desenvolvimento Habitacional e Urbano (CDHU), entreprise de l'Etat de São Paulo. Depuis 1997, elle est responsable du projet MOST-UNESCO « Genre, ville et environnement » au Brésil. 


\title{
Citoyenneté, environnement et politiques publiques dans une favela au Brésil
}

\author{
Marta Cassaro-Silva
}

\section{Introduction}

1 Cet article est basé sur l'expérience développée durant quelques années dans la favela Gamboa, dans la ville de Santo André, São Paolo, Brésil, par l'équipe brésilienne en charge du projet «Villes, environnement et rapports homme-femme». Nous reprendrons ici quelques idées issues des discussions avec la population qui participait aux activités du projet, ainsi que quelques-unes des réflexions qui en ont découlé. Si nous sommes arrivés une fois de plus à la conclusion qu'il faut environnementer et genderiser les réalités étudiées et les politiques publiques pour pouvoir arriver à une meilleure situation des quotidiens, surtout pour les populations les moins favorisées, le moyen pour y arriver transite par l'éducation et la conscientisation des vécus, à travers les droits et les devoirs de chacun que ce processus va mettre en place. Pour les politiques publiques, il faut que les droits humains puissent être envisagés aussi sous l'angle des droits des femmes et pas simplement des "droits de l'homme», ainsi qu'il est encore convenu de nos jours...

2 La conclusion de plusieurs études démontre que les politiques et actions de développement durable sont plus efficaces quand les facteurs de genre sont pris en compte, et quand les femmes et les hommes sont également impliqués dans chaque étape de l'identification et la mise en œuvre de solutions des problèmes (Seager \& Toepfer, 2005).

3 Une bonne partie de la littérature qui se préoccupe des relations entre genre et environnement a tendance à se focaliser essentiellement sur les femmes, de surcroit dans le cadre des contextes ruraux. Elle porte, par exemple, sur l'analyse de la propriété juridique de la terre, les répercussions que celle-ci peut entraîner, les divisions sexuelles des tâches dans les collectivités rurales. Elle considère aussi le rôle 
des femmes dans la préservation de la biodiversité, le processus de désertification ou encore les changements climatiques, constatant que celles-ci sont toujours à la fois les plus vulnérables et injustement considérées comme les plus responsables. Depuis quelques années pourtant, on commence à se préoccuper aussi des problèmes environnementaux que les femmes et les hommes rencontrent dans les villes et notamment dans celles des pays du Sud, où ils sont les plus aigus.

\section{Le terrain}

Santo André est une ville très industrialisée d'environ 650'000 habitants située en périphérie de São Paulo. Les villes brésiliennes rassemblent plus de $80 \%$ de toute la population du pays, dont environ $20 \%$ vit en favelas. En l'an 2000, celle de Santo André est estimée à 110 '000 habitants! Cette ville connaît par ailleurs de fortes inégalités sociales, car même si le revenu per capita a augmenté de près de $19 \%$ de 1991 à 2000, son indice de Gini (indicateur de pauvreté) s'est lui aussi accru de 0.48 à 0.53 pendant la même période (Políticas de Inclusão Social de Santo André, Prefeitura Municipal de Santo André, 2004).

5 Une des activités de notre recherche a consisté à interroger la population de notre terrain sur la nature des difficultés quotidiennes qu'elle rencontre le plus fréquemment. Les réponses (et celles des femmes en premier lieu) concernaient le plus souvent la distribution de l'eau potable, qu'elle soit canalisée et de bonne qualité, l'importance d'avoir des égouts, la collecte des déchets et l'accès à l'énergie électrique. Ces problèmes se rencontrent dans la plupart des quartiers où nous avons travaillé et relèvent $\mathrm{du}$ quotidien. Toutefois, au-delà de ces urgences indiscutables, d'autres éléments, situés parfois à un échelon de complexité supérieure, doivent impérativement être pris en compte. De manière non exhaustive, il faut mentionner le traitement adéquat des eaux usées en station d'épuration, celui des déchets solides (à inclure dans la mise en place d'une collecte sélective et d'une gestion appropriée), la protection des sources ou des nappes phréatiques qui fournissent les populations en eau potable, la création de jardins publics et la préservation des espaces verts à finalités ludiques ou didactiques, les types de mise en culture des terrains agricoles en surface ou à proximité des nappes phréatiques et des zones naturelles protégées.

6 Parmi les grandes questions qui se posent, figurent de manière récurrente l'usage de l'eau, celle de l'accès et de la répartition des ressources énergétiques, la conservation de la biodiversité (ce qui conduit encore à s'interroger sur l'utilisation, le partage et la préservation des richesses naturelles et non renouvelables), la pollution de l'air et celle des nuisances sonores, sans oublier les changements climatiques et leurs conséquences. En outre, il convient de mentionner des composantes plus subtiles comme les spécificités des relations humaines, ainsi que celles que l'espèce humaine (comme les autres espèces) entretient avec son milieu. Les relations avec les éléments non vivants $\mathrm{du}$ (dans le cas d'un environnement urbain, l'air, les infrastructures de mobilité et résidentielles, le sol, etc.) devraient également être considérées.

\section{L'écosystème urbain dans la Gamboa}

7 Cette combinaison d'interactions constitue un ensemble qui peut être appelé écosystème urbain. Outre ses similitudes avec d'autres types d'écosystèmes, il se caractérise par 
d'autres facteurs incontournables qui contribuent à en saisir vraiment toute sa complexité. Parmi eux, mentionnons le politique (incluant les processus de décision et de gestion avec l'aide de l'administration et des services publics), l'économie (y compris sa dimension informelle), tous les services de l'appareil reproductif de la société (santé, éducation, protection sociale,...), les systèmes d'information, les loisirs, sans oublier le rôle aussi capital qu'ambivalent des technologies Mais ce qui distingue l'écosystème urbain des autres semble bien être sa consommation excessive en biens matériels et énergétiques qui ont pour conséquence évidente l'augmentation croissante de la production des déchets.

8 Les problèmes qui nous interpellent tout particulièrement concernent aussi bien les processus relatifs à la croissance souvent exponentielle et anarchique des villes, les différentes conceptions politiques et économiques qui les façonnent, que les conditions de vie de la population. Dans des environnements urbains difficiles, où l'occupation des terrains se fait dans le désordre, les activités de construction et les conditions de vie précaires engendrent de gigantesques problèmes "éco-sociaux " accompagnés de situations à risque : érosion, glissements de terrains, inondations, destructions de zones protégées, contamination de l'eau, épidémies, etc. (Grostein, 2001). Rappelons encore à ce propos qu'une caractéristique importante des favelas est que nombre d'entre elles sont installées dans des zones protégées (dunes, marécages, fortes pentes, rives des fleuves, zones de protection des sources, etc.), zones qui non seulement constituent un espace disponible parce qu'elles sont dangereuses, mais où le risque d'expulsion est également plus faible puisqu'elles sont la plupart du temps propriété d'une collectivité publique (municipalités, communes), et non de privés qui pourraient sans problème de conscience faire expulser ou, selon la loi, s'approprier toute construction sise sur leurs terrains.

C'est dans un contexte similaire, à la fois très tourmenté et en fortes transformations, que les habitants de la favela de Gamboa ont négocié le projet de construction de nouveaux logements qui devraient les accueillir prochainement. D'une certaine manière, on peut dire que pour ce qui est de la procédure, cette population est privilégiée, car il est rare qu'une municipalité soit aussi ouverte au débat avec les populations concernées. Pour l'administration municipale de Santo André, les relations entre environnement, genre et politiques sociales sont évidentes puisque la commune dispose d'un programme explicitement dénommé "genre, citoyenneté et environnement ".

Comme ce projet a été mis en œuvre depuis plusieurs années (le transfert de population avait été décidé depuis longtemps, mais il n'y avait pas de financement suffisant pour la construction des logements), il faut rappeler brièvement dans quelles conditions ont vécu les 600 familles de cette favela d'environ 3000 habitants : habitat précaire sous de gigantesques pylônes électriques à haute tension, égouts à ciel ouvert, piratage de l'eau potable et de l'électricité. Pourtant, de nombreuses personnes disaient préférer habiter là où elles se trouvaient plutôt qu'aller quelques kilomètres plus loin dans le quartier de Alzira Franco où sont construits les nouveaux logements, et ce parce que, selon elles, elles quitteraient une favela pour intégrer, en quelque sorte, une autre favela à peine plus acceptable!

11 Pendant toute la deuxième phase du projet MOST-Brésil (2001-2004), notre équipe a développé des activités avec le groupe d'habitants qui allaient être transférés, dans le but de les inciter à participer de manière plus présente et active aux discussions avec 
les autorités, avec l'objectif de disposer de compétences et d'arguments solides pour entrer en force dans les processus de décision en partenariat avec la municipalité.

Dans le cadre d'une dynamique élaborée par notre équipe, nous avons d'abord travaillé à l'identification et à la définition de ce que les habitants considèrent comme une favela et ce qu'ils appellent une " habitation normale ». Parmi les réponses, les différences par rapport à une "habitation normale » portaient davantage sur l'espace disponible et privatif, une meilleure intimité, des murs peints et de bonne finition, à l'existence d'un balcon, d'un escalier, etc., sans oublier une revendication des espaces verts, en l'occurrence plutôt sous forme de places ou d'espaces publics, mais jamais de sérieuse aspiration à des jardins privés, l'idée étant peut-être par trop irréaliste !

Pour ce qui est de la qualité de l'environnement proprement dit, il a été mentionné cidessus les urgences exprimées. En revanche, certaines exigences sont étonnamment absentes. Rien à propos de la pollution de l'air. Comme si cela n'avait aucune conséquence néfaste sur les individus, petits ou grands, ou du moins comme s'ils n'accordaient pas d'importance à cette question pourtant primordiale vu la proximité des industries et des axes routiers.

Aucune remarque non plus à propos des nuisances sonores. Il faut dire que dans une favela il est normal d'écouter très fort la musique sans que personne ne se plaigne, et que les conversations et autres éclats de voix sont entendus dans tout le voisinage. Dans une favela, personne n'interviendra ni ne cherchera querelle pour cela, car cela pourrait lui coûter la vie ou celle d'un membre de sa famille!

Quand on compare les différents terrains d'investigation, il est clair que la plupart de ces questions sont présentes et doivent être envisagées sous la forme de priorités. Pourtant, lorsque les gens s'organisent pour dénoncer ou lutter contre certains problèmes d'environnement, les motivations réelles sous-jacentes aux investissements personnels et collectifs sont obligatoirement de nature et de priorité diverses.

16 La non-prise en considération de la nature dans les théories économiques et sociales occidentales modernes explique peut-être pour une bonne part comment a pu se faire, sans trop de difficulté, l'appropriation massive des ressources naturelles et non renouvelables par les sociétés capitalistes du Nord. Si un aspect de cette réalité explique la dynamique séculaire et aliénante qui lie société industrielle et nature, un autre renvoie sans aucun doute à cette échéance à court terme qui menace aussi bien nos écosystèmes, espèce humaine incluse, bien entendu.

17 Face à ces enjeux capitaux, nous pouvons nous référer à l'écologie urbaine comme démarche pour mieux comprendre (et faire comprendre) le fonctionnement des villes (ou plutôt, comme nous l'avons dit, des écosystèmes urbains) et les rôles que les habitants entretiennent entre eux et avec elles. S'appuyer sur les apports de l'écologie urbaine est un outil précieux dans le cadre de programmes d'éducation qui visent à une sensibilisation à l'environnement, considéré au sens large du terme. C'est cette expérience qui a été tentée à la Gamboa, selon la démarche de la recherche-action. Les chercheuses de l'équipe brésilienne ont abordé les difficultés des habitants de la favela en prenant en compte non seulement leurs conditions de vie, mais aussi les discours légitimés par leur quotidien. L'objectif n'était pas seulement de comprendre la problématique de l'écologie urbaine, mais aussi de travailler avec la population concernée. 
Répondant en 2002 à une sollicitation d'un groupe de femmes, en prévision du transfert imminent de leur lieu d'habitation, l'équipe de MOST-Brésil a organisé une série de discussions. Lorsque nous avons présenté cette animation-formation à la population, nous avons proposé de traiter des sujets choisis par les habitants sur la base d'une liste de suggestions, visant le développement des capacités de communication et de négociation de chacun. Parmi les thèmes traités lors de cette formation, nous mentionnerons les relations hommes - femmes (y compris une réflexion sur le genre), la violence domestique, la construction d'une citoyenneté et les pratiques de participation, l'accès aux droits sociaux, les interactions entre environnement et société, les aptitudes à la communication et à la négociation.

Ce dernier thème confirme par ailleurs certaines constatations émanant des travaux conduits sur les autres terrains du projet MOST. Au Brésil aussi, on est face à un fait déjà bien documenté dans la littérature: d'une manière générale, les habitants marginalisés, vivant de surcroît dans des situations problématiques et d'urgence, ceci vaut tout particulièrement pour les femmes, ont de grandes difficultés à dialoguer avec les pouvoirs publics pour faire entendre leurs besoins et leurs revendications ou encore pour faire valoir leurs droits. La participation active des femmes dans les processus et organes de décision passe donc par une formation, tel le modèle que nous avons élaboré à la Gamboa et constitue un premier pas dans la bonne direction, même si le chemin à parcourir est encore long.

\section{La participation citoyenne}

20 Si l'on veut faciliter un certain nombre de transformations sociales dans la ville, il est nécessaire que les initiatives et les projets proposés mettent en priorité des réalisations qui interpellent les populations concernées. Leur réussite est souvent fonction du degré de compréhension et d'intérêt des processus mis en œuvre. Ici aussi, toute information ou sensibilisation sous forme d'éducation paraît être un moteur essentiel.

21 Une éducation à l'environnement, si possible en y insérant une perspective de genre, y a sans aucun doute sa place, de sorte à faire comprendre que, contrairement à ce qui se dit ou ce qui semble, ce ne sont pas les femmes qui sont responsables des incidences sur l'environnement mais que ce sont les types d'activités domestiques que la société les appelle à remplir qui les génèrent (achat et préparation des aliments, nettoyage, corvée de bois, etc.). Mais une telle perspective aussi pour leur enseigner à agir de manière cohérente, en toute connaissance des problèmes que ces activités engendrent... à défaut de les partager avec les hommes!

Comprendre comment le milieu est modifié. Comment les ressources sont contrôlées par une chaîne complexe d'actions humaines. Comment se façonnent les politiques publiques. Telles sont quelquesunes des questions qui intéressent à condition qu'elles soient abordées à titre d'exemple à l'échelon local, même si les problématiques dépassent presque toujours ce niveau de réflexion.

23 De fait, des valeurs de solidarité et de responsabilité, par trop étouffées par les effets pervers de l'économie néolibérale, par définition très articulée sur la performance et l'individualité, peuvent être valorisées par une sensibilisation aux problèmes liés à l'environnemental, parce que par définition ils relèvent de la responsabilité collective. En stimulant ainsi les réflexions sur des questions environnementales bien insérées 
dans leur contexte local et si possible en n'omettant d'y inclure une perspective de genre, on dispose d'un outil précieux, non seulement en termes de capacité de compréhension et d'analyse des réalités vécues, mais aussi politiquement, car ces questions ne peuvent que renforcer le sentiment de citoyenneté et les pratiques qui lui sont liées.

Les organisations de base constituent des forums privilégiés pour étudier ces notions, car en principe les gens s'y engagent en associant droits et devoirs, citoyenneté et participation. Ce n'est pas un hasard si Paulo Freire, il y a quelques décennies, les utilisait dans ses projets d'éducation pour adultes pour enrichir le processus d'éducation. L'éducation formelle, dont fait partie l'alphabétisation, façonne les relations sociales, en particulier celles qui relèvent de la formation des classes sociales, des rôles sexuels, et de toutes autres formes de domination. En plus de cela, la culture implique des questions de pouvoir et constitue un champ de différences et de luttes sociales. L'apprentissage scolaire, à quelque âge que ce soit, est un processus d'acculturation aux pratiques des catégories les plus cultivées, ce qui va dans le sens de la thèse de Paulo Freire, selon laquelle l'école formelle reproduit et renforce la domination des dominants.

Si l'école formelle favorise le processus de domination et oblige "l'étudiant-e » à délaisser sa culture au profit d'une autre, et si le refus de participer à ce processus constitue un argument pour ne pas suivre les cours offerts, la méthodologie de Paulo Freire propose alors de valoriser le contexte social de l'apprenant, donnant ainsi à tous deux une forte légitimité. On retombe à nouveau sur l'importance de l'empirisme du vécu et donc du connu, de sorte à construire une véritable culture locale environnementale. Il y a là par ailleurs un excellent prétexte pour illustrer localement les grandes questions planétaires d'éco-développement ou de développement durable, de lier cela aux pratiques familiales quotidiennes, mais aussi à celles des entreprises et des organismes publics, à commencer par tout ce qui touche aux politiques urbaines et de quartier où ces préoccupations sont progressivement intégrées.

Une difficulté supplémentaire est que la qualité de l'environnement diffère considérablement d'une région à l'autre, aussi d'un quartier à l'autre et que ces disparités s'ajoutent souvent à d'autres inégalités déjà existantes en termes de salaires, d'accès au travail, ou encore touchant des populations les plus pauvres dans les zones les plus à risques. $\mathrm{Si}$, dans le passé, les politiques environnementales n'ont pas fait de l'équité sociale une priorité, le concept même de développement durable fort à la mode aujourd'hui ne lui laisse pas non plus une place importante. En témoignent les projets de villes vivables, bien arborisées, à trafic mesuré et bénéficiant de bons équipements de proximité, le plus souvent destinés à des quartiers où résident les populations favorisées de la société, parce que justement revendiqués par elles.

Ce sont des situations « insoutenables » qui contribuent à la mise en forme de ce que l'on pourrait qualifier de divers apartheids urbains. En effet, on assiste toujours davantage au développement ou à la concentration dans certains quartiers d'inégalités économiques, sociales et écologiques graves ; à la création de nouveaux ghettos dans les banlieues des grandes villes, ce qui ajoute de sérieux problèmes sociaux et politiques aux difficultés écologiques liées à la dispersion urbaine. On constate la marginalisation définitive de certaines zones de reconversion industrielle et la reproduction de ce type de vulnérabilités dans des régions à forte monoactivité. On voit exploser des mégaagglomérations au sein de grandes métropoles, accompagnées des déséquilibres de tous 
types qui en résultent (comme São Paulo, qui concentre bientôt 20 millions d'habitants et une grande partie de la richesse nationale). On assiste à une explosion incontrôlée de la mobilité individuelle motorisée, source de problèmes écologiques irréversibles; à une concentration des populations et des activités dans des régions plus vulnérables et écologiquement très riches; une vulnérabilité excessive de certains territoires (littoral, régions avec forts risques d'inondations, zones urbaines exposées à des catastrophes naturelles ou technologiques); à l'aggravation continue de la pollution agricole et de ses conséquences sur le secteur agroalimentaire, la biodiversité et le tourisme; à l'héritage, imposé aux générations futures, de problèmes écologiques actuellement sans solution (changement climatique, traitement des déchets nucléaires, expansion de la culture de plants transgéniques, croissance exponentielle du trafic aérien, etc.); et finalement à la perte irréversible de valeurs ou à des restrictions associées à la disparition critique de différents types de "capitaux », tels les régions protégées, les patrimoines naturels ou culturels irremplaçables, les espèces menacées, les nappes phréatiques fragilisées, etc.

\section{L'« alphabétisation » à l'environnement}

Il ne s'agit pas de tomber dans le catastrophisme facile, mais il faut savoir regarder les problèmes en face. Pour cela, nous pensons qu'il est nécessaire d'initier des changements dans les modes de gestion, d'élaborer de nouvelles modalités institutionnelles (comités d'urbanisation, institutions du patrimoine, associations villecampagne) et un mode de gouvernance locale plus participative et démocratique, en prévoyant un espace suffisant pour la médiation, le travail associatif, et pour les délégations, principalement celles des quartiers, des associations de voisinage et des minorités. Dans ce modèle, l'administration municipale de Santo André fait preuve de son avant-gardisme par rapport à la plupart des autres municipalités. Comme nous l'avons déjà mentionné, elle a su mettre en œuvre un bon système pour le transfert de la population de la Gamboa vers le quartier Alzira Franco.

De fait, l'éducation en tant que forme de libération à l'encontre de l'oppression était à la base des propositions faites dans les années 1970 par Freire $(1967,1978)$. C'est précisément contre le conformisme que Paulo Freire propose sa pédagogie de la libération, destinée à l'alphabétisation des adultes dans les communautés de base, pédagogie qui aide l'apprenant à réfléchir sur la base de sa propre expérience, à éveiller en lui la perspective du changement, un pouvoir qui, une fois éveillé, cherche à s'exprimer dans une action sociale collective et transformatrice.

S'il est vrai que les gens vivant dans des environnements urbains difficiles ne mettent pas, dans un premier temps, ces problèmes en tête de leurs listes de préoccupation, on constate que la préservation ou l'amélioration du contexte fait appel à des décisions et des actions à forte connotation locale, la population se sentant mieux concernée et capable d'exercer un certain contrôle sur les décisions prises à cette échelle.

Dans cette situation, le rôle d'une éducation environnementale, parfois même ce que l'on pourrait appeler la mise en place d'une véritable alphabétisation à l'environnement, tant les connaissances de base semblent parfois absentes ou déficientes, apparaît central; elle constituerait un instrument efficace de sensibilisation à l'égard des problèmes qui se posent. Elle offre des possibilités à chacun d'intervenir positivement dans son propre processus éducatif, surtout si on développe celui-ci selon la pédagogie 
de Paulo Freire, dans le contexte spécifique des participants, alors utilisé en exemple comme instrument de sensibilisation et d'apprentissage.

L'accès des hommes et des femmes aux ressources naturelles, comme le pouvoir qu'ils et elles ont sur celles-ci (collecte ou acquisition, utilisation, conservation de ces ressources et élimination des déchets), en bref, leurs rôles respectifs, conduisent à des priorités différentes et quelquefois opposées aussi bien sur les aspects considérés comme nécessaires que sur le moment de les réaliser. L'éducation environnementale nous semble constituer la bonne voie vers l'incorporation des connaissances et des savoir-faire des femmes et des hommes dans les pratiques courantes, non seulement dans la réalité quotidienne, mais également dans le cadre de la définition et de la mise en œuvre des politiques publiques.

Dans les principes énoncés par Freire (2000), le processus d'aptitude à travers l'éducation pour la libération est collectif et non individuel. La participation aux processus de décision et la recherche d'un bien commun conduiraient les participants à davantage de pouvoir, alors que le pouvoir d'une minorité aux dépens de la majorité constitue une forme d'oppression. C'est exactement dans ce type de démarche citoyenne que l'éducation environnementale se situe: elle a pour objectif de faire prendre conscience de la nécessité d'une répartition plus égalitaire des droits et plus participative dans les devoirs des hommes et des femmes. Cet apprentissage devrait mener au contrôle de son propre destin, se traduisant dans la pratique par l'exercice de la citoyenneté. Nous sommes bien là dans le processus d'empowerment qui nous intéresse.

C'est dans cette même perspective que nous avons travaillé. L'objectif est de sensibiliser aux problèmes environnementaux, en partant des problèmes du quotidien rencontrés par les populations concernées. Or les hommes et les femmes, celles-ci encore trop souvent mises à l'écart, ont un rôle absolument essentiel à jouer dans cette démarche. C'est de cette manière que les habitants de la Gamboa ont pris en main leur destin pour pouvoir quitter leur favela, mais aussi pour bénéficier de conditions de transfert qui leur conviennent. Ils le font en faisant part avec force de leurs doutes, de leurs craintes et de leurs revendications, parfois jusqu'à descendre manifester dans la rue, pour vivre dans un environnement qui soit le plus en cohérence avec leurs aspirations... La bataille est loin d'être facile et la partie n'est pas encore tout à fait gagnée.

Récemment, les quatorze premières familles ont été transférées au quartier Alzira Franco. En dépit de leurs doutes, elles ont trouvé les moyens d'améliorer leur demeure, soit en travaillant à leur finition comme elles le souhaitaient, soit parfois en modifiant même la construction, en créant de nouvelles chambres ou en agrandissant celles existantes. Cela signifie non seulement que même dans des situations d'extrême pauvreté on peut trouver des alternatives, et que cela peut être un bon stimulus pour celles et ceux qui résistent encore à l'idée de « quitter une favela pour une autre ». 


\section{BIBLIOGRAPHIE}

Freire, P., Educação como prática da liberdade, Rio de Janeiro, Paz e Terra, 1967.

Freire, P., Pedagogia do oprimido, $5^{\mathrm{a}}$ ed, Rio de Janeiro, Paz e Terra, 1978.

Freire, P., Pedagogia da autonomia. Saberes necessários à prática educativa, São Paulo, Paz e Terra, 2000.

Grostein, M. D., Metrópole e expansão urbana, a persistência de processos « insustentáveis », São Paulo Perspect., 15 (1), 182-190, 2001.

Seager, J. \& Toepfer, K. Gender, environment and the millenium development goals : the UNEP perspective. Perceptions, 10(2) : 115-140. 2005.

\section{RÉSUMÉS}

Cet article décrit la conscientisation sur les problèmes environnementaux rencontrés dans la favela Gamboa, São Paulo, Brésil. Cet aspect a été travaillé en recourant à la recherche-action et à l'écologie urbaine, tout en tenant compte de la perspective de genre. Il met en valeur le contexte social de l'apprenant et fait appel aux questions locales et globales pour aider à comprendre les réalités vécues et pour travailler les dimensions d'un éco-développement.

This article describes how awareness was raised on the environment problems that exist in the favela of Gamboa in Sao Paulo, Brazil. The people concerned were sensitised through researchaction and urban ecology and through integration of the gender perspective. In this process, the social context of the people concerned were valued and local and global issues were used to help better understand realities and to work on the dimensions of an eco-development.

Este artículo describe la concientización por los problemas medioambientales encontrados en la favela Gamboa, São Paulo, Brasil. Este aspecto se trabajó recurriendo a la investigación-acción y a la ecología urbana, teniendo en cuenta la perspectiva de género. Valoriza el contexto social del aprendizaje y se refiere a las cuestiones locales y globales para ayudar a comprender las realidades vividas y para trabajar las posibles dimensiones de un ecodesarrollo.

\section{AUTEUR}

\section{MARTA CASSARO-SILVA}

Biologiste, elle a un doctorat de l'Université fédérale de San Carlos (Brésil) en écologie et ressources naturelles. Elle prépare actuellement un Master en écologie auprès de l'Université des sciences de Neuchâtel. 


\title{
L'essor du mouvement urbain à Sofia, Bulgarie
}

\author{
Iskra Dandolova
}

\section{Introduction}

1 Après la chute du Mur de Berlin en 1989 et la suppression du modèle soviétique de socialisme et de communisme, une période de transition vers l'économie du marché fut installée dans tous les pays de l'Europe de l'Est, accompagnée par un processus d'instauration des principes du régime démocratique. Mais la société civile qui va de pair avec la démocratie n'existait pas dans ces pays. Sous le régime totalitaire, la société civile était opprimée dans ses manifestations et diluée dans des camouflages. La " dictature du prolétariat » était censée prendre la place du collectif social et de l'action sociale. C'est elle qui devait accorder aux citoyens l'égalité et les droits sociaux, la justice et le libre accès aux institutions et aux services. Elle devait apporter par la lutte contre l'exclusion la participation à la prise de décisions pour des conditions dignes de vie.

2 L'introduction graduelle du gouvernement démocratique dans les pays ex-socialistes et notamment en Bulgarie devait inévitablement être liée à l'éclosion de la société civile. Sans cet acteur majeur dans la vie politique, la démocratie ne pouvait pas s'établir réellement.

3 La réanimation de la société civile a vite trouvé sa motivation et un point de départ dans avec les problèmes de l'environnement urbain: son état et son développement, ses qualités comme environnement immédiat des habitants et leurs conditions de vie. Ainsi, la ville est devenue un générateur d'énergie de contestation et de défis, un révélateur qui produisait chez les citoyens des inquiétudes, des mécontentements et des protestations. Les hommes et les femmes étaient poussés à se révolter, leur force d'opposition et leur envie de participer à l'amélioration de leur environnement urbain les ont incités à envisager leur pouvoir en tant que communauté réunie, en tant que société civile. 
D'après l'histoire de la société européenne, le processus de création d'une société civile exige une longue évolution, faite de tourmentes et de contradictions, d'erreurs et de quantité d'obstacles. La situation d'aujourd'hui se complique encore plus puisqu'il s'agit d'une transition d'un régime de restrictions et de répression vers un autre régime, où les conditions d'expression de la personnalité et de la communauté sont relativement libres, sans oublier la pression des intérêts néolibéraux et de la mondialisation. L'émergence d'une nouvelle expression de la société civile devrait sauvegarder le point de départ spontané de sa construction.

5 Le projet MOST-UNESCO de longue durée a permis de dévoiler et poursuivre la renaissance de la société civile en Bulgarie. La situation de la ville et son environnement a provoqué la réaction des hommes et des femmes. Pendant ses deux phases de la recherche-action entre 1997 et 2005, l'équipe bulgare du projet a participé à des événements révélateurs qui ont exprimé la force de l'unification et de la solidarité sociale, étouffée et oubliée au cours du socialisme soviétique. Le mouvement urbain à Sofia a réussi à réconcilier les femmes et les hommes en parité pour combattre l'adversaire commun: les acteurs responsables de la dégradation de l'environnement urbain.

\section{Le point de départ : la dégradation de l'espace urbain et des espaces verts à Sofia}

Depuis toujours, Sofia, capitale de la Bulgarie, était reconnue comme une "ville verte ", admirée pour ses espaces verts et pour son aménagement de territoire "humain »: conforme aux principes de la Charte d'Athènes, adaptée à l'environnement naturel, à la culture locale et à la l'évolution permanente de la vie urbaine aussi bien physique que sociale. La verdure entourait les immeubles des grands ensembles d'habitation et les quartiers résidentiels, bordait les rues et les boulevards, elle était concentrée dans les squares, les jardins, les parcs, les espaces de loisirs, les montagnes. Mais à partir de 1990, végétation de la ville a commencé à se fondre et à se perdre. L'environnement urbain a subi une forte dégradation, suite à des procédures de conversions massives des espaces publics en espaces privés, des espaces verts en espaces bâtis. Cette régression a provoqué le grand mécontentement des habitants. Ils ont réalisé que peu à peu l'image verte de la ville se perdait. Leurs conditions de vie se détérioraient.

7 La pomme de discorde pourrait s'exprimer aussi bien par les chiffres des statistiques. Au cours des seize dernières années de transition (1989-2005), la surface des espaces verts à Sofia diminue de 1300 hectares environ ${ }^{1}$. De nouvelles constructions se dressent dans des parcs et des jardins, sans permis ou avec des «permis » douteux, délivrés sur des données falsifiées. La spéculation foncière se développe sans contrôle ni sanction de la part des collectivités locales et des institutions étatiques. De nouveaux bâtiments à usages divers se dressent entre les immeubles résidentiels des grands ensembles d'habitation. On réalise bien que les autorités publiques ne défendent pas les biens publics et ne répondent pas à la volonté des collectivités locales et des citoyens qui lui ont confié l'environnement urbain de Sofia. 


\section{La société civile : combattre la peur pour s'opposer aux autorités et défendre les espaces verts - une nouvelle réalité pour les Bulgares}

8 Les bouleversements déplorables dans la situation des espaces verts de la ville au cours de la transition vers l'économie de marché déclenchent dès le début inquiétude et insatisfaction chez les habitants de Sofia. Après une longue hésitation, les gens commencent à exprimer timidement leur désaccord, puis leur réaction grandit et s'exacerbe. Mais elle reste encore timide, au sein des groupes et parmi les habitants. Spontanée et sporadique, peu à peu cette tension croissante commence à s'extérioriser et à s'orienter vers une action de contestation organisée et active. La dégradation progressive de l'espace urbain provoque des réactions de plus en plus fréquentes, intenses et concentrées des citoyens déjà unis dans leur mécontentement contre la baisse de la qualité de vie en ville. Ils sont prêts à se rassembler dans des organismes volontaires.

Mais pourquoi cette hésitation? Pourquoi ne pas s'opposer immédiatement à la dégradation de l'espace urbain? Pourquoi cette lenteur à réagir pour défendre les espaces verts menacés par l'appétit sans limite des investisseurs? Pourquoi ne pas attaquer sans tarder les autorités - les vrais complices des métamorphoses urbaines qui détériorent les conditions de vie dans la ville de Sofia? Pourquoi supposent-ils aussi que le gouvernement central et local, en tant que pouvoir public financé par la société, assumerait la responsabilité de l'organisation de l'environnement public urbain?

La réponse est simple et traumatisante pour ceux qui ont vécu sous le régime socialiste: la peur. La peur infiltrée dans l'esprit de la société et le grand bouleversement succédant à la chute du Mur de Berlin. Les habitants sont frustrés par les modifications de leurs conditions de vie et n'arrivent pas à s'exprimer clairement contre l'absurdité de la réalité. Bien qu'ils la conçoivent. Car à partir de 1989, l'environnement urbain se dégrade fortement. Pendant cette période d'hésitation, les actions des spéculateurs cupides se renforcent. Les institutions d'Etat et la législation se révèlent relativement faibles pour s'opposer. Parfois, elles se font complices. La restructuration sociale est profonde et se déroule en permanence : une situation idéale pour profiter et abuser des droits sociaux. On réalise que la dénonciation des actes non démocratiques est lente et chaotique. Mais l'origine de cette hésitation est compréhensive.

11 La peur générée par les autorités ou la peur «sociale » ressentie chez les citoyens vivant sous le régime socialiste est une des caractéristiques les plus présentes dans leur comportement comme sous tous les régimes totalitaires. Le socialisme de modèle soviétique ne faillit pas à ce processus. La Bulgarie appartient à cette expérimentation gigantesque. Les goulags, les camps de travail dur et forcé forgent la méfiance des individus, renforcent l'insécurité et la vulnérabilité dans leurs relations, provoquent la peur.

12 Les tortures physique et psychique sont le paroxysme de l'oppression : elles racontent et expliquent la peur sociale suscitée par un tel régime. Il existait par ailleurs nombre d'autres pratiques de manipulation et d'oppression quotidienne. La peur était l'essence même de leur nature, comme obtenir ou non le droit de faire des études universitaires selon l'avis de la cellule communiste de proximité, ou se voir attribuer un logement par 
la volonté d'un comité politique de la municipalité, conserver son poste de travail ou changer de lieu de travail par la détermination des unités communistes de contrôle ou par les «camarades» toujours guidés par la bonne obéissance au parti. La peur se manifestait partout dans la vie quotidienne. Elle influençait doublement la vie de l'individu: officiellement à l'extérieur de la famille et des proches et individuellement, dans le cadre familial et amical. La peur des autorités, de leur intervention éventuelle créait cette psychose. Des générations ont été manipulées et formatées dans ce moule.

La grande question qui se posait alors était plutôt de l'ordre : Comment éradiquer la peur après la chute du communisme? Devait-elle vraiment disparaître? Comment construire une société civile dans la nouvelle réalité des Bulgares après 1990 ? Comment s'opposer aux autorités en cas de désaccord avec leurs décisions?

\section{La lutte pour sauver les espaces verts : les femmes, suivies par les hommes} des infractions commises par des institutions. Une première liste de 18 cas d'abus est déposée chez le procureur de Sofia. Les ONG, au premier rang desquelles l'ONG MLADOST, décident parallèlement de se mobiliser et d'initier la réhabilitation des espaces verts. Elle décide d'organiser un concours architectural pour la réhabilitation du grand parc de l'arrondissement Cent ans de la capitale de Sofia - en pleine dégradation à partir de 1990. Des contacts sont pris avec des spécialistes et des universitaires. Les collectivités locales sont aussi contactées.

La prise de conscience de la détérioration de l'environnement dans la ville est tout d'abord le fait des femmes. Elles sont issues de la classe moyenne et de l'intelligentsia et habitent différents quartiers de Sofia. Leur motivation s'articule autour de thèmes qui touchent particulièrement les femmes, en raison de leur sensibilité et de leurs réactions plus rapides et émotionnelles, sans négliger la division sexuelle des tâches (réelle ou imaginaire) qui leur attribue certaines responsabilités. Ainsi, le mouvement urbain se mobilisera initialement autour d'enjeux comme la disparition des terrains de jeux destinés aux enfants ou des espaces verts autour des habitations, les problèmes des accidents liés au trafic routier intense et non maîtrisé, la sécurité du logement et l'éducation des enfants.

17 Les femmes forment l'avant-garde du mouvement mais un équilibre relatif entre hommes-femmes est vite installé. Cette situation est exemplaire par rapport à d'autres 
où la femme perd du terrain dans la vie publique et privée. Les réformes vers l'économie de marché, la restitution des terres agricoles, la privatisation et la désétatisation du secteur public entraînent des bouleversements importants dans la vie sociale et dans les relations hommes-femmes. Le chômage touche une personne sur quatre, et 30 à $50 \%$ parmi les jeunes. Les emplois précaires et à durée déterminée se développent, en particulier chez les jeunes et les femmes. La pauvreté s'accentue et oblige la population à chercher des solutions alternatives, sans l'appui d'un Etat providentiel.

Durant la période communiste, les femmes pouvaient compter sur certains acquis importants, comme l'assurance d'un salaire, des infrastructures pour l'accueil des jeunes enfants, une participation relativement plus équitable (en comparaison avec d'autres pays du monde) aux instances formelles de pouvoir. Les femmes ont atteint des niveaux d'éducation élevés. Avec l'irruption de l'économie de marché, les rapports sociaux entre hommes et femmes sont fortement ébranlés. L'indépendance économique de la femme diminue rapidement et fortement, à cause du chômage (plus accentué pour les femmes), des faibles revenus et du surcroît de responsabilités auquel elle est soumise. La femme urbaine est confrontée à une dévaluation de sa situation et de sa valeur humaine.

Prenant conscience de la détérioration de la qualité de vie quotidienne, les femmes de Sofia au cours de la transition ont été menées à analyser la cause de ces problèmes, et à aborder les sujets de corruption, de gouvernance, de politique, de choix économiques, entraînant dans le mouvement les hommes résidant avec elles dans les quartiers soumis à la spéculation foncière. Les gens se mobilisent et s'unissent sans former de véritables structures hiérarchiques, sans aspirer à une participation au pouvoir politique, mais en cherchant un empowerment afin de produire des changements sociaux favorables aux causes qui les mobilisent.

Contrairement aux premières années de notre recherche, où aucune réaction organisée et collective n'avait été observée, mais seulement des initiatives individuelles et sporadiques pour résister à la crise (nous avions parlé de " privatisation des luttes "), cette situation à Sofia semble très différente. La peur est surmontée. Progressivement, un groupe de citoyens, au début surtout des femmes, en a eu assez et a spontanément pris l'initiative de s'unir pour protester et lutter contre les actions de la municipalité détériorant l'environnement urbain et leurs conditions de vie. Le mouvement est né d'en bas, à l'instigation des citoyens. Très rapidement, les femmes sofiotes, accompagnées des hommes, se sont mobilisées pour le droit de profiter des espaces publics de leur quartier.

\section{La lutte pour l'environnement durable : ensemble contre l'adversaire commun}

Le mécontentement des citoyens au cours de la transition a commencé à se précipiter par la naissance d'une ségrégation rapide dans la situation des différentes couches sociales représentatives de l'espace urbain. L'appauvrissement massif et flagrant de la population bulgare après 1989 a coïncidé avec l'enrichissement rapide d'un groupe social restreint, mais ambitieux. En un temps record, bipolarisation sociale et ségrégation de l'espace urbain se sont installées de façon durable et spectaculaire, avant de s'amplifier dans des proportions menaçantes. Ce processus va de pair avec le 
démantèlement des structures institutionnelles et administratives, avec les infractions massives à la réglementation, le manque de contrôle et la tendance à la corruption à tous les niveaux de l'administration et du pouvoir. De cette façon la ville a amorcé son développement à deux vitesses: l'une pour celles et ceux qui habitent les grands ensembles d'habitation collective et arrivent à grand-peine à survivre, et l'autre pour celles et ceux qui investissent des logements de luxe ou de haut standing, dans des unités et des cités résidentielles fermées et surveillées par des vigiles et des chiens.

La lutte des citoyens pour la défense de l'environnement urbain à Sofia est révélatrice de la manière dont prend corps la société civile dans les conditions du posttotalitarisme. La ségrégation est mal vécue. Les abus dans les terrains verts de la ville, dus aux actions sans précédent des nouveaux riches et à la corruption des fonctionnaires attisent vite la réaction négative et la lutte des habitants de Sofia. Cette lutte vise à modifier le mode d'administration de l'environnement urbain avec comme point de départ la défense des espaces verts. Les hommes et les femmes s'expriment ensemble, côte à côte. La domination sexuelle est oubliée. La situation de l'environnement urbain est également important pour les femmes et pour les hommes et leurs enfants. L'intérêt est commun et il va de soi que la lutte doit être menée par tous les genres et tous les groupes.

Il est important de rappeler l'évolution des interactions de genre au cours de la période de transition en Bulgarie. Les fortes transformations sociales, économiques et politiques ont eu des conséquences sur les identités et rapports de genre, et durant la première phase de la recherche la crise de l'identité masculine a été mise en évidence. Les identités féminines ont été mises à rude épreuve, avec la perte d'emploi stable et sécurisé, la disparition des acquis sociaux, la surcharge de responsabilités. Après une longue période d'émancipation réelle, les femmes ont donc subi un brusque revirement. Avec la démission de l'Etat-providence, les femmes ont dû réassumer la responsabilité de beaucoup de tâches productives que celui-ci assumait, réactivant ainsi les tensions autour de la division sexuelle des tâches au sein des familles. Les rapports entre hommes et femmes se sont tendus (crises d'identité masculine, stress, dépressions, nombreuses séparations,...) et les rapports de pouvoir entre hommes et femmes ont dû être renégociés. Mais malgré les difficultés, on constate aussi que les femmes, auparavant "groupe cible» bénéficiant des programmes économiques et sociaux, sont devenues actrices des transformations. C'est ce processus que la deuxième phase de notre recherche a suivi, d'une certaine manière guidé et analysé. Elle révèle une nouvelle forme de prise de conscience.

L'évolution de la prise de conscience de la population civile se faisait lentement et difficilement. En revanche certains acteurs étaient impatients. Les plus dynamiques étaient ceux qui voulaient profiter au maximum de la période de transition pour s'enrichir personnellement par l'expropriation des richesses publiques et de là tisser leurs réseaux d'influence et leurs lobbies politiques. Les nouvelles conditions idéologiques de développement social avaient leurs propres règles et exigeaient de nouvelles structures et des institutions dirigeantes appropriées. Mais la mise en œuvre de ces dernières allait conduire à un développement unilatéral et déséquilibré, par manque de contrepoids. Pour l'établissement d'un pouvoir authentiquement démocratique, l'émergence d'une force et d'un pouvoir citoyens et la formation d'une société civile étaient nécessaires. 

作 dans tous les pays européens postcommunistes, en Bulgarie et à Sofia y compris. L'observation et l'accompagnement de ces phénomènes cruciaux pour le continent européen révèlent des mécanismes d'émergence de la société civile spécifiques à chaque pays est-européen concret, considérés autrefois comme la pierre d'un bloc monolithique. Mais ils montrent également quelque chose de très important dans le processus d'européisation : où et comment un processus issu de la reprise en main des leviers de contrôle peut être encouragé au plan politique et dans quelle mesure peuvent être transférés des dispositifs éprouvés, testés dans d'autres pays ou des modèles pouvant éviter aux sociétés démocratiques émergentes au moins une part des erreurs commises dans d'autres pays.

\section{Les premiers résultats positifs suite à l'essor du mouvement urbain}

Les tentatives des habitants de Sofia pour ouvrir un dialogue avec les collectivités locales sur les questions de la gouvernance urbaine se sont avérées dès le début très difficiles. La réticence face à la présence d'un autre acteur - les simples habitants ou les contribuables - était très forte. Ils n'apparaissaient pas réellement à l'horizon des responsabilités et dans les comptes des fonctionnaires au pouvoir local. La pression des investisseurs ou des compagnies qui voulaient profiter le plus rapidement possible de la situation perturbée faisait peur et stimulait le développement de la machine de corruption. Le respect des normes législatives par les autorités elles-mêmes amoindri.

Une fois compris le fonctionnement des affaires publiques et après avoir tout essayé pour rompre la résistance des pouvoirs locaux envers eux, les habitants n'ont pu que constater des résultats décevants. En 2005, le nombre d'organismes non gouvernementaux à Sofia qui luttent pour l'environnement urbain était de 35-40. Un comité d'initiative s'est alors formé, en majorité composé de femmes, pour constituer un réseau de ces organismes non gouvernementaux. Leur but: se faire reconnaître comme acteur dans la gouvernance de la ville, afin de lutter contre les injustices liées à la dégradation de l'environnement. 
30 Le comité a déjà œuvré pour se faire reconnaître afin de devenir un facteur ne incontournable et pour obtenir le droit d'intervenir dans la gouvernance foncière et le cas échéant pour entamer des poursuites. A la fin de 2005, les habitants ont commencé à constater les premiers effets de leur force et de leur opposition. L'objectif était d'identifier les causes de leur mécontentement, de leur désaccord dans la gouvernance urbaine et de signaler au public le fonctionnement des institutions locales. Ils faisaient prétendre leur droit à la ville, leurs intérêts sur leurs actions de rejet de ces situations entraînant des effets négatifs sur la population des 24 arrondissements de la capitale. Leur action était destinée aux élus et au maire de la ville de Sofia. Le but : demander des comptes aux collectivités locales et, en quelque sorte, dynamiser le mouvement social urbain. Les dérives dans la gouvernance par les collectivités locales furent nombreuses à être mises en évidence.

31 Suite à des actions organisées par des ONG le réseau organise sa lutte à partir des données du plan directeur de la ville. Il a mis sur pied plusieurs rencontres-débats et tables-rondes sur la situation des terrains verts de la ville, la spéculation foncière, le rôle des collectivités locales, etc. Les lois et les normes sont analysées dans les détails. Habitants et représentants des institutions, malgré les réticences, font l'effort de chercher des compromis et de proposer des décisions politiques, y compris la création d'une commission d'enquête parlementaire pour évaluer la politique de la municipalité de Sofia concernant les espaces verts urbains, la spéculation du sol dans les grands ensembles et autres abus.

Le mouvement urbain de la ville de Sofia fait appel aux différents partis politiques pour transmettre son mécontentement à la commission parlementaire et protester contre l'impossibilité à exprimer ses commentaires sur le Plan directeur. Les représentants du mouvement sont immédiatement reçus par les deux partis au pouvoir, et pour la première fois, le mouvement urbain s'exprime au Parlement. Les habitants de Sofia se sentent enfin représentés dans ce mouvement émanant de la société civile qui lutte pour son environnement urbain. Le basculement se profile vers une autre composition des forces dans la gouvernance de la ville de Sofia. Un nouvel acteur est reconnu sur la scène de la gouvernance : les citoyens organisés !

\section{Conclusions : reconnaître les habitants comme acteurs dans la gouvernance urbaine}

Quelques années après la naissance en 2001 de la première ONG MLADOST-Sofia, apparaît un réseau d'ONGs orienté vers la politique de l'urbanisme de Sofia qui se constitue en mouvement social. Ce mouvement constitué des habitants de tous les quartiers de la ville de Sofia prend en main la lutte pour la participation dans la gouvernance de la ville, mais une ville adaptée aux aspirations et aux besoins des citoyens.

A partir de 2005, par leurs actes de contrôle et d'opposition contre la dégradation des espaces verts et de l'environnement urbain, les habitants de Sofia marquent l'émergence incontestable d'un mouvement qui lutte pour la protection de sa ville. L'idée de consolider les ONG nées sur le territoire de Sofia et centrées sur les problèmes urbains et l'environnement prend vite corps. Au début de l'année 2004, on assiste déjà à un fonctionnement régulier du réseau des ONG, qui a maintenant son local. Notre 
équipe MOST soutient toujours fortement le projet et facilite l'organisation et le fonctionnement du réseau. En 2004, le réseau est nommé La communauté des citoyens pour la ville verte de Sofia (CCVS). Il se renforce après de nombreuses réunions, des débats tourmentés et diverses effervescences urbaines, jugées quasi «désespérées ", suite à des abus sur les espaces verts du territoire de la ville.

\section{Habitants et collectivités locales : un dialogue manqué qui commence à se construire}

35 Un des gros problèmes identifiés comme tel à Sofia dans le domaine de la gestion urbaine reste le dialogue manqué ou difficile entre les habitants et la municipalité. Mais il n'est plus impossible. La collaboration envisagée entre les ONG de la ville et les collectivités locales dans la perspective d'une nouvelle gouvernance (ajustement des objectifs et des actions, participation des ONG aux prises de décisions, etc.) est encore insatisfaisante malgré les nombreux efforts. Les collectivités locales n'assurent pas une réelle participation au débat urbain, le dialogue reste difficile.

36 A partir de novembre 2005 et le changement des élus et du maire de Sofia, un virage positif se produit. La gestion des relations entre les ONG et les collectivités locales au sujet de l'environnement et des espaces verts à Sofia commence à se faire jour malgré de nombreux défis et obstacles. L'administration de la municipalité ne rejette plus leurs approches pour accéder à la gouvernance du territoire. Les collectivités locales commencement timidement ou parfois ouvertement à accepter l'idée d'une participation des habitants aux prises de décisions sur la politique urbaine, la situation $\mathrm{du}$ foncier et les espaces verts. Les actions des habitants ne se heurtent plus autant à la bureaucratie locale. L'inertie compte encore, mais la pression du réseau des citoyens se renforce aussi. Les fonctionnaires de la municipalité ne restent plus autant corruptibles et se commencent timidement à exprimer l'intérêt de défendre les droits des habitants contre la restitution "sauvage » des terrains. Établir un dialogue entre les habitants et les fonctionnaires de la municipalité est toujours un des buts du mouvement urbain à Sofia.

\section{Les principaux résultats du mouvement urbain à Sofia}

Les thèmes mobilisateurs qui ont enclenché le mouvement concernent des questions proches des soucis de la vie quotidienne (gestion des déchets, espaces verts aux alentours des maisons pour enfants ou pour retraités, services de proximité, etc.), dont la responsabilité retombe parfois trop, de manière inéquitable, sur les femmes. Mais elle relève aussi bien des hommes que des enfants. En effet, dans une situation de crise économique, de démission de l'Etat et de remise en question de la division sexuelle des tâches, les femmes et les hommes recouvrent les charges productives auparavant mieux réparties.

Les femmes ont été nettement plus actives que les hommes dès le début du mouvement. Mais l'équilibre a été vite rétabli. Parfois, elles sont plus présentes que les hommes au niveau de l'exécution des tâches concrètes, ou de la communication et des rapports avec les institutions étatiques et municipales. Aujourd'hui, une grande partie des ONG des quartiers de Sofia sont gérées par des femmes. Les femmes se sentent valorisées par leur engagement dans les activités associatives. Etant donné le haut niveau d'éducation 
hérité du régime antérieur, des femmes qualifiées prennent des responsabilités au sein de ces ONG. Ce niveau d'éducation des participants aux ONG, aussi bien femmes qu'hommes, est la question clé et l'explication de la grande réussite du mouvement urbain de la ville de Sofia.

Leur niveau d'éducation élevé a permis aux femmes et aux hommes de rapidement comprendre les causes de la détérioration de la situation (corruption, spéculation foncière, manque de représentativité des responsables politiques). Ils se sont associés dans les luttes contre l'adversaire commun. Avec la baisse de la représentation des femmes dans les instances politiques, il reste à suivre l'évolution de leur pouvoir de décision dans les instances locales, dans les ONG, et au niveau domestique.

Le premier résultat de la lutte pour l'espace urbain en ville de Sofia a été de combattre la crainte devant les autorités. Puis la constitution des ONG se mobilisant sur la politique urbaine et la gouvernance, et le mouvement urbain lui-même. Les activités du réseau des ONG manifestent incontestablement l'émergence de la société civile. Elle s'est construite spontanément, d'en bas, avec l'aide des chercheurs, des forces locales, des ONG et le soutien d'institutions internationales.

41 Le deuxième résultat concerne la solidarité des femmes et des hommes dans ce mouvement. Ils mûrissent dans le processus d'analyse et de contestation et ils s'organisent pour réagir ensemble.

Le troisième résultat est le début d'un dialogue entre le mouvement urbain et les pouvoirs. Le mouvement urbain organise des débats avec les représentants des institutions concernées et cherche par différents moyens que les collectivités locales soient à l'écoute des citoyens. Les négociations aboutissent à un résultat plutôt positif, comme par exemple la signature par les deux parties - autorités et mouvement urbain - d'un document d'accord pour procéder à la protection des espaces verts en septembre 2004, déposé au Parlement. Les conditions d'un vrai dialogue ont déjà pris place. Les efforts continuent pour arriver à un certain équilibre dans les rôles des acteurs.

\section{Pour une nouvelle gouvernance de l'environnement urbain à Sofia}

Le but du mouvement urbain créé à Sofia est de participer à la gouvernance du territoire de l'espace public. L'action a démarré avec les femmes, mais aussi les hommes, habitant un grand ensemble d'immeubles à Sofia. Elle s'est développée et concerne maintenant toute la ville, autour des enjeux liés aux espaces verts publics. L'influence du mouvement s'étend à d'autres grandes villes bulgares, comme Plovdiv, Bourgas. Plusieurs débats ouverts à tous sont organisés en ville avec la participation des habitants. Des émissions à la télévision et à la radio se développent. Les lois, les normes et les règlements existants sont analysés en détail devant la population. La presse se penche sur des cas d'abus. Le nouveau Plan Directeur de Sofia est contesté avant son approbation au Parlement. La société civile à Sofia émerge et confirme sa présence active dans la lutte pour l'environnement urbain.

Les rapports des femmes et des hommes au sein du mouvement urbain à Sofia s'adaptent déjà aux nouvelles conditions économiques, sociales et politiques. Les identités des femmes et des hommes changent. La détérioration de la situation des femmes et les difficultés identitaires des hommes, la précarisation, peuvent être discutées, analysées, dans les rencontres que facilitent les associations de quartiers. Le mouvement urbain ouvre une porte de sortie à une situation qui semblait sans issue et 
offre des possibilités de réagir face aux exaspérations. Les hommes et les femmes redeviennent acteurs et actrices de leur vie, qui était auparavant dirigée d'en haut, certes de manière relativement équitable, mais sans créativité ni remise en question. Si elles et ils ont perdu des droits, ils apprennent maintenant à se battre pour les reconquérir.

\section{NOTES}

1. D'après le rapport de service spécialisé de la ville de Sofia de 2005 (3300 hectares le 31.12.1988 et 2000 hectares en 2005) la diminution représente $1 / 3$ de la verdure totale. Les statistiques précises font défaut à la mairie de Sofia, elles peuvent être beaucoup plus élevées. Il n'existe pas de registre des espaces verts dans la ville, ce qui peut être expliqué soit par la négligence, soit par la volonté de camoufler les procédures de privatisation des espaces verts. Mais il faudrait examiner en détail si les crédits accordés étaient dévoués par la mairie à d'autres actions.

\section{RÉSUMÉS}

Libérés de la peur et des complexes introduits dans l'esprit des citoyens par l'ancien régime socialiste, les habitants de Sofia s'organisent pour former une société civile qui lutte pour préserver les valeurs urbaines de l'environnement public qui est en train de subir de graves transformations. Pour défendre leurs droits de citoyens et l'environnement les Sofiotes se mettent spontanément en réseaux et prétendent devenir un partenaire majeur dans la gouvernance de la ville.

Liberated from the fear and the complexes imposed on the citizens by the former socialist regime, Sofia's inhabitants organise themselves as civil society actors who struggle to preserve the urban values of public environment as it is under serious transformations. To defend their rights and the environment, Sofia inhabitants spontaneously develop networks and intend to become one major partner in the city governance.

Liberados del miedo y los complejos introducidos en el espíritu de los ciudadanos por el antiguo régimen socialista, los habitantes de Sofía se organizan para formar una sociedad civil que lucha por preservar los valores urbanos relacionados al medio ambiente público, que, lamentablemente, está sufriendo graves transformaciones. Es así que, para defender sus derechos ciudadanos y medioambientales, los habitantes de Sofía se organizan espontáneamente en redes sociales y pretenden convertirse en una parte importante de la gobernabilidad en la ciudad. 


\section{AUTEUR}

\section{ISKRA DANDOLOVA}

Docteure en lettres et sciences humaines de l'Université de Paris X-Nanterre ; sociologue urbaine, architecte ; directrice de recherche à l'Institut de sociologie auprès de l'Académie bulgare des sciences de Sofia. Ses champs de recherche sont la politique de la ville, les inégalités sociales, la politique sociale et l'exclusion, le genre et l'espace urbain. Depuis 1997, elle est responsable du projet MOST-UNESCO « Genre, ville et environnement » en Bulgarie. 


\title{
Bénéficiaires actives ou citoyennes critiques? La participation des femmes pauvres dans la gouvernance locale, Kerala, Inde
}

\author{
Sandra Walter
}

\section{Introduction}

Dans les années 1990, le Kerala a connu plusieurs réformes institutionnelles qui visaient notamment à transformer la prise de décision et la planification du développement au niveau local. Dans le cadre de cette recherche, nous nous intéressons plus particulièrement aux implications de ces réformes pour le développement des infrastructures et services environnementaux dans les quartiers défavorisés ${ }^{1}$. Selon le Gouvernement du Kerala, le processus de décentralisation a contribué à améliorer l'accès des populations démunies aux infrastructures et services de base ${ }^{2}$. Cependant, il est aussi dit que si le processus de décentralisation a été un tant soit peu favorable aux pauvres, cela est dû à l'intervention des femmes, membres de Kudumbashree, dans les assemblées de circonscription et de village. Kudumbashree est le nom de la mission étatique de lutte contre la pauvreté, une lutte qui repose essentiellement sur l'activisme des femmes pauvres. Ces dernières, en plus de jouer un rôle clé dans la mise en œuvre des programmes de développement financés par le Centre et l'Etat, auraient donc aussi investi en force les assemblées de circonscriptions, la première étape du processus de planification. Ce qui n'est pas rien dans un contexte où les nouveaux espaces politiques n'échappent généralement pas aux hiérarchies locales, notamment celle de caste, de classe et de genre. Avant de pouvoir parler d'une reconfiguration sociale du processus de participation, il est cependant nécessaire d'observer de plus près la qualité et le sens de cette participation et la nature des nouveaux espaces démocratiques créés par le processus de décentralisation. 
2 Notre recherche a lieu dans la ville de Thiruvananthapuram, la capitale du Kerala. En 2004 et 2005, nous avons effectué plusieurs dizaines d'interviews avec les conseillers municipaux et membres de Kudumbashree dans les diverses circonscriptions de la ville, afin d'obtenir une vue d'ensemble des transformations occasionnées par les réformes. Puis nous avons sélectionné un quartier comme étude de cas où nous poursuivons nos interviews depuis. Le terrain devrait se compléter en 2006.

\section{Les réformes et le développement des quartiers défavorisés}

3 L'Etat du Kerala a longtemps été perçu comme un modèle, pour avoir atteint un niveau de développement social élevé, sans pour autant être accompagné par un développement économique équivalent. Ces résultats sont attribués par de nombreux chercheurs à la mobilisation politique et sociale de la population et aux politiques publiques qui s'ensuivirent. ${ }^{3}$ Cependant, depuis le milieu des années 1980 , de plus en plus de voix s'élèvent pour souligner que le modèle du Kerala est un modèle en crise, voire un échec. Et, malgré les réformes mises en œuvre, le Kerala des années 1990 reste confronté au taux de chômage le plus élevé de l'Inde et à une crise fiscale qui remet en question le rôle de l'Etat en terme de développement humain et de redistribution. Dans ce contexte, le Front de Gauche, de retour au pouvoir en 1996, a saisi l'opportunité présentée par les $73^{\mathrm{e}}$ et $74^{\mathrm{e}}$ amendements constitutionnels ${ }^{4}$ pour chercher à résoudre la crise structurelle de l'Etat. L'objectif de la réforme engagée était non pas de diminuer le rôle de l'Etat, mais de renforcer le secteur public en déléguant la responsabilité de la provision des services et du développement aux gouvernements locaux. Cette tentative, connue sous le nom de "People's Plan", consistait à instaurer un processus de planification participatif.

En ce qui concerne les développements des infrastructures et services environnementaux dans les quartiers défavorisés, ces réformes ont plusieurs implications. Premièrement, la lutte contre la pauvreté et le développement des quartiers défavorisés sont devenus des fonctions municipales, dans le cadre des nouvelles législations municipales. Deuxièmement, 35 à $40 \%$ des fonds du budget alloué à l'Etat sont dévolus aux gouvernements locaux. Il y a donc une réelle augmentation des moyens financiers de ces derniers, même si cela ne se fait pas sans résistance ${ }^{5}$. Par ailleurs, des mesures ont été prises pour s'assurer que les populations marginalisées jusqu'à présent dans le processus de développement ne soient pas laissées pour compte. Un pourcentage est donc réservé à ces catégories, notamment: $10 \%$ pour le développement des bidonvilles et la réinstallation des populations délogées des quartiers insalubres; $5 \%$ pour les $\mathrm{SC} / \mathrm{ST}$, dans des quartiers où au moins $50 \%$ de la population appartient à ces catégories ; $2 \%$ pour la cellule locale de Kudumbahsree et $10 \%$ pour des projets concernant les besoins spécifiques des femmes. Et, troisièmement, on assiste à la création de comités ${ }^{6}$ et de conventions de circonscription qui sont à la base du processus de planification. Les comités prévus par le $74^{\mathrm{e}}$ amendement constitutionnel ont notamment pour fonction d'établir les priorités concernant le développement local et de sélectionner les bénéficiaires des programmes d'aide. Les conventions, elles, sont liées à la Campagne pour une planification populaire. Elles visent à donner l'opportunité à tous les citoyens d'exprimer leurs besoins, au lieu de laisser cette tâche aux experts du comité. Les besoins exprimés par 
les participants sont ensuite traités en priorité par les membres du comité de circonscription puis envoyés aux échelons supérieurs du processus de planification.

Dans le cas de la colonie choisie comme étude de cas, un des leaders politiques résume l'impact de ces réformes en ces termes :

«La différence est qu'auparavant, nous devions réclamer les services et infrastructures désirés. Comme lorsqu'il n'y avait pas de toilettes, nous allions les réclamer. Réclamer signifie que nous en avons besoin et que vous devez nous les donner. Mais aujourd'hui, au travers du "People's Plan", c'est différent. Ils disent que si c'est un bidonville, ils doivent donner. Nous n'avons donc plus besoin d'aller et de demander. Le gouvernement a une provision que les gens ont un droit, donc ils doivent les donner. [...] Ceci est la différence $»^{7}$

\section{Kudumbashree : la lutte contre la pauvreté devient une affaire de femmes}

6 A l'origine de Kudumabshree, il y a le programme UBSP (services urbains de base pour les pauvres), sponsorisé par le Gouvernement indien et UNICEF. Ce programme, lancé à Thiruvananthapuram en 1992, cherchait à mettre les femmes pauvres, en tant que mères de famille, au centre de la distribution des services de base dans les quartiers défavorisés. Il repose sur une structure spécifique en trois niveaux ${ }^{8}$ et implique donc une décentralisation du processus de décision concernant l'usage de ces fonds. Les objectifs étaient cependant prédéfinis et la participation des femmes devait permettre surtout d'améliorer la mise en œuvre de ce programme. Il subira plusieurs transformations à partir de 1995, notamment liées au retrait de l'UNI-CEF et à l'intégration d'autres objectifs, sa structure reste cependant utilisée pour la distribution des principaux programmes de lutte contre la pauvreté. En 1999, se crée la nouvelle "mission étatique de lutte contre la pauvreté ", nommée " Kudumbashree » (prospérité de la famille) qui conserve cette structure et la propage progressivement à l'ensemble de la ville. Il est bon de noter que depuis le lancement du programme national de développement des bidonvilles en 1997, Kudumbashree contrôle la principale source de fonds pour le développement des infrastructures et services de base dans les quartiers démunis. Cependant, les activités de microcrédit et d'épargne prennent de plus en plus d'importance, en comparaison des enjeux qui étaient à la base du projet: santé, éducation et assainissement. ${ }^{9}$ Outre, un meilleur usage des fonds et une sélection des bénéficiaires plus juste, des constructions de plus grande qualité (sous l'œil vigilant des femmes) seraient les principaux avantages de ce système. Le soususage des fonds existe aussi, principalement lié à la difficulté pour les potentiels bénéficiaires de répondre aux exigences administratives, notamment celle du titre de propriété.

7 Outre les études concernant les conséquences concrètes de ce programme sur la pauvreté et le statut des femmes dans leur famille, d'autres se sont intéressées aux implications de ce type de réformes pour la citoyenneté des femmes pauvres. $\mathrm{Si}$, un nouveau rôle est offert aux femmes pauvres ou une nouvelle forme d'agency, la question qui se pose est celle de la nature de ce rôle et ses implications pour la citoyenneté des femmes pauvres. Un premier élément est que ce programme repose sur l'idée que les femmes pauvres sont plus vulnérables mais aussi plus responsables vis-àvis de leur famille et moins corrompues, si ce n'est aussi plus fiables en matière de remboursement. La responsabilisation des femmes fait face à un discours qui justifie 
l'exclusion des hommes de par le fait qu'ils sont alcooliques, irresponsables et incapables de s'unir au-delà des divisions partisanes. ${ }^{10}$ L'implication des femmes dans ces programmes a cependant eu, de leur point de vue, plusieurs avantages, outre les potentiels gains matériels. En ce qui concerne plus particulièrement les présidentes ADS, il s'agit notamment de l'augmentation de leur confiance en elle, de l'acquisition d'un certain statut dans la société, de l'amélioration de leur capacité d'interaction avec les autorités. Ce qui n'est pas négligeable dans le contexte indien, où le problème n'est pas tant l'inexistence de programmes d'aide que l'accès à ces programmes par les populations ciblées. Cependant, pour les membres leaders, les coûts sont aussi élevés. Tout d'abord, le travail de présidente ADS implique des dépenses (déplacements, téléphone) mais reste impayé, car basé sur le mode de l'activisme. Il nécessite du temps, ce que les femmes qui doivent travailler pour vivre et s'occuper de leur famille n'ont pas forcément. Par ailleurs, il implique souvent des conflits, parfois même violents, au sein des membres des unités ou de la communauté regardant la distribution des bénéfices. Les injures et accusations sont fréquentes et impliquent pour certaines présidentes ADS une tension et des soucis permanents. Et cela se répercute sur les relations familiales, lorsque les médisances et les rumeurs, atteignent le mari ou les enfants. ${ }^{11}$ Ce qui pousse parfois les femmes qui en sont victimes à se retirer de l'organisation.

8 Si l'empowerment des femmes est au cœur de ce programme, il est avant tout dans le discours du Gouvernement du Kerala: "un instrument pour résoudre les enjeux complexes de ce secteur (eau et assainissement) $»^{12}$. Ainsi, comme le souligne plusieurs chercheuses, les femmes pauvres deviennent les agentes de l'Etat pour le développement local et la réduction de la pauvreté. ${ }^{13}$ Le type d'agency qui leur est offert, par ailleurs, se focalise sur leur rôle de gardienne du foyer et de la communauté et reste dans le domaine du domestique, même si étendu à la sphère communautaire. Ce qui contribuerait à renforcer les normes de genre qui ont prévalu tout au long du $\mathrm{XX}^{\mathrm{e}}$ siècle. La seule nouveauté est que ce type d'agency est aujourd'hui offert aux femmes pauvres, même si adaptée à leur situation économique par l'ajout d'activités d'épargne et de microcrédit. ${ }^{14} \mathrm{Un}$ autre argument est que la représentation des femmes comme apolitiques aurait aussi pu jouer un rôle dans la volonté de l'Etat de promouvoir la participation des femmes. Ce, dans un contexte où les divisions partisanes affectent le processus de développement de manière conséquente. Pour J. Devika, de telles politiques ne visent donc pas à donner une place aux femmes dans l'espace public en tant que citoyennes, en tant que catégorie politique ayant des droits mais à les utiliser comme agentes pour améliorer l'utilisation des fonds au niveau local. Et, au cœur de ce régime de transformation se trouve non pas un sujet politique - le travailleur homme mais un agent de développement - la femme travaillant dans le secteur informel. ${ }^{15}$

9 Les tensions avec les conseillers municipaux ou les leaders locaux des partis sont pourtant fréquentes, ce qui souligne le fait que le contrôle de ces fonds est un enjeu de pouvoir. Les leaders politiques locaux ont vu leur monopole sur la distribution de ces fonds remis en question. Comme le souligne la présidente CDS, la signature d'une femme pauvre devient tout aussi importante, si ce n'est plus importante que celle du conseiller élu, ce qui n'est pas facile à accepter pour ce dernier qui cherche de fait à s'immiscer dans le choix des bénéficiaires et à s'approprier le mérite lié à la distribution de ces fonds. Dans certains cas, notre impression était que la présidente ADS était carrément choisie par le parti dirigeant dans la circonscription. Dans d'autres, même si elle parle de coopération avec le conseiller élu, les rapports de 
pouvoir sont clairement en faveur de ce dernier. Cet extrait d'interview avec une présidente ADS reflète ce point :

Quoi que nous fassions dans la circonscription, nous devons le faire avec l'aide du conseiller élu. Nous ne pouvons pas prendre nos propres décisions. Nous devons faire ce que le conseiller élu nous dit, quoi qu'il dise. Nous ne pouvons pas dire que ce n'est pas juste, lorsqu'il fait quelque chose de mal. Ils sont les représentants du peuple, ils ont le public derrière eux. Même s'il y a des femmes derrière eux, elles ne vont pas forcément nous soutenir. Parce que tout est fonction du parti, nous pouvons seulement faire ce que le conseiller nous dit. Quelle que soit la colonie, c'est le parti qui est important. Même si nous faisons quelque chose, les gens ne sauront pas que nous l'avons fait. Cela sera connu comme quelque chose qui est fait par le parti ou le conseiller élu. Le nom de Kudumbashree n'est pas cité.

Dans les cas où le conseiller élu favorise son parti, sa famille ou ses amis, ce rapport de forces peut donc contrer les objectifs de Kudumbashree. Ce rapport de pouvoir a, par ailleurs, été renforcé en faveur du conseiller élu, depuis que la municipalité a exigé que les décisions prises par la présidente ADS soient cosignées par le conseiller élu, ce qui n'était pas le cas auparavant. Ce suite aux plaintes des conseillers élus qui se voyaient exclus de la distribution des programmes d'aide et donc des bénéfices que celui qui les contrôle en retire ${ }^{16}$ Les tensions et conflits sont de fait fréquents. Et dans les quelques cas où la présidente ADS s'oppose ouvertement à l'élu ou aux membres locaux des partis, elle est soumise à insultes, menaces et violence. Il est aussi bon de souligner que les présidentes ADS qui semblaient rencontrer le plus de tensions avec les partis ou élus locaux, mais qui s'avéraient capables d'y résister et de dénoncer le mauvais usage des fonds ou la sélection malhonnête des bénéficiaires, étaient celles qui avaient le plus d'expérience. Une des stratégies employées par les partis pour déstabiliser le travail des groupes de femmes était de convaincre les maris, membres du parti, d'empêcher leurs femmes de se rendre aux réunions avec des arguments du type: "si tu es un homme, pourquoi laisses-tu ta femme sortir de la maison et se promener librement dans le public ? $»^{17}$.

\section{La participation des femmes pauvres au processus de planification}

11 En dehors de Kudumbashree, une autre source de fonds pour le développement des infrastructures et services environnementaux est le processus de planification au niveau local. La participation aux conventions de circonscriptions est la seule façon pour les femmes pauvres d'accéder à ce processus. La création de ces conventions ainsi que celles des comités font partie de ces réformes qui selon les termes de A. Cornwall visent à reconfigurer un certain type d'espace : celui existant entre les institutions et les citoyens, surtout celles de l'Etat. Pour comprendre le potentiel de ces espaces pour la participation citoyenne, il faut se poser des questions sur leur nature et leur dynamique de participation interne. Ces espaces sont, de fait, rarement neutres et ne sont pas toujours utilisés de manière égale par les différents acteurs. ${ }^{18}$ Nous allons donc nous arrêter sur les conditions d'accès à ces conventions, sur la nature de la participation et le type d'enjeux soulevés, afin de réfléchir à l'identité avec laquelle les femmes entrent dans ces espaces. souligné, souvent dominantes dans les assemblées de circonscriptions. Selon, la 
présidente CDS, dans certaines conventions, elles représentent jusqu'à $90 \%$ des participants. Cette participation était par ailleurs plus faible au départ, elle aurait progressivement augmenté suite au développement des groupes de Kudumbashree. Parallèlement avec le processus de décentralisation, Kudumbashree aurait pour mission, selon le Gouvernement du Kerala, de faciliter la participation des pauvres dans le processus de décentralisation au travers des CDS, comme sous-systèmes des corps locaux. ${ }^{19}$ Etre membre de Kudumbashree devient donc une condition pour les femmes pauvres, pour accéder au processus de planification. Seulement celles qui font partie de Kudumbashree seront invitées à participer aux conventions et seront donc informées sur le type de bénéfices distribués. Ce sont, par ailleurs, généralement les leaders qui s'y rendent pour représenter les différentes unités. Ce sont aussi souvent les seules qui sont au courant et connaissent plus ou moins l'objectif de ces conventions. Dans le cas du quartier étudié, à l'exception de ces leaders, la plupart des femmes interviewées ignoraient l'existence de ces assemblées ou les confondaient avec les réunions de partis ou de Kudumbashree. Il ne suffit pas cependant d'être membre de Kudumbashree pour avoir accès à ces conventions. La tenue régulière de ces conventions par le conseiller élu, son invitation à participer sont les principaux facteurs expliquant pourquoi, dans certaines circonscriptions, les présidentes ADS et autres membres ne s'y sont jamais rendues. Les bonnes relations avec le conseiller élu sont donc un élément clé pour être invité à participer. Cependant, un élément positif est que certaines leaders de Kudumbashree osent se plaindre lorsqu'elles n'ont pas été invitées ou se rendent aux conventions malgré leurs mauvaises relations avec l'élu local. Il est cependant le fait d'une minorité de présidente ADS qui ont de longues années d'expérience derrière elles.

Si l'on s'intéresse maintenant au mode de participation des membres de Kudumbashree dans ces conventions, l'impression qui ressort est qu'elles s'y rendent avant tout dans l'espoir d'obtenir des bénéfices. Cependant, cela caractérise la plupart des participants. De fait, nous avons souvent entendu lors de nos interviews avec les autorités, les élus, voire les leaders de Kudumbashree que seuls les pauvres se rendent à ces réunions, car eux seuls ont des besoins. Certains concluaient que ces conventions n'étaient de fait pas bien utilisées par les participants qui, au lieu d'engager une discussion sur les besoins collectifs, ne se préoccupaient que de leurs propres besoins. Dans certaines circonscriptions, la diminution progressive des participants était attribuée au fait que les gens ne voyaient plus l'intérêt de venir alors qu'ils n'obtenaient de toute façon jamais rien. ${ }^{20}$ Les hommes qui participent à ces conventions sont cependant pour la plupart représentants des associations de résidents, des partis, d'organisations de castes ou de syndicats. Selon les circonscriptions, ils peuvent appartenir à différentes classes. Mais, bien souvent, ils sont perçus comme issus majoritairement des classes supérieures. Par ailleurs, ils semblent participer plus pour représenter les intérêts de leur quartier, de leur parti ou de leur caste, que ceux de leur famille. Les participants hommes sont ainsi représentés comme discutant de choses publiques, de politique ou des problèmes importants, pendant que les femmes parlent de problèmes personnels, individuels ou familiaux. Dans certains cas, la distinction se faisait cependant entre les femmes qui discutent des besoins de la communauté et les hommes qui débattent de politique. Comme l'exemple d'une présidente ADS ci-dessous :

$Y$ a-t'il des différences entre ce que les hommes et les femmes demandent? Oui, les femmes parlent principalement des besoins de la famille et du public, mais les hommes parlent des affaires importantes concernant la politique. Les femmes 
parleront de leur besoins, quelque chose de bien pour la société. Si la société a besoin d'une salle communautaire, les hommes en parleront. Les femmes demanderont des latrines et ce genre de besoins. Les femmes exprimeront aussi des besoins en rapport avec l'éducation et la santé. ${ }^{21}$

Nos interviews semblent cependant suggérer que les membres de Kudumbashree qui occupent des fonctions plus élevées ont aussi plus tendance à parler des besoins de leur quartier et de la collectivité. Dans le cas de la colonie choisie, la présidente ADS et une autre membre, fortement politisée depuis sa petite enfance, semblaient prendre la parole sur les besoins collectifs. Sinon, cela restait en général la prérogative des hommes leaders politiques ou représentants des associations de résidents. Ainsi, les besoins exprimés par les femmes et les hommes diffèrent, non pas seulement de par leur genre, mais aussi de par la fonction qu'ils occupent dans la société et l'identité avec laquelle ils entrent dans ces conventions.

Si la plupart des femmes participent à ces conventions dans l'espoir d'avoir accès à certains bénéfices, leur présence massive a cependant une autre fonction, celle de s'assurer que la distribution des bénéfices soit faite de manière juste. L'exemple de Narmala, une femme de 47 ans, sur sa participation à la convention reflète ce point :

En fait, je ne sais pas très bien ce qui se passe là-bas. Quelqu'un peut me demander mon opinion sur quelque chose, par exemple les problèmes concernant mon quartier ou les femmes, alors je donne mon opinion. Plus que ça, je ne sais pas. Aussi, quand quelqu'un dit qu'il n'a rien reçu, et la plupart des gens qui ont reçu des bénéfices ou construisent une maison parlent de cette manière, si je sais cela je parle et je dis : j'ai entendu dire par quelqu'un que tu es en train de construire cela avec tel ou tel argent que tu as reçu, n'est-ce pas vrai ?. Comme cela, je parle.

La présence des membres de Kudumbashree permet de contrôler les abus dans la distribution de certains bénéfices. La présidente CDS soulignait fièrement que la présence des femmes de Kudumbashree, dans les conventions de circonscriptions empêchait les hommes de "tricher». Selon elle, si auparavant les hommes allaient dans les conventions de circonscriptions, prenaient les décisions et contrôlaient les travaux, aujourd'hui rien ne se passe sans les femmes. Si cela semble optimiste au vu de la situation dans certains quartiers, cela semble effectivement être le cas dans son quartier. Ce qui n'est étranger à sa présence.

\section{Conclusion}

17 Si la mobilisation des femmes pauvres au travers de Kudumbashree a, dans une certaine mesure, permis d'élargir la participation des femmes dans la gouvernance locale, des doutes restent quant à la capacité de ce programme d'assurer une présence active et critique des femmes. ${ }^{22}$ Les femmes pauvres semblent être cantonnées à un rôle d'agent de mise en œuvre, plutôt que de participantes critiques du processus de développement. ${ }^{23}$ L'amélioration de la mise en œuvre des programmes de lutte contre la pauvreté, si elle n'est pas négligeable, n'est par ailleurs pas forcément accompagnée par une meilleure représentation des intérêts des plus démunis dans la gestion et le développement municipal. Les cas de mésusage des fonds réservés aux catégories défavorisées sont fréquents, malgré la participation des membres de Kudumbashree. De fait, la présence de ces dernières es nettement moins forte au niveau des comités de circonscriptions, là où les décisions se prennent vraiment. Les services de base (ramassage des ordures, nettoyage des canaux, des étangs et des canalisations) sont 
toujours mieux assurés et mieux maintenus dans les quartiers riches que dans les quartiers pauvres. Les habitants de ces quartiers ayant nettement plus de contacts et d'influence auprès des autorités responsables de ces services (municipal ou étatique). Le sentiment que le Gouvernement néglige la situation des quartiers démunis existe ainsi en parallèle avec la reconnaissance des aides reçues. Une conversation entre notre interprète et une présidente ADS reflète ce point :

$\mathrm{T}:$ Ce quartier est agréable, il est très vert.

ADS P : Oui, ils cherchent à nous tenir content et silencieux en nous distribuant à chacun quelques petites aides, pendant qu'ils dépensent beaucoup d'argent pour construire des quartiers hi-tech, coupant au passage tous les arbres.

$\mathrm{T}$ : C'est vrai, maintenant lorsqu'il faut marcher d'un carrefour à l'autre, il fait tellement chaud, ce n'était pas comme cela auparavant. ADS P : Oui, et c'est qui qui doit encore marcher?

L'entrée en politique reste pour plusieurs leaders de Kudumbashree la seule manière de vraiment changer les choses. L'existence d'un quota pour les femmes dans les gouvernements locaux a de fait donné l'opportunité à plusieurs membres de se présenter aux élections. En 2005, un peu moins de 1000 ex-membres de Kudumbashree ont gagné les élections locales. Les leaders qui, de par leur travail, ont gagné une certaine renommée locale, deviennent, de fait, des candidates idéales pour les partis dans les circonscriptions réservées. Cependant, la présidente CDS soulignait qu'il est loin d'être sûr que les nouvelles élues seront plus sincères et moins corrompues dans leur travail. Selon son expérience, si certaines élues restent proches de Kudumbashree après leur élection, d'autres ne pensent qu'à l'argent. Ainsi, une fois élues, leur mentalité de travailleuses sociales disparaît et elles deviennent des travailleuses politiques. ${ }^{24}$ Ce qui signifie faire passer le développement du parti avant celui de la communauté. Par ailleurs, même si l'élue reste concernée par le social, il faut être conscient que les conseillers locaux ont très peu de marge de manœuvre face aux ordres du parti. ${ }^{25}$ Une femme pauvre, de caste souvent inférieure, risque d'en avoir encore moins.

\section{NOTES}

1. Ce terme inclut l'eau, l'assainissement, les égouts et le ramassage des ordures, tous ayant une influence clé sur la qualité de l'environnement dans le foyer et le quartier. In Nunan Fiona and Satterthwaite David, 2000, Governance for Environmental Improvement: A Comparative Analysis of the City Case studies, Urban Governance, Partnership and Poverty, Theme Paper 21, University of Birmingham.

2. Government of Kerala, 2002, Economic Review, State Planning Board, Thiruvanathapuram.

3. Jeffrey Robin, 2001 (1992), « Politics, Women and well-being : How Kerala Became "A Model” " Oxford India Paperbacks, New Delhi; Ramachandran V. K., 1996, «On Kerala's Development Achievements" in Sen Amartya \& Drèze Jean (Editors), Indian Development: Selected Regional Perspectives, Oxford University Press, New Delhi, pp. 205-356.

4. Le $74^{\mathrm{e}}$ amendement constitutionnel visait à renforcer l'autonomie politique et administrative des autorités urbaines. Il rend aussi obligatoire la réservation d'un tiers des sièges pour les 
femmes dans les gouvernements urbains. Et, de même, une réservation réserve existe pour les castes intouchables et les populations tribales.

5. La décentralisation en tant que processus politique ne se fait pas sans résistance. Dans le cas du Kerala, depuis le retour du Congrès au pouvoir, les tensions entre l'Etat et la municipalité sont fréquentes et complexes, ce qui affecte souvent le travail des élus et de la municipalité.

6. Ces comités sont composés d'au moins 50 membres sélectionnés par le conseiller élu. Ils doivent être tenus tous les trois mois. Auparavant, les conseillers élus pouvaient prendre les décisions seuls.

7. Interview, octobre 2005.

8. Société de développement communautaire (CDS) au niveau municipal, Société de développement zonal (ADS) au niveau des circonscriptions (parfois 2-3 circonscriptions sont réunies) et unités au niveau du quartier de 10 à 15 femmes. La ville de Thiruvananthapuram, entre 2001 et 2005, contenait 54 ADS présidentes pour 81 circonscriptions.

9. Kadiyala Suneeta, 2004, «Scaling up Kudumabshree - Collective Action for Poverty Allievation and Women's Empowerment », FCND Discussion Paper No. 180, Washington : International Food Policy Reserach Institutes, 37-8.

10. Ces termes furent utilisés par le chef de projet responsable du CDS de Thiruvananthapuram pour m'expliquer pourquoi Kudumbashree ne travaillait qu'avec les femmes. De nos interviews sur le terrain ressort le fait que bien que la contribution monétaire des hommes à la famille leur donne encore le statut de "chef de famille ", elle ne dépasse pas pour autant automatiquement celle des femmes. De fait, dans un contexte de sous-emploi ou d'emploi irrégulier massifs parmi les hommes, la préoccupation de nombreuses femmes est de trouver un emploi pour assurer un revenu régulier. Par ailleurs, une majorité des répondantes ont souligné que les hommes ramènent en général au mieux la moitié de leur salaire à la maison le reste étant utilisé pour leur consommation personnelle, notamment alcool, cigarettes et nourriture. Dans le pire des cas, les femmes doivent cacher leurs économies pour éviter que leur mari n'utilise cet argent pour boire. Nombreuses femmes auraient cependant souhaité que les jeunes hommes, la plupart au chômage, puissent aussi bénéficier de ce programme.

11. Les divisions partisanes, la jalousie et le refus de voir son voisin obtenir davantage, quelle que soit sa situation, sont souvent cités comme causes principales de ces tensions.

12. Government of Kerala, Economic Review 2003, State Planning Board, Thiruvananthapuram, 170.

13. Devika J, 2005, Modernity with Democracy? Gender and Governance in the People's plan Campaign, Keralam, Working Paper 368, Centre for Development Studies, Thiruvananthapuram, February ; Muralidharan, Sarada (2003) 'Gender and Decentralization :

Opportunities and Challenges', Kerala Calling, October.

14. Devika J, 2005, Modernity with Democracy..., p. 26. L'auteur ajoute que face à l'augmentation des programmes de microcrédit, certains chercheurs ont souligné la prévalence d'une conception largement économique de l'empowerment. Les questions de violence domestique, de harcèlement sexuel et de viols sont en contrepartie négligées.

15. Ibid, p. 19.

16. Pourtant, selon la présidente CDS, Kudumbashree fonctionne mieux à Thiruvananthapuram que dans d'autres villes où le chef de projet gère tout le programme et les unités sont laissées à l'abandon. Un des avantages d'être situé dans la capitale est que dès qu'elle a des problèmes avec la municipalité, elle peut se rendre au siège de Kudumbashree et obtenir le soutien de l'administrateur en charge.

17. Interview 10 octobre 2005.

18. Cornwall Andrea, 2002, «Locating Citizen Participation » in IDS Bulletin, Vol. 33, No. 2, p. 51.

19. Government of Kerala, Government Orders (M. S), No. 240/97/LAD.

20. Il faut souligner cependant que la dynamique à l'intérieur de ces conventions semble varier en fonction du niveau de développement de la circonscription. 
21. Interview, octobre 2004.

22. Muralidharan, Sarada (2003) 'Gender and Decentralization..., p. 5-6.

23. Ibidem.

24. L'opposition entre travailleur social et travailleur politique ou "Pakkha politicien » était souvent utilisée par les présidentes ADS pour distinguer leur travail de la politique. De même, certains conseillers élus l'utilisaient pour se définir.

25. Un argument que nous avons souvent entendu sous diverses formes. Notamment, à notre question de savoir si la présence d'une femme à la tête de la municipalité changeait quelque chose, la réponse était souvent : «Femme ou homme, ce qui compte c'est le parti. »

\section{RÉSUMÉS}

Dans les années 1990, l'Etat du Kerala a mis en œuvre plusieurs réformes institutionnelles qui ont transformé, dans une certaine mesure et à différents niveaux, le processus de décision concernant le développement des infrastructures et des services environnementaux dans les quartiers défavorisés. Par l'une de ces réformes, les femmes pauvres se sont vu confier un rôle majeur dans la lutte contre la pauvreté et pour le développement de leur quartier. Cet article présente brièvement les implications du renforcement de la participation des femmes pauvres au niveau local et les contraintes auxquelles ces dernières se retrouvent confrontées. Il se base sur les résultats préliminaires de notre recherche de terrain dans la ville de Thiruvananthapuram au cours des années 2004 et 2005.

In the 1990s the state of Kerala implemented several institutional reforms that transformed, to a certain extent and at various levels, the decision-making process about infrastructure and environmental services development in the poorer neighbourhoods. Following one of these reforms, women have been assigned a major role in the fight against poverty and for development in their neighbourhoods. This article briefly presents the implications of the strengthening of poor women's participation at local level and the constraints that these women have to face. It is based on the preliminary results of my field research in the city of Thiruvananthapuram during 2004 and 2005.

En los años 90, el Estado del Kerala puso en marcha varias reformas institucionales que transformaron, en cierta medida y a distintos niveles, el proceso de decisión relativo al desarrollo de las infraestructuras y servicios medioambientales en los barrios desfavorecidos. A través de una de estas reformas, las mujeres pobres han sido elegidas o priorizadas (confiadas) para ejercer un rol principal en la lucha contra la pobreza y el desarrollo de su barrio. Este artículo presenta brevemente las implicancias del fortalecimiento de la participación de las mujeres pobres a nivel local y las dificultades a las cuales estas últimas se encuentran enfrentadas. El artículo se basa en los resultados preliminares de nuestra investigación en el terreno, en la ciudad de Thiruvananthapuram durante los años 2004 y 2005. 


\section{AUTEUR}

\section{SANDRA WALTER}

Sandra Walter a une licence en sciences sociales de l'Université de Lausanne et un DES de l'IUED.

Elle prépare une thèse intitulée Genre, citoyenneté et gestion de l'environnement urbain : les

implications des réformes institutionnelles au Kerala. Cette thèse est financée par le programme de recherche NCCR Nord-Sud, soutenu par la Direction du développement et de la coopération suisse et le fonds national pour la recherche scientifique suisse. 


\title{
Groupements d'Intérêts
} Economiques Féminins, privatisation des services publics et accès équitable au politique : enseignements tirés à Ouagadougou, Burkina Faso

\author{
Kadidia Tall
}

\section{Avant-propos}

1 Membre du réseau à partir de ma contribution au colloque de l'IUED tenu à Genève en février 1995 sur « Femmes, villes et environnement », c'est un honneur pour moi d'y revenir, dix ans après, pour dire ce que j'en ai tiré comme enseignements et quel profit en a tiré mon pays. Pour tout cela, nous voudrions rendre grâce à la Commission suisse pour l'UNESCO.

2 Ma pensée aujourd'hui va à Yvonne Preiswerk qui a guidé généreusement mes premiers pas et à ma sœur Mariam Karembega qui s'occupait de mes enfants, en ce moment elles nous regardent sans doute du haut des cieux.

3 Ma reconnaissance à François Hainard qui m'a poussée et encouragée en jouant son rôle de professeur et de responsable averti.

4 Mes amitiés à Christine Verschuur qui n'a jamais douté de ma volonté d'être à la hauteur du réseau.

5 Mes félicitations à Germán Solinís qui inlassablement était aux cotés de l'équipe pour la faire bénéficier de son savoir et de son expérience ; 
6 Mes remerciements à tous les membres du réseau, aux hommes et aux femmes du terrain de recherche-action du Burkina Faso dont la collaboration m'a été très précieuse et me motive à continuer dans la recherche-action.

7 Mes sentiments profonds à mon mari et à mes enfants que j'abandonne souvent pour la cause de la femme.

8 Mes remerciements à l'UNESCO et à la DDC pour la confiance qu'ils ont placée dans le réseau et pour leurs appuis financiers.

9 Mes vœux de succès à l'IUED qui forme des chercheurs et qui permet d'en découvrir au travers de ses colloques.

\section{Introduction}

10 Notre exposé s'articule autour de trois grands points essentiels. Il ne s'agit pas de donner la méthodologie et les résultats de notre recherche-action qui sont déjà consignés dans plusieurs documents, mais de partager ce qui nous reste et ce qu'on peut en faire après tant d'années de travail. Nous sommes persuadés que les hommes et les femmes du terrain, et les membres de l'équipe, ayant pris part à cette rechercheaction, sont tous fiers d'avoir fait parti du réseau MOST-UNESCO Suisse. Ce réseau a permis de faire connaître une catégorie de femmes burkinabé qui travaillent pour leur propre développement, celui de leur famille et de leur communauté, partant au développement de leur pays.

11 Les différents points s'intitulent comme suit:

- Nos vécus sur le terrain et avec l'équipe de la recherche-action;

- Notre conviction sur les résultats obtenus ;

- La capitalisation des acquis de la recherche-action. 


\section{Nos vécus sur le terrain et avec l'équipe}

\section{Le terrain de la recherche-action}

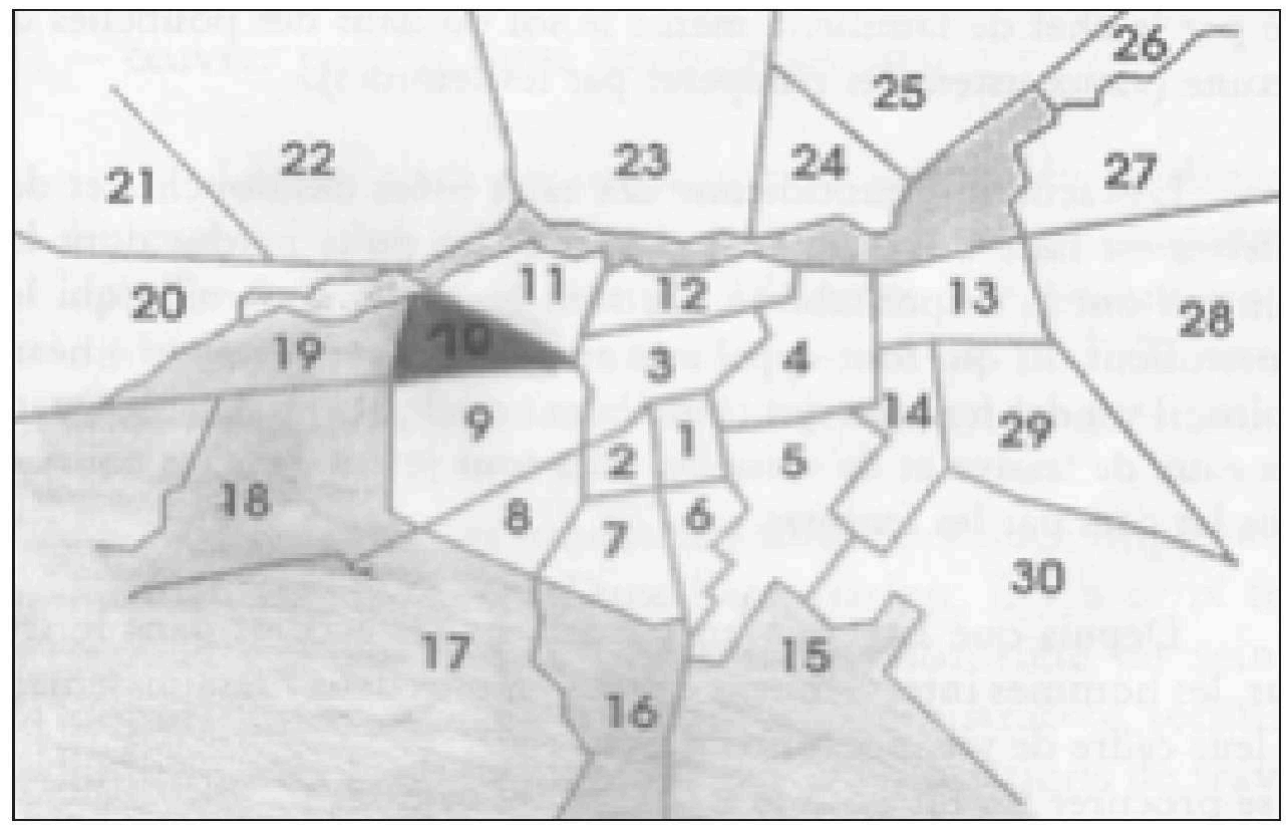

DU SECTEUR 10 (gRIS FONCÉ) AUX SECTEURS 15, 16, 17, 18, 19 ET OUAgA 2000 (gRIS CLAIR) AVEC L'AVÈNEMENT DES GROUPEMENTS D'INTÉRÊTS ÉCONOMIQUES (GIE)

12 Le terrain de la recherche-action du Burkina Faso aurait été pratiquement le même si le "schéma directeur de l'assainissement de la ville de Ouagadougou », dans le cadre du $3^{\mathrm{e}}$ Projet urbain financé par la Banque mondiale, ne lui avait pas donné une autre tournure. En effet, après la première phase au cours de laquelle l'association Lagem Yam, dirigée par des femmes, fut le centre de notre recherche, nous avons entrepris de continuer sur la même lancée avec la coordination des coopératives et des associations pour l'assainissement et la valorisation des déchets (CAVAD) qui est une organisation plus grande, mais travaillant dans le même esprit que Lagem Yam. Les femmes, particulièrement visibles dans ces mouvements associatifs, ayant été contraintes de s'organiser en Groupements d'intérêts économiques (GIE), notre terrain a donc évolué vers cette nouvelle forme et s'est élargi aux secteurs 15, 16, 17, 18, 19 et Ouaga 2000 de la commune de Ouagadougou.

Malheureusement ou heureusement, les associations devaient-elles quitter leur cadre social pour un domaine purement économique ? C'est là toutes les réalités du terrain face à notre recherche-action. Dans tous les cas il n'y avait pas de raison que l'équipe change de terrain. Toutefois, inutile de dire que si la problématique de notre recherche-action demeurait toujours, les hypothèses quant à elles, étaient devenues difficiles à formuler. La recherche-action a pu continuer sur le même terrain, grâce à un certain nombre d'activités ayant permis de la circonscrire et de la recentrer par rapport au renforcement de la capacité de gestion du processus de développement et de l'instinct de survie non des organisations, mais plutôt des femmes qui constituent plus de $80 \%$ des membres actifs de notre terrain. Jouer le jeu de la complicité en poussant les femmes à avoir confiance en elles-mêmes et en ne se laissant pas faire au 
niveau de la municipalité a été alors la force de l'équipe dans la continuation de sa recherche-action.

Aider les femmes à faire front avec d'autres acteurs et actrices, à renforcer leur détermination et à développer davantage leur pouvoir de négociation en direction des autorités politiques malgré la pression des bailleurs de fonds n'est pas chose aisée. En effet, il s'agit là de toute action obligeant non seulement l'implication des femmes dans les prises de décision mais également la reconnaissance et le respect de leurs potentialités et de leurs acquis.

\section{L'équipe de la recherche-action}

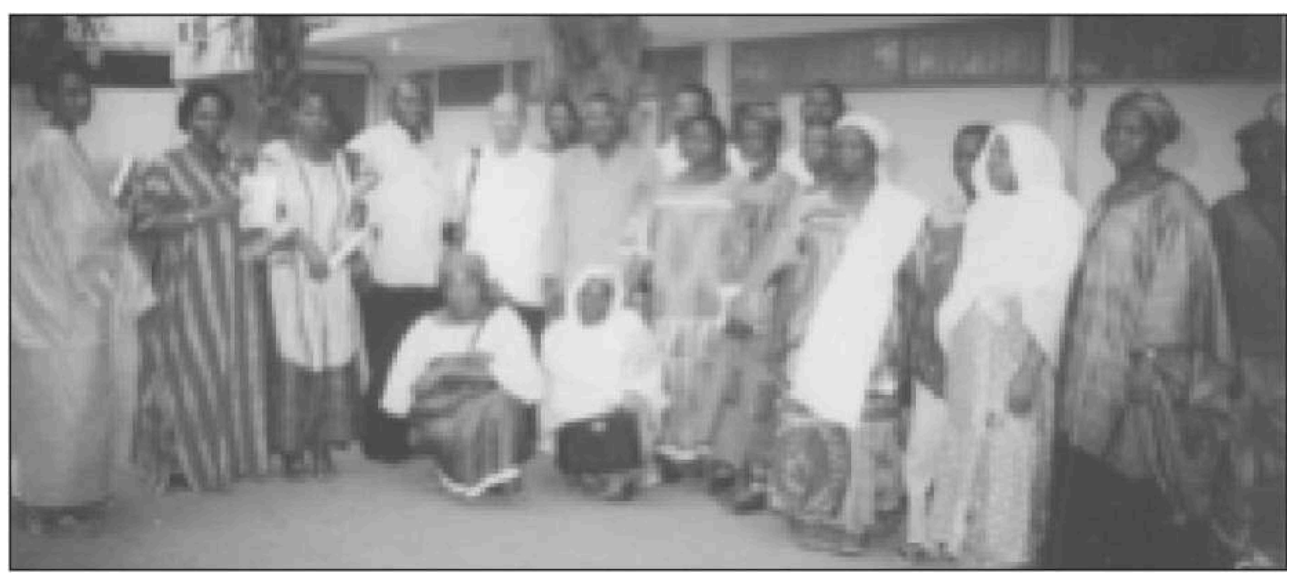

EQUiPe ET MEMBRES de LA CAVAd QUI Ne TARDERONT PAS À SE SUBdiVISER EN deUX GIE

L'équipe de la recherche-action n'était pas composée de chercheurs professionnels mais d'agents de développement qui sont des travailleurs des services publics ou du secteur privé. Si donc, par moments, l'équipe a connu une certaine lenteur dans son rythme de travail et si également certaines personnes ont dû être remplacées, cela n'était pas lié à la recherche proprement dite. La recherche d'une même compréhension de la problématique et de la méthode de travail sur la base de la capitalisation des connaissances individuelles et de ce qu'est une recherche-action a permis aux membres de se sentir concernés et d'apporter chacun sa contribution. L'expérience de la recherche-action a été parfois vécue difficilement mais, à mon niveau il y a eu du plaisir, voire de la passion. C'est dire que la capacité de discernement, le respect du travail et des engagements, la conviction d'œuvrer pour une cause juste pour les femmes m'ont animée et guidée tout au long de la rechercheaction durant les sept années.

L'équipe de recherche ne peut prétendre être à la base de l'évolution du positionnement de l'association Lagem Yam, du GIE Clean Environment et du GIE pour la «Salubrité et le développement social »; néanmoins, je reste persuadée qu'elle a contribué, si peu soit-il, à éveiller les consciences et à donner des idées aux femmes pour leur survie et leur positionnement au sein des organisations locales dépendant des communes, de l'Etat et des institutions internationales. Je crois que cela a été possible parce que l'équipe a eu pour souci d'apporter un plus aux femmes de son terrain, en les aidant à découvrir la dynamique sociale de leur cadre de vie, de leur communauté et de leur commune. Nous disons que c'est d'ailleurs cette approche qui a aidé l'équipe à 
obtenir des résultats qu'elle a pu consigner dans les documents produits par le réseau et dont l'expérience sera partagée avec d'autres personnes, d'autres pays.

Tout cela me montre les réalités et les difficultés d'une recherche-action puisque partie des femmes maîtresses de leur association et du secteur 10 de la commune de Ouagadougou, l'équipe a vu son champ s'étendre à d'autres types d'organisations où les femmes doivent faire face aux hommes et mener leurs activités dans des secteurs inconnus auparavant par elles.

\section{Ma conviction sur les résultats obtenus}

Comprendre les blocages et rechercher des solutions dans la gestion de l'environnement, en partenariat avec d'autres acteurs tels que les services municipaux, les Ministères de l'environnement, de la promotion de la femme, ainsi que les entreprises privées nous a paru une recherche-action intéressante. C'était à notre avis permettre aux femmes, cette catégorie sociale vulnérable, de s'affirmer et d'avoir plus d'espace. En outre c'est rendre justice aux femmes qui, traditionnellement et même dans la vie moderne, sont les premières à être concernées par l'assainissement du cadre de vie. L'empowerment des femmes par leur responsabilisation à travers les politiques publiques et gouvernementales dans le domaine de l'assainissement est visible, dans nos villes, même si elle n'est pas définitivement acquise.

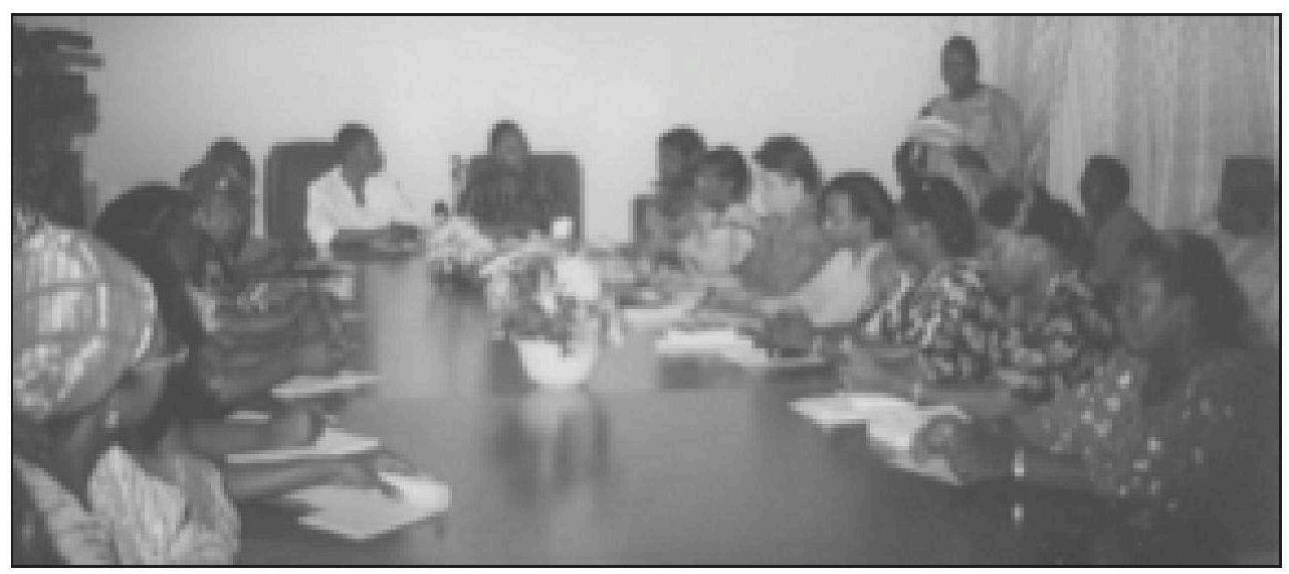

IMMORTALISATION D'UN TRAVAIL : PRÉSENTATION DE LA BROCHURE NATIONALE SOUS LA PRÉSIDENCE DE LA MINISTRE DE LA PROMOTION DE LA FEMME ASSISTÉE DE SON HOMOLOgUE DES DROITS HUMAINS

Nous osons croire que le travail de l'équipe au cours des deux phases de notre recherche-action a permis quelque peu aux associations de comprendre la problématique genre au sein de leurs organisations, de la commune et de la politique de l'assainissement. N'a-t-il pas contribué à susciter en elles l'autoanalyse de leur bilan d'activités et de leur capacité face à la situation que leur imposaient la municipalité et ses partenaires? La détermination des femmes de notre terrain à lutter pour se maintenir dans le système de gestion des déchets apparaît comme un exploit dans leur passage en GIE. Ces femmes ne nous disaient-elles pas qu'elles sont prêtes à se battre pour recouvrer leurs droits? Ces réflexions nous réconfortaient face aux difficultés de vision à long terme de l'intérêt d'une recherche-action par les femmes et au vu de leur sollicitation constante d'appuis matériels et financiers à cause de leur pauvreté face aux hommes et aux entreprises. 
20 L'équipe de recherche-action du Burkina Faso a bien sûr aidé les femmes et les hommes à mieux aborder, dans leur travail quotidien, la relation de genre qui constitue une ouverture pour des changements réels et durables au sein d'une communauté. Mais qu'avons-nous mené comme action répondant à leurs besoins immédiats pour les aider dans leur détermination et leur évolution vers l'empowerment des femmes? C'est pour dire que dans la recherche-action, il faut distinguer souvent l'action de la recherche, car les actions et la dynamique sociale du terrain orientent obligatoirement les hypothèses de recherche. Dans tous les cas, je ressens de la satisfaction pour être restée sur le même terrain et avoir assisté à l'évolution de l'association Lagem Yam. Laquelle évolution laisse percevoir l'atteinte incontestable des objectifs de la recherche-action qui consistait en la mise en évidence des potentialités des associations dont la majorité des membres sont des femmes. Je pense que pour ce qui est de notre terrain, l'empowerment des femmes dans un pays africain comme le Burkina Faso consiste en ce simple constat.

21 C'est pourquoi nous pensons que la politique de décentralisation, menée dans le cadre du processus de développement durable, pourrait activer ou renforcer l'empowerment des femmes. Le rapport inégal entre les hommes et les femmes dans la répartition des tâches et le partage du pouvoir est à reconsidérer dans cette dynamique sociale. Il faut travailler dans le sens d'amener les femmes à acquérir des connaissances qui les mettent à la hauteur de leurs tâches et de leur pouvoir. Car tout au long de la recherche-action deux sentiments importants nous ont animés :

- celui des chercheurs qui accordent davantage de crédit à la maturité des femmes, afin qu'elles aillent au-delà des réalités quotidiennes dans lesquelles elles baignent ;

- celui des femmes du terrain qui croient que seuls les appuis concrets (matériels ou financiers) constituent une condition sine qua non pour leur réussite face à un monde de combativité et d'inégalité.

Cela est tout à fait normal que la recherche-action soit vécue différemment par les chercheurs et le terrain. Pourtant la solidarité, l'engagement et le défi à relever se sont installés assez rapidement en eux, car nous avions tous envie de réussir et de partager ce que nous faisions, convaincus de son utilité si lointaine soit-elle. Ces visions ne rejoignent-elles pas la définition de Yves Vaillancourt qui dit que la recherche-action est « une pratique de recherche désireuse de s'inscrire à la manière d'un apport ou d'un rapport pour l'action collective plus ou moins organisée ».

Au-delà des réalités qui englobent les faits de notre terrain et les résultats de nos analyses, nous nous sommes souvent demandé s'il n'y a pas de limites pour la progression de l'empowerment des femmes dans le cadre des transformations des rapports hommes-femmes. C'est pourquoi dans nos propos, bien des questions demeurent. Nous sommes convaincues que pour réussir l'empowerment des femmes, il va falloir que les femmes s'intègrent dans un ordre politique dont elles seront seules à choisir leur mode d'expression en conciliant leurs responsabilités et rôles familiaux et sociaux à leurs besoins stratégiques. Personnellement, je suis vraiment convaincue que j'ai envisagé, puis conçu un projet dans ce sens en faveur des femmes alphabétisées et de leurs leaders. 


\section{La capitalisation des acquis}

Les sept années de recherche-action ont été une source d'inspiration pour moi dans la mesure où elles m'ont persuadée de la compétence de la femme, surtout lorsqu'elle évolue dans un groupe. Vous comprendrez alors pourquoi j'ai suivi les recommandations de François Hainard et de Christine Verschuur pour la poursuite de cette recherche-action toujours dans le cadre de l'empowerment des femmes.

La recherche-action entreprise dans le cadre de la Commission suisse MOST-UNESCO et de la DDC était très pertinente. Je pense avoir bénéficié d'une certaine maturité pour affronter de face le problème du pouvoir en envisageant une recherche-action dans le domaine politique. Tout ce qui touche la politique étant soumis à une grande prudence dans nos pays, il m'a fallu du temps de réflexion, d'expériences auprès des partis politiques et des femmes engagées afin de décider de tenter une nouvelle rechercheaction, et me lancer dans l'éveil de conscience politique et de militantisme responsable des femmes. Le projet est prévu pour une durée de cinq ans en fonction des résultats des élections successives des différents pouvoirs politiques. Le choix du public cible m'a conduite vers les femmes alphabétisées des associations et des groupements.

L'acceptation du financement de notre projet par le Bureau de la Coopération suisse au développement au Burkina Faso et la mise à disposition des associations par le Programme Alpha/Formations Techniques de la coopération suisse pour une durée de dix-huit mois permettent de réaliser mon idée. J'espère que les résultats les amèneront à poursuivre le partenariat.

Cela m'apparaissant comme un défit à relever, cette capitalisation se veut, pour ma part, une recherche-action à l'instar de ce que j'ai vécu dans le cadre du projet MOSTUNESCO Suisse. J'ai intitulé simplement le document que j'ai élaboré comme suit :

\section{"Projet de formation politique pour un empowerment des femmes alphabétisées et de leurs leaders »}

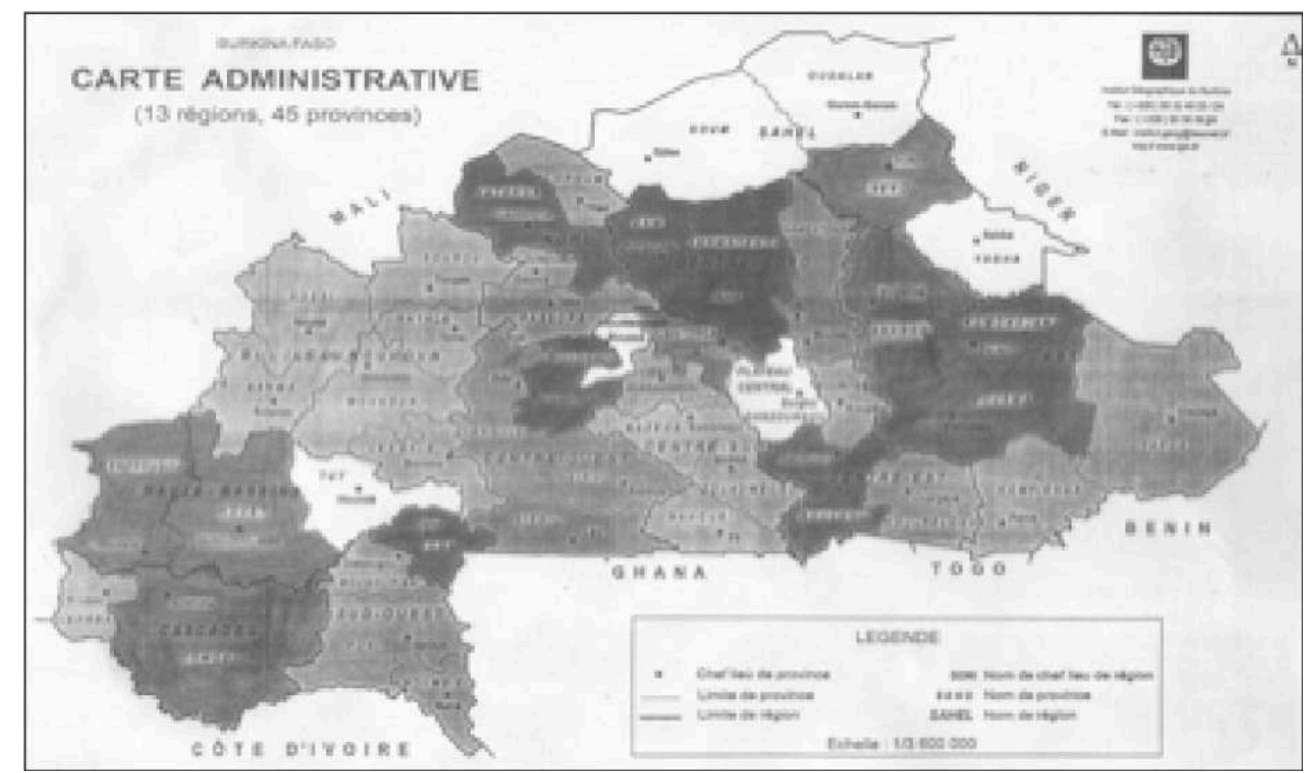

PROVINCES TOUCHÉES EN gRIS FONCÉ 


\section{Quelques résultats enregistrés}

- Villes ciblées et touchées

Cinq villes ciblées : Koudougou, Fada N’Gourma, Ouahigouya, Kaya et Bobo Dioulasso. Quatorze provinces environ.

- Nombre de personnes formées en politique

Cent quatre personnes dont soixante-dix-huit femmes alphabétisées. Soit: Quatrevingt-seize (96) femmes. Huit (8) hommes.

- Sept modules conçus

- la démocratie: sa définition et son historique, les différentes institutions politiques au Burkina Faso, comment accéder à chacune d'elles ;

- la citoyenneté : l'intérêt que la Constitution accorde à l'homme et à la femme au sein des différents partis politiques ;

- la politique : la définition du concept, les acteurs politiques, les activités des partis politiques et des militants et militantes;

- genre et politique, genre et développement: concepts que les femmes ont appréciés parce qu'elles ont perçu les différents pouvoirs en termes de connaissances et d'efficacité ;

- le militantisme, l'engagement et la responsabilité politique: l'adhésion à un parti politique, la nécessité de militer dans un parti et d'occuper des postes à responsabilités ;

- conciliation entre la vie familiale et politique : ce thème interpelle davantage les femmes, leurs responsabilités et leurs rôles, loin d'être occultés, doivent être pris en compte pour réussir la conciliation;

- poids et potentialités des femmes alphabétisées : à partir de leur position de leadership et de la capitalisation de l'alphabétisation, les femmes doivent développer davantage leurs savoirs et leurs savoir-faire.

- Soutien des autorités régionales et locales La liste des personnalités ayant présidé les sessions de formations est la suivante :

- Koudougou : le secrétaire général de la province ;

- Fada N'Gourma : la reine du Gulma ;

- Ouahigouya : la députée Cécile BELOUM ;

- Kaya : le haut-commissaire représentant Madame le Gouverneur ;

- Bobo Dioulasso : la première conseillère du maire de la commune.

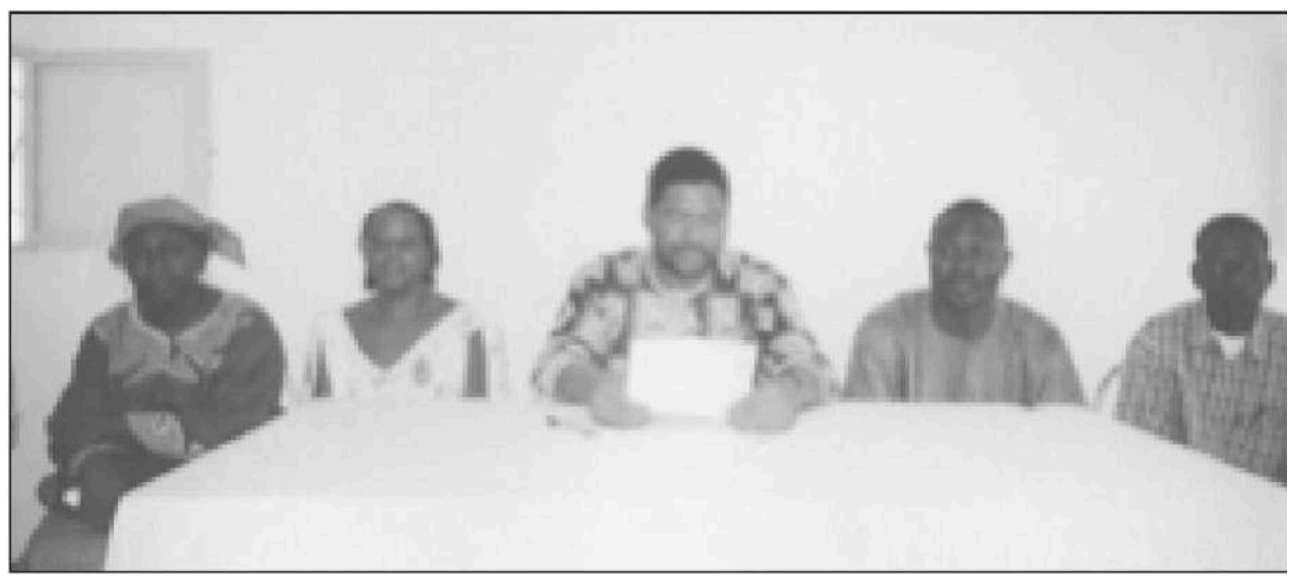

CLÔTURE de LA SESSION DE FORMATION DE KOUDOUgOU PAR LE SECRÉTAIRE GÉNÉRAL DE LA PROVINCE DU BULKIEMDÉ 
- Intérêt de plusieurs journalistes de la presse écrite et de la radio

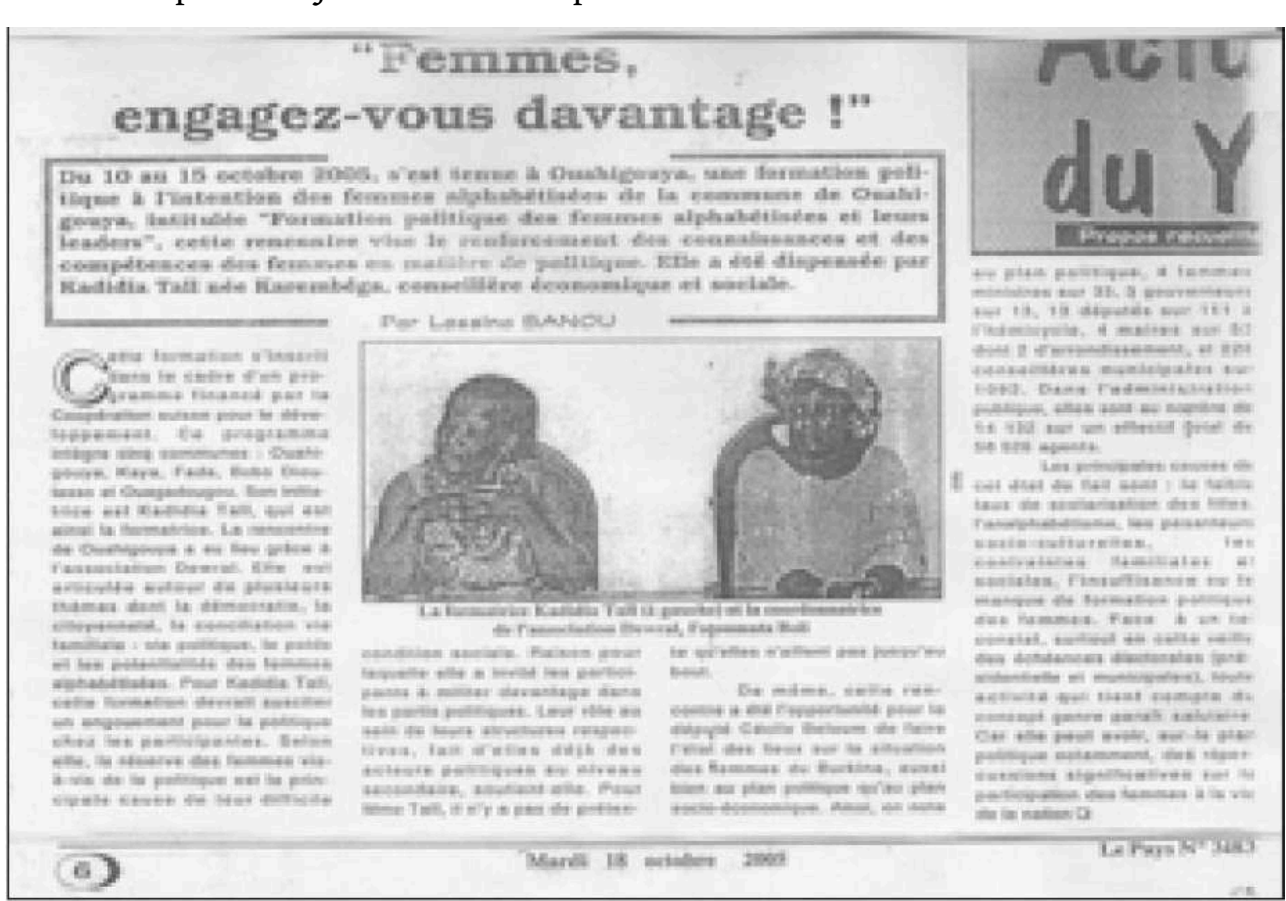

REPORTAgE DU JOURNAL LE PAYS LORS DE LA FORMATION À OUAHIgOUYA n'est pas l'affaire des seuls hommes et femmes qui sont allés à l'école ou qui savent parler le français. Nous femmes alphabétisées, intéressons-nous à la politique, militons si le cœur nous en dit, battons-nous pour mériter et occuper des postes de responsabilités pour nous faire valoir.

- Par rapport au militantisme et à la conciliation entre vie politique et vie familiale facile et difficile. Les activités politiques sont importantes mais ne doivent pas remettre 
en cause la vie familiale car la famille est la cellule de base de la société. Nous devons veiller à concilier vie familiale et politique.

- Chanson écrite à l'occasion de la formation par une femme de Ouahigouya

- Madame TALL, vous vous êtes engagée à éclairer les femmes en matière de politique. Pour cela nous vous disons merci.

- Madame NIGNAN, vous vous êtes engagée à éclairer les femmes en matière de politique. Pour cela nous vous disons merci.

- Madame BOLY, vous vous êtes engagée à éclairer les femmes en matière de politique. Pour cela nous vous disons merci.

- Coopération suisse, tu t'es engagée à éclairer les femmes en matière de politique. Pour cela nous te disons merci.

Si les femmes sont éclairées en politique :

- les familles voteront bien;

- les localités voteront bien;

- les femmes burkinabé auront accès aux postes à responsabilités.

Pour cela nous vous disons merci.

- Les partis politiques vous disent merci.

- Les associations vous disent merci.

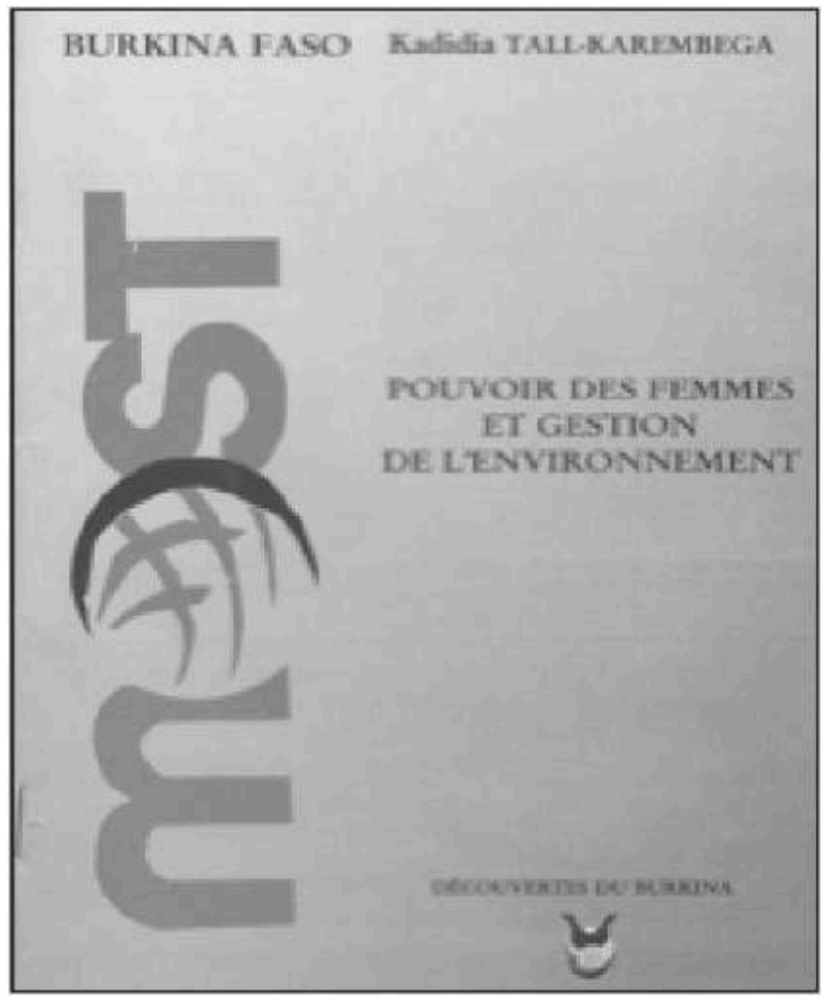

FIN D'UNE RECHERCHE-ACTION : 1997-2004 


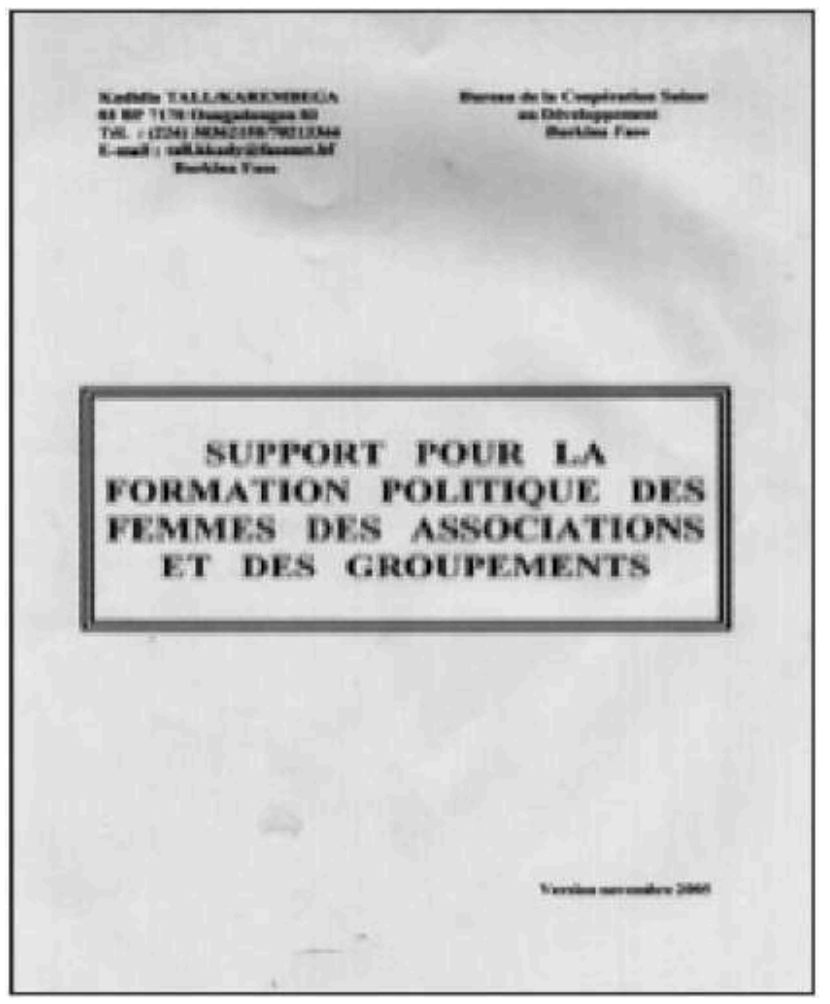

DÉBUT D'UNE RECHERCHE-ACTION : 2005- ?

\section{RÉSUMÉS}

Cet article présente la réalité et les difficultés du projet de rechercheaction mené à Ouagadougou sur le pouvoir des femmes en matière de gestion de l'environnement. Il analyse ensuite les résultats de ce projet, lesquels montrent combien il est nécessaire maintenant de soutenir l'empowerment des femmes dans le domaine plus proprement politique.

This article presents the reality and the difficulties of the researchaction project that was carried out in Ouagadougou on women's power in environment management. Then it analyses what came out of this project, the results showing that what needs to be done now is to support women's empowerment in the more specific political field.

Este artículo presenta la realidad de los hechos y las dificultades del proyecto de investigaciónacción realizado en Uagadugú sobre el poder de las mujeres en materia de gestión del medio ambiente. Luego se analizan los resultados de este proyecto, los cuales muestran cuán necesario es actualmente apoyar el empowerment de las mujeres, en la esfera más propiamente política. 


\section{AUTEUR}

\section{KADIDIA TALL}

Conseillère en économie sociale et familiale. Elle travaille pour la promotion des femmes par des formations, des études, des programmes de suivi-appui-conseil dans le domaine social et politique. Depuis 1997, elle est responsable du projet MOST-UNESCO « Genre, ville et environnement » au Burkina Faso. 


\title{
Organisations associatives, espace public, accès au débat public et à la prise de décision par les femmes à Santhiaba, ville de Pikine, Sénégal
}

\author{
Mohamadou Abdoul
}

\section{NOTE DE L'AUTEUR}

Cette communication est une version résumée, revue et augmentée du texte " transformations urbaines et rapports de pouvoir entre hommes et femmes : l'exemple de Santhiaba, Thiaroye sur mer " paru dans François Hainard et Christine Vershuur, 2005, Mouvements de quartiers et environnements urbains, la prise de pouvoir des femmes dans les pays du Sud et de l'Est, Dakar/Paris, ENDA Diapol/KARTHALA, $363 \mathrm{p}$.

\section{Introduction}

1 Le thème du colloque Genre de cette année, Des brèches dans la ville, organisations urbaines, environnements et transformations des rapports de genre, ne pouvait être plus approprié pour le cas sénégalais du réseau international de recherche MOST-UNESCO sur les relations entre environnements urbains et rapports sociaux hommes-femmes.

2 Une recherche-action de plusieurs années dans la commune d'arrondissement de Thiaroye-sur-mer située dans la ville de Pikine, au Sénégal, en interaction avec différents acteurs dans une perspective de genre, a contribué à ouvrir des brèches dans le sens de l'accès des femmes aux décisions dans l'espace public local à travers notamment la génération de revenus et la privatisation des services publics (assainissement, santé, etc.). 


\section{Les sites de la recherche-action}

La recherche-action a été conduite sur plusieurs sites :

- un site de transformation et de commercialisation des produits de la pêche dénommé Pencum Sénégal. Ce site est un espace féminin ; les femmes qui en sont les dépositaires et qui le gèrent interagissent entre elles et avec les hommes (responsables du service déconcentré de l'Etat, en l'occurrence le service départemental des pêches; les mareyeurs/fournisseurs des produits halieutiques pour les femmes, les employés des femmes, les décideurs, etc.) dans des rapports de négociation et de conflits selon les circonstances, les enjeux et les intérêts du moment. Cet espace public local focalise des rapports de pouvoirs entre les femmes et entre celles-ci et les hommes avec qui elles ont des rapports professionnels.

- un projet de précollecte des ordures ménagères géré par un Comité de salubrité des femmes de Santhiaba. Ce projet né de la dynamique de la recherche-action et appuyé par la coordination du réseau, fait l'hypothèse que les femmes sont capables de s'investir dans l'espace public local et de fournir à la communauté un service public digne de ce nom. En conséquence, contrairement aux idées dominantes, les femmes peuvent faire montre d'un activisme effectif et d'une participation aux processus de prises de décisions. Ce projet a démontré la force de la résistance des hommes à la prise d'une position forte par les femmes dans l'espace public local: les charretiers vivant très mal l'autorité des femmes, le chef de village demandant la gestion du projet et le Comité de développement intégré de Santhiaba (CODIS) dominé par les jeunes qui se voyait superviseur du projet des femmes. Mais également la forte expression des rapports de pouvoir et de prééminence entre les femmes. A quoi s'ajoute la mauvaise volonté de la communauté à contribuer financièrement au service rendu. Tous ces facteurs, en plus de l'absence d'un gain financier par les femmes du Comité de salubrité, ont beaucoup pesé sur le projet, au point de conduire à son échec.

- un projet de mise en place d'une mutuelle de santé qui connaît une forte divergence entre deux structures représentatives de la commune d'arrondissement de Thiaroye-sur-mer: l'Union locale des groupement d'intérêt économique de pêche qui est une organisation mixte dominée par les hommes et le Réseau Lebougui, une structure fédérative constituée de plusieurs associations féminines menant des activités génératrices de revenus. Ces deux organisations sont dans des perspectives de développement et de diversification de leurs activités. Aussi ont-elles décidé de mettre chacune en place une mutuelle de santé au bénéfice de toute la communauté de Thiaroyesur-mer. De toute évidence, ce projet renforce la place, la position et le rôle de son initiateur dans l'espace public local notamment en terme de participation à la prise de décisions. L'enjeu était ainsi tel que la médiation de l'équipe de recherche action n'a pas pu infléchir les positions dans le sens d'une collaboration des différentes structures autour d'un seul et même projet de mutuelle de santé.

- un processus de redynamisation du Réseau Lebougui qui regroupe plusieurs associations de femmes travaillant dans le secteur de la transformation des produits locaux et le commerce. Un appui essentiellement orienté vers le renforcement des capacités organisationnelles a été fourni dans le cadre du projet. Mais force est de reconnaître que les ressources financières constituent une contrainte majeure au développement des activités de génération de revenus pour les membres de ce réseau. La participation à la satisfaction des besoins du ménage et à leurs propres besoins ne permet pas aux femmes de se constituer un capital conséquent propre à leur assurer une bonne assise financière permettant le développement de leur affaire et une mobilité sociale, synonymes de position plus forte dans les processus de prise de décisions tant dans la sphère privée que publique. 
Dans la conduite de la recherche, l'équipe a autant que faire se peut essayé de favoriser l'empowerment des femmes dans la perspective de leur participation dans le débat public et à la prise de décisions. Le diagnostic de leurs manières de participer à ces débats et prises de décisions, notamment leur influence sur les élus et autres décideurs locaux (pouvoirs traditionnels, chefs de quartier, etc.), leur implication effective et directe ainsi que leurs stratégies de plaidoyer et de lobbying ont également retenu notre attention.

5 Cette posture méthodologique caractérisée par un ancrage fort sur le terrain et une complicité avec les différentes familles d'acteurs a permis, grâce à l'information, la conscientisation et l'appui-conseil, de renforcer la confiance mutuelle qui a joué un rôle non négligeable dans les résultats obtenus. Cette démarche volontariste et militante avait comme soubassement l'exploration et l'encouragement de la possibilité d'une nouvelle forme de gouvernance urbaine dans laquelle les femmes sont pleinement impliquées dans un contexte de mutations urbaines et socioculturelles importantes.

\section{Vers un espace public local plus ouvert aux femmes?}

6 L'urbanisation accélérée, la croissance démographique, la crise économique, le chômage, les réformes économiques, administratives et territoriales et les difficultés quotidiennes ont induit des bouleversements notables dans l'environnement urbain. Ces mutations ont cours dans un contexte dans lequel des jeunes, des hommes et des femmes s'emploient à faire démarrer des activités génératrices de revenus, à développer des initiatives et des mobilisations collectives, des structures et des réseaux divers pour assurer leur survie et leur reproduction sociale mais également pour agir sur leur cadre de vie. Aussi, prennentils d'assaut l'espace public local et nouent-ils des relations selon les opportunités qui s'offrent à eux avec d'autres « partenaires » situés à des échelles nationales, régionales et/ou internationales.

7 Cet implication/opportunisme tous azimuts leur donne un sentiment de sécurité (relative certes) et une certaine aptitude à (re)produire journellement un cadre vivable dont les soubassements sont les régulations au quotidien et des créativités et inventions au jour le jour. Ces dynamiques s'observent à travers les nombreux réseaux sociaux qui se construisent et se renforcent chaque jour. Les initiatives mises en branle selon des «lignes de fuite» et "cercles de résonance» sont d'ordre économique (groupement d'intérêt économique), financier (tontines, caisse d'épargne et de crédit), sportif et culturel (association sportive et culturelle), environnemental et d'amélioration du cadre de vie (associations de développement de quartier).

Il découle de ces processus des enjeux économiques et politiques nouveaux qui, à leur tour, s'expriment au travers des contradictions, des (re)négociations des rôles, statuts et fonctions qui ont pour terrain d'expression l'espace public local (Abdoul et Dahou, 2002). En celui-ci coexistent différents types de régulation politique et de légitimités où se négocient les accords, (re)distributions de pouvoir entre autorités étatiques, traditionnelles et les acteurs du mouvement associatif et/ou professionnel. Ces jeux d'acteurs structurent les (re)configurations des espaces, des liens sociaux et des réseaux de relations qui, en dernière instance, régulent le procès du politique, de l'économique et de l'appropriation et des usages de l'espace. 
Cette reconfiguration de l'espace public local subodore la prise en compte d'une diversité d'acteurs et d'une variété d'initiatives et d'actions au sein des flux qui traversent et animent le corps urbain. Les organes sociaux, institutionnels et les corporations d'intérêts complémentaires ou contradictoires forment la trame de ces flux selon des constructions parfois réfléchies, organisées et négociées mais aussi souvent aléatoires et fortuites. C'est ainsi que des stratégies combinant des postures diverses et surfant sur des opportunités variées sont développées. Ce complexe de relations, cette «micro-politique ", placés dans le temps long de l'histoire, préfigurent des changements notables dans l'action politique au niveau local.

Mais l'action « urbanisante» des structures associatives et professionnelles et des organisations d'appui est également notable dans les fonctions de gestion des infrastructures et d'allocation des services. Ces fonctions sont désormais partagées - ou laissées par la municipalité - à de nouveaux acteurs qui sont de plus en plus présents dans l'espace public. A côté d'un secteur privé qui prend de l'envergure dans l'espace public local, les associations de développement participent à la mise en place et à la gestion des infrastructures d'assainissement et des services sociaux (éducation, santé). Parmi ceux-ci les organisations féminines. Celles-ci, sans s'afficher au grand jour, influent sur les processus de décision. Ces gestionnaires participent activement au remodelage de l'espace public et à la construction de nouvelles formes de gouvernementalité.

11 Ce phénomène pose la question du jeu d'acteurs (quels acteurs, complexité des interrelations, et diversité des types d'interactions ?). Le développement des initiatives associatives et professionnelles et leur féminisation de plus en plus poussée d'une part, et la promotion d'une gestion publique de proximité d'autre part, envisagés dans leurs interrelations, permettent de cerner avec précision les rapports de pouvoirs dans le cadre de la mission de développement local.

12 En effet, la rencontre dans l'espace public local d'une variété d'acteurs ouvre des perspectives de participation au débat et à la décision politiques et à la confrontation/ coexistence d'agendas et de programmes et projets divers dans cet espace. Ce faisant, les différents acteurs sont dans des rapports de coopération et de conflit selon les enjeux du moment et les intérêts du groupe. C'est dans ce sens qu'il est opportun d'envisager les rapports sociaux hommes-femmes dans la sphère publique : la tension entre coopération et conflit en sont les deux variables analytiques.

\section{Hommes et femmes dans l'environnement urbain}

13 La phase I de la recherche de l'équipe sénégalaise du réseau MOST-UNESCO avait démontré que le respect de l'autorité masculine dans les rapports conjugaux est une réalité à Santhiaba et dans la commune d'arrondissement de Thiaroye-sur-mer en dépit des mutations intervenues dans le paysage urbain et dans les rapports de genre. Cet état de fait est très fortement sous-tendu par les référents socioculturels et l'invocation de la tradition et de la religion qui tempèrent le fait que l'homme n'assure plus seul la subsistance du ménage. Cette crise de la dette familiale, fondement matériel de la domination masculine dans le foyer, se manifeste par une irruption des femmes dans la sphère publique, notamment à travers les activités génératrices de revenus. 
14 La crise de la dette familiale entraîne une crise des rôles masculins encore assez mal perçue par la communauté. Cette dernière ouvre aux femmes des brèches dans la sphère publique où elles participent à la gestion de l'environnement et à l'amélioration du cadre de vie.

15 La phase II de ce même projet survient dans un contexte politique nouveau. En effet, depuis mars 2001, le Sénégal vit sous un régime politique dit de l'alternance. Ce qui en soi est historique : le parti socialiste qui a dirigé le pays pendant quarante ans a été battu aux élections présidentielles par une coalition de partis d'opposition. Par ailleurs, des élections locales ont été organisées en mai 2002. Le nouveau régime a gagné la quasi-totalité des sièges dans les collectivités locales.

16 Tout au long du processus de recherche-action, il a été loisible d'observer les rapports sociaux hommes-femmes dans l'espace public relativement à la prise de décisions. Les lieux d'observation ont amplement montré la très faible implication et dans certains cas l'absence des femmes dans les organes de décisions des structures locales. De par leur présence dans l'espace public, elles sont néanmoins consultées notamment à certaines occasions telles que les visites entre structures et lors des ateliers, fora et autres rencontres à caractère sociale (baptêmes, mariages, etc.). En ces occasions, la coopération entre les hommes et les femmes prend la forme d'une relation d'échange, de complémentarité et de négociation dans les dynamiques de la gestion et de la régulation urbaines, c'est-à-dire dans les débats publics, la prise de décisions, l'élaboration, la mise en en œuvre et le suivi de projets, dans la production des biens et des services, et dans l'organisation de la vie collective dans l'espace public.

Il apparaît, compte tenu des contraintes organisationnelles, des difficultés à accéder à l'information stratégique et des modes de structuration des différents organes, que les atouts et les ressources à la disposition des femmes sont très limitée. Par exemple, la prise de parole en public est très rare. Elle est généralement le fait des seules femmes leaders derrière lesquelles les autres font bloc. Elles aimeraient de leur propre aveu apprendre à parler en public et regarder les gens dans les yeux. Le désir de participation à la décision se manifeste à travers les demandes réitérées d'appui à l'organisation et de formations notamment celles qui permettent l'accès direct et le contrôle de l'information. La maîtrise technique des outils de leur action collective et la connaissance des enjeux sont ainsi des ressources très utiles pour leur participation à la décision.

Elles ont conscience de leur représentativité sociale et économique et de la reconnaissance dont elles jouissent en tant qu'acteur important du développement local. Cette position qui renforce leur rôle de protagoniste les pousse à demander que les ONG travaillent directement avec elles sans l'intermédiation des structures techniques étatiques et/ou des associations de développement animées par les jeunes garçons. Dans les discours, et généralement en aparté, transparaissent des critiques des modes de gestion des associations, organisations professionnelles: irrégularité des renouvellements des instances, faible représentation des femmes, opacité de la gestion financière notamment, direction des structures par les mêmes personnes qui adhèrent à plusieurs organisations en même temps, etc.

19 Ce faisant, les règles du jeu de la coopération sont très souvent brouillées et les régulations des rapports interactoriels aussi bien entre les femmes qu'entre celles-ci et les hommes sont, se font, selon les cas de coopération, négociation ou dans un climat de 
blocage ou de conflit généralement latent. Cette situation est souvent surdéterminée par des clivages politiques partisans.

20 La maîtrise des enjeux de la relation sociale par les femmes est une réalité dans les différents lieux d'observation des rapports hommes-femmes. Les manifestations de désaccord avec les décisions, si elles existent, sont cependant rarement exprimées par les femmes de façon explicite et claire y compris au sein de leurs propres structures où le refus de l'autorité de la présidente, par exemple, est le plus souvent tacite.

21 Cette situation complexifie les processus de gestion urbaine et rend difficile la mise en place de larges fédérations d'acteurs qui, si elles sont créées, connaissent au bout de quelques années d'existence le phénomène de scissiparité. Dans ces conditions, l'articulation des différentes initiatives et la mutualisation des moyens et des compétences sont un exercice particulièrement délicat et long à mettre en place.

\section{Conclusion}

22 Même si les tendances à l'approfondissement de la démocratie participative rencontrent encore des goulots d'étranglement, il est évident que la décentralisation telle qu'elle évolue actuellement donne beaucoup de raisons d'espérer.

La mondialisation, les politiques publiques inspirées par la coopération internationale, l'ouverture d'interstices et des opportunités, la diversité des acteurs et la pluralité des légitimités en ces espaces, les balbutiements de la collaboration et de la cogestion du domaine public local sont autant de phénomènes qui élargissent l'éventail des perspectives et qui balisent les champs des possibles.

24 Sans nier que le chemin du développement local est semé d'embûches, il s'agira de parier sur l'avenir en travaillant au renforcement du scénario de la coélaboration des normes et de la cogestion des activités de développement local. Pour y arriver, le pouvoir devra réellement et effectivement être partagé et fondé sur un système de monitoring quasi quotidien de l'action municipale et des enjeux du développement local. 


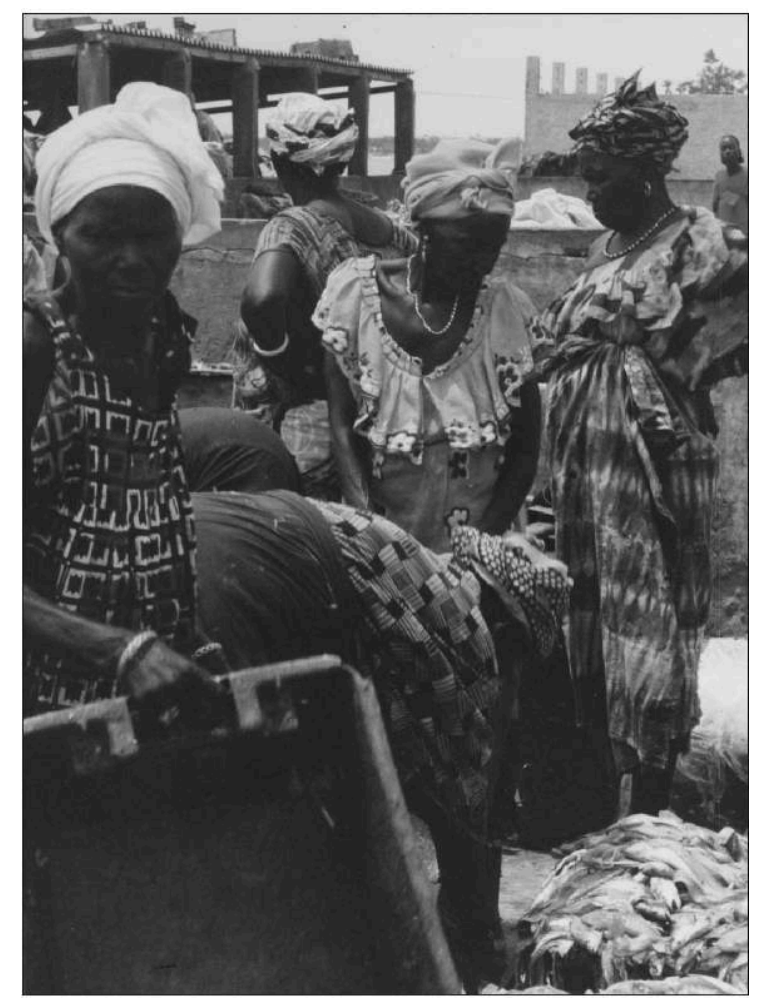

SANTHIABA, SÉNÉgAL.

\section{BIBLIOGRAPHIE}

ABDOUL, Mohamadou, 2005, « Transformations urbaines et rapports de pouvoir entre hommes et femmes : l'exemple de Santhiaba, Thiaroye-sur-mer ", in François Hainard et Christine Verschuur, Mouvements de quartiers et environnements urbains, la prise de pouvoir des femmes dans les pays du Sud et de l'Est, Dakar/Paris, ENDA Diapol/KARTHALA, pp. 275-300.

ABDOUL, Mohamadou, 2001 « Les rapports sociaux hommes-femmes à travers les activités économiques féminines et la gestion du cadre de vie : cas de Santhiaba (Thiaroye-surmer) », in HAINARD, François et VERSCHUUR, Christine, (éd.), 2001, Femmes dans les crises urbaines, Relations de genre et environnements précaires, Karthala-MOST-UNESCO.

\section{RÉSUMÉS}

Au Sénégal, les bouleversements de l'environnement urbain ont entraîné une reconfiguration de l'espace public local où interviennent désormais des acteurs nombreux et nouveaux. Le contexte socio-économique a également favorisé une participation croissante des femmes à la gestion de l'environnement et à l'amélioration du cadre de vie. L'expérience de la recherche-action MOSTUNESCO au Sénégal a montré que l'articulation entre les diverses initiatives et la mutualisation des moyens et des compétences sont des exercices complexes et précaires. 
In Senegal the revolutions in the urban environment have brought about a transformation of the local public space where new and numerous actors now play a role. The socio-economic context as well fostered women's increasing participation in the management of environment and in improving their living environment. The experience of the MOST-UNESCO research action programme in Senegal showed how complex and precarious the links between the various initiatives and the mutualisation of the resources and competences are.

En Senegal, las convulsiones del medio ambiente urbano implicaron una reconfiguración del espacio público local donde intervienen nuevos y numerosos actores. El contexto socioeconómico favoreció igualmente una creciente participación de las mujeres en la gestión del medio ambiente y en la mejora del marco de vida. La experiencia de la investigación-acción MOST-UNESCO en Senegal mostró que la articulación entre las diversas iniciativas y la mutualización de los medios y competencias son ejercicios complejos y precarios.

\section{AUTEUR}

\section{MOHAMADOU ABDOUL}

Docteur en histoire et chercheur de nationalité mauritanienne. Il travaille depuis de nombreuses années à ENDA à Dakar où il occupe actuellement des fonctions de chargé de programmes Enda «Prospectives Dialogues Politiques ». Ses travaux portent sur les questions urbaines:

participation/citoyenneté, cultures populaires urbaines ; les processus politiques en Afrique et l'intégration régionale en Afrique de l'Ouest. Depuis 1997, il est responsable du projet MOSTUNESCO «Genre, ville et environnement » au Sénégal. 
Instrumentalisation des femmes ou nouvelles perspectives? Recherche et politiques publiques 


\title{
Women's Grass-Roots Organisations and Solidarity Networks: A Rediscovered Policy Resource
}

\author{
Maxine Molyneux
}

\section{AUTHOR'S NOTE}

This article is based on a paper commissioned by the Barrow Cadbury Trust as part of the 2005 Global Exchange Forum dedicated to Women's Social Capital and supported by the Foreign Policy Centre.

\section{Introduction: Valuing women's social capital}

1 In recent years the concept of social capital has entered policy debates in fields as diverse as community regeneration, health, migration, education, welfare, and development. Commonly understood, following Putnam, as the social cement generated by associational life and by citizens' networks of trust and solidarity, social capital also appears to have the potential to increase productivity, to provide support against poverty, to create stronger democracies, to help reconstruct war-torn communities, and to enhance mental and physical well-being. In a more general sense it is also hailed as the essential counter to the socially corrosive trends associated with contemporary economic life. By extension it is opposed to the celebration of a selfserving individualism as the natural correlate of market governance. The current interest in social capital reflects a growing awareness that the realm of social life matters not only for individual well-being but because it has implications for government policy and service delivery. By enriching civic and social interaction and engaging in forms of co-operation to achieve common goals, citizens can not only enhance their quality of life but also make policy initiatives more accountable and effective. 
2 Despite the extensive literature on social capital and its increasing visibility in public policy, there is a surprising absence of attention to the role women play in creating and maintaining social life through their own networks and forms of solidarity (Molyneux 2002). Yet across the world, women participate in a wide variety of voluntary and community activities, whether for charities, churches, kin groups, neighbourhoods or clubs. Women frequently have the strongest local and kin ties; they network and engage in reciprocal supportive relations, and they are often among the most active supporters of neighbourhood and participants in local forms of associational life. They are to be found at the heart of voluntary self-help schemes whether in health, education or neighbourhood food and housing programmes, in cultural associations, supporting communities hit by sudden unemployment, running barter groups, childminding circles and safe houses for abused or marginalised women. This range of activities takes place in what some have called the "social economy" understood as those forms of co-operation that citizens engage in without being driven primarily, or even at all, by material interest. The social economy can be important in helping to overcome social exclusion of various kinds, and can at the same time provide safe spaces for women, where trust based relationships can be built, and where skills and experience can be developed.

3 The broader significance of this kind of activity, beyond the contribution it makes to the quality of social life, is that neither states nor markets can provide for all social needs. As a result citizens either choose, or are obliged, to depend on some mix of formal and informal social institutions for their welfare, well-being and security. For those in precarious livelihoods, informal networks and the support they offer may be the only way to ensure that basic needs are met. Research on household livelihoods, social networks, and voluntary institutions has shown that there is a considerable reliance on informal arrangements and organisations that exist independently of, or work with, the state. Women are commonly found in these activities, especially in those associated with caring, whether in the inner cities of the industrialised world or in the developing countries of the global south.

Across the world and in very different socio-economic environments women play a vital role in sustaining low income households, engaging in an informal economy of exchange, involving credit, care-giving, and services. Childminding for neighbours, shopping, cooking and ironing, borrowing and lending, are all essential to household survival on the margins. Women also frequently engage in collective survival strategies. They have set up and managed successful credit unions, canteens, and small business co-operatives. They have also organised around service provision, demanding improvements in waste collection, road maintenance, security and community management. Women are very often engaged in projects designed to improve health, housing and education, sometimes working with NGOs, often self-supporting, and, increasingly today, in collaboration with government anti-poverty initiatives. In times of severe economic hardship women's grass-roots organisations have sprung up to provide low cost food for their neighbourhoods by creating urban gardens to grow food or setting up communal cooking facilities to supplement local needs. In Peru, for example during the economic crisis of the 1980 s some 800,000 collective canteens run entirely by women served more than two million people. Women's efforts have also been essential in conflict and post-conflict situations where by working on common agendas, women have helped to heal deeply divided communities as well as to 
participate in the difficult task of post-conflict reconstruction. Most starkly, and tragically, women are those who are holding whole communities together in HIV/AIDS stricken parts of Africa, taking care of the millions of orphans and the sick, in a situation where more women than men are now falling victim to the pandemic.

In the industrialised countries of the North which enjoy extensive state provision, women's groups play an active role in social life, supporting those who are not adequately served either by the state or by the market. Examples include providing extra childminding support for working mothers, looking after the elderly and disabled, or improving access to training for women who want to return to work. Women's organisations have often come into being in response to urgent needs that government provision does not cover, as in the cases of refuges set up to help women suffering from abuse and centres that provide support and legal advice to survivors of rape. Women's organisations also support vulnerable women who fall outside the safety nets or who suffer from exclusion of various kinds, such as asylum seekers, stateless women and those who live on the margins of the informal economy. In such cases, informal associations can be easier to work with than government agencies. In other words, informal associations can meet needs that are not covered by state provision, but they also have the potential, especially if adequately funded, to provide a more satisfactory alternative to state managed provision.

\section{Women's social capital: common features}

While women's activities, networks and associations are important in sustaining social life in the ways already outlined, they are too often poorly resourced and supported. This can be explained in part by some typical characteristics of women's grass-roots organisations which are outlined in Box 1.

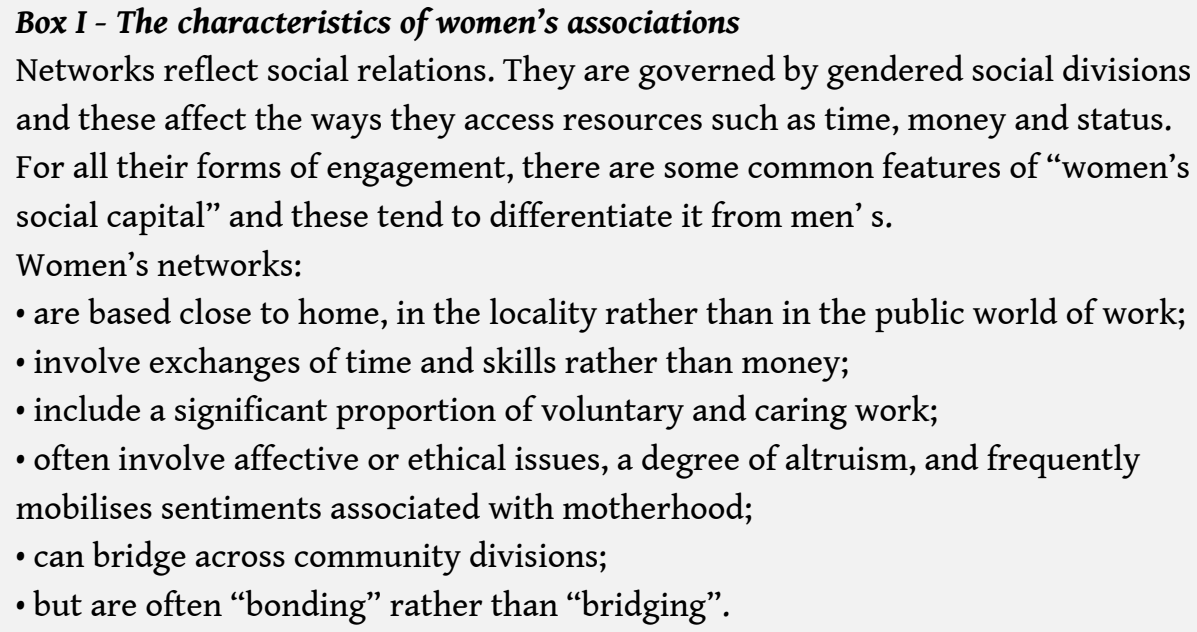

7 These differences imply that women's networks are often found in different social spaces to men's. Men's networks are typically associated with the public world of work and politics, while women's networks and ties are typically closer to home. Studies of the informal networks that sustain immigrant populations have tended to focus on the ways that men help each other to secure jobs and business contacts. Less research has been published on the ways in which women manage in such contexts, but with some 
exceptions women's networks seem to be more concerned with resolving domestic problems than being directed at economic and employment issues.

8 Networks depend on resources to sustain them - time or money, usually both. Most women dispose of less of these resources since they have to combine paid work with family responsibilities. In addition, the pay gap in men and women's wages works to women's disadvantage. If female networks tend to command fewer economic resources they rely more on time and non-monetised exchanges (work, skills) that can be accommodated within their daily lives. Moreover, since relations of power and advantage are reflected in social networks, women find themselves excluded from the kinds of networks that might bring them economic and political power. When women do form networks they often service the group (i. e. they create "bonding" social capital) rather than developing contacts with the wider world of economic and public power ("bridging" social capital). Yet the very fact of working together for a common goal can be a vital spur to developing leadership skills and bridging the power divide.

The common features of women's networks described above help to explain why they have tended to be invisible and marginalised from mainstream debates. Women are still located within unequal power relations and occupy gendered social spaces. They generally dispose of less power in the public world and have fewer assets. Their work, for all the changes that have occurred in recent times, is still regarded as secondary to their family responsibilities. Indeed much of what they do whether paid or unpaid is typically seen as a natural extension of their family and domestic responsibilities and as such is invisible or taken for granted. Even when women are in paid work, what they do in their localities, as volunteers or activists, is often constructed as a "natural" extension of their caring roles in the social division of labour - it is simply "what women do".

One consequence of naturalising women's work is that it is considered outside the sphere of economic relations; in short it is not paid work. We might ask, then why do women do it? In some ways the question itself is a problem: it implies that the only reason people do things is for self-interest and for material incentives such as cash. Yet motivation is far more complex and involves identity issues and forms of reward that escape these material categories. Care-giving is an example of an activity that has the potential to provide satisfaction and give meaning to people's lives in ways that do not equate to cash reward, as is the case with regard to women's occupational status in nursing and teaching. Work of this kind can be associated with satisfaction, selfesteem, recognition and respect, but it remains the case that it is work that women tend to do, and as such it is often undervalued and taken for granted. However, as illustrated in box 2 , female identities have also been a basis for collective action.

\section{Box 2 - Identity and affect}

In regions such as Latin America, cultural constructions of femininity are strongly identified with motherhood. Serving the needs of children and the household is generally considered to be women's primary responsibility. For many women, being a mother and a wife remain important primary identities that can govern motivation to engage in public action. We have only to think of the Mothers of the Disappeared in Argentina, ordinary housewives who took to the streets in a defiant protest against the disappearance and torture of their children in the Dirty War years when the country was governed by state terror. 
Women's groups often become active in peace movements out of concern for their families and participate in campaigns against civil violence such as in Northern Ireland where they have worked in grass-roots projects that seek to reconcile divided communities. Female solidarity around such concerns can be the basis for a kind of informal citizenship that relocates women's domestic concerns and activities from the isolation of the family into public spaces and public life. Grassroots organisations often have this transformative potential in which the experience of engaging in collective activity turns private actors into public citizens. In this process, the organisers of neighbourhood protests or support activists are transformed into community leaders, able to negotiate with governments on behalf of their communities' needs.

The distinctive combination of characteristics that define most women's organisations can make them particularly well suited to tackling social needs that other organisations ignore or cannot easily reach. Yet these same reasons help to account for the fact that women's organisations so often find themselves struggling for resources and reliant to a significant degree on voluntary supporters. The next section considers how women's organisations engage with other policy actors and what challenges they face in so doing.

\section{Women's organisations and policy actors}

The work that women do in groups and associations is increasingly (if still only partially, or problematically), recognised by policy actors. NGOs have found women to be natural allies in their efforts to develop community initiatives around health, education and service provision; governments have also increasingly called on women to help them to administer and service their anti-poverty, community regeneration or welfare programmes. This attention may be given a cautious welcome if it goes along with programmes that serve common aims, but are at the same time sensitive to women's needs. The latter, unfortunately, does not tend to be the norm. On the contrary, the accumulating experience of how outside agencies work with women's organisations and networks suggests that there are often tensions between the needs of women participants and the goals of the external agency. What are these tensions and what lessons have women's organisations and those who work with them drawn from the experience so far?

\section{Instrumentalism}

\footnotetext{
"The harsh reality is that the governments take women for granted. They are keen to consult with them but simply fail to recognise that these women are already resource scarce and as such need to be adequately compensated for the time sacrificed as well as the resources needed to operate their organisations. Quite simply, women's organisations have access to little or no funding" (Women's Organisation Activist).
}

The first problem arises where women's organisations and/or their voluntary work is not only relied upon as a central support for social policy but becomes a substitute for appropriate government action. In such cases women's groups face two kinds of risk: either struggling on without funding yet finding themselves with responsibilities which 
they are not adequately resourced to undertake; or being incorporated into government programmes on unacceptable terms, where their project is taken over by government agencies but administered in ways that depart from the original conception and good practice associated with it. For example a women-centred and administered project which serves the needs of vulnerable women and provides safe spaces for them is likely to be far more successful in generating trust and selfesteem among participants than one administered by men and made to conform to government priorities and guidelines. The lesson here is that outside agencies working with women's organisations need to help strengthen them, respecting their experience and autonomy rather than simply making use of them to plug gaps in provision.

\section{Capture}

14 A second and related problem involves the capture or co-optation of grass-roots organisations, where women's participation is secured to make use of their efforts for direct political gain. Where governments, political groups and parties are prone to practice forms of clientelism and seek to co-opt women's organisations for their own ends, the latter might experience short term gains in recognition and reward, but as a result can rapidly lose legitimacy in their communities and among the women they seek to serve. The use of women's organisations for political purposes is common throughout the world. One example is that of the Peruvian comedores populares noted earlier, which started as a women's movement, but was gradually taken over by government agencies, with the women leaders entering into a close and public association with government. As government popularity waned, the women's organisations suffered by association and lost public confidence, and in the process they had also lost their autonomy and sense of purpose.

15 In Europe, community groups have become a cornerstone of the government's local development initiatives with government funds directed at supporting the voluntary and community sector. While the injection of resources has been welcomed, there is mounting concern over the paperwork burden placed by increased government bureaucracy on participating organisations. Many feel that this hampers their ability to campaign and that the pressure to align themselves with government priorities distances them from being more responsive to local needs.

\section{Overloading}

16 A third problem concerns the kind and quantity of work that women are often asked to do by NGO or state run initiatives. In many cases they are expected to do jobs that men will not do, such as cleaning schools and tidying up neighbourhoods, and jobs that offer little satisfaction or reward for their efforts. The assumption appears to be that women have the inclination and the time to do these tasks whereas men do not; yet in reality many of the women drafted into these programmes are time-poor, juggling household survival with childcare as well as with their efforts to generate income. Project managers rarely investigate the circumstances of the women on whom they are relying and make unrealistic assumptions about their availability and willingness to undertake the work assigned. This generally leads to a rapid turnover of volunteers and participants with negative consequences for the stability and efficiency of the project. 
There is a considerable number of cases where women and their networks are targeted and drafted into projects or programmes principally to service the needs of the programme, but where the needs of the women themselves are not taken into account. If the work that women do is valued, and it is understood that women are juggling difficult lives, they should not to be overloaded by the extra demands made upon them, but instead should be given the support they need to ensure their participation. In particular, they might need flexible childcare arrangements to be part of the programme, or training in marketable skills, or health provision and education. This question of women's needs is all too rarely posed by those who develop programmes that depend on women's social capital, despite the long-term beneficial outcomes that such attention could deliver. Moreover, participation in these programmes can entail opportunity costs for women undermining their ability to undertake paid work or training.

\section{Organisational principles}

\section{A cooperative approach: autonomous organisation and external agencies}

18 In the light of the dangers of instrumentalism, capture and overloading we can now move on to consider what kind of relationship women's grass-roots associations might develop with external agencies. A fundamental issue in any organisational structure and their relationships with others is who decides the agenda?

The question of organisation is one that women's movements and activists in political parties, trade unions and grass-roots organisations have long debated. Two issues have been particularly contested; that of autonomy and that of what principles should govern internal organisation. Over time there emerged strong arguments in favour of autonomous all-women spaces where participants could elaborate programmes of action, debate goals and develop strategies free from outside influence. Flat, non hierarchical organisational structures were often considered more appropriate ways of ensuring democratic principles, allowing greater debate and increased participation in the formulation of objectives.

20 To the question of who decides the agenda there are three classic answers - the collectivity decides; an external agent decides; or the decision is taken on a shared, cooperative basis. The first of these tends to be associated with autonomous organisations in which women themselves set their own goals and decide their own forms of organisation and objectives. Here the organisation is a self-governing association that recognises no superior authority and is independent of other political agencies. Authority here resides in the membership. Examples of this kind of organisation are those that emerge from independent initiatives such as Rape Crisis centres, barter movements and credit unions.

21 In contrast, where an external agency sets the agenda, authority and initiative come from outside and stand above the collectivity itself. The control of the agenda, the purpose of the organisation and the development of the women's group are subject to this external authority - they may coincide or not with what the membership itself determines. 
The third possibility is a co-operative approach where an external agency, such as an NGO, works with the women's organisation and together they set the agenda, agree the style of working and take decisions on a democratic participatory basis. This kind of link represents a different type of organisational principle and a different conception of authority - it is co-operative and associational in the sense that independent women's organisations with their particular goals and institutional autonomy choose to form alliances with other organisations with which they are in agreement on a range of issues. These forms can be called "associative" in recognition of their quasi independent status within an alliance of interests. They are not directed by a superior power, and they are not completely independent, but the collectivity remains in control of its own organisation and sets its own agenda. In this arrangement women's organisations may choose to delegate power to outside agencies such as NGOs or government departments, an arrangement which, if it is to work, has to be based on trust and established procedures of accountability. Power and authority in this model are negotiated, and cooperation is conditional on some or all of the women's demands being incorporated into the organisation with which co-operation is established. This kind of linkage escapes the polar dilemma of autonomy versus integration which has long divided the different currents within women's movements and it has the potential to be an effective means of securing concrete agendas. However, it runs the risk of cooptation, if the women's organisation loses the capacity to set the agenda. To minimise this danger, women's movements can set conditions on the organisation with which they are prepared to cooperate. Clearly in such cases, the outcomes depend on the strength and negotiating capacity of the women's movement concerned.

\section{Transformative interventions - why the nuts and bolts of women's organisations matter}

Beyond these questions of organisation there are several important issues that have to be taken into account if women's projects are to work to greatest effect for the women concerned. Positive effects can be understood as those processes that enhance women's capabilities in ways that enable them to challenge relations of inequality and subordination in both the public and private spheres. Here three principles are helpful in thinking of ways this might be achieved; these are: ownership, self-esteem and empowerment.

\section{Ownership}

One lesson that can be drawn from the experience of working with women's organisations is that the question of ownership is central. Organisations and their projects work best when they are not imposed from above but develop on the basis of an organic relationship among participants. Effective grass-roots associations can rarely be created merely by external intervention, so the question of the "ownership" of projects and goals as well as participants'identification with the values of the project are all critical to its success. Some key questions that can be posed of specific projects are, for example:

- Do participants have a voice in programme aims, design, evaluation and management?

- Are they sensitive to women's constraints? 
- Are they "family friendly"? Do they acknowledge care-giving, childcare arrangements, time management issues?

\section{Self-esteem}

A second vital ingredient of successful projects concerns that of whether they promote the self-esteem and respect of participants. This follows from ownership, but it has to do with the internal organisation of the project and how the goals of the project are formulated. One of the most important benefits to those involved in the not-for-profit sector is that of self-esteem, and this can often outweigh other factors such as time burdens. For participants, whether volunteers or beneficiaries, the project can be a place where they are valued, where the work they do among others is experienced as positive. Where projects work with groups who normally suffer stigma and exclusion these questions are vitally important since building self-esteem and confidence is often the first step in realising other goals. If projects and programmes are to take this question seriously they need to ask:

- Are equality principles built into the design of the programme?

-What principles govern internal organisation and assignment of responsibilities?

- How are participants treated in the project?

- Is rights awareness built into the programme?

- Are training and resources allocated to enhance women's capabilities?

- Are economic independence and well-being (health, both mental and physical, freedom from violence) a priority?

"It's about looking beyond the day-to-day of fire fighting that often preoccupies women's time and resources. Increasingly we are keen to develop a structured approach to sustaining our own organisations in a strategic attempt to influence a wider sphere and more importantly empower and transform our own lives and the lives of the women we support. Essentially, women acquire the skills to swim in a policy pool". (Women's Grassroots Network Co-ordinator).

\section{Empowerment}

A third important question to ask of projects is whether they are able to contribute significantly to the empowerment of their members. Project goals can be broadened in ways that enhance participants'knowledge base, marketable skills and citizen's participation rather than simply satisfying immediate needs. Here the tough questions to ask of any project are what do participants gain from the project collectively and on their own account? What are the significant transformations that participants may undergo as project members? They may gain certain material benefits, they may gain subjectively through enhanced selfesteem and companionship, and they may feel that the rewards of working together on a project that they believe in is sufficient. But if the project can also enhance their capabilities through education, language instruction, knowledge of their citizenship rights, leadership skills or other training, then it will have succeeded on a broader spectrum. Those working in projects need to see the results of their efforts, and need to feel that something tangible and sustainable is being achieved. At the very least, those who benefit from the efforts of the project need to leave it with an enhanced set of life chances. For socially disadvantaged and politically marginalised groups, acquiring voice in the public worlds of politics and 
policy and acting collectively to advance strategic goals is an important measure of empowerment. rely on time and non-monetised labour exchanges. However, in recent years, povertyreduction or social inclusion programmes that address women's income needs, and work with women's groups have enjoyed considerable success. Micro-finance schemes for example, depend on group-lending techniques which draw on women's kin and community ties to secure loan repayments. Similar ideas inspire the development of community funds which mobilise resources through women's social ties, for investment in local development programmes. Co-operative, informal organisations can also support such activities as credit unions which aim to provide more control over economic resources on better terms than those available through informal or commercial agencies. In India, SEWA, the Self Employed Women's Association, helps poor women obtain credit to start their own small enterprise. SEWA was established over thirty years ago and is now a large organisation with a membership of over 700,000. It helps to establish cooperatives for women who work on the margins of the economy, and runs its own bank for savings and credit. In addition, it offers a primary health care programme and has just started an insurance scheme for its members. SEWA's success has made it a model for similar initiatives across the world.

31 Such initiatives help to answer questions about the ways in which women's social capital can help to strengthen their access to economic resources, in an overall context in which their command of such resources is weak. Women can, with well conceived projects, move out of poverty and secure livelihoods; they can work together to create small businesses, acquire skills and markets for their products and services. Economic empowerment can be a step towards political empowerment if it provides the basis for secure livelihoods, generates organisational strength, and enables those involved to see themselves as full citizens of the localities and societies in which they live. 


\section{Communities under stress}

32 Conflicts of all kinds, whether in the form of war or neighbourhood violence, impacts heavily on social life. However the fact that it affects women in particular ways has only recently been recognised both in international law and in community regeneration work. Women, along with children, are exposed to the effects of violence and social breakdown - in extreme cases becoming their victims through rape, robbery or kidnapping - but more generally as those who both have to manage families'emotional needs and ensure that the more routine necessities are met. Women have in many different contexts become important actors in healing divided communities and helping in efforts at post conflict reconstruction; sometimes it is only women's groups that are able to rise above communal or political divisions to find ways to co-operate for the common good. However, while women are widely acknowledged as having a history of involvement in peace movements and can be valued as peacemakers and bridge builders they are all too rarely involved directly in community or peace negotiations or in policy concerning post conflict reconstruction. Many of their organisations emerge out of their own experience, sometimes out of a personal tragedy, and for this very reason they can acquire the trust and respect of the community they are active in. Indeed, more generally, this is an area where women's organisations can sometimes play a vital role and can gain considerably more trust than conventional government interventions.

Conflict situations however reveal the dual character of social capital. In communities under stress, social capital can strengthen community ties but at the same time can deepen existing divisions, create exclusive identities and exacerbate tensions. Where resources are at stake and where minority needs are successfully claimed and addressed, accusations of preferential treatment can arise, heightening tension and causing further retreat into group interests and identities. Women's groups also often find themselves in such circumstances under considerable pressure to surrender their own interests to what are claimed by community leaders to be the general interest. Autonomy is difficult to maintain and they can become vulnerable to capture by political forces aiming to use them for their own purposes. Women's organisations in conflict situations often find that they are walking a tightrope, trying to balance loyalty to their particular community with work that involves challenging some of its leaders'assumptions about women's place in society. Careful strategising, learning from the experience of others in such situations, and forming wider, regional and national networks have been important in the work of such organisations. Networks also have the potential to become effective advocates in the policy world and providing they can agree on common principles and a common agenda can achieve considerable visibility and impact.

\section{Civic regeneration}

34 At neighbourhood level, as noted earlier, it is not uncommon to find that women's informal networks are involved in supporting domestic and caring responsibilities, and in providing services that help meet needs in health and education. These are crucial resources for communities, especially for those in particular hardship. But while such activities can provide practical relief they do not necessarily promote the changes that 
bring women into public life to participate in decisions that affect both their communities and their lives as women. Community regeneration programmes offer women's groups and networks considerable potential for advancing new ideas about the social and spatial organisation of services, but to take advantage of the opportunities on offer, such programmes have to make a serious effort to involve women. This can take many different forms, involving not only government agencies and NGOs, but also the private sector where appropriate. One step is to encourage community organising and to recognise informal networks that can participate in decision-making. NGOs can promote women's involvement through awareness raising, leadership and political participation programmes which are a crucial component in ensuring that women's networks become meaningful actors in decision-making processes. At the same time, the linking of women's concerns to wider policy issues helps to ensure that organisations do not remain inward looking and exclusive.

\section{Conclusions}

The accumulating experiences from around the world suggest ways in which women's networks and organisations have confronted some of the problems that arise when they work with NGOs and governments. These problems however remain largely unaddressed in many of the new government programmes. The critical question remains that of how projects that involve women as participants or beneficiaries can achieve two goals simultaneously: to bring about long term, that is sustainable results in reducing poverty, inequality and injustice, and to identify effective strategies to help women overcome the various forms of gender injustice that they are subject to. With regard to the policy interest in social capital, on the basis of the evidence so far three main lessons can be drawn: first, we need to be attentive to how a focus on social capital can support "sticking plaster" approaches to deeper structural issues, notably inequities in the distribution of power and assets and the social (and gendered) costs of macro economic and public policies. Social capital in the form of networks and associational activity can be an important resource in tackling poverty and social disintegration and in assisting in the effective delivery of social welfare. But it is no substitute for sound development policies.

Second, in developing projects and policies designed to enhance social capital, a critical gender perspective is essential if social divisions and existing power relations are not to be strengthened. One way of countering this is to ask: what resources of social capital do women command and what do these resources allow women to do and to be? Whether women can deploy "their" social capital to enhance their leverage over resources and policy depends crucially on whether they can develop their capabilities, political as much as economic, collective as much as individual. Women's organisations have been aiming to do just that through training programmes, through "empowerment" strategies and by helping to enhance women's collective and individual claims on citizenship.

37 Third social capital begs a number of questions as to the purposes it is designed to serve, who benefits and why? Fostering women's social capital is not usefully understood as restoring some ideal traditional "community" or "family values" women's interests are all too often submerged in such appeals. Supporting women's associational life is helpful if it implies allowing women to find voice and presence 
within and across their collectivities in ways that strengthen rather than weaken their claims on citizenship.

In sum, if from a gender perspective the current policy interest in grass-roots women's organisations has an ambivalent potential, its positive appeal depends on being brought into alignment with ongoing efforts aimed at building up citizens' movements, and supporting cooperative and democratic forms of associational activity in ways that strengthen local initiatives and help confront the formidable negativity of modern societies - whether this be in the form of criminal gangs, corrupt public administrations, exclusionary elites or authoritarian communities. Public policymakers would do well to avoid taking what women do for granted, and to give more support to those engaged in constructively working in this area. Effective policies will only result from a critical and more finely grained approach to social capital, one which takes both women's organisations and gender relations more seriously.

\section{BIBLIOGRAPHY}

Durston, J. (2001) “Capital Social, parte del problema, parte de la solución. Su papel en la persistencia y en la superación de la pobreza en América Latina y el Caribe", <www.eclac.cl>.

Edwards, M. (nd) "Enthusiasts, Tacticians and Sceptics: The World Bank, Civil Society and Social Capital", < www.worldbank.org/poverty/scapital >.

Fine, B. (2001) Social Capital versus Social Theory: Political Economy and Social Science at the Turn of the Millennium. London and New York: Routledge.

Fox, J. (1997) “The World Bank and Social Capital: Contesting the Concept in Practice", Journal of International Development 9 (7): 963 - 71.

Gonzales de la Rocha, M. (1994) The Resources of Poverty. Oxford: Blackwell.

Harriss, J. and P. de Renzio (1997) "Policy Arena:"Missing Link” or Analytically Missing? The Concept of Social Capital - An Introductory Bibliographic Essay", Journal of International Development 9 (7): 919 - 37.

Kliksberg, B (nd) "Capital Social y Cultura: Claves Olvidadas del Desarrollo", < www.worldbank.org/poverty/scapital >.

Mayoux, L. (2001) “Tackling the Down Side: Social Capital, Women's Empowerment and West African Micro-Finance", Development and Change 32 (3): 435 - 64.

Molyneux, M. (2000a) Women's Movements in International Perspective. Basingstoke: Palgrave.

Molyneux, M. (2000b) "Citizenship and Social Policy in Comparative Perspective", in S. Reuben (ed.) La Política Social en una Epoca de Transicíon, pp. 23-47 Universidad de Costa Rica: San José.

Molyneux, M. (2001) “Ethnography and Global Processes”, in Ethnography 2 (2).

Molyneux, M. (2002) "Gender and the Silences of Social Capital: Lessons from Latin America”, Development and Change, 33: 2, April 2002, pp 167-189 
Molyneux, M. (2003) Los movimientos de Mujeres: Estudios Comparativos y Históricos, España: Cátedra.

Moser, C. (1996) Confronting Crisis: A Comparative Study of Household Responses to Poverty and Vulnerability in Four Poor Urban Communities. Washington, DC: The World Bank.

Nussbaum, M. (2002) “Women's Capabilities and Social Justice”, in M. Molyneux and S. Razavi Gender Justice, Democracy and Rights, Oxford: Oxford University Press.

Pearson, R. (1997) “Renegotiating the Reproductive Bargain: Gender Analysis of Economic Transition in Cuba in the 1990s", Development and Change 28 (4): 671 - 706.

Portes, A. (1998) "Social Capital: Its Origins and Applications in Modern Sociology", Annual Review of Sociology, 24: 1 - 24 .

Portes, A. and P. Landolt (2000) "Social Capital: Promise and Pitfalls of its Role in Development", Journal of Latin American Studies 32: 529 - 47.

Woolcock, M. (1998) "Social Capital and Economic Development: Toward a Theoretical Synthesis and Policy Framework", Theory and Society 27: 151 - 208.

Woolcock, M. (1999) “Managing Risk, Shocks, and Opportunity in Developing Economies: The Role of Social Capital", < www.worldbank.org/poverty/scapital >.

\section{ABSTRACTS}

Although women have played a vital role in sustaining grass-roots solidarities, they have until recently remained marginal to mainstream debates on public policy thinking and practice. As these organisations are gaining growing attention from policy makers, this article maps some key issues for women's organisations in the present development policy context.

Bien qu'elles aient joué un rôle déterminant dans les processus de solidarité de base, les femmes sont longtemps restées marginales dans les débats portant sur la réflexion et la pratique en matière de politique publique. Les décideurs politiques leur accordent maintenant de plus en plus d'attention, et cet article détermine certaines des questions clés pour les organisations de femmes dans le contexte des politiques de développement actuelles.

A pesar de que han desempeñado un papel determinante en los procesos de solidaridad de base, durante mucho tiempo las mujeres siguieron siendo marginales en los debates referentes a la reflexión y a la práctica en materia de política pública. Los responsables de las decisiones de políticas les prestan ahora cada vez más atención, y este artículo determina algunas de las cuestiones claves para las organizaciones de mujeres en el contexto de las actuales políticas de desarrollo.

\section{AUTHOR}

\section{MAXINE MOLYNEUX}

Professeure de sociologie à l'Institut d'étude des Amériques à l'Université de Londres. Elle a fait partie du comité éditorial du projet de l'UNRISD Beijing Plus 10 dont le rapport a été publié en 2005. 


\title{
Les défis actuels qui se posent à la
} recherche et aux décideurs en matière de politique de développement dans un monde globalisé

\author{
Serge Chappatte
}

\section{Introduction}

1 La DDC est une agence de coopération opérationnelle au niveau bilatéral et multilatéral mais elle est aussi responsable pour la définition de la politique suisse de coopération au développement pour laquelle elle s'entoure d'avis compétents et spécifiques. Elle interpelle la recherche mais est également interpellée par elle dans un mouvement dialectique. La DDC veut être créatrice d'espaces de réflexion et a des attentes particulières vis-à-vis du monde de la recherche. Les centres de réflexion en matière de politique de développement ont donc non seulement le droit mais surtout le devoir de poser des questions que personne ne pose et de donner souvent des réponses que personne n'aime. Les chercheurs ont le grand privilège de pouvoir déranger les agences de coopération qui doivent saisir cette chance de s'élever audessus du courant normal. Je vous encourage dès lors à poser ces questions et vous assure que nous sommes là sinon pour les aimer, du moins pour prendre très au sérieux les réponses ou plutôt les pistes de réflexion que vous donnez.

Dans ma présentation je vais d'abord aborder les défis actuels qui se posent à la recherche et aux décideurs en posant l'analyse en termes globaux et en concevant la globalisation sur d'autres lignes de démarcation que les frontières traditionnelles. J'aborderai ensuite les défis actuels constatés sur le marché international de la recherche, puis la manière d'établir et de renforcer les ponts entre la recherche et la 
politique. Et en dernier lieu, je passerai rapidement en revue ce que la DDC fait dans ce domaine.

\section{Les frontières traditionnelles s'estompent, les lignes de démarcation et de clivage se modifient}

On a toujours tendance à parler de gouvernance globale d'une part, qui s'appliquerait avant tout aux processus de gouvernance à l'intérieur d'un monde dominé par les pays industrialisés, et de relations plus ou moins conflictuelles, Nord-Sud d'autre part, qu'on applique dès qu'il s'agit de faire participer les acteurs du Sud à la conception et à la définition de la politique de développement global. Cette opposition n'est plus très efficace car de nouveaux clivages apparaissent qui déterminent dans une large mesure les orientations de la recherche en matière de politique de développement.

La perspective Nord-Sud ne couvre qu'imparfaitement la réalité car :

- les lignes globales de conflits ne sont plus clairement tracées entre pays industrialisés d'une part et pays en développement d'autre part; les lignes de conflit traversent les sociétés du Nord et du Sud ;

- les lignes de conflits varient selon le champ politique auquel elles s'appliquent ;

- La conception de conflits Nord-Sud dans le sens d'échanges et de confrontations entre Etats est peu porteuse, voire même stérile, face à l'ampleur des problèmes qui touchent l'ensemble de la société et au rôle moins important joué par l'Etat dans le mouvement de désétatisation progressive de la politique.

5 Parmi les questions et les angles d'analyse qui gagnent toujours en importance pour la politique et la recherche en matière de développement qui la soutient, on peut identifier :

- l'émergence toujours plus marquée, au Nord comme au Sud, d'acteurs privés de la société civile ou d'acteurs étatiques décentralisés qui posent leurs revendications par rapport à la gouvernance globale ;

- l'émergence de réseaux politiques transcendant les réseaux gouvernementaux ;

- le renforcement de partenariats entre Etat et secteur privé, porteurs à la fois d'espoirs mais aussi de craintes ;

- l'exacerbation progressive des conflits liés à la pauvreté ainsi que l'étendue des zones qui sont peu ou pas placées sur l'autorité étatique, ce qui fixe des limites relativement contraignantes au concept de gouvernance globale.

6 On assiste à un changement de paradigmes dans l'approche de la gouvernance au niveau global, ce qui nous pousse à nous questionner sur l'adaptation de la discussion conceptuelle aux relations entre le monde industrialisé et le monde en développement et sur les nouvelles formes de gouvernance au Nord et au Sud.

\section{Les défis actuels constatés sur le marché international de la recherche}

7 La globalisation conduit à une commercialisation progressive de la recherche et de la formation dont profitent avant tout les pays riches. Les institutions du Sud ne sont pas ou sont peu équipées pour faire face à la concurrence très vive qui règne sur le marché 
international de la formation et qui renforce leur faiblesse par rapport aux gros établissements de formation et de recherche du monde industrialisé. C'est une tendance que des agences de coopération au développement comme la DDC essaient de réduire et d'en retourner l'orientation.

Elle aussi est peu encourageante et est en opposition à la réalisation de plus en plus généralement acceptée que la formation supérieure et la recherche sont absolument essentielles pour que les pays du Sud et en transition puissent maitriser leur développement.

9 L'espoir est que le projet du Millénaire des Nations unies devrait contribuer à orienter davantage la société mondiale du savoir vers une nouvelle valorisation de la science et de la recherche pour le développement. Depuis l'an 2000, année de la Déclaration du Millénaire, et aussi depuis la Conférence des Nations unies sur le Financement du Développement de Monterrey (2002), une nouvelle orientation se dessine qui bénéficie d'une série de documents extrêmement importants dont je ne mentionnerai ici que le document du Secrétaire Général des Nations unies. "In larger freedom... ». Les débats internationaux depuis le début du siècle sont porteurs de l'espoir d'une relecture de la situation globale. Cette réorientation se traduit par des avancées de plus en plus grandes des pays du Sud dans la politique et la recherche en matière de développement; c'est une réorientation que la coopération suisse s'est attachée à renforcer.

En Suisse, la recherche en matière de politique de développement a de la peine à prendre pied dans le monde scientifique et universitaire. Quand on examine de plus près l'ensemble des recherches effectuées, on constate une orientation vers les mécanismes du marché dans le sens d'une concentration des domaines de recherche sur ceux qui génèrent des profits au sens économique voire aussi au sens financier. La recherche liée au développement et en particulier aux politiques de développement au niveau global doit constamment se battre pour avoir une place au soleil. J'aimerais mentionner ici le pôle de recherche national axé sur les pays en développement intitulé "Nord-sud Partenariat de recherche pour un allégement des syndromes de changement global » qui n'a été possible que par un engagement financier important de la coopération suisse.

11 L'encouragement de la recherche à aborder des thèmes importants pour le développement reste donc un très grand défi pour la Suisse. La DDC s'attache à relever ce défi, même si elle se sent parfois un peu seule, et cherche à encourager une recherche critique en matière de coopération au développement qui tienne compte des pouvoirs de force asymétriques dans le processus de développement, aussi bien chez nous que dans le monde en développement, et qui analyse les causes de ce développement déséquilibré.

\section{Etablir et renforcer des ponts entre la recherche et la politique}

12 Les changements de politiques ne sont possibles que sur la base de recherches théoriques empiriques importantes sur l'impact des différentes formes de l'intervention étatique. Il s'agit d'identifier des priorités par rapport à l'impact recherché en terme de diminution de la pauvreté, de mesurer l'impact des processus 
participatifs dans la formulation et la mise en œuvre de politiques de développement et d'analyser plus finement les liens entre politique et comportement des pays du Nord d'une part et ces processus d'autre part.

Dans ce contexte, un rôle déterminant est joué par les passeurs de savoir qui grâce à leur crédibilité au sein des deux communautés (recherche et politique) ont pu créer des ponts. Leur rôle n'est pas simplement de simplifier et de rendre accessibles les résultats de la recherche ainsi que de les traduire dans des recommandations aboutissant à l'approbation de meilleures politiques, mais aussi d'aider à éviter les malentendus et les banalisations. Les passeurs de savoir sont des personnes ou des institutions qui peuvent renforcer la crédibilité de leur message dans le monde scientifique et dans le monde politique. L'IUED a la capacité de se renforcer dans ce rôle-là aussi.

De nombreux domaines de recherche restent encore largement orphelins et méritent d'être encouragés. Un exemple est donné par la réflexion sur les Etats fragiles: comment est-ce que les donateurs peuvent encourager le développement dans un contexte fragile? Notre désir de bien faire dépasse largement à l'heure actuelle notre compréhension de ce qu'il faudrait faire. Nous avons besoin de davantage de travail empirique, de plus d'études de cas, de l'organisation d'un nombre plus grand de recherches pluridisciplinaires dans ce domaine qui à vues humaines restera un objectif fondamental pour la politique à l'avenir.

J'aimerais mentionner aussi un autre exemple d'un domaine encore en friche qu'il s'agit de mieux comprendre et qui est d'ailleurs très lié aux objectifs et aux activités de l'IUED, il s'agit de l'exclusion. Comment est-ce que les groupes marginalisés et exclus peuvent être placés dans le sillage du développement et de la croissance? Une recherche plus précise sur les mécanismes d'exclusion dans les pays riches et dans les pays pauvres permettra certainement de prendre des décisions plus justes parce que tenant mieux compte de la réalité du développement.

\section{Que fait la DDC dans ce domaine?}

16 La DDC a une tâche opérationnelle et conceptuelle. Afin d'augmenter son efficacité et son efficience dans ses programmes bilatéraux, qu'elle mène dans plus d'une trentaine de pays, et dans ses activités multilatérales avec les organisations des Nations unies, les institutions financières internationales, les réseaux et fonds globaux, etc., la DDC a besoin de renforcer ses activités en matière de recherche afin d'améliorer ses politiques. Depuis la création de la DDC, l'évolution de ses activités s'est très fortement nourrie des échanges constants entre recherche et pratiques sur le terrain. La DDC finance des projets visant à renforcer les capacités de recherche dans les pays du Sud et en transition et met sur pied des partenariats de recherche entre chercheurs du Sud et chercheurs suisses. Le MOST est d'ailleurs un bon exemple de cette collaboration NordSud.

17 La DDC collabore avec des centres de compétence, avec des organismes et des instituts de différentes natures qui disposent de capacités particulières dans certains domaines d'intérêt pour la politique suisse de coopération au développement, qu'ils soient politiques, thématiques, techniques ou méthodologiques. Cette collaboration est entretenue aussi bien avec des Universités que des entreprises du secteur privé et des organisations sans but lucratif au sens large et couvre la formation et le 
perfectionnement, la conception et la production d'instruments, la réalisation d'analyses globales et d'évaluations externes, etc. A l'heure actuelle, la DDC consacre plus de $5 \%$ de son budget à l'encouragement de la recherche en matière de développement suisse, dans le Sud, à l'Est ou en partenariat.

\section{RÉSUMÉS}

Dans un environnement mondialisé complexe, la DDC soutient une recherche en science sociale qui permette de mieux comprendre les inégalités et déséquilibres du développement et qui soit une recherche critique de la coopération pour le développement. Car, grâce aux apports de la recherche, elle peut mieux jouer son rôle conceptuel et opérationnel dans la politique de développement.

In a complex globalised context, the SDC supports a social sciences research that helps better understand the inequalities and unbalances of development and a research that brings critical view of development cooperation. Thanks to research results the SDC can improve its role as a conceptual and operational actor of development policy.

En un entorno globalizado y complejo, la COSUDE (Agencia Suiza para el Desarrollo y la Cooperación) apoya una investigación en ciencias sociales que permite comprender mejor las desigualdades y desequilibrios del desarrollo. Se trata de una investigación crítica de la cooperación para el desarrollo, y, gracias a las contribuciones de la investigación, la COSUDE puede ejercer mejor su rol conceptual y operativo en las políticas de desarrollo.

\section{AUTEUR}

\section{SERGE CHAPPATTE}

Directeur adjoint de la Direction du développement et de la coopération (DDC) suisse, en charge de la politique de développement et de la coopération multilatérale. 


\title{
Gestion des transformations sociales
}

\author{
Christina Von Fürstenberg
}

\section{NOTE DE L'AUTEUR}

Ce texte d'information n'est pas un document officiel de l'UNESCO. Il présente, à des fins d'information du public, le thème "Gestion des transformations sociales " développé lors de la $18^{\mathrm{e}}$ semaine (09-15.01.2006) du 60 anniversaire de l'UNESCO.

1 Le Secteur des sciences sociales et humaines (SHS) de l'UNESCO s'attache de plus en plus à renforcer les liens entre la recherche et les politiques. Le programme pour la "Gestion des transformations sociales » (MOST), créé en mars 1994, a pour mission de « continuer à promouvoir le développement et l'utilisation des connaissances en sciences sociales qui contribuent à une meilleure compréhension et une meilleure gestion des transformations sociales, conformément aux valeurs universelles de justice, de liberté, de dignité humaine et de développement durable ».

\section{Développer la recherche en sciences sociales}

2 Le programme MOST est piloté par un Conseil intergouvernemental et un Comité scientifique consultatif indépendant. Il travaille avec les Comités nationaux de liaison MOST, mis en place dans une soixantaine de pays. Le programme MOST innove à plus d'un égard: c'est le premier programme intergouvernemental pour la recherche en sciences sociales et la formulation de politiques créé au sein d'une institution des Nations unies.

3 Il a pour but de développer la recherche interdisciplinaire et comparative sur des questions contemporaines et s'inscrit dans une perspective internationale. Enfin, il favorise l'articulation entre la recherche en sciences sociales et la formulation des politiques, ainsi que l'établissement de partenariats entre les différents acteurs économiques et sociaux, notamment les ONG, les médias et le secteur privé. 
L'axe d'action prioritaire de MOST consiste à établir et relier entre eux des réseaux internationaux d'action publique et de chercheurs renommés afin de mettre la recherche en sciences sociales au service de politiques concrètes. Après dix ans d'existence, MOST a entamé sa seconde phase.

\section{Impératifs sociaux et intervention politique}

Ses objectifs prioritaires sont d'améliorer la production de connaissances en matière de transformations sociales, accroître la pertinence de la recherche et du savoir-faire pour élaborer des politiques, développer et renforcer les capacités scientifiques, professionnelles et institutionnelles, notamment dans les pays en développement.

En vue de diffuser des informations pertinentes, le Secteur SHS travaille, entre autres, sur de nouveaux outils technologiques de communication.

7 En attendant un service interactif international, des Documents d'orientation, Policy Papers, sont publiés en versions papier et électronique (disponibles sur le site de MOST, voir plus bas). Ces textes s'adressent aux responsables politiques, aux groupes de défense des intérêts, au monde des affaires et des médias. Ils sont basés sur les conclusions d'analyses politiques provenant des travaux de MOST et d'autres sections de SHS. Cette série de Documents, disponible en anglais, espagnol et français, facilite l'appropriation des connaissances et leur analyse (voir encadré ci-dessus).

De plus, un Forum International sur les interfaces entre Politiques et Sciences sociales se tient en Argentine et en Uruguay en février 2006. Le Forum vise à comprendre et analyser cinq thèmes clés où l'expertise en sciences sociales est indispensable pour une intervention politique efficace :

- les dynamiques et les problèmes mondiaux ;

- les politiques sociales ;

- les politiques urbaines et la décentralisation ;

- les politiques d'intégration régionale ;

- la migration.

Conscient que la société civile peut apporter sa contribution face aux transformations sociales, MOST prépare chaque année la participation de l'UNESCO au Forum Social Mondial (FSM). Le Forum est un lieu de rencontres et d'échanges où convergent et s'articulent des propositions, des acteurs et des mouvements de la société civile de tous les pays du monde.

10 Quant aux thématiques de la recherche destinée à informer les politiques, des consultations effectuées auprès des partenaires de l'UNESCO ont fait ressortir les priorités régionales suivantes:

- Amérique latine et Caraïbes : combattre la pauvreté ;

- Afrique : les politiques d'intégration régionale ;

- Etats arabes : le rôle de l'Etat dans le développement des politiques sociales ;

- Asie Pacifique : la sécurité humaine ;

-Europe, y compris Europe de l'Est et Europe centrale : l'interface entre sciences sociales et politiques dans le développement social ;

- Petits Etats insulaires en développement Pacifique/Caraïbes : le développement durable. 
11 Le programme MOST, durant sa seconde phase 2004-2013, coordonnera les efforts de recherche, ainsi que les réseaux d'acteurs et parties prenantes des sphères scientifiques et politiques qui y sont liés.

Série de Documents politiques MOST

La série des Documents politiques MOST a pour objectif de faciliter l'appropriation des connaissances et leur analyse. Ces Documents contiennent des recommandations directement utilisables pour la formation de politiques. Ils sont disponibles en anglais, espagnol et français. A titre d'exemple, un dossier récent (juin 2005) traite de la culture des drogues illicites, en Bolivie, en Colombie et au Pérou, et du non-respect des droits humains des communautés concernées (paysans et autochtones). Un autre met en avant une réussite argentine : l'intercommunalité. Un troisième analyse le projet chilien « Chile Solidario » qui permet de combattre la pauvreté par la citoyenneté et la solidarité. Un dernier se penche sur l'impact des organisations non gouvernementales luttant contre la pauvreté en Amérique latine.

Le Document « Migration de la main d'œuvre rurale en Chine : défis pour les politiques » étudie la question des travailleurs migrants et apporte des solutions aux problèmes d'éducation et d'intégration des jeunes migrants, notamment les femmes.

Finalement, le dossier « Sciences sociales et politique sociale : des dilemmes nationaux aux opportunités mondiales » analyse les relations entre les sciences sociales et la politique sociale. Les auteurs interrogent les vieux modèles et dressent de nouvelles politiques sociales.

Site du programme MOST : < www.unesco.org/most >.

\section{RÉSUMÉS}

Cet article présente le programme MOST de l'UNESCO, un programme international et intergouvernemental novateur. MOST cherche à développer les sciences sociales pour soutenir la formulation des politiques et pour appuyer l'établissement de partenariats entre les différents acteurs concernés par ces politiques.

This article presents UNESCO's MOST programme, an international and intergovernmental innovative programme. MOST aims at developing social sciences research to support policy formulation and to help establish partnerships between the various stakeholders of these policies.

Este artículo presenta el programa MOST de la UNESCO, un programa internacional e intergubernamental de carácter innovador. MOST pretende desarrollar las ciencias sociales para sostener la formulación de políticas y apoyar el establecimiento de partenariados (acuerdos de colaboración y cooperación) entre los distintos actores concernidos por estas políticas. 
AUTEUR

CHRISTINA VON FÜRSTENBERG

Cheffe de section à l'UNESCO, en charge de la Section politique et coopération et sciences sociales. 


\title{
Un outil pour la diffusion des résultats des recherches en sciences sociales
}

\author{
Vincent Maugis
}

1 Le besoin accru de connaissances pertinentes destinées à informer les décideurs nationaux et internationaux a dépassé les capacités actuelles d'accès à l'information, de recherche documentaire, d'organisation et d'interprétation des données. Ce problème prend une importance particulière en sciences sociales, domaine dans lequel les connaissances, si elles se veulent utiles pour la formulation de politiques, se doivent d'être faciles d'accès, comparables et vérifiables. En effet, sans un accès direct aux conclusions d'une recherche de qualité il est difficile d'obtenir des réponses politiques efficaces, ciblées et dans les temps, tant au niveau national qu'international. Les décideurs seraient donc bien servis par des outils aux contenus et aux fonctionnalités adaptés qui leur permettent de réduire l'incertitude et l'ambiguïté des choix qui s'offrent à eux, et prendre ainsi des décisions mieux informées.

2 Des décideurs seraient bien servis notamment par un accès mieux privilégié aux résultats de la recherche comparative présentée lors du colloque «Organisations urbaines, environnement et transformations des rapports de genre ». Le bilan de cette recherche conduite durant sept années dans sept pays différents rend en effet compte des stratégies imaginées par des populations locales, tout particulièrement celles initiées par les femmes dans leurs quartiers, pour tenter de pallier les problèmes d'environnements urbains vécus au quotidien. Il amène à penser le changement social selon d'autres paradigmes de développement que ceux qui prédominent actuellement, passant par l'empowerment des femmes dans les organisations de base.

3 C'est afin de donner meilleure visibilité à des innovations comme celles du réseau «Ville, environnement et genre » et pour permettre leur utilisation opérationnelle pour la formulation des politiques publiques que le Programme MOST a spécialement conçu un service en ligne de recherche et d'information. Celui-ci a pour but de transmettre aux décideurs politiques les résultats des expériences de recherche en sciences sociales. Le projet vise ainsi à encourager la mise en place de nouveaux modes 
de décision basés sur des faits concrets en lien direct avec les situations vécues par la communauté.

4 L'outil fournira un accès rapide à une information comparative nationale, régionale et internationale pertinente pour la formulation de politiques. Les utilisateurs pourront créer des profils de recherche individuels basés sur des catégories thématiques et produire des rapports «à la carte » en sélectionnant des contenus au sein même des documents originaux. Grâce à un format standardisé pour les documents (chaque élément du format agit comme un document à part entière), cet outil novateur de gestion des connaissances permettra de comparer les cas ayant des caractéristiques similaires et d'évaluer l'applicabilité des options politiques disponibles.

Dans le cadre d'une recherche documentaire sur le thème des relations de genre et de l'environnement urbain, on accèdera donc aux neuf études de cas qui nous sont présentées pendant ce colloque. L'utilisateur sera à même de naviguer simplement, via le format standardisé, entre les différents documents. Il pourra compiler, au sein de chacun d'entre eux et selon ses besoins, des informations détaillées sur les problématiques, les cadres réglementaires et les programmes existants ainsi que des recommandations, des indicateurs et des références, pour créer un rapport personnalisé. Ce dernier sera ainsi une collection d'expériences (d'options) provenant de terrains différents, contextualisées et documentées en fonction de la situation spécifique qui occupe l'utilisateur; il contient l'information réellement pertinente puisque sélectionnée par celui-ci, et présentée sous une forme qui facilite la comparaison et favorise les inférences.

6 Cet exemple illustre l'utilité des résultats de recherche du réseau «Ville, environnement et genre » et montre de façon pratique comment ils peuvent aider à soutenir la formulation de politiques également dans d'autres pays que ceux directement concernés. Le service sera gratuit et disponible dans plusieurs langues, en commençant par l'anglais, le français et l'espagnol, avant d'être étendu aux autres langues de travail des Nations unies. Il permettra aux politiques d'être « la meilleure des options possibles » du fait qu'elles seront basées sur des données empiriques liées aux dynamiques locales et documentées par une vaste évaluation d'expériences similaires. L'objectif premier de ce projet est de permettre que l'intervention politique soit la mieux adaptée aux besoins spécifiques du public concerné.

\section{RÉSUMÉS}

Outil de recherche MOST pour les politiques. L'outil de recherche et d'information sur les politiques conçu par le Programme MOST (Gestion des transformations sociales) de l'UNESCO vise à transmettre aux décideurs les résultats des expériences de recherche en sciences sociales. L'objectif du projet est d'encourager la mise en place de nouveaux modes de décision, basés sur des faits concrets en lien direct avec les situations vécues par la communauté.

MOST Policy Research Tool. The policy research tool designed by the MOST (Management of Social Transformations) Programme at UNESCO aims at transferring social science research 
results to decision makers. This project is expected to foster new modes of decision-making, based on actual evidence from situations in the community.

La herramienta de investigación para las políticas diseñada por el Programa MOST (Gestión de las Transformaciones Sociales) de la UNESCO busca transmitir a los actores políticos los resultados de las experiencias de investigación en ciencias sociales. Este proyecto espera favorecer nuevas formas de toma de decisiones, basándose en experiencias concretas de la comunidad.

\section{AUTEUR}

\section{VINCENT MAUGIS}

Consultant auprès du Programme de Gestion des Transformations Sociales (MOST) de l'UNESCO, Vincent Maugis est responsable des méthodologies de transfert de connaissances recherchepolitique. Après un Master Information Stratégique et Innovation Technologique à l'Institut des Sciences et Techniques de l'Ingénieur d'Angers (ISTIA), Vincent Maugis a collaboré avec le Système pour le Développement Durable Mondial (GSSD), un laboratoire du Département des Sciences Politiques du Massachusetts Institute of Technology (MIT) où il a mené des recherches sur les contributions des technologies de l'information à la prise de décision en matière de développement durable. 


\title{
Enjeux de l'action publique dans la ville face aux mouvements sociaux
}

\author{
Isabelle Milbert
}

1 Le colloque « Des brèches dans la ville » a montré comment les femmes intègrent leur action dans le processus d'aménagement urbain à travers leur participation aux organisations de quartier, à la fourniture des services et aux instances démocratiques. Ces initiatives s'inscrivent dans une démarche plus large qui cherche à rétablir les équilibres sociaux dans la ville.

2 Ainsi, dans la ville en croissance, ces initiatives contribueraient-elles au développement durable, mais encore faut-il définir ce dernier. Le développement durable se positionne aujourd'hui comme une métanorme (Kelsen 1962, 1996, Axelrod 1986), un objectif politique visant à un processus de changement dans lequel l'utilisation des ressources naturelles et économiques est en harmonie avec les besoins humains et favorise notre capacité future à les satisfaire. Il établit une relation entre les systèmes socioéconomiques et les environnements physiques. La dimension sociale du développement durable est essentielle : il cherche à préserver les capacités de résilience, c'est-à-dire l'aptitude des systèmes économique, social et physique à se reproduire dans le long terme en s'adaptant et en se renouvelant (Milbert, 2003) Il inclut l'équité sociale, y compris dans les relations de genre. Enfin, il intègre la responsabilité sociale et la prise en charge par le citoyen de sa responsabilité écologique.

Cependant, le contraste entre les objectifs du développement durable et l'évolution des villes du Sud est si grand que l'on est en droit de s'interroger sur la capacité du concept à se concrétiser. Un objectif a donc été de le détailler et de le raffiner (Cunha, Ruegg, 2003), pour pouvoir le traduire en action publique.

4 Le but de cet article est de montrer que, depuis les années 1990, de nombreux outils, stratégies ou méthodes ont été mis au point, en particulier au sein des institutions internationales, pour faire passer la métanorme "développement durable » dans la pratique, y compris dans sa dimension d'équité sociale. Les politiques «d'inclusion urbaine ", y compris la prise en compte des habitants des quartiers pauvres et des équilibres de genre à l'intérieur de la ville peuvent être considérées comme des 
éléments de concrétisation de la métanorme. Dans les deux cas (réhabilitation de bidonvilles, équilibres de genre), la construction de normes internationales a été suivie de l'élaboration d'outils locaux destinés à les appliquer et à répondre à la demande des mouvements sociaux et groupes d'action locaux. Dans les deux cas, la question est posée de l'efficacité des politiques publiques et de la liaison entre actions internationale, étatique et locale.

\section{La vulnérabilité des villes du Sud et des quartiers pauvres}

5 La plupart des villes du Sud sont caractérisées par une vulnérabilité grandissante, qu'elle soit sociale, infrastructurelle ou industrielle. Des déficits très importants en matière de services essentiels (Milbert, 2003: 315) rendent la vie quotidienne très difficile. Les problèmes d'accès à l'eau ont été largement documentés (Zerah, 1999), de même que l'accès à l'éducation, aux soins de santé (Obrist and Tanner, 2002, Harpham, 2002), aux transports (Deike, 2005) et à l'électricité (Ruet, 2001). Cet article tentera donc de se concentrer sur la réhabilitation des quartiers pauvres, enjeux centraux du développement durable et de la relation entre mouvements sociaux et politiques publiques.

6 La féminisation de la pauvreté dans les villes et l'impact plus lourd de la pauvreté sur les femmes des bidonvilles ont été largement documentés. Caren Levy, dans le secteur des transports, Jo Beall, dans le secteur de la santé, Ann Schlyter dans le domaine de l'habitat, ont longuement décrit les conséquences des déficits en services pour les femmes vivant dans la ville et sur les mesures que devraient prendre les autorités (Levy, 1991, Beall 1995). Par ailleurs, les travaux de recherche de Caroline Moser se sont concentrés sur la demande en infrastructure des femmes et les impacts de la pauvreté et de la violence en milieu urbain, et sur les moyens d'y remédier, en particulier en Amérique latine (Moser, 1987, 2001). Ces travaux sont donc très orientés vers les mesures concrètes de politiques publiques qui prendront en considération la demande spécifique des femmes dans la ville.

7 A ce titre, l'exemple des grandes villes indiennes apparaît particulièrement éclairant. Ces dernières connaissent une forte croissance économique, qui est aujourd'hui mise au défi par les questions environnementales et la croissance des inégalités sociales. En cela, elles constituent un excellent laboratoire d'analyse. Les bidonvilles, qui abritent jusqu'à $50 \%$ de la population dans les plus grands centres urbains (Mumbai, Kalkota, Chennai), sont le témoignage de la faillite des politiques publiques nationales et de projets internationaux qui ne sont pas parvenus à se généraliser à l'échelle de la ville. Les bidonvilles sont à l'épicentre des risques environnementaux urbains. Leur aménagement et la prise en compte des besoins des habitants nécessitent des investissements importants, qui sont la condition indispensable au fonctionnement correct de la ville, en particulier dans une économie globalisée. Les femmes des quartiers pauvres s'y trouvent particulièrement pénalisées, en situation de danger permanent, non seulement par leur pauvreté, mais aussi du fait de leur spécificité de femmes : non-reconnaissance de nombreux droits citoyens, absence de services qu'elles doivent compenser par un surcroît de travail, non-prise en considération de préoccupations spécifiques, vulnérabilité face à une violence grandissante, situations personnelles dramatiques (Parkar, Fernandes and Weiss, 2003). 


\section{La construction de normes au niveau supranational}

8

Pour faire face aux défis créés par la triangulation croissance/menaces environnementales/exigences de développement social, l'organisation de conférences internationales a constitué une tentative de créer un consensus autour de normes de droit, de stratégie et d'action, y compris l'inclusion de nouveaux acteurs. l'élaboration et la mise en œuvre de normes ayant trait à l'inclusion urbaine (c'est-àdire l'intégration sociale et économique de tous les habitants de la ville) et la reconnaissance du rôle des femmes dans le développement, avec la prise en compte de leur spécificité. Cette interface est apparue évidente dans le court laps de temps qui a séparé la Conférence de Beijing (1995) et celle d'Istanbul (1996). "In 1994, the Super Coalition on Women, Homes, and Community was formed from four worldwide networks so that women working on community development could be involved in Habitat II planning and could incorporate human settlement issues into the Fourth World Conference on Women (WCW) and it attendant NGO (nongovernmental organization) Forum. The Super Coalition paved the way for grassroots women to contribute ideas to the Preparatory Committee for Habitat II. When the women discovered that many of the gains achieved at the WCW were not reflected in the Habitat agenda, they drafted amendments that were later discussed by official bodies. The women also lobbied delegations and governmental groups on gender issues and found that many of their concerns were included in bracketed paragraphs for further consideration during Habitat II. Another success occurred when the Secretary-General of Habitat II appointed many women to the newly-created Huairou Commission, which will offer advice on gender issues and highlight women's concerns during Habitat II (Abbott 1996).

10 La Déclaration d'Istanbul et l'Agenda d'Habitat réaffirment leur engagement pour améliorer la qualité de la vie et progressivement appliquer la promesse d'un droit au logement. L'Agenda d'Habitat s'engage à poursuivre les objectifs d'augmentation de l'offre de logement accessible financièrement, à mettre en œuvre des stratégies d'aménagement urbain durable ("sustainable urban development»), à adopter des stratégies de partenariat et de participation, à mobiliser les ressources financières nécessaires à ce programme. (Devas, 1999) Dans cette tentative normative, on peut considérer que l'Agenda d'Habitat a été élaboré d'une façon relativement consensuelle, puisque la Conférence d'Istanbul a rassemblé un nombre et une diversité d'acteurs sans précédent pour le secteur urbain. Cela aussi bien dans la conférence officielle, aux côtés des représentants nationaux, que dans les très nombreuses manifestations annexes, associant ONG, mouvements de femmes, groupements citoyens, secteur privé, représentants officiels et organisations internationales.

11 Dans cette période des trente dernières années, de nombreuses autres conférences internationales ont abordé les politiques de la ville sous d'autres angles, qu'il s'agisse des droits de l'homme, du statut de la femme (Beijing, 1995), du développement social (Copenhague, 1995, Genève, 2000). Mais les débats les plus cruciaux ont eu lieu lors des trois principales conférences sur l'environnement, qu'il s'agisse de la Conférence de Stockholm sur l'environnement en 1972, de la Conférence sur l'environnement et le développement (Sommet de la Terre) à Rio en 1992 ou du Sommet mondial de Johannesburg en 2002. L'un des principaux résultats de la Conférence de Rio a été 
l'élaboration de l'Agenda 21, qui a eu de nombreuses conséquences concrètes sur les modalités de gestion de l'environnement urbain, au Nord et au Sud.

En septembre 2000, une large majorité des chefs d'Etat a signé la Déclaration du Millenium, qui se veut l'agenda le plus complet concernant les objectifs de développement. Officiellement, les MDG renforcent, entre autres, les engagements pris à Beijing concernant les droits des femmes et à Istanbul concernant l'inclusion urbaine. Cette nouvelle façon de mettre en œuvre des normes d'action a été largement relayée à l'intérieur des pays, et saluée comme une méthode, beaucoup plus concrète et coordonnée, de concentrer les objectifs de diverses institutions (de recherche, de coopération, entreprises privées, fondations etc.) sur des priorités clairement exprimées et réalisables. De cette façon en effet, les MDG « insistaient non seulement sur les ressources mais aussi sur les capacités ». Les MDG ont certainement eu l'avantage de focaliser l'attention sur un certain nombre de problèmes clés énoncés de façon simple, et d'aider les institutions, y compris dans les pays du Nord, à coordonner leur action en direction de certains objectifs. On peut craindre dès à présent le sousdimensionnement de ces objectifs, et, de nouveau, les difficultés de la mise en œuvre.

Le Sommet de Johannesburg en 2002 (Rio+10), a réaffirmé son engagement vis-à-vis de l'Agenda d'Habitat et des Millenium Development Goals et a réaffirmé l'engagement des pays signataires à mettre en œuvre un certain nombre de normes: promouvoir la sécurité foncière et l'accès à la terre pour tous, promouvoir l'accès à l'eau potable, l'assainissement et les services de base pour les groupes vulnérables, mettre en œuvre la réhabilitation des bidonvilles et la régularisation des quartiers spontanés. Le lien avec le rôle des femmes est fait à travers l'objectif : "Promote gender equality and empower women ». Tout comme le Sommet de Rio, le Sommet de Johannesburg a donc reconnu la réalité de l'habitat de pauvreté et rappelé «the need to address, in an integrated manner, poverty, homelessness, unemployment, lack of basic services, exclusion of women and children and of marginalised groups, including indigenous communities, and social fragmentation, in order to achieve better, more liveable and inclusive human settlements worldwide».

Ces grandes conférences ont eu l'énorme avantage de mettre les différents acteurs face à face, d'établir un dialogue, et de faire naître la conscience du fait que l'habitat de pauvreté en milieu urbain constitue un désastre humain, environnemental, social et économique. Elles ont tenté d'édifier des normes de droit, tel le droit à l'habitat, sans y parvenir complètement. Elles ont tenté d'édifier des normes de stratégie et d'action, qui restent larges, difficiles à appliquer concrètement et non traduites en financements internationaux.

15 La construction de ces normes montre d'évidence un front commun d'acteurs qui promeuvent avec la même énergie les principes de l'équité de genre, l'exigence de la participation démocratique, les droits sociaux (droit à l'habitat, à la santé, à l'éducation...), la lutte contre la pauvreté et le montage d'une stratégie de développement durable urbain. Ces conférences internationales, en particulier Rio et Istanbul, ont puissamment contribué à la reconnaissance de nouveaux acteurs sur la scène urbaine, tels que municipalités, mouvements sociaux, groupes d'action locaux et mouvements de femmes. Il en est résulté une modification profonde des stratégies et des projets urbains, qui ont désormais visé à développer l'interaction entre l'action publique et une "société civile », qui, dans l'esprit des organisations internationales, englobe l'ensemble des acteurs locaux. 

doute la validité de la tentative normative, à la lumière crue de financements fortement déclinants. En ce qui concerne les Etats du Sud, cette priorité est venue s'ajouter à la pile des injonctions, à un moment où ils disposaient de budgets et de pouvoirs amoindris et tandis que la libéralisation donnait le beau rôle aux initiatives privées. L'aide dans le secteur urbain a cessé d'être affiché comme une priorité dans la majorité des agences de coopération bilatérales, dans les années qui ont suivi la Conférence d'Istanbul (1996). Pis encore, les agences internationales qui ont le plus vigoureusement soutenu le dynamisme des villes et appuyé le principe de la réhabilitation de bidonville et du logement pour le plus grand nombre ont, dans le même temps, diminué leurs propres financements et réorienté leurs priorités, au point que le secteur urbain a pratiquement disparu des organigrammes et des statistiques de l'aide au développement. Leur stratégie globale et même leur idéologie ont aussi eu un impact sur l'aménagement urbain : elles ont insisté sur la suppression des subventions.

Dune certaine façon, on peut donc poser la même question pour le développement durable urbain que pour l'objectif de l'équité de genre: tandis que la question est discutée au niveau international et que les principes d'action sont avalisés, le contenu du dossier s'avère beaucoup plus difficile à mettre en œuvre que prévu sur le plan politique.

Malgré une conjonction qui paraissait très favorable, on constate, dix ans après Beijing, que les bilans de la mise en œuvre de l'Agenda d'Habitat ne prennent que faiblement en compte les avancées concernant les femmes (Commonwealth Human Ecology Council for Com-Habitat, 2005). Tout au plus ces évaluations notent-elles l'augmentation du nombre de femmes conseillères municipales, qui s'explique en Inde par la politique de sièges réservés, et l'apparition de mesures favorisant le crédit à la petite entreprise. Dans ce cas, les femmes sont mentionnées de concert avec les basses castes et les personnes handicapées comme bénéficiaires de ces crédits, à titre social.

\section{La construction de quatre types d'outils communs aux objectifs d'inclusion sociale et d'équité de genre}

19 En moins de vingt ans, les modalités de participation à la gestion de la ville ont considérablement évolué, au Nord (Le Galès, 1996) comme au Sud (Baud and Post, 2004). De nombreuses villes semblent progresser vers un objectif de développement durable, avec le soutien de méthodes et d'outils renforcés. Les agendas 21 ont permis de mettre en œuvre des plans de développement prenant en compte les contraintes environnementales. Les programmes de gestion urbaine, les projets participatifs, la transparence des budgets se sont multipliés sans se généraliser.

20 Il est reconnu que le développement des quartiers pauvres exige une interaction et un minimum d'intérêts communs et de consensus entre une multiplicité d'acteurs, dont un certain nombre de chercheurs se sont appliqués à analyser le statut et les ressources. Nous ne reviendrons donc pas sur une description détaillée de ces différents acteurs, dont Nick Devas dresse la liste : les agences internationales définissent des normes en interaction avec les autres acteurs, appuient les politiques publiques, en accord avec le gouvernement central, les municipalités, les établissements publics et les autorités déconcentrées, les chefs traditionnels, les représentants du secteur privé, le secteur 
informel. Les ONG, y compris les groupes d'actions locaux et les organisations ayant leur siège à l'étranger, jouent à la fois un rôle de groupe de pression et, par leur proximité avec la population, permettent de définir les besoins réels de celle-ci et d'organiser leur participation. Les organisations de la société civile formelle, tels les syndicats, les partis politiques ou les organisations représentatives des groupes religieux, relaient l'effort des autorités et facilitent l'établissement d'un consensus. Les organisations locales, fondées sur la communauté, permettent, avec les slum leader, d'organiser le dynamisme des hommes et des femmes des quartiers pauvres.

L'analyse des relations de pouvoir qui président à l'aménagement d'un quartier s'est donc considérablement complexifiée. Il n'est pas certain que, sur le terrain, ces relais interinstitutionnels, permettant à des normes fixées sur le plan international de se concrétiser, apparaissent aussi simples que leur description officielle. Nous avons ainsi identifié quatre points de débat, en évolution rapide, qui nous paraissent des points clés pour l'évolution des politiques publiques urbaines au cours des prochaines années : les alliances entre institutions globales et locales, l'évolution de la décentralisation, le développement des mécanismes de participation, les questionnements autour de l'accès à la citoyenneté.

\section{Contestation du niveau étatique et alliances entre institutions globales et locales}

Une des explications concernant la situation grave dans laquelle se trouvent les villes du Sud porte sur une évaluation négative des politiques publiques. Ainsi, la Cities Alliance rappelle, en introduction de son rapport d'activité, que « Many cities suffer from the effects of genuinely bad national and local urban policies, including misguided incentives, little financial autonomy, and consistent exclusion of much of the population on which the cities depend. And given inadequate policy responses, inequality is also growing. This challenge is greatest in Sub-Saharan Africa and South Asia, where slum dwellers now make up the majority of urban populations and where, not coincidentally, policies have been the weakest. » Dès le début des années 1990, les organisations internationales ont perçu les lacunes d'une approche top-down par projet, et la nécessité de construire des partenariats aboutissant à des politiques publiques ciblées.

Mais ces injonctions internationales en matière de politiques publiques sont venues se contredire avec d'autres, au lieu de se compléter: ainsi les plans d'ajustement structurel et la libéralisation ont affaibli les Etats du Sud. L'action publique a été dénigrée, les Etats attaqués en particulier dans leur rôle de planificateur, de financier $\mathrm{du}$ logement, de régulateur du foncier, et surtout dans leurs responsabilités vis-à-vis du logement social. Ces fonctions, directement critiquées pour leur gestion et leur coût grandissant, ont souvent été fortement diminuées et au mieux confiées au bénéfice d'institutions privées ou semi-privées. Si certaines d'entre elles ont pu connaître un large succès (d'ailleurs aujourd'hui contesté), telles HUDCO pour le logement social ou SULABH International pour l'assainissement en Inde, nombre d'autres n'ont pas rempli leurs objectifs vis-à-vis des $40 \%$ les plus pauvres des habitants des villes. Les agences internationales, porteuses d'objectifs de libéralisation économique, ont été critiques face aux subventions, y compris les subventions croisées, sans lesquelles il est difficile d'envisager une réhabilitation de bidonvilles et l'installation de services rendue particulièrement coûteuse par la densité démographique. Mais sans subventions ou 
sans compensations concrètes et immédiates en propriété foncière, le logement du plus grand nombre n'intéresse pas le secteur privé, comme le montre le rapport Mckinsey intitulé « Vision Mumbai » (Katakam 2003). Il est clair que la croissance économique, si elle profite aux autorités urbaines, peut permettre la mise en place de mesures de relogement. Cependant, en général, bidonvilles et bidonvillois sont une gêne à la croissance, symbolique et physique, et le besoin de terrains provoque la destruction des bidonvilles et la précarisation des bidonvillois.

Ces constats ont conduit à la nécessité de créer des alliances contractualisées entre acteurs internationaux, nationaux et locaux, mettant en avant ce que l'on appelle la gouvernance multi-niveaux. L'idée est de créer un partenariat entre acteurs, qu'il s'agisse d'organisations internationales, d'ONG ou de groupes d'actions locaux. Elle implique de façon grandissante les citoyens et leurs délégués. La contractualisation est soumise aux règles de la «bonne gouvernance». Enfin, la présence de plusieurs financeurs réduit les dépenses de chacun, au moment où bien peu d'agences de coopération donnent la priorité à la ville.

C'est ainsi que de très nombreux types d'« alliances » et "d'initiatives » se sont mises en place dans le secteur urbain au cours des dix dernières années, y compris dans les villes du Nord (tree city initiative, children friendly city initiative, green city initiative, safe sity initiative ...). Des groupes de femmes y jouent souvent un rôle clé et savent mettre en avant des questions nouvelles et spécifiques liées à leur insertion dans la ville, par exemple dans le cas de familles monoparentales. L'idée de la contractualisation associant des acteurs locaux est une pierre angulaire de la coopération décentralisée et des unions de villes. La recherche d'alliances est aussi à la base des city consultations du Programme de gestion urbaine, qui a été créé pour favoriser les cofinancements de projets urbains, et qui a systématiquement appuyé les initiatives locales, en particulier lorsqu'elles étaient issues des organisations de femmes.

Mais l'exemple le plus achevé de cette démarche est la Cities Alliance, lancée en 1999 par la Banque mondiale et Habitat (UNCHS), qui se caractérise par une approche extrêmement positive et dynamique de la ville, qui affiche la reconnaissance de la valeur productive des habitants pauvres des villes, qui met en place les circuits de négociation et de prise de décisions permettant d'associer habitants et gouvernements locaux dans des politiques pro poor. Des équipes associant chercheurs et praticiens, villes du Nord et du Sud, organisations internationales et différents niveaux de gouvernement effectuent un important travail sur les organisations, sur les méthodes d'intervention et sur la coordination des acteurs.

27 Cependant, ces alliances avec des institutions locales ne constituent pas en elles-mêmes un succès, mais seulement une condition du succès. En toute bonne foi, au cours de ces vingt dernières années, les chercheurs spécialisés sur l'habitat de pauvreté dans les villes du Sud ont cherché à montrer les méthodes qui marchent, les réussites, les « best practices ». Malheureusement, ces initiatives passionnantes sont souvent restées à l'état de projets pilotes et se sont avérées difficiles à reproduire.

Les citer en exemple, et vouloir croire que ces réalisations constituaient en elles-mêmes des voies qu'il suffisait de décrire pour qu'elles soient reproduites, a créé une atmosphère optimiste qui a satisfait tous les acteurs: les ONG et les bailleurs, qui considèrent ainsi avoir trouvé une méthode, les chercheurs et les disséminateurs d'information qui ont à proposer autre chose qu'une vision lugubre de la situation 
sociale dans les villes du Sud, et surtout les responsables des politiques publiques, que ces projets et initiatives dispensent d'une stratégie à long terme.

\section{Les perspectives de la décentralisation} serait donc le bon outil pour promouvoir l'élaboration d'une stratégie de développement durable, prenant en compte les enjeux liés au genre. La décentralisation permet le renforcement d'un nouveau système de gouvernance, qui entérine l'affaiblissement de la relation de tutelle avec l'Etat central, privilégie la négociation entre acteurs (chacun d'entre eux disposant d'une parcelle de pouvoir) et qui renforce les capacités de promotion économique de la ville (Le Galès, 1995). L'action de la municipalité décentralisée s'exerce à travers la réglementation, par sa présence sur le terrain et grâce à plusieurs types de mesures qui ont un impact direct, positif ou négatif, sur le niveau de vie des habitants des bidonvilles: l'accès à la terre et au logement, l'accès aux services tels que santé, éducation, eau, assainissement, l'exercice de la citoyenneté, l'action en faveur d'un meilleur environnement, et même, de plus en plus souvent, les mesures en faveur de la création d'emplois. d'être clarifiée dans de nombreux pays, et la gestion urbaine constitue l'un des points les plus délicats à régler, ne serait-ce que parce que la croissance urbaine et la gestion des services nécessitent une approche bien plus large que les limites municipales; nombre de bidonvilles périphériques se développent aujourd'hui largement au-delà des frontières administratives de la ville. Il a été établi que la démocratisation au niveau local a permis l'apparition de nouvelles capacités d'initiative et une meilleure participation des citoyens (Fiszbein, 1997). Il reste que les instruments financiers à la disposition des municipalités demeurent faibles, et que peu d'entre elles sont équipées pour mener à bien une politique répondant aux besoins pour le plus grand nombre. La maîtrise des services techniques par les municipalités est le plus souvent peu performante. Dans l'ensemble, la marge de manœuvre de la municipalité est limitée, qu'il s'agisse de sa relation aux institutions de tutelle, de sa situation politique ou de ses capacités financières, du fait de la très faible élasticité des impôts.

31 Les difficultés, et parfois les réticences du gouvernement local à mettre en œuvre une politique structurée qui inclurait réhabilitation des bidonvilles et croissance maitrisée sont aggravées par le fait que les habitants des quartiers pauvres, hommes et plus souvent encore femmes, ne possèdent souvent pas de carte d'électeur local. Leur inscription comme électeur est en milieu rural, voire dans une autre région, tandis que les électeurs de la classe moyenne, avec lesquels il est aisé de construire une politique efficace de concertation (Kundu, 2005), ont souvent comme premier objectif de voir disparaître les bidonvilles qui gênent le développement de leur quartier ou de leurs activités. Les habitants des bidonvilles ne font pas partie des priorités des municipalités.

La question de l'efficacité des politiques de lutte contre la pauvreté dans un contexte décentralisé reste donc un débat en cours. Les dépenses en direction des groupes sociaux défavorisés n'ont pas augmenté, (Campbell et al 1991 p. 34), même si on assiste parfois à une meilleure répartition des investissements en infrastructures sociales (Ranis and Stewart, 1994). De même, l'efficacité de la politique de décentralisation pour 
la promotion des femmes en politique n'est pas démontrée (Milbert 1995, Tawa-Lama 2004). Dans le jeu des élites, il apparaît souvent plus facile d'être élue députée au niveau national en appartenant à la famille d'un politicien connu, que d'être élue au sein d'une communauté locale, sauf dans le cas, tel que l'Inde, où une politique de réservation de sièges pour les femmes a été mise en place en même temps que la décentralisation.

Les politiques de décentralisation, en déchargeant l'Etat de nombreuses responsabilités et en confiant aux villes la responsabilité de la gestion des quartiers pauvres, ont créé de fortes disparités. Tandis que certaines villes, exemplifiées par les Best Practices et la Cities Alliance, parvenaient à mener à bien des aménagements et des réformes, la majorité des villes décentralisées n'ont jusqu'à aujourd'hui ni les moyens ni la volonté politique de s'attaquer aux différentes composantes de «l'inclusion sociale ».

\section{L'impératif de la participation}

L'option de la participation avait, dès les années 1970, été intégrée à une stratégie assez modeste de réhabilitation de bidonvilles, celle de l'UNICEF avec les Urban Basic Services, dont l'exemple le plus achevé a été développé à Hyderabad (Inde). Cette initiative a mêlé la participation active des habitants et l'effort de la municipalité, appuyée par l'UNICEF, pour apporter les services minima à la population de plusieurs bidonvilles, tels que les adductions d'eau, l'assainissement, les services d'éducation pour les enfants et les femmes, des services de formation et de santé. Ce programme a eu une influence importante sur la stratégie indienne de planification participative. Cependant, nos visites répétées sur les sites de ces projets montrent une absence de continuité dans le suivi aussi bien par la municipalité que par la communauté, résultant dans de nombreux problèmes de maintenance des services.

De nombreuses ONG exécutent des projets de façon ponctuelle, dans les quartiers de bidonvilles, en essayant de répondre à la demande de la population locale, en général avec des financements internationaux. Un certain nombre de ces opérations, systématiquement citées, ont connu un grand succès du fait de la participation importante de la population. Cet engagement a parfois été structuré à travers des coopératives. La plus documentée est sans doute le Orangi Pilot Project à Karachi, qui fonctionne depuis les années 1980. De même, le programme d'inclusion sociale de Santo Andre a permis l'amélioration des conditions de vie de 16'000 habitants de favelas dans cette municipalité du sud de Sao Paulo. Le programme participatif développé à Dakar, lancé à la fin des années 1990, cherche à rendre l'initiative aux associations de quartier, et touche environ 1 million d'habitants (Legros, 2004). Dans les cas où ces opérations fonctionnent et prennent une dimension à l'échelle de la ville, on constate toujours les mêmes caractéristiques une municipalité très engagée, un sursaut citoyen, la participation active des habitants des quartiers pauvres (y compris les femmes), une bonne communication et des financements continus pendant plusieurs années. Mais il arrive aussi que les projets se terminent discrètement en quelques mois. Les financements reçus par l'ONG se sont taris, ou des intrigues politiques ont eu raison de la priorité donnée à ce quartier, laissant alors la population du bidonville dans une situation de frustration extrême et d'espoirs déçus.

Legros (2004), dans ses enquêtes en Tunisie et surtout au Sénégal, s'est trouvé confronté à une participation d'opportunisme. Il a bien montré l'importance des évolutions en matière de participation démocratique et administrative, à l'égard de 
l'allégeance politique, à Tunis, ou à l'égard de mécanismes de " participation obligée ", à Dakar, pour accéder aux financements de projets d'équipement: « dans la banlieue dakaroise, la règle de l'allégeance politique cède aujourd'hui le pas à celle de la "participation obligée". Lorsque l'Etat était le principal fournisseur d'équipements, ces derniers étaient diffusés via les canaux du parti au pouvoir, certainement à des fins de fidélisation de la société. Accéder aux équipements nécessitait donc d'intégrer les clientèles politiques de l'Etat-parti et de prouver ainsi son soutien au régime en place. (...) Par exemple, à Yeumbeul, dans la banlieue de Dakar, des projets de lutte contre la pauvreté sont initiés par l'aide internationale et par les ONG. Ces projets combinent des actions d'équipement ou d'amélioration du cadre de vie avec des actions de soutien aux initiatives locales, dans le domaine social ou économique. La conditionnalité aux financements, par exemple, entre autres, de la coopération canadienne, est liée à l'appartenance à des associations, lesquelles ont comme point commun d'être des organisations reconnues par les pouvoirs publics malgré leur variété : associations de quartiers, associations sportives et culturelles, groupements d'intérêt économique, groupements de promotion féminine... » Les règles fixées par l'Etat et par les agences internationales sont donc parfaitement assimilées par la population, qui s'adapte avec une grande souplesse aux exigences de "participation » fixées par les instances de financement.

Sans vouloir, en aucun cas, déprécier ceux qui, à l'intérieur des quartiers, savent représenter et défendre leur communauté avec courage et droiture, notre expérience personnelle en Inde du nord nous amène à constater que le leadership dans le bidonville est assuré uniquement par des hommes dont le statut est souvent douteux : les slumlords, appelés à New Delhi les pradhans. Il est rarissime que ces personnes soient élues ou désignées dans une assemblée. Les bidonvilles sont souvent divisés, par ethnie, par religion, par caste, par origine géographique ou par statut social. La puissance de ces hommes se révèle de façon informelle : ils conquièrent leur position grâce à leur entregent, leur aptitude à se positionner entre les différentes administrations et les habitants du bidonville. Cette capacité peut s'expliquer par leur appartenance à un parti, à une communauté religieuse, ou du fait de leurs qualités personnelles. Certains mettent en avant leur capacité à écrire, écouter et conseiller, et surtout connaissent des intermédiaires à l'intérieur de l'administration.

Il est frappant de constater que ces leaders sont redoutés beaucoup plus qu'ils ne sont aimés et respectés. Au sein d'un même bidonville, leur territoire est très défini, et souvent ils ne se risquent pas à pénétrer dans les ruelles voisines, territoire d'un autre leader. Leur rôle demeure très ambigu, même s'ils se présentent en direction de l'extérieur comme des "travailleurs sociaux ", "slum leaders ", tout dévoués à la cause de leur quartier. Propriétaires informels des huttes, usuriers, intermédiaires monnayant leur entregent vis-à-vis de petits employés de l'administration, voici l'autre visage de la plupart de ces pradhans. Même lorsque leur travail peut véritablement s'apparenter à celui de "travailleur social ", par exemple pour aider à la réinsertion d'un enfant à l'école, organiser l'accès aux cartes d'identité, faciliter les soins de santé pour une femme, s'informer sur les possibilités de relogement, force est de constater que le réseau fonctionne d'abord et principalement en fonction de leurs intérêts personnels et ceux de leur famille. La principale force des pradhans est leur réseau d'information et leur capacité à connaître, même par bribes, des mesures politiques à venir, qu'ils ne distilleront que parcimonieusement, qu'il s'agisse du lieu du resettlement, de l'administration en charge de l'opération, de la procédure... (cf. Lavigne 
et Milbert, 1983). Ces exemples montrent que les individus ne peuvent relayer pleinement les institutions dans "l'intermédiation sociale » telle qu'elle est décrite par F. Navez-Bouchanine (1997). Certes, comme le rappelle Legros, le leadership local est largement tributaire de l'aptitude des individus à pénétrer les rouages du système politico-administratif : «les systèmes d'action liés à la revendication des équipements de base esquissent dans la banlieue tunisoise, comme dans la banlieue dakaroise d'ailleurs, un pouvoir local largement déterminé par l'aptitude de personnalités locales ou d'individualités fortes à servir d'intermédiaires entre la population et les institutions publiques». Mais, selon notre expérience à New-Delhi et Kanpur, ce pouvoir local, une fois conquis, sert à l'intermédiaire à entrer dans le cénacle du pouvoir au lieu de promouvoir le quartier qui l'a élu.

La plupart des municipalités sont très peu armées pour mettre en œuvre la participation, si tant est qu'elles ont la volonté de la faire fonctionner auprès des habitants des bidonvilles. L'UNICEF en a fait l'amère expérience au Karnataka, lorsque les femmes promues "animatrices de quartier" se sont trouvées, à leur corps défendant, manipulées politiquement, selon l'exemple donné par E. Palm (1998). De même, Banashree Banerjee, à propos du programme APUSP en Andhra Pradesh (Inde) montre comment le gouvernement central a mis à disposition des autorités locales des fonds spécifiques destinés aux femmes les plus pauvres, dans le cadre de ses programmes de lutte contre la pauvreté urbaine. Les municipalités sont chargées de mettre en place des structures de groupes d'action locaux dans les bidonvilles, pour permettre la mise en place de ce programme. Alors que l'Andhra Pradesh est l'un des Etats les plus progressistes, pourtant les mécanismes de participation n'ont pas été mis en place dans la plupart des villes. Les femmes « représentantes » n'ont pas été formées pour mettre en œuvre le projet. Quelques individus, parmi lesquels des élus, prenaient les décisions à leur place et gardaient le contact avec la municipalité. La plupart des municipalités n'avaient pas les équipes ou les structures pour assurer la formation et le fonctionnement des groupes d'action locaux. Ils avaient néanmoins accepté immédiatement le projet et ses financements (APUSP, 2000, Banerjee, 2002). La question est donc de savoir si les formes de participation introduites par l'aide internationale vont prendre racine, permettre de dépasser les clivages et les clientélismes et modifier le rapport traditionnel hommes-femmes qui continue à structurer les relations à l'intérieur des municipalités et des quartiers, y compris les bidonvilles.

\section{Citoyenneté et mouvements sociaux}

Dans de nombreuses villes indiennes, les bidonvillois sont considérés comme des "citoyens de seconde zone ». S'ils ne font pas partie d'un bidonville "reconnu» (notified), ils ne sont pas reconnus officiellement comme des habitants de la ville. Tous les efforts faits pour redonner une capacité d'initiative au citoyen, comme cela a été le cas à Delhi, vont vers les classes moyennes. Or celles-ci expriment un fort antagonisme vis-à-vis des habitants des bidonvilles. Cet antagonisme a toujours existé, mais il est aujourd'hui renforcé par l'appétit social et, paradoxalement, par la décentralisation et par la mise en œuvre de la démocratie locale, qui est dirigée vers les habitants officiels de la ville., La situation semble moins tranchée dans les villes latino-américaines. Cependant, rarissimes sont les villes dont les maires, tel Celso Daniel, maire de Santo 
Andre, ont eu le courage de s'attaquer aux intérêts établis pour essayer de résoudre frontalement la question des bidonvilles, parfois au prix de leur vie.

On pourrait craindre qu'il n'y existe pas encore un système d'alliances suffisamment solide pour qu'un front international se crée et soit capable d'interférer dans le rapport de forces existant entre habitants du bidonville et pouvoir en place. Si l'on prend le cas des évictions à Mumbai et à Delhi, par exemple, celles-ci se sont multipliées au cours des trois dernières années, de façon discrète et efficace. Les bidonvilles sont éliminés un par un, par bulldozer, sans provoquer beaucoup d'émoi dans la presse locale et aucun écho dans la presse internationale. Des groupes d'action civiques créés au niveau international font circuler l'information parmi les spécialistes, lesquels réagissent avec les armes habituelles de l'advocacy, par courriers et campagnes de pétitions.

On assiste donc à une série d'initiatives pour fédérer les grassroots movements sur le plan global, pour en faire un mouvement social transnational, comme cela s'est produit après la Conférence de Beijing, avec les mouvements de femmes (Batliwala, 2002). Certains de ces réseaux possèdent ancienneté, audience et un bon système d'informations, tel Habitat International Coalition, qui documente les grossières violations du droit à l'habitat, par exemple les évictions de mai 2005 à Harare (Zimbabwe). D'autres réseaux, plus locaux, et auxquels participent de nombreuses femmes, répondent aux mêmes objectifs de rassemblement de mouvements sociaux d'habitants et de mise en œuvre du droit à l'habitat (Afrique du Sud).

Cependant, on remarque en Inde un paradoxe. D'une part, les mouvements de femmes y sont particulièrement développés; les femmes ont participé activement aux manifestations agraires et au processus politique d'accession à l'Indépendance, et leur lutte a été couronnée de succès dans des nombreux combats liés au statut de la femme, au respect des droits humains, à l'accession à l'égalité entre hommes et femmes. Les Indiennes sont bien représentées dans les réseaux internationaux et dans les mouvements transnationaux liés à l'équité de genre. Elles ont également un bon accès aux sphères de la décision, et elles sont fréquemment parvenues à obtenir des modifications de la loi, à leur avantage, dans des circonstances rapides. Ainsi, à partir d'exemples tels que la loi de 1994 interdisant l'avortement sélectif de fœtus de sexe féminins, ou à partir de la mise en place des lois prenant en compte les conclusions de la Conférence de Beijing en 1995, on peut considérer que les mouvements sociaux ont un accès transparent aux milieux politiques, ce qui favorise la mise en œuvre de politiques publiques favorables à la condition féminine (la question de l'application de ces législations est d'un autre ordre de difficulté). Dans l'ensemble, les mouvements de femmes en Inde restent aujourd'hui préoccupés par des sujets qui ont trait au statut de la femme : bride-burning, dot, statut de la famille, égalité des femmes dans un Etat de droit. La préoccupation concernant la sécurité des femmes dans la ville est assez nouvelle, elle est discutée depuis l'apparition du travail de nuit pour les femmes de la classe moyenne (en particulier du fait des call centers).

D'autre part, on constate le silence autour des politiques urbaines et la faiblesse des ONG de femmes qui s'y intéressent spécifiquement. De très nombreuses associations de femmes militent et travaillent dans les villes, mais très peu travaillent de façon directe sur l'aménagement, aux services et l'environnement de la ville. Peut-on donc faire l'hypothèse que les femmes indiennes, contrairement à la démarche menée par C. Lévy, J. Beall et C. Moser au cours des années 1990, ne voient ni la ville ni leur quartier selon une perspective de genre? Cette situation semble en contraste avec de nombreuses 
situations latino-américaines, en particulier au Brésil, en Argentine ou au Pérou, où des femmes ont pris la tête de mouvements de lutte pour des logements, pour des services essentiels ou pour la conservation de l'environnement (Hainard, Verschuur, 2005), Nos recherches de terrain en Inde nous amènent à constater que les femmes dans les quartiers pauvres sont conscientes, mais pas assez confiantes : elles sont soumises à un poids social, à des responsabilités vitales, lourdes et immédiates et surtout à une somme d'incertitudes, en particulier sur le plan familial et de la sécurité foncière tels qu'elles ne peuvent lancer des luttes liées à leur environnement immédiat. Cela alors qu'elles sont parfaitement conscientes des enjeux liés à la sécurité foncière, à l'approvisionnement en eau, à un accès sûr à des toilettes ou à un environnement propre pour les enfants en bas âge, toutes préoccupations communes à toutes les femmes du quartier.

\section{Conclusion}

Il apparaît donc très difficile de mettre en œuvre la composante sociale du développement durable, "l'inclusion sociale urbaine", qui permettrait d'assurer la satisfaction des besoins fondamentaux des groupes sociaux les plus défavorisés. Pourtant, une alliance objective et productive existe entre les institutions internationales, les mouvements sociaux transnationaux et les groupes d'action locaux. Ils se traduisent par des projets pilotes, des innovations, des publications. Il est impossible aujourd'hui de savoir si ces projets pilotes vont triompher du statu quo. Pour l'instant, il apparaît que la décentralisation n'a pas un impact décisif sur les politiques d'inclusion sociale dans la ville. Malgré la multiplication des acteurs, l'Etat et les municipalités sont maîtres des politiques publiques, de la loi et surtout de leur mise en œuvre. Prendre en compte les revendications et les attentes des femmes et des habitants des quartiers pauvres implique une remise en cause d'un ordre établi et d'une hiérarchisation sociale que la plupart des administrateurs, juges et politiciens des pays concernés ne sont pas prêts à faire.

\section{BIBLIOGRAPHIE}

Abbot S., 1996, From Beijing to Istanbul : the Super Coalition on Women, Homes and Community, Countdown Istanbul, 1996 May ; 1 (7) : 18.

APUSP, 2000, Review of existing community structures and participatory mechanisms in urban local bodies, unpublished report, mimeo, Hyderabad.

Axelrod, Robert, 1986, « An evolutionary approach to norms », in American Political Sciences Review, 80 : 04, December, 1095-1111.

Balbo, Marcello, 2001, «Shelter : Emerging Trends and Policies », Habitat Debate, September 2001, Vol 7, No. 3, pp. 2-3. 
Banerjee, Banashree, 2002, « Mainstreaming the Urban Poor in Andhra Pradesh », in Westendorff, David and Eade, Deborah (eds), Development and Cities, London : Oxfam, pp. 204-226

Batliwala, Srilatha, 2002, « Grassroots Movements as Transnational Actors : Implications for Global Civil Society », Voluntas : International Journal of Voluntary and Nonprofit Organizations, Vol 13, No. 4, December 2002, pp. 393-409.

Baud, I. S. A., Post, J., 2004, Realigning Actors in an urbanizing work : Governance and Institutions from a Development Perspective, London : Taylor and Francis.

Beall, J. 1995 « In Sickness and in Health : Engendering Health Policy for Development », in Third World Planning Review, 12 (2) May.

Beall, J., 1996, Urban Governance : Why Gender Matters, UNDP, New York.

Beall, Jo, 1996, Participation in the city : where do women fit in? In Gender and Development, Volume 4, Number 1/February 01, pp. 9 - 16

Berner, Erhard, 2000, « Poverty Alleviation and the Eviction of the Poorest : Towards Urban Land Reform in the Philippines ", International Journal of Urban and Regional Research, Vol 24, No. 3, pp. 536-553.

Blom, I., (2004) Les féminismes et l'Etat : une perspective nordique, in Gubin, E. et al., Le siècle des féminismes, Paris : Les Editions de l'Atelier/Editions Ouvrières, pp. 253-268.

Browne, Stephen, 2002, Developing Capacity through Technical Cooperation. Country Experiences, London and Sterling, Virginia : Earthscan Publications.

Bunsha, Dionne, 2005, « On the highroad to Shanghai », Frontline, Vol 22, No. 16, July 30 August 12 , pp. 22-25.

Campbell, Tim et al, 1991, Decentralization to Local Government in LAC : National Strategies and Local Responses in Planning, Spending and Management, Washington D. C. : World Bank Regional Studies Program.

Chen, M. A., Snodgrass, D., Managing Resources, Activities and Risk in Urban India : The Impact of Siwa Bank, AIMS, Report submitted to the Office of Microenterprise Global Development Bureau, USAID, mimeo, Washington D. C., September 2001.

Cities Alliance, 2005, 2004 Annual Report, Washington D. C. : Cities Alliance.

Commission on Global Governance, 1994, Our Global Neighbourhood, London : Oxford.

Commonwealth Human Ecology Council for ComHabitat, 2005, Measuring Progress in Implementing the Habitat Agenda in 12 Commonwealth Countries Synthesis Report, March 2005, April2006 : <http://www.comhabitat.org/public/SynthesisReport(HabitatNationalReports).pdf>.

Cunha, A. da, Ruegg, J., 2003, Développement durable et aménagement du territoire, Lausanne : Presses Polytechniques et Universitaires Romandes.

Deike, Peters, 2005, Breadwinners, Homemakers and Beasts of Burden : a Gendered Perspective on transport and Mobility, Institute For City And Regional Planning (ISR), Berlin, Germany, Sustainable Development International, pp. 93 - 97

Devas Nick, 1999, Who Runs Cities? The Relationship between Urban Governance, Service Delivery and Poverty, Urban Governance, Poverty and Partnerships Theme Paper 4, International Development Department School of Public Policy, Birmingham : University of Birmingham.

Datta, Rekha, 2003, « From Development to Empowerment : The Self-Employed Women's Association in India ", International Journal of Politics, Culture, and Society, Vol 16, No. 3 pp. 351 - 368 
Fiszbein, Ariel, 1997, « The emergence of local capacity : lessons from Colombia », World Development, Vol 25 No. 7.

Hainard, François, Verschuur, Christine, 2005, Mouvements de quartier et environnement urbain. La prise du pouvoir des femmes dans les pays du Sud et de l'Est, Paris : Karthala.

Harpham, Trudy, 2002, Urban Health Research in the 21st century, in Urban Health and Development Bulletin, vol. 5, n 3 \& 4, September-December, pp. 11-14.

«India : From Emerging to Surging » in The McKinsey Quarterly, 2001 Special Edition : Emerging markets.

Katakam, Anupama, « A Blueprint for Mumbai », Frontline, Vol 20, No. 24, 22-29 November 2003, pp. 31-32.

Katakam, Anupama, « For a New Mumbai, at Great Cost », Frontline, Vol 22, issues 02, January 15-28, 2005.

Kelsen, Hans, 1962, La théorie pure du droit, Paris : Dalloz.

Kelsen, Hans, 1996, Théorie générale des normes, Coll. Léviathan, Paris : P. U. F.

Kundu, Debolina, Kundu, Amitabh, 2005, « Governance in Delhi - A Study of the Decentralised System with Specific Reference to Ward Committees/Civil Society Organisations ", Paper presented at the Seminar on "New Forms of Government in Indian Mega Cities ", Center for the Study of Regional Development, J. N. U, New-Delhi, mimeo, 10-11 January 2005.

Lavaud, Jean-Pierre, 2001, « Municipalisation et participation populaire en Bolivie », Cahiers du GEMDEV, No 27, pp. 113-122.

Lavigne, Jean-Claude, Milbert, Isabelle, 1983, La Réhabilitation des bidonvilles de Kanpur, Paris : Plan Construction et Habitat.

Lavigne, Jean-Claude, Milbert, Isabelle, 1982, Habitat adapté et sécurité civile à Djakarta, mimeo, unpublished report, Paris : Plan Construction et Habitat.

Lavigne, Jean-Claude, Milbert, Isabelle, Panwalkar Pratima, 1984, Ville nouvelle et réhabilitation d'habitat ancien à Bombay : évaluation critique des politiques volontaristes d'aménagement, mimeo, unpublished report, Paris : Ministère de la recherche.

Lavigne, Jean-Claude, Milbert, Isabelle, 1985, L'intervention sanitaire et sociale et la stratégie des usagers dans une grande métropole indienne: Hyderabad, mimeo, unpublished report, Paris : Ministère de la recherche.

Le Galès, Patrick, 1995, « Du gouvernement des villes à la gouvernance urbaine », Revue Française de Science Politique, Vol 45, No 1, pp. 137-159.

Legros, Olivier, 2004, « Les effets de l'internationalisation des politiques urbaines sur le gouvernement des villes du "Sud". L'exemple des opérations d'équipement dans les quartiers mal lotis de Dakar et de Tunis ", mimeo, Communication au séminaire annuel de N-AERUS, Barcelone, 15 septembre.

Levy, C. 1991. «Towards Gender-Aware Provision of Urban Transport » in Gender and Third World Development : Module 5. University of Sussex : Institute of Development Studies.

Milbert, Isabelle, Peat, Vanessa, 1999, What Future for Urban Cooperation? An Assessment of PostHabitat Strategies, Bern : SDC.

Milbert, Isabelle, 2002, « Politiques sociales et pauvreté » in Saglio-Yatzimirsky, M. C.(ed.), Population et développement en Inde, Paris : Ellipses, pp. 132-151. 
Milbert, Isabelle, 2003, « Vulnérabilité et résilience des métropoles », in Cunha, A. da, Ruegg, J., Développement durable et aménagement du territoire, Lausanne : Presses Polytechniques et Universitaires Romandes.

Moser, C, 1987, « Mobilisation is Women's Work : struggles for insfrastructure in Guayaquil, Ecuador ", in Moser, C, et Peake, L., eds, Women, Housing and Human Settlements, London : Tavistock Publications.

Moser, Caroline, Clark, Fiona, (Ed.) 2001, Victims, perpetrators or actors? Gender, Armed Conflict and Political Violence, London : Zed Books.

Navez-Bouchanine Françoise, 1997, « Compétences citadines et intermédiation sociale », projet d'intervention pour la rencontre IRMC, mimeo, Rabat.

Obrist, Birgit, Tanner, Marcel, 2002, Building Research Networks and Partnerships. Experience from a joint post graduate programme on urban Health in African and Asian cities, in Urban Health and Development Bulletin, vol. 5, $\mathrm{n}^{\circ} 3$ \& 4, September-December, pp. 8-10.

Palm, Elina, 1998, Community participation and management of urban basic services in intermediate cities : case study of Gulbarga City, India, mimeo, Geneva : Graduate Institute of Development Studies (IUED), Mémoire de diplôme de recherche $\mathrm{n}^{\circ} 116$.

Parkar, S., Fernandes, J., Weiss, M., 2003, Contextualizing mental health. Gendered Experiences in a Mumbai Slum, in Anthropology and Medicine, Volume 10, n 3, December, pp. 291-308.

Patel, Sheela, d'Cruz, Celine, Burra, Sundar, 2002, « Beyond Evictions in a Global City : Peoplemanaged Resettlement in Mumbai », Environment and Urbanization, Vol. 14, No. 1, pp. 159-172

Ranis, G., Stewart, F., 1994, « Decentralisation in Indonesia », Bulletin of Indonesian Economic Studies, Vol 30, No. 3, pp. 41-74.

Saglio-Yatzimirsky, Marie-Caroline, 2002, Intouchable Bombay. Le bidonville des travailleurs du cuir, Paris : CNRS Editions.

Sharma, Kalpana, 2000, Rediscovering Dharavi, Stories from Asia's Largest Slum, New-Delhi : Penguin. Sivaramakrishnan, K. C., 2000, Power to the People? The Politics and Progress of Decentralisation, Delhi : Konark Publishers.

Tawa-Lama Rewal, Stéphanie, 2004 Femmes et politique en Inde et au Népal. Image et présence. Paris : Karthala.

UNCHS, 2001, 2001, Istanbul + 5. Le millénaire urbain. Chacun a droit à un logement décent, mimeo, Extraordinary Session of the General Assembly of the United Nations, mimeo, June 6-8, 2001, New York, UNCHS.

UNHSP, 2003, Global Report on Human Settlements, London and Sterling : Earthscan.

Ruet, Joël, « Le secteur électrique en Inde : réforme libérale ou persistance d'une forme de développement à l'indienne? », Revue Tiers Monde, t. XLII, n 165, janvier-mars 2001, pp. 83-103. Shah, Ghanshyam (Ed.), 2002

Social movements and the state, Readings in Indian Government and Politics 4, Sage Publications : New Delhi.

Schlyter, Ann, 2005, Urban housing, power of ownership and the exclusion of women. Experiences from Africa, communication to NAERUS Symposium on « Urban Inclusion », Lund University, 15-17 septembre 2005. 
Yuval-Davis, Nira, Werbner Pnina, (Ed.), Women, Citzenship and Difference, Zubaan : New Delhi.

Zérah Marie-Hélène, «L'accès à l'eau dans les villes indiennes », Collection Villes, Paris, Editions Economica, 1999.

\section{RÉSUMÉS}

Les politiques "d'inclusion urbaine", avec la prise en compte des habitants des quartiers pauvres et des équilibres de genre à l'intérieur de la ville, peuvent être considérées comme des éléments de concrétisation du «développement durable» défini notamment par les organisations internationales. Dans ces processus, la construction de normes internationales a été suivie de l'élaboration d'outils locaux destinés à les appliquer et à répondre à la demande des mouvements sociaux et groupes d'action locaux. Dans les deux cas, la question est posée de l'efficacité des politiques publiques et de la liaison entre actions internationale, étatique et locale.

This article aims at highlighting the main theoretical and methodological aspects of our researches on the processes of change and development of the urban environment with a gender perspective. For seven years these researches were conducted in the cities of Havana and Santo Domingo with the participative research-action and popular education approach. Our work was structured by these elements. Among the policies that were established on our research sites with the participation of the communities, we followed and studied more specifically those policies that promote community participation in the definition of their projects for life on the territories where they live, following the equity and "urban inclusion" principles. Our studies helped stir and deepen the debate on asymmetries, especially on gender asymmetries. Our research, addressing social, urban, environmental and gender transformations in the specific context of the Cuban revolutionary process, generates very interesting reflections.

Las políticas «de inclusión urbana», que tienen en cuenta a los habitantes de los barrios pobres y los equilibrios de género al interior de la ciudad, pueden ser consideradas como elementos de concretización del «desarrollo duradero» definido particularmente por las organizaciones internacionales. En estos procesos, la construcción de normas internacionales fue seguida por la elaboración de herramientas locales destinadas a aplicarlas y responder la demanda de los movimientos sociales y grupos de acción locales. En los dos casos, se plantea la cuestión de la eficacia de las políticas públicas y de la relación entre las acciones internacionales, estatal y local. (acciones internacionales y locales, estatales y privadas).

\section{AUTEUR}

\section{ISABELLE MILBERT}

Docteure en droit et professeure à l'Institut universitaire d'études du développement, Isabelle Milbert est spécialisée dans les domaines des réseaux sociaux dans la ville et de la gestion urbaine, des questions de gouvernance et citoyenneté. 
Postface 


\title{
L'introduction progressive de la perspective de genre à l'IUED
}

\author{
Christine Verschuur
}

1 Depuis plus d'une trentaine d'années, le champ de savoir " genre et développement " s'est construit, permettant de documenter les inégalités entre hommes et femmes dans le développement, de les analyser et d'en comprendre les causes structurelles.

2 L'IUED s'attache à ce que soit incluse une perspective de genre dans les études de développement, avant tout parce qu'ignorer la puissance qu'a le genre pour façonner les rapports sociaux déforme la réalité, empêche de faire une analyse juste (au sens conforme) de la réalité. Mais aussi parce que ne pas prendre en compte les inégalités sociales entre hommes et femmes, au nom de quelque argument que ce soit, dans les études ou les pratiques de développement, empêche d'avoir une approche juste (au sens équitable) pour agir sur la réalité.

Plusieurs facteurs ont concouru à faire prendre conscience, à l'IUED, de la nécessité de prendre les inégalités sociales entre hommes et femmes en compte dans les activités de recherche et d'enseignement. Cela ne provenait pas, initialement, d'une conviction profonde de la part de l'ensemble de l'institution que cette perspective apporterait un éclairage nouveau à la compréhension des inégalités dans le développement, d'une reconnaissance du pouvoir de ce concept.

4 Le premier facteur est la pression intérieure, provenant des étudiantes de pays du Sud inscrites à l'IUED, et de leur intérêt pour ce que cette problématique ne soit plus absente de la réflexion menée dans les enseignements. Un mémoire de recherche d'une étudiante brésilienne s'était ainsi intéressé à La question du genre à l'IUED en interpellant le regard masculin sur les études de développement et le biais masculin de l'institution. Une journée ouverte avait été organisée en 1994 où ce mémoire avait servi de base aux discussions et à l'autoréflexion critique. A partir de l'année suivante, s'est ensuite tenu chaque année un colloque international sur genre et développement.

5 Le deuxième facteur est la pression extérieure, d'une part celle exercée par des organisations féministes à Genève, qui suivaient de près et soutenaient les mouvements féministes des pays du Sud ainsi que les débats et rapports des conférences 
internationales des Nations unies sur les femmes. D'autre part, l'influence de certaines personnes de la DDC, le principal bailleur de fonds de l'IUED à l'époque, pour introduire ce questionnement à l'Institut a été cruciale. Cette volonté de prendre en compte les rapports hommes-femmes dans le développement, nouvelle pour la DDC également, ne pouvait être absente à l'IUED, supposé être un think-tank pour les programmes de la DDC. Petit à petit, s'insinuait à l'IUED l'idée qu'il était impossible de ne pas aborder cette thématique

6 Une enseignante anthropologue de l'IUED, Yvonne Preiswerk (elle avait écrit sa thèse de doctorat sur les accoucheuses en Suisse), féministe genevoise, a pu prendre appui sur ces pressions pour entamer diverses activités dans ce domaine des études femmes/ genre et développement. La première initiative a consisté à lancer le cycle des colloques internationaux genre, à partir de 1995, avec le soutien financier de la DDC ainsi que de la Commission nationale suisse pour l'UNESCO. Ensuite, et dès 1995, dans la foulée du premier colloque international, proposer au Programme MOST de l'UNESCO une vaste recherche dans laquelle la perspective de genre était centrale, avec un réseau d'équipes de chercheurs dans sept pays différents. Enfin, introduire dans chacun des quatre enseignements du Tronc commun (suivis par tous les étudiants de l'IUED), une conférence afin d'intégrer cette perspective genre de manière transversale. Des séminaires spécifiques sur cette problématique étaient alors également proposés.

En 2000, l'IUED décidait d'engager une personne pour intensifier les enseignements dans ce domaine, puis en 2002, une deuxième personne ${ }^{1}$. En 2000, démarrait également la publication annuelle des Cahiers genre et développement. A partir de 2005-2006, avec la mise en place du Master en études du développement, le séminaire "Anthropologie et genre, genre et développement", auparavant semestriel, devenait annuel. Par ailleurs, un «Pôle de renforcement des compétences en genre et développement » se mettait en place, avec un financement de la DDC. Il existe maintenant, outre les séminaires en genre et développement, des «journées genre » de l'école doctorale en études du développement; des modules genre au sein de l'International Master in Development Studies, un projet de création de Master européen en genre et développement. L'enrichissement du fonds documentaire, la création d'un site web, la construction d'une banque de données des personnes ressources et personnes intéressées par cette problématique, ont été possibles grâce au Pôle genre et développement.

8 Diverses recherches ont été entreprises (celle déjà mentionnée avec le Programme MOST de l'UNESCO, avec l'OMS, dans le cadre du NCCR), des liens ont été tissés avec des organismes internationaux ou non gouvernementaux basés à Genève et des Universités suisses et européennes. L'équipe de personnes actives sur cette problématique s'est renforcée, avec une participation au sein de la direction ${ }^{2}$. Le nombre d'étudiantes de l'IUED par rapport aux étudiants s'est proportionnellement renforcé, grâce à une plus grande vigilance lors des processus d'admission. Un nombre croissant de mémoires et de thèses de doctorat ont été ou sont entrepris sur cette problématique.

9 Le processus d'institutionnalisation semble irréversible. L'un des effets les plus positifs de ce travail d'institutionnalisation est la constitution d'un réseau de personnes et d'institutions partageant cette conviction que l'absence de prise en compte des inégalités de genre déforme l'analyse de la réalité.

10 Mais surtout, ce processus, à l'IUED et dans d'autres institutions, joint au travail des mouvements de base et des mouvements de femmes, favorise la reconnaissance 
progressive de la puissance qu'a le genre pour "structurer la perception et l'organisation concrète et symbolique de toute la vie sociale $»^{3}$.

\section{NOTES}

1. Fenneke Reysoo et Christine Verschuur, toutes deux anthropologues.

2. L'équipe genre est maintenant constituée de plusieurs personnes: Fenneke Reysoo, Christine Verschuur, Emmanuelle Chauvet, Anne Piraux, Elena de la Rosa, Ariane Mariot, Catherine Fragnière; sans compter les personnes impliquées dans les projets de recherche en cours (Françoise Grange, Séverine Rey, Maïmouna Ndioye, Isabel Rauber, Alvaro San Sebastian, Norberto Inda,), ni sur celles impliquées dans les anciens projets de recherche récemment terminés, qui devraient bientôt être relancés (équipe MOST-UNESCO). En 2005, Fenneke Reysoo a été nommée directrice-adjointe de l'IUED.

3. Joan Scott, 2000, "Genre, une catégorie utile d'analyse historique ", in Le Genre, un outil nécessaire, Cahiers Genre et Développement $n^{\circ} 1$, dir. Bisilliat J. et Verschuur, Ch., Paris, L'Harmattan, p. p. 41-67.

\section{AUTEUR}

\section{CHRISTINE VERSCHUUR}

Anthropologue, chargée de cours en genre et développement à l'Institut universitaire d'études du développement, IUED, Genève. 
Annexes 


\section{Présentation des intervenant-e-s}

\section{Mohamadou Abdoul}

1 Mohamadou Abdoul est docteur en histoire et chercheur de nationalité mauritanienne. Il travaille depuis de nombreuses années à ENDA à Dakar où il occupe actuellement des fonctions de chargé de programmes Enda «Prospectives Dialogues Politiques». Ses travaux portent sur les questions urbaines: participation/citoyenneté, cultures populaires urbaines; les processus politiques en Afrique et l'intégration régionale en Afrique de l'Ouest. Depuis 1997, il est responsable du projet MOST-UNESCO «Genre, ville et environnement » au Sénégal.

2 Abdoul Mohamadou, 2005, "Transformations urbaines et rapports de pouvoir entre hommes et femmes: l'exemple de Santhiaba, Thiaroye-sur-Mer ", in Hainard F., Verschuur C. (dir.), Mouvements de quartiers et environnements urbains. La prise de pouvoir des femmes dans les pays du Sud et de l'Est, Paris, ENDA Diapol-Karthala, pp. 275-300.

3 Abdoul Mohamadou, Dahou Tarik, 2003, «Décentralisation et construction d'un espace public local en milieu urbain. Les Comités de Développement Local (CDL) au Sénégal ", inTotté M., Dahou T. et Billaz R. (dir.), La décentralisation en Afrique de l'Ouest: entre politique et développement, Bruxelles, Paris, Dakar, Cota-Karthala-Enda Graf, pp. 183-199.

4 Abdoul Mohamadou, 2003, "Les transformations des rapports de genre et l'accès au pouvoir dans le quartier de Santhiaba » in Reysoo F. et Verschuur C. (dir.), On m'appelle à régner. Mondialisation, pouvoir et rapports de genre, Les colloques de l'IUED, Collection Yvonne Preiswerk, Genève, Institut universitaire du développement, pp. 93-104.

\section{Sonia Alves Calio}

5 Sonia Alves Calio est géographe de formation et a un post-doctorat en géographie urbaine à l'Université de São Paulo. Chercheuse en urbanisme, elle travaille actuellement sur les questions de l'habitat à la Companhia de Desenvolvimento Habitacional e Urbano (CDHU), entreprise de l'Etat de São Paulo. Depuis 1997, elle est responsable du projet MOST-UNESCO « Genre, ville et environnement » au Brésil.

6 Alves Calio Sonia, Massias Mendes Iranilde José, 2005, "Droit au logement: le mouvement des femmes au Brésil et l'expérience dans la favela Gamboa de Santo 
André ", in Hainard F., Verschuur C. (dir.), Mouvements de quartiers et environnements urbains. La prise de pouvoir des femmes dans les pays du Sud et de l'Est, Paris, ENDA DiapolKarthala, pp. 169-186.

7 Alves Calio Sonia, 2001, «Les femmes de la Gamboa II : prise de conscience et limites ", in Hainard F., Verschuur C. (dir.), Femmes dans les crises urbaines, Paris, Karthala-MOST.

8 Alves Calio Sonia, 1998, Cartografando a Violência contra a Mulher : o caso do Município de Santo André, post-doctorat, Université de São Paulo.

\section{Michel Carton}

9 Titulaire d'un doctorat en sciences de l'éducation de l'Université de Genève, Michel Carton $^{1}$ a accompli sa carrière académique à la Faculté de psychologie et des sciences de l'éducation de l'Université de Genève (jusqu'en 2002) et à l'Institut universitaire d'études du développement (IUED) à Genève, où il est professeur titulaire et dont il est le directeur depuis 2004. Ses travaux de recherche et ses interventions sur le terrain du développement portent sur les politiques de formation et de développement des compétences en Afrique de l'Ouest et du Sud ainsi qu'en Asie du Sud-Est. Il anime, avec Kenneth King, le réseau NORRAG consacré à l'analyse critique des politiques d'aide à l'éducation et à la formation. C'est dans ce cadre qu'il participe à des études sur les relations entre éducation, économie du savoir et société de la connaissance dans le contexte des processus de globalisation qui tendent à faire de l'éducation et des savoirs des biens marchands plutôt que des biens publics.

10 Michel Carton, Jean-Baptiste Meyer (dir.), La société des savoirs. Trompel'oeil ou perspectives ?, coll. Travail et Mondialisation, coéd. L'Harmattan-IUED-IRD, 2006.

11 Michel Carton, Jean-Baptiste Meyer, «Savoirs, travail et inégalités : la nouvelle Afrique du Sud au banc d'essai », in Transformations du travail et croissance économique, Bruno Lamotte et Alain Mounier (coord.), coll. Travail et Mondialisation, L'Harmattan, 2002.

\section{Marta Cassaro-Silva}

Marta Cassaro-Silva est biologiste et a un doctorat de l'Université fédérale de San Carlos (Brésil) en écologie et ressources naturelles. Elle prépare actuellement un Master en écologie auprès de l'Université des sciences de Neuchâtel.

13 Cassaro Silva Marta, 2005, "L'écologie urbaine: un outil pour une éducation environnementale citoyenne dans les favelas brésiliennes ", in Hainard F., Verschuur C. (dir.), Mouvements de quartiers et environnements urbains. La prise de pouvoir des femmes dans les pays du Sud et de l'Est, Paris, ENDA Diapol-Karthala, pp. 125-146.

\section{Serge Chappatte}

Serge Chappatte est le directeur adjoint de la Direction du développement et de la coopération (DDC) suisse, en charge de la politique de développement et de la coopération multilatérale.

\section{Iskra Dandolova}

Iskra Dandolova est docteure en lettres et sciences humaines de l'Université de Paris XNanterre; sociologue urbaine, architecte; directrice de recherche à l'Institut de 
sociologie auprès de l'Académie bulgare des sciences de Sofia. Ses champs de recherche sont la politique de la ville, les inégalités sociales, la politique sociale et l'exclusion, le genre et l'espace urbain. Depuis 1997, elle est responsable du projet MOST-UNESCO «Genre, ville et environnement » en Bulgarie.

Dandolova Iskra, 2005, «L'émergence de la société civile en Europe de l'Est : le rôle des femmes dans la construction du mouvement urbain à Sofia ", in Hainard F., Verschuur C. (dir.), Mouvements de quartiers et environnements urbains. La prise de pouvoir des femmes dans les pays du Sud et de l'Est, Paris, ENDA Diapol-Karthala, pp. 217-248.

Dandolova Iskra, 2004, Le logement social en Europe de Sud-Est : états de savoir, réformes et politiques, Paris \& Strasbourg, Conseil de l'Europe.

Dandolova Iskra, 2002, "The De-urbanization process in Bulgaria » in Eckardt F., Hassenpflug D., (dir.), Consumption and the Post-Industrial City, Francfort, Berlin, Bruxelles, New York, Oxford, Vienne, Peter Lang, pp. 127-139.

Dandolova Iskra, 2002, «Genre et crise. Les enjeux de la famille urbaine entre la ville et la campagne » in Hainard F., Verschuur C. (dir.), Femmes dans les crises urbaines. Relations de genre et environnement précaires, Paris, Karthala-MOST, pp. 203-230.

\section{Christina von Fürstenberg}

Christina von Fürstenberg est cheffe de section à l'UNESCO, en charge de la Section politique et coopération et sciences sociales.

\section{François Hainard}

21 François Hainard est professeur et directeur de l'Institut de sociologie de l'Université de Neuchâtel en Suisse. Ses travaux de recherche portent sur l'économie, l'environnement et les problèmes sociaux. Depuis 1997, il est l'un des deux coordinateurs du projet MOST-UNESCO « Genre, ville et environnement ».

Cassaro Marta, Hainard François, 2005, 0 ambiente: uma urgência interdisciplinar, Campinas (Brésil), Papirus Editora.

Hainard François, Verschuur Christine (dir.), 2005, Mouvements de quartiers et environnements urbains. La prise de pouvoir des femmes dans les pays du Sud et de l'Est, Paris, ENDA Diapol-Karthala.

Hainard François, Verschuur Christine, 2004, Femmes et politiques urbaines. Ruses, luttes et stratégies, Paris, Editions UNESCO-Karthala.

\section{Norberto Inda}

Norberto Inda est psychologue à l'Université de Buenos Aires (Argentine) et professeur sur les questions de dynamique de groupe et de liens sociaux à l'Université de Quilmes et à l'Université de Mar del Plata (Argentine). Membre de l'International Association Studies on Masculinities (IASOM), il est chercheur dans le domaine du genre et plus spécifiquement de la condition masculine. Il est membre de la partie argentine du projet MOST-UNESCO « Genre, ville et environnement ».

Inda Norberto, 2005, «La perspective de genre dans la recherche en sciences sociales: une étude de cas à San Cayetano, Argentine ", in Hainard F., Verschuur C. (dir.), 
Mouvements de quartiers et environnements urbains. La prise de pouvoir des femmes dans les pays du Sud et de l'Est, Paris, ENDA Diapol - Karthala, pp. 301-324.

Inda Norberto, 2000, «La construcción del padre ", in Verschuur C. (dir.), Quel genre d'homme? Construction sociale de la masculinité, relations de genre et développement, Les colloques de l'IUED, Collection Yvonne Preiswerk, Genève, Institut universitaire d'études du développement.

Inda Norberto, 2000, «L'homme : le sexe surévalué », in Bisilliat J., Verschuur C. (dir.), Le genre: un outil nécessaire, Cahiers genre et développement, $\mathrm{n} \cong 1$, Paris, L'Harmattan, pp. 77-82. Inda Norberto, 1996, « Género masculino, número singular » in Burin M., Dio Bleichmar E., Género, Psicoanálisis, Subjetividad, Edit. Paidos, Buenos Aires.

\section{Vincent Maugis}

Consultant auprès du Programme de Gestion des Transformations Sociales (MOST) de l'UNESCO, Vincent Maugis est responsable des méthodologies de transfert de connaissances recherche-politique. Après un Master Information Stratégique et Innovation Technologique à l'Institut des Sciences et Techniques de l'Ingénieur d'Angers (ISTIA), Vincent Maugis a collaboré avec le Système pour le Développement Durable Mondial (GSSD), un laboratoire du Département des Sciences Politiques du Massachusetts Institute of Technology (MIT) où il a mené des recherches sur les contributions des technologies de l'information à la prise de décision en matière de développement durable.

\section{Isabelle Milbert}

31 Docteure en droit et professeure à l'Institut universitaire d'études du développement, Isabelle Milbert est spécialisée dans les domaines des réseaux sociaux dans la ville et de la gestion urbaine, des questions de gouvernance et citoyenneté.

Milbert Isabelle, 2004, «Designing Future Research Projects », in Hurni H., Wiesmann U., Schertenleib R. (dir.), Research for Mitigating Syndromes of Global Change. A Transdisciplinary Appraisal of Selected Regions of the World to Prepare Development-Oriented Research Partnerships. Perspectives of the Swiss National Centre of Competence in Research (NCCR) North-South, Vol. 1. Berne, Geographica Bernensia.

\section{Maxine Molyneux}

Maxime Molyneux est professeure de sociologie à l'Institut d'étude des Amériques à l'Université de Londres. Elle a fait partie du comité éditorial du projet de l'UNRISD Beijing Plus 10 dont le rapport a été publié en 2005.

UNRISD, 2005, Egalité des sexes. En quête de justice dans un monde d'inégalités, Genève, UNRISD.

Lazar Sin, Molyneux Maxine (dir.), 2003, Doing the Rights Thing : Rights-Based Development and Latin American NGOs, Rugby, Intermediate Technology Development Group Publishing.

36 Craske Nikki, Molyneux Maxine (dir.), 2002, Gender and the Politics of Rights and Democracy in Latin America, Basingstoke, Palgrave Macmillan. 
Molyneux Maxine, Razavi Shahra, (dir.), 2002, Gender Justice, Development, and Rights, Oxford, Oxford University Press.

Dore Elizabeth, Molyneux Maxine (dir.), 1999, The Hidden Histories of Gender and the State in Latin America, Durham, Duke University Press.

\section{Isabel Rauber}

Isabel Rauber est docteure en philosophie, professeure de la faculté de philosophie de l'Université de La Havane, directrice de "Pasado y Presente XXI ", chercheuse du Centre d'études de l'Amérique basé à La Havane, responsable du projet MOST-UNESCO «Environnement, villes et rapports sociaux entre hommes et femmes » en République dominicaine et à Cuba. Elle étudie les mouvements sociaux latino-américains, elle est spécialiste du genre et des processus de participation citoyenne. Depuis 1997, elle est responsable du projet MOST-UNESCO « Genre, ville et environnement » à Cuba.

Rauber Isabel, 2005, Sujetos políticos, Panamá, Ruth Editorial

Rauber Isabel, 2005, «Education populaire, genre et transformations sociales: réflexions à partir des études réalisées en République dominicaine et à Cuba ", in Hainard F., Verschuur C. (dir.), Mouvements de quartiers et environnements urbains. La prise de pouvoir des femmes dans les pays du Sud et de l'Est, Paris, ENDA Diapol - Karthala, pp. 99-124.

2 Rauber Isabel, 2004, Movimientos sociales y representación política, La Havane, Ciencias Sociales.

Rauber Isabel, 1998, Género y poder, Buenos Aires, Ediciones UMA.

\section{Fenneke Reysoo}

44 Anthropologue néerlandaise possédant une licence en ethnologie de l'Université de Neuchâtel, Fenneke Reysoo ${ }^{2}$ est directrice adjointe chargée de l'enseignement à l'Institut universitaire d'études du développement (IUED) depuis 2005. Depuis l'automne 2000 elle est chargée de cours en Anthropologie, genre et développement. Elle a une mission de transversalité afin de faciliter l'intégration de l'analyse de genre dans toutes les disciplines professées et les projets de recherche. Elle a une solide carrière de chercheuse dans différentes universités et au sein de réseaux internationaux dans le large domaine des questions de "genre et développement »; sa spécialisation porte sur les questions de santé et de droits reproductifs et sexuels. Elle est coresponsable du pôle genre et développement de l'IUED et des colloques genre.

5 Verschuur Christine, Reysoo Fenneke, (dir.), 2005, Genre, nouvelle division internationale $d u$ travail et migrations, Cahiers genre et développement $n{ }^{\circ} 5$, Paris, L'Harmattan

Reysoo Fenneke, Verschuur Christine (dir.), 2004, Femmes en mouvement. Genre, migrations et nouvelle division internationale du travail, actes du colloque genre de l'IUED, Collection Yvonne Preiswerk, Genève, Institut universitaire d'études du développement.

\section{Álvaro San Sebastián}

Álvaro San Sebastián est architecte (UBA) et psychologue social. Il est chercheur à la faculté d'architecture, de design et d'urbanisme (FADU) à l'Université de Buenos Aires. 
Il a participé à divers projets de recherche nationaux et internationaux et est responsable de la formation du centre POIESIS. Il a coordonné pendant 4 ans le programme RED, un programme de coordination et de développement entre l'université et l'entreprise. Il a été Secrétaire des Relations Institutionnelles de la FADU. Il a participé à la gestion et l'organisation de projets de recherche et de gestion. Depuis 1997, il est responsable du projet MOST-UNESCO «Genre, ville et environnement » en Argentine.

Inda, Norberto, San Sebastián Álvaro, 2005, Ciudad, medio ambiente y género, Buenos Aires

San Sebastián Álvaro, 2005, "Les associations féminines de quartier: un espace politique en gestation? ", in Hainard F., Verschuur C. (dir.), Mouvements de quartiers et environnements urbains. La prise de pouvoir des femmes dans les pays du Sud et de l'Est, Paris, ENDA Diapol-Karthala, pp. 147-168.

Inda, Norberto, San Sebastián, Álvaro, 2002, Proyecto Campana, Barrio San Cayetano, 1997/2000, Buenos Aires.

\section{Rolf Steppacher}

51 Docteur, chargé de cours à l'Institut Universitaire d'études du développement; orientations théoriques: économie écologique, institutionnelle et évolutive; écodéveloppement et développement durable. Deux de ses publications portent sur les questions de genre ${ }^{3}$.

52 Steppacher Rolf, 1994, «Die verlorene Weiblichkeit der Ökonomie », Moneta, N • 3, 9 septembre 1994, pp. 2-4.

53 Steppacher Rolf, 1993, "Le féminin et le masculin, les femmes et les hommes: une perspective élargie sur les problèmes de développement " in Ballouz-Cherad S., Preiswerk Y. (dir.), Questions de "genre", Itinéraires, notes et travaux, $n^{\circ} 41$, IUED, Genève, pp. 37-52.

\section{Kadidia Tall}

54 Kadidia Tall est conseillère en économie sociale et familiale. Elle travaille pour la promotion des femmes par des formations, des études, des programmes de suivi-appuiconseil dans le domaine social et politique. Depuis 1997, elle est responsable du projet MOST-UNESCO « Genre, ville et environnement » au Burkina Faso.

55 Tall Kadidia, Tangara Mouniratou, 2005, « Associations féminines et entreprises privées dans la filière de gestion des déchets à Ouagadougou : un empowerment laborieux ", in Hainard F., Verschuur C. (dir.), Mouvements de quartiers et environnements urbains. La prise de pouvoir des femmes dans les pays du Sud et de l'Est, Paris, ENDA Diapol-Karthala, pp. 249-274.

56 Tall Kadidia, 2002, Pouvoir des femmes et gestion de l'environnement, Découvertes du Burkina-MOST.

57 Tall Kadida, 2001, Place des femmes aux élections municipales, Association des Municipalités du Burkina Faso, Fédération Canadienne des Municipalités, Ouagadougou, PACD. 


\section{Christine Verschuur} de l'IUED. Elle prépare une thèse intitulée Genre, citoyenneté et gestion de l'environnement urbain : les implications des réformes institutionnelles au Kerala. Cette thèse est financée par le programme de recherche NCCR Nord-Sud, soutenu par la Direction du développement et de la coopération suisse et le fonds national pour la recherche scientifique suisse.

Anthropologue, titulaire d'un doctorat de l'université de La Sorbonne, chargée de cours en genre et développement à l'Institut universitaire d'études du développement, Christine Verschuur travaille depuis de nombreuses années dans le domaine du genre et développement, dans des projets de recherche et d'enseignement. Elle est coordinatrice du projet Suisse «Villes, environnement et rapports sociaux entre hommes et femmes » du programme MOST de l'UNESCO depuis 1996 avec François Hainard. Directrice de la publication Les Cahiers genre et développement, qui paraissent annuellement depuis 2000 chez L'Harmattan, elle est co-responsable du pôle genre et développement de l'IUED et des colloques genre.

Hainard François, Verschuur Christine (dir.), 2005, Mouvements de quartiers et environnements urbains. La prise de pouvoir des femmes dans les pays du Sud et de l'Est, Paris, ENDA Diapol-Karthala.

Verschuur Christine, Reysoo Fenneke (dir.), 2005, Genre, nouvelle division internationale du travail et migrations, Les cahiers genre et développement, $\mathrm{n}^{\circ} 5$, Paris, L'Harmattan.

Hainard François, Verschuur Christine, 2004, Femmes et politiques urbaines. Ruses, luttes et stratégies, Paris, Editions UNESCO-Karthala.

\section{Sandra Walter}

Walter Sandra, 2003, Genre, Gouvernance et Environnement: une revue de la littérature, Working Paper, $\mathrm{n}^{\circ} 1$, IP8, Genève, IUED.

Walter Sandra, 2003, « Genre, gouvernance et environnement urbain en Inde : le cas du Kerala », in Reysoo F., Verschuur C. (dir.), On m'appelle à régner. Mondialisation, pouvoirs et rapports de genre, Les colloques de l'IUED, Collection Yvonne Preiswerk, Genève, Institut universitaire d'études du développement.

\section{NOTES}

1. La contribution de Michel Carton au colloque n'est pas reproduite dans le présent ouvrage.

2. La contribution de Fenneke Reysoo au colloque n'est pas reproduite dans le présent ouvrage.

3. La contribution de Rolf Steppacher au colloque n'est pas reproduite dans le présent ouvrage. 


\section{Presentation of the speakers}

\section{Mohamadou Abdoul}

1 Mohamadou Abdoul is a researcher from Mauritania and has a PhD in history. He is now in charge Enda's "Prospectives - Dialogues Politics" programme. His work focuses on urban issues: participation/citizenship, popular urban cultures; political processes in Africa and regional Integration in West Africa.

\section{Sonia Alves Calio}

2 Sonia Alves Calio is a geographer and has a post-doctorate in urban geography from the University of São Paulo. A researcher on urbanism, she now works on habitat issues in the CDHU, a State enterprise in São Paulo. Since 1997, she has managed the MOSTUNESCO project in Brazil: "Gender, city, and environment".

\section{Michel Carton}

3 Holding a PhD in science of education of the University of Geneva, Michel Carton ${ }^{1}$ has accomplished his academic career at the Faculty of psychology and science of education of the University of Geneva (up to 2002) and at the Graduate Institute of Development Studies in Geneva where is has a professor position and which he has been heading since 2004. His research and field interventions focus on training and skills enhancement policies in Western and Southern Africa and in Southeast Asia. Together with Kenneth King he is the co-leader of the NORRAG network addressing the critical analysis of aid policies in the fields of education and training. Within this network he takes part in studies on the relations between education, knowledge economy and knowledge society in the context of globalisation processes tending to turn education and knowledge from commons into commodities.

\section{Marta Cassaro-Silva}

Marta Cassaro-Silva is a biologist and has a Phd in ecology and natural resources from the Federal University of San Carlos, Brazil. She is currently preparing a Master degree in ecology at the Sciences university of Neuchâtel (Switzerland). 


\section{Serge Chappatte}

5 Serge Chappatte is the Assistant Director General of the Swiss Agency for Development and Cooperation (SDC), in charge of the development policy and multilateral cooperation.

\section{Iskra Dandolova}

6 Iskra Dandolova has a PhD in literature and human sciences from the University of Paris X-Nanterre; she is an urban sociologist, architect, research director at the Sociology Institute of the Bulgarian Academy of Sciences in Sofia. Her research fields include urban politics, social inequalities, social politics and exclusion, gender and urban space.

\section{Christina von Fürstenberg}

7 Christina von Fürstenberg is the chief of UNESCO's Section of Policy, international cooperation and knowledge sharing in the social sciences.

\section{François Hainard}

8 François Hainard is a professor and the Director of the Sociology Institute at the University of Neuchâtel in Switzerland. His research fields are economy, environment and social problems.

\section{Norberto Inda}

9 Norberto Inda is a psychologist from the University of Buenos Aires (Argentina) and a professor of "Group Dynamics" and social links at the University of Quilmes and University of Mar del Plata (Argentina). A member of IASOM - International Association Studies on Masculinities, he conducts research in the gender field and more specifically on men's condition. He is a member of the Argentinean part of the Swiss project "Gender, city and environment".

\section{Vincent Maugis}

10 A consultant to the Management of Social Transformations (MOST) programme, Vincent Maugis is in charge of the issue of knowledge transfer from research to policy. He holds a Master degree on Strategic information and technological innovation from the Institut des Sciences et Techniques de l'Ingénieur d'Angers (ISTIA) and collaborated to the Global System for Sustainable Development (GSSD), a laboratory from the Political Science department of the Massachusetts Institute of Technology (MIT) where he conducted research on the contributions of information technologies to decisionmaking in the field of sustainable development. 
Isabelle Milbert

11 Isabelle Milbert has a $\mathrm{PhD}$ in law and is a professor at the Graduate Institute of Development Studies (IUED). Her research and teaching focus on social networks in the cities and urban management, and on governance and citizenship.

\section{Maxime Molyneux}

Maxine Molyneux is a Professor of Sociology at the Institute for the Study of the Americas at the University of London. She has been a member of the Editorial Committee of the UNRISD Beijing Plus 10 Project, the report of which will be soon published.

\section{Isabel Rauber}

Isabel Rauber has a Phd. in Philosophy. Professor of the Faculty of Philosophy of the Havana University. Director of "Pasado y Presente XXI", a researcher in the Centre of Studies of America, in charge of the MOST-UNESCO Project: "Environmental transformation in cities and social relationships between men and women" in the the Dominican Republic and Cuba. She studies Latin American social movements and is a specialist in gender and in the participation process of citizens in the new community.

\section{Fenneke Reysoo}

Fenneke Reysoo ${ }^{2}$ is a Dutch anthropologist and holds a BA in ethnology from the University of Neuchâtel. She is now the deputy director in charge of teaching programmes of the Graduate Institute of Development Studies (IUED). Since 2000 she has been a teacher in "Anthropology, gender and development". She has a mission of mainstreaming gender analysis in all the disciplines studied at IUED. She has a solid research experience in different universities and within international networks on the vast field of gender and development issues; she is specialised in health and reproductive and sexual rights issues. She is the co-manager of IUED's gender colloquia.

\section{Álvaro San Sebastián}

15 Álvaro San Sebastián is an architect (UBA) and social psychologist. Since 1986 he has been a researcher at the architecture, design and urban Faculty of the University of Buenos Aires. He participated in different national and international research projects and is in charge of the training of the POIESIS centre. During 4 years he coordinated the RED programme for interaction and development between university and enterprise. He participated in the management and organisation of research and management projects. Since 1997, he has been in charge of UNESCO's MOST project in Argentina on gender, city, and environment.

\section{Rolf Steppacher}

Rolf Steppacher ${ }^{3}$ teaches at IUED (Graduate Institute of Development Studies); his theoretical orientations include: ecological, institutional and evolutionary economics, 
eco-development and sustainable development. Two of his publications are related to gender issues.

\section{Kadidia Tall}

17 Kadidia Tall is an adviser in social and family economy. She works to promote women by the means of trainings, studies, follow-up-support-counselling in the social and political field.

\section{Christine Verschuur}

18 An anthropologist and a teacher on gender and development at the Graduate Institute of Development Studies, Christine Verschuur has been working on gender and development issues for a long time through research projects, projects evaluations or training programmes.

19 She is the coordinator of the Swiss UNESCO's MOST project on Cities, environment and gender relations together with François Hainard. She also coordinates the publication Cahiers genre et développement, a yearly publication created in 2000 and published by L'Harmattan. She is the co-manager of IUED's gender colloquia with Fenneke Reysoo.

\section{Sandra Walter}

Sandra Walter has a BA in social Sciences from the University of Lausanne and got a Master from the Graduate Institute of Development Studies (IUED). She is currently working on a PhD on "Gender, citizenship and urban environment management: the implications of institutional reforms in Kerala". This research is funded by the national research programme NCCR North-South, a program funded by the SNSF and SDC.

\section{NOTES}

1. Michel Carton's presentation is not included in this publication.

2. Fenneke Reysoo's presentation is not included in this publication.

3. Rolf Steppacher's presentation is not included in this publication. 